\title{
RUPTURA E RECRESCIMENTO DE FLOCOS EM ÁGUA COM SUBSTÂNCIAS HÚMICAS AQUÁTICAS COAGULADA COM SULFATO DE ALUMÍNIO E CLORETO FÉRRICO
}

Luís Truppel Constantino

Dissertação apresentada à Escola de Engenharia de São Carlos da Universidade de São Paulo, como parte dos requisitos para obtenção do título de Mestre em Hidráulica e Saneamento.

ORIENTADOR: Prof. Dr. Luiz Di Bernardo

São Carlos

2008 



\section{AGRADECIMENTOS}

Aos meus pais Ricardo e Norma, meus irmãos Bruno e Gabriel e toda minha família, que durante todos estes anos foi meu porto seguro, sempre me apoiando e incentivando.

Ao Professor Luiz Di Bernardo, por sua instrução e orientação para que este trabalho fosse encaminhado da melhor forma possível.

Ao grande amigo Paulo Voltan pela preciosa colaboração sempre com disposição e muita amizade.

À Angela Di Bernardo Dantas, cuja ajuda foi imprescindível para a realização da pesquisa.

Aos amigos e colegas que ajudaram a desenvolver este trabalho, Eliane, Gustavo e Camila.

Aos professores do Departamento de Hidráulica e Saneamento da EESC/USP, pelos ensinamentos adquiridos. Aos funcionários e técnicos deste departamento que sempre se encontram à disposição na prestação de serviços, realizando-os com ânimo e disposição.

Ao Conselho Nacional de Desenvolvimento Científico e Tecnológico CNPq pela concessão da bolsa de mestrado.

Aos colegas de república, que conviveram comigo durante todos esses anos, sendo uma segunda família, Jalasca, Praga, Jaja, Ralo, Maluco, Salmão, Ronaldão, Fiduboto, Danu, Gueda, Chiva e outros mais. 
A todos os grandes amigos que fiz nos anos que passei em São Carlos, CAASO, Atlética e handebol com os quais passei por inúmeros momentos de alegria e companheirismo, que para sempre estarão em meu coração. Caaso, Caaso, ara ara ara incrusive cran cran!

E aos colegas e amigos do curso de Pós Graduação em Hidráulica e Saneamento da USP São Carlos. 


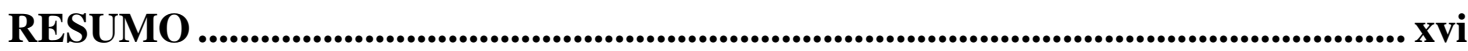

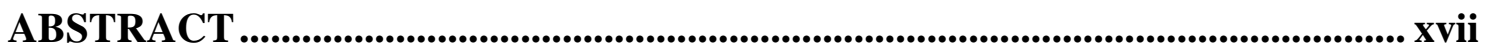

1 INTRODUÇÃO E JUSTIFICATIVA ..................................................................... 1

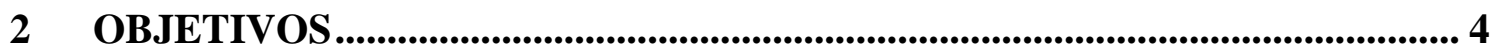

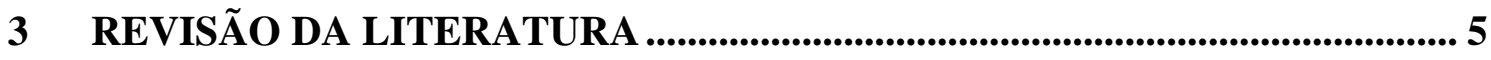

3.1 Substâncias Húmicas .....................................................................................

3.2 Remoção de cor por coagulação ………………….......................................

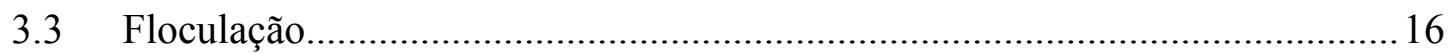

$3.4 \quad$ Ruptura e recrescimento de flocos ............................................................. 19

4 MATERIAIS E MÉTODOS ............................................................................. 30

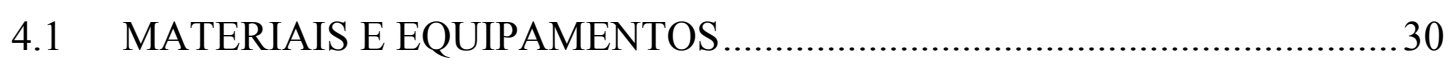

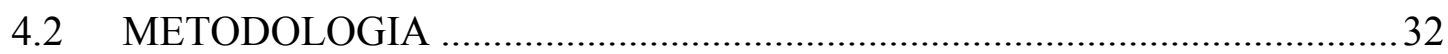

4.3 Coleta da água bruta e extração das substâncias húmicas aquáticas ..................34

4.4 Preparo da água de estudo …………………………………………….....36

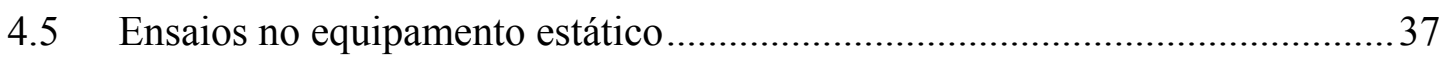

4.5.1 Ensaios para determinação das dosagens de coagulante e de correção de

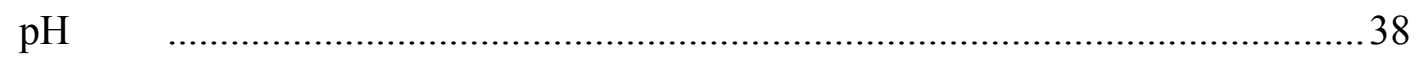

4.5.2 Ensaios para a determinação dos parâmetros da Mistura Rápida ..............39

4.5.3 Ensaios para a determinação dos parâmetros de Floculação ......................39

4.5.4 Ensaios para a caracterização da Sedimentação...........................................40

4.5.5 Ensaios de ruptura dos flocos............................................................... 40

4.5.6 Ensaios de refloculação............................................................................. 
$5 \quad$ RESULTADOS E DISCUSSÕES ........................................................................ 42

5.1 Caracterização da água de estudo............................................................. 42

5.2 Ensaios utilizando o Sulfato de Alumínio como coagulante............................43

5.2.1 Escolha da dosagem de coagulante e pH de coagulação ......................... 43

5.2.2 Escolha dos parâmetros da Mistura Rápida .............................................. 48

5.2.3 Escolha dos parâmetros de Floculação ...................................................51

5.2.4 Ensaios de Coagulação, Floculação e Sedimentação................................59

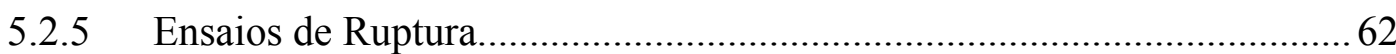

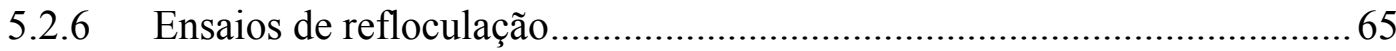

5.2.7 Comentários gerais sobre os ensaios de refloculação com o sulfato de

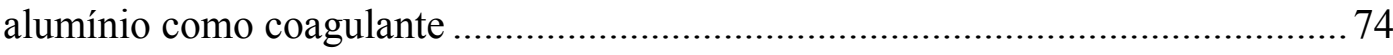

5.3 Ensaios utilizando o Cloreto Férrico como coagulante.....................................75

5.3.1 Escolha da dosagem de coagulante e pH de coagulação ......................... 75

5.3.2 Escolha dos parâmetros da Mistura Rápida ............................................ 80

5.3.3 Escolha dos parâmetros de Floculação ....................................................... 83

5.3.4 Ensaios de coagulação, floculação e sedimentação ................................. 91

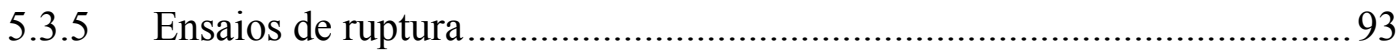

5.3.6 Ensaios de refloculação...................................................................... 95

5.3.7 Comentários gerais sobre os ensaios de refloculação com o cloreto férrico

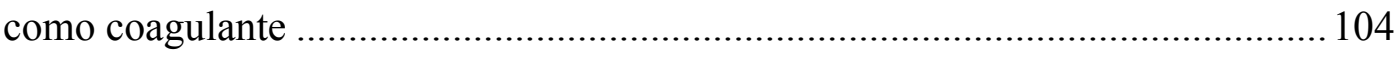

5.4 Comparações entre os ensaios com os diferentes coagulantes........................ 105

6 CONCLUSÕES E RECOMENDAÇÕES ...................................................... 108

7 REFERÊNCIAS BIBLIOGRÁFICAS ................................................................ 111

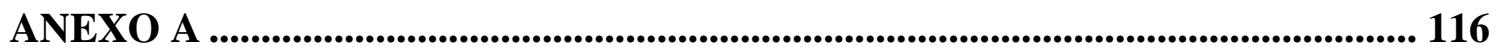

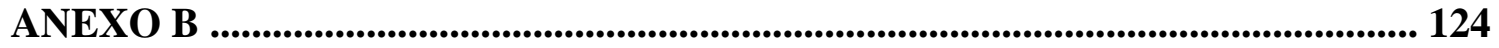


ANEXO C 128

ANEXO D 136

ANEXO E 140

ANEXO F 149

ANEXO G 153

ANEXO $\mathrm{H}$ 160 


\section{LISTA DE ILUSTRAÇÕES}

Figura 3.1 - Resultados da análise elementar para SHA Fonte - SLOBODA (2007). .7

Figura 3.2 - Porcentagem de AH e AF nas diferentes frações das SHA Fonte SLOBODA (2007).

Figura 3.3 - Regiões de remoção de Cor Verdadeira (100uC), Turbidez (0uT) com Sulfato de Alumínio. Fonte - AMIRTHARAJAH (1989).

Figura 3.4 Curvas com valores de cor aparente remanescente $(\mathrm{uH})$ em função da dosagem de coagulante e pH de coagulação. Água de estudo com cor verdadeira de $100 \mathrm{uH}$, coagulada com cloreto férrico, Vs $=1 \mathrm{~cm} / \mathrm{min}$. Fonte - PAVANELLI (2001).

Figura 3.5 - Cor Aparente da água filtrada após coagulação com sulfato de alumínio o e filtração em FLA - Ensaios com a água filtrada em membrana de 0,45 $\mu \mathrm{m}$ Fonte SLOBODA (2007).

Figura 3.6 - Gráfico típico de remoção por gradiente de velocidade, para cada tempo de floculação.Fonte - VOLTAN (2007).

Figura 3.7 - Gráfico típico de turbidez mínima remanescente em função do tempo de floculação com os respectivos gradientes de velocidade de Floculação (Gf), Fonte VOLTAN 2007.

Figura. 3.8 - Desempenho da floculação, ruptura e refloculação, para diferentes rotações durante a ruptura. Fonte: YUKELSEN E GREGORY (2002).

Figura 3.9 - Desempenho da floculação, ruptura e refloculação, para diferentes tempos de ruptura. A ruptura ocorreu à 400 rpm. Fonte: YUKELSEN E GREGORY (2004a). 
Figura 3.10 - Distribuição do tamanho dos flocos durante a floculação, ruptura e refloculação, para os coagulantes: Sulfato de Alumínio e Sulfato Férrico; Fonte: JARVIS et al. (2005a).

Figura 3.11.- Capacidade de recrescimento dos flocos após serem submetidos a um gradiente de ruptura Fonte - JARVIS (2006).

Figura 3.12 - Fração remanescente de turbidez em função da velocidade de sedimentação, para o gradiente de velocidade na ruptura de 75 s-1 e gradiente de velocidade de refloculação de 25 s-1. Fonte - VOLTAN (2007).

Figura 3.13 - Vista frontal do jarro mostrando os flocos ao final da floculação e após a ruptura, para os gradientes de velocidade de ruptura de 75,150 e $250 \mathrm{~s}-1$ Fonte VOLTAN (2007).

Figura 3.14 - Rotação das paletas do equipamento Jarteste em função do tempo de ensaio e a relação entre a rotação e o respectivo gradiente de velocidade, para os ensaios realizados Fonte - VOLTAN (2007).

Figura 3.15 - Esquema dos jarros do equipamento jarteste mostrando altura de sedimentação média em cada coleta. Fonte - VOLTAN (2007).

Figura 4.1 - Foto dos equipamentos utilizados nos ensaios de bancada.

Figura 4.2 - Foto do equipamento Jarteste (reator estático de bancada).

Figura 4.3 - Fluxograma dos procedimentos realizados para cada coagulante. 33

Figura 4.4 -Foto do Rio Itapanhaú. 34

Figura 4.5 - Foto da Instalação de Extração das SHA. 35

Figura 4.6 - Água bruta e extrato de SHA após a eluição.

Figura 5.1 - Diagrama de coagulação com cor aparente em função da dosagem de coagulante versus pH de coagulação $(\mathrm{Vs}=3,0 \mathrm{~cm} / \mathrm{min})$. Fonte: Tabelas A.1 a A.17 do Anexo A. 
Figura 5.2 - Diagrama de coagulação com cor aparente em função da dosagem de coagulante versus $\mathrm{pH}$ de coagulação $(\mathrm{Vs}=1,5 \mathrm{~cm} / \mathrm{min})$. Fonte: Tabelas A.1 a A.17 do Anexo A.

Figura 5.3 - Diagrama de coagulação com cor aparente em função da dosagem de coagulante versus $\mathrm{pH}$ de coagulação $(\mathrm{Vs}=0,5 \mathrm{~cm} / \mathrm{min})$. Fonte: Tabelas A.1 a A.17 do Anexo A.

Figura 5.4 - Cor aparente remanescente em função do gradiente de mistura rápida (Gmr) versus tempo de mistura rápida (Tmr) para a velocidade de sedimentação Vs1 $=1,5 \mathrm{~cm} / \mathrm{min}$ Fonte: Tabelas B.1 a B.5 do Anexo B. .50

Figura 5.5 - Cor aparente remanescente em função do gradiente de mistura rápida (Gmr) versus tempo de mistura rápida (Tmr) para a velocidade de sedimentação Vs2 $=1,0 \mathrm{~cm} / \mathrm{min}$ Fonte: Tabelas B.1 a B.5 do Anexo B.

Figura 5.6 - Cor aparente remanescente em função do gradiente de mistura rápida (Gmr) versus tempo de mistura rápida (Tmr) para a velocidade de sedimentação Vs3 $=0,5 \mathrm{~cm} / \mathrm{min}$ Fonte: Tabelas B.1 a B.5 do Anexo B.

Figura 5.7 - Cor aparente mínima remanescente e o respectivo gradiente de velocidade, para cada tempo de floculação $(\mathrm{Vs} 1=1,5 \mathrm{~cm} / \mathrm{min})$. Fonte: Tabelas C.1 a C.12, Anexo C.

Figura 5.8 - Cor Aparente mínima remanescente e o respectivo gradiente de velocidade, para cada tempo de floculação (Vs2 =1,0 cm/min). Fonte: Tabelas C.1 a C.12, Anexo C.

Figura 5.9 - Cor Aparente mínima remanescente e o respectivo gradiente de velocidade, para cada tempo de floculação (Vs3 = 0,5 cm/min). Fonte: Tabelas C.1 a C.12, Anexo C.

Figura 5.10 - Cor Aparente mínima remanescente em função do tempo de floculação com os respectivos gradientes de velocidade de Floculação (Gf), para a velocidade de sedimentação Vs1 = 1,5cm/min Fonte: Tabelas C.1 a C.12, Anexo C. 
Figura 5.11 - Cor Aparente mínima remanescente em função do tempo de floculação com os respectivos gradientes de velocidade de Floculação (Gf), para a velocidade de sedimentação Vs2 =1,0 cm/min Fonte: Tabelas C.1 a C.12, Anexo C.

Figura 5.12 - Cor Aparente mínima remanescente em função do tempo de floculação com os respectivos gradientes de velocidade de Floculação (Gf), para a velocidade de sedimentação Vs3 = 0,5 cm/min Fonte: Tabelas C.1 a C.12, Anexo C.

Figura 5.13 - Cor aparente remanescente em função da velocidade de sedimentação.

Figura 5.14 - Jarros com flocos formados, ao final da floculação, para Tf = 15 min e Gf $=10 \mathrm{~s}^{-1}$.

Figura 5.15 - Vista frontal dos jarros mostrando os flocos ao final da floculação

Figura 5.16 - Vista frontal dos jarros mostrando os flocos ao após a ruptura, para o gradiente de velocidade de ruptura de $50 \mathrm{~s}-1$.

Figura 5.17 - Vista frontal dos jarros mostrando os flocos após a ruptura, para o gradiente de velocidade de ruptura de $100 \mathrm{~s}-1$.

Figura 5.18 - Vista frontal dos jarros mostrando os flocos após a ruptura, para o gradiente de velocidade de ruptura de $150 \mathrm{~s}-1$.

Figura 5.19 - Cor Aparente remanescente em função da velocidade de sedimentação, para diferentes gradientes de velocidade de ruptura.

Figura 5.20 - Vista frontal dos jarros durante o ensaio para Gr igual a $50 \mathrm{~s}-1$ e Grf igual a 10 s-1. Observa-se os dois primeiro jarro ao final da sedimentação, o segundo no inicio da sedimentação e o terceiro e quarto ainda refloculando.

Figura 5.21- Cor Aparente remanescente em função da velocidade de sedimentação, para o gradiente de velocidade na ruptura de $50 \mathrm{~s}-1$ e gradiente de velocidade de refloculação de 10 s-1. Fonte: Tabela D.1, Anexo D.

Figura 5.22 - Cor Aparente remanescente em função da velocidade de sedimentação, para o gradiente de velocidade na ruptura de $50 \mathrm{~s}-1$ e gradiente de velocidade de refloculação de 20 s-1. Fonte: Tabela D.2, Anexo D. 
viii

Figura 5.23 - Cor Aparente remanescente em função da velocidade de sedimentação, para o gradiente de velocidade na ruptura de $100 \mathrm{~s}-1$ e gradiente de velocidade de refloculação de 10 s-1. Fonte: Tabela D.1, Anexo D.

Figura 5.24 - Cor Aparente remanescente em função da velocidade de sedimentação, para o gradiente de velocidade na ruptura de $100 \mathrm{~s}-1$ e gradiente de velocidade de refloculação de 20 s-1. Fonte: Tabela D.2, Anexo D.

Figura 5.25 - Vista frontal dos jarros durante um ensaio. Observa-se o primeiro jarro ao final da sedimentação, o segundo no inicio da sedimentação e o terceiro ainda refloculando.

Figura 5.26 - Cor Aparente remanescente em função da velocidade de sedimentação, para o gradiente de velocidade na ruptura de $150 \mathrm{~s}-1$ e gradiente de velocidade de refloculação de 10 s-1. Fonte: Tabela D.1, Anexo D.

Figura 5.27 - Cor Aparente remanescente em função da velocidade de sedimentação, para o gradiente de velocidade na ruptura de $150 \mathrm{~s}-1$ e gradiente de velocidade de refloculação de 20 s-1. Fonte: Tabela D.2, Anexo D.

Figura 5.28 - Diagrama de coagulação com Cor Aparente remanescente (uT) em função da dosagem de cloreto férrico versus $\mathrm{pH}$ de coagulação $(\mathrm{Vs}=3,0 \mathrm{~cm} / \mathrm{min})$. Fonte: Tabelas E.1 a A.E17 do Anexo E.

Figura 5.29 - Diagrama de coagulação com Cor Aparente remanescente (uT) em função da dosagem de cloreto férrico versus $\mathrm{pH}$ de coagulação $(\mathrm{Vs}=1,5 \mathrm{~cm} / \mathrm{min})$. Fonte: Tabelas E.1 a A.E17 do Anexo E.

Figura 5.30 - Diagrama de coagulação com Cor Aparente remanescente (uT) em função da dosagem de cloreto férrico versus $\mathrm{pH}$ de coagulação $(\mathrm{Vs}=0,5 \mathrm{~cm} / \mathrm{min})$. Fonte: Tabelas E.1 a A.E17 do Anexo E.

Figura 5.31 - Cor aparente remanescente em função do gradiente de mistura rápida (Gmr) versus tempo de mistura rápida (Tmr) para a velocidade de sedimentação Vs1 $=1,5 \mathrm{~cm} / \mathrm{min}$ Fonte: Tabelas F.1 a F.6 do Anexo F. 
Figura 5.32 - Cor aparente remanescente em função do gradiente de mistura rápida (Gmr) versus tempo de mistura rápida (Tmr) para a velocidade de sedimentação Vs1 = 1,0 cm/min Fonte: Tabelas F.1 a F.6 do Anexo F.

Figura 5.33 - Cor aparente remanescente em função do gradiente de mistura rápida (Gmr) versus tempo de mistura rápida (Tmr) para a velocidade de sedimentação Vs1 $=0,5$ cm/min Fonte: Tabelas F.1 a F.6 do Anexo F.

Figura 5.34 - Cor aparente mínima remanescente e o respectivo gradiente de velocidade, para cada tempo de floculação $(\mathrm{Vs} 1=1,5 \mathrm{~cm} / \mathrm{min})$. Fonte: Tabelas G.1 a G.12, Anexo G.

Figura 5.35 - Cor aparente mínima remanescente e o respectivo gradiente de velocidade, para cada tempo de floculação $(\mathrm{Vs} 2=1,0 \mathrm{~cm} / \mathrm{min})$. Fonte: Tabelas G.1 a G.12, Anexo G. 86

Figura 5.36 - Cor aparente mínima remanescente e o respectivo gradiente de velocidade, para cada tempo de floculação (Vs3 $=0,5 \mathrm{~cm} / \mathrm{min})$. Fonte: Tabelas G.1 a G.12, Anexo G.

Figura 5.37 - Cor Aparente mínima remanescente em função do tempo de floculação com os respectivos gradientes de velocidade de Floculação (Gf), para a velocidade de sedimentação Vs1 = 1,5 cm/min Fonte: Tabelas G.1 a G.12, Anexo G.

Figura 5.38 - Cor Aparente mínima remanescente em função do tempo de floculação com os respectivos gradientes de velocidade de Floculação (Gf), para a velocidade de sedimentação Vs2 = 1,0 cm/min Fonte: Tabelas G.1 a G.12, Anexo G.

Figura 5.39 - Cor aparente mínima remanescente em função do tempo de floculação com os respectivos gradientes de velocidade de Floculação (Gf), para a velocidade de sedimentação Vs3 = 0,5 cm/min Fonte: Tabelas G.1 a G.12, Anexo G. 89

Figura 5.40 - Cor aparente remanescente em função da velocidade de sedimentação. 92

Figura 5.41 - Jarros com flocos formados, no inicio da sedimentação, para $\mathrm{Tf}=25 \mathrm{~min}$ $\mathrm{e}$ Gf $=10 \mathrm{~s}-1$. 
Figura 5.42 - Vista frontal dos jarros mostrando os flocos ao final da floculação sem ruptura.

Figura 5.43 - Vista frontal dos jarros mostrando os flocos ao após a ruptura, para o gradiente de velocidade de ruptura de $50 \mathrm{~s}-1$.

Figura 5.44 - Vista frontal dos jarros mostrando os flocos ao após a ruptura, para o gradiente de velocidade de ruptura de $100 \mathrm{~s}-1$

Figura 5.45 - Vista frontal dos jarros mostrando os flocos ao após a ruptura, para o gradiente de velocidade de ruptura de $150 \mathrm{~s}-1$.

Figura 5.46 - Cor aparente remanescente em função da velocidade de sedimentação, para diferentes gradientes de velocidade de ruptura.

Figura 5.47 - Vista frontal dos jarros durante o ensaio para Gr igual a 50 s-1 e Grf igual a 10 s-1. Observa-se o primeiro jarro ao inicio da sedimentação e os demais ainda refloculando.

Figura 5.48 - Cor aparente remanescente em função da velocidade de sedimentação, para o gradiente de velocidade na ruptura de $50 \mathrm{~s}-1$ e gradiente de velocidade de refloculação de 10 s-1. Fonte: Tabela H.1, Anexo H.

Figura 5.49 - Cor aparente remanescente em função da velocidade de sedimentação, para o gradiente de velocidade na ruptura de $50 \mathrm{~s}-1$ e gradiente de velocidade de refloculação de 20 s-1. Fonte: Tabela H.2, Anexo H.

Figura 5.50 - Cor aparente remanescente em função da velocidade de sedimentação, para o gradiente de velocidade na ruptura de $100 \mathrm{~s}-1$ e gradiente de velocidade de refloculação de 10 s-1. Fonte: Tabela H.3, Anexo H.

Figura 5.51 - Cor aparente remanescente em função da velocidade de sedimentação, para o gradiente de velocidade na ruptura de $100 \mathrm{~s}-1$ e gradiente de velocidade de refloculação de 20 s-1. Fonte: Tabela H.4, Anexo H.

Figura 5.52 - Vista frontal dos jarros durante um ensaio. Observa-se o primeiro jarro durante a sedimentação e os demais ainda refloculando. 
Figura 5.53 - Cor aparente remanescente em função da velocidade de sedimentação, para o gradiente de velocidade na ruptura de $150 \mathrm{~s}-1$ e gradiente de velocidade de refloculação de 10 s-1. Fonte: Tabela H.5, Anexo H.

Figura 5.54 - Cor aparente remanescente em função da velocidade de sedimentação, para o gradiente de velocidade na ruptura de $150 \mathrm{~s}-1$ e gradiente de velocidade de refloculação de 20 s-1. Fonte: Tabela H.6, Anexo H.

Figura 5.55 - Comparação entre a sedimentação com cloreto férrico e com sulfato de alumínio.

Figura 5.56 - Sedimentação para diferentes gradientes de velocidade de ruptura em água coagulada com sulfato de alumínio

Figura 5.57 - Sedimentação para diferentes gradientes de velocidade de ruptura em água coagulada com cloreto férrico. 


\section{LISTA DE TABELAS}

Tabela 3.1 - Características da água estudada por JARVIS et al.(2006).

Tabela.4.1- Faixa de valores dos parâmetros da água de estudo.

Tabela 5.1- Caracterização da água de estudo.

Tabela 5.2- Faixa de valores dos parâmetros da água de estudo monitorados diariamente.

Tabela 5.3 - Resultados do ensaio de reprodução dos pontos selecionados.

Tabela 5.4 - Resultados dos ensaios de escolha dos parâmetros de floculação. .59

Tabela 5.5 - Resultados do ensaio de coagulação, floculação e sedimentação. .60

Tabela 5.6 - Resultados do ensaio de ruptura, para diferentes gradientes de velocidade durante a ruptura.

Tabela 5.7 - Resultados do ensaio de reprodução dos pontos selecionados. 80

Tabela 5.8 - Resultados dos ensaios de escolha dos parâmetros de floculação.

Tabela 5.9 - Resultados do ensaio de coagulação, floculação e sedimentação.

Tabela 5.10 - Resultados do ensaio de ruptura, para diferentes gradientes de velocidade durante a ruptura. 


\section{LISTA DE ABREVIATURAS E SIGLAS}

$\begin{array}{ll}\text { AF } & \text { ácidos fúlvicos } \\ \text { AH } & \text { ácidos húmicos } \\ \text { EESC } & \text { - Escola de Engenharia de São Carlos } \\ \text { ETA } & \text { - estação de tratamento de água } \\ \text { USP } & \text { - Universidade de São Paulo } \\ \text { G } & \left.\text { - gradiente de velocidade médio ( } \mathrm{s}^{-1}\right) \\ \text { Gf } & \text { - gradiente de velocidade médio na floculação }\left(\mathrm{s}^{-1}\right) \\ \text { Gmr } & \text { - gradiente de velocidade médio na mistura rápida }\left(\mathrm{s}^{-1}\right) \\ \text { IV } & \text { - infravermelho } \\ \text { Gr } & \text { - gradiente de velocidade médio na ruptura }\left(\mathrm{s}^{-1}\right) \\ \text { RHN } & \text { - ressonância magnética nuclear } \\ \text { Grf } & \text { - gradiente de velocidade médio na refloculação }\left(\mathrm{s}^{-1}\right) \\ \text { pH } & \text { - potencial hidrogeniônico } \\ \text { SH } & \text { - substâncias húmicas } \\ & \\ \text { GH } & \end{array}$


- tempo de floculação (min)

Tmr $\quad$ - tempo de mistura rápida (s)

$\operatorname{Tr} \quad$ - tempo de ruptura (s)

Trf $\quad$ - tempo de refloculação (min)

Vs - velocidade de sedimentação $(\mathrm{cm} / \mathrm{min})$ 


\section{LISTA DE SIMBOLOS}

$\begin{array}{ll}\text { rpm } & \text { - rotações por minuto } \\ \mathrm{uH} & \text { - unidade de cor } \\ \mathrm{uT} & \text { - unidade de turbidez } \\ \mathrm{cm} & \text { - centímetros } \\ { }^{\circ} \mathrm{C} & \text { - Grau Celsius } \\ \mathrm{s} & - \text { segundo } \\ \mathrm{L} & - \text { litro } \\ \mu \mathrm{m} & - \text { micrometro } \\ \mathrm{mg} & - \text { miligrama } \\ \mathrm{mL} & - \text { mililitro } \\ \mathrm{min} & - \text { minutos } \\ \mathrm{kDa} & \text { unidade de massa atômica }\end{array}$




\section{RESUMO}

CONSTANTINO, L.T. (2008). Ruptura e recrescimento de flocos em água com substâncias húmicas aquáticas coagulada com sulfato de alumínio e cloreto férrico. São Carlos, 2008. 166 p. Dissertação (Mestrado) - Escola de Engenharia de São Carlos, Universidade de São Paulo.

Por meio de ensaios em reatores estáticos (em equipamento de jarteste) foram estudados os efeitos da ruptura e da refloculação na sedimentação dos flocos, para diferentes velocidades de sedimentação. A água de estudo foi preparada com substâncias húmicas aquáticas (SHA) extraídas de água coletada do rio Itapanhaú Bertioga/SP, resultando cor verdadeira de $100 \mathrm{uH}$, e coagulada com sulfato de alumínio e cloreto férrico. Para os dois coagulantes, foram realizadas as etapas de coagulação, mistura rápida, floculação, ruptura $\left(\mathrm{G}=50,100\right.$ e $\left.150 \mathrm{~s}^{-1}\right)$ e refloculação $\left(\mathrm{G}=10\right.$ e $\left.20 \mathrm{~s}^{-1}\right)$. $\mathrm{Na}$ sedimentação sem a ocorrência de ruptura o cloreto férrico teve um desempenho superior ao sulfato de alumínio, principalmente nas velocidades de sedimentação mais altas. Isso se deve ao fato da floculação da água coagulada com o cloreto férrico ter gerado flocos de tamanho muito superior aos flocos gerados com o sulfato de alumínio. A ruptura, em poucos segundos, prejudicou a remoção dos flocos por sedimentação. Quanto maior o gradiente de velocidade na ruptura, maiores foram os valores da cor aparente remanescente, mesmo após a refloculação. A refloculação, mesmo nos primeiros minutos, diminuiu a cor aparente remanescente se comparada a logo após a ruptura. $O$ menor gradiente de velocidade durante a refloculação testado $\left(10 \mathrm{~s}^{-1}\right)$ apresentou menores valores da cor aparente remanescente. Tanto na água coagulada com o sulfato de alumínio quanto na coagulada com o cloreto férrico a refloculação se comportou de modo semelhante, havendo recuperação na eficiência de remoção de cor sem, porém, atingir os resultados obtidos antes da ruptura.

Palavras-chave: floculação, ruptura, refloculação, sedimentação, substâncias húmicas aquáticas. 
xviii

\section{ABSTRACT}

CONSTANTINO, L. T. (2008). Breakage and regrowth of flocs in water with aquatic humic substancs coagulated with aluminum sulphate and ferric chloride . São Carlos, 2008. 166 p. Dissertação (Mestrado) - Escola de Engenharia de São Carlos, Universidade de São Paulo.

By using the jar test equipment, the effects of breakage and reflocullation on the efficiency of floc sedimentation were studied, using different settling velocities. Water of study was prepared with aquatic humic substances (AHS) extracted from the Itapanhaú River (Bertioga, SP, Brazil), resulting a true color of $100 \mathrm{uH}$. Coagulation was performed by using aluminum sulfate and ferric chloride. For both coagulants, Coagulation, flocculation, breakage $\left(\mathrm{G}=50,100\right.$ and $\left.150 \mathrm{~s}^{-1}\right)$ and reflocculation $(\mathrm{G}=10$ and $20 \mathrm{~s}^{-1}$ ) tests were carried out. In the sedimentation without the floc breakage occurrence the ferric chloride had a superior performance to aluminum sulphate, mainly in higher settling velocities. This occurred because of flocculation of the ferric chloride coagulated water have generated higher size flocs than that generated with aluminum sulphate. The breakage of flocs, in few seconds, hindered the settling removal. The higher the average shear rate in the break-up, the higher result the residual turbidity even after the reflocculation.. The reflocculation, even in the first minutes, decreased the apparent color if compared to the results just after the break-up and sedimentation.. The lower average share rate used during the reflocculation $\left(10 \mathrm{~s}^{-1}\right)$ resulted lower values of the remaining apparent color. During the flocculation, the aluminum sulphate coagulated water as well as in the ferric chloride coagulated water held in similar way, recovering the efficiency of removal of color without, however, reach the results gotten before the breakage..

Keywords: flocculation, flock break up, reflocculation, settling, aquatic humic substances. 


\section{INTRODUÇÃO E JUSTIFICATIVA}

Diversos mananciais usados como fonte de abastecimento apresentam baixa turbidez e elevada cor verdadeira como principais características físicas. A cor é causada principalmente pela presença de substâncias húmicas ( $\mathrm{SH}$ ) na água. As substâncias húmicas são de natureza orgânica, uma mistura complexa de moléculas provenientes da decomposição de resíduos animais e vegetais, formando complexos estáveis de difícil remoção. Uma remoção deficiente destas SH pode ocasionar diversos problemas como a redução da eficiência do processo de desinfecção, servir como substrato para o crescimento de microrganismos e ainda podem reagir com os desinfetantes produzindo substâncias com sabor e odor desagradáveis, algumas das quais são tóxicas e potencialmente cancerígenas.

O tratamento convencional de ciclo completo (coagulação / floculação / decantação convencional ou de alta taxa / filtração), uma das principais tecnologias empregadas no tratamento de águas superficiais, normalmente apresenta problemas operacionais para tratar águas com essas características pela dificuldade de coagulação, floculação e sedimentação das substâncias húmicas. Apesar disso, existem diversas ETAs no Brasil que funcionam em ciclo completo com águas que apresentam cor verdadeira elevada e baixa turbidez, como por exemplo a ETA Principal de Salvador$\mathrm{BA}$, que recebe água do reservatório Pedra do Cavalo.

A coagulação e a floculação são processos utilizados para auxiliar a remoção de impurezas da água. A primeira consiste em alterar a força iônica do meio, desestabilizando as partículas, e é realizada através de uma agitação intensa e adição de sais de alumínio ou ferro, ou de polímeros sintéticos ou vegetais catiônicos. A floculação acontece através de uma agitação relativamente lenta, promovendo formação 
e crescimento de flocos para posterior remoção através de sedimentação, flotação ou filtração.

A cinética dos encontros entre partículas durante a floculação leva em consideração dois efeitos: a agregação e a ruptura. A agregação ocorre dos encontros das partículas desestabilizadas, onde a agitação promove uma maior taxa de encontros e forma aglomerados ou flocos. $\mathrm{Na}$ ruptura ocorre erosão dos flocos por forças de cisalhamento, e é normalmente acentuada com uma agitação intensa ou um tempo de floculação excessivo.

Uma agitação intensa na água com flocos pode levar a ruptura dos mesmos. Velocidades relativamente altas nas passagens de água entre as câmaras e na saída do floculador, na entrada do decantador, flotador ou filtro podem gerar agitações que propiciam a erosão dos flocos antes de sua remoção. Isto ocorre devido a diversos fatores, como o mau dimensionamento das passagens, dos orifícios das cortinas de distribuição de água nos decantadores, do fechamento de comportas, de variação de vazão nas estações de tratamento de água, entre outros.

Neste contexto, utilizando uma água com alta turbidez, VOLTAN (2007) avaliou a formação de flocos previamente rompidos e sua sedimentação. Verificou que a refloculação ocorre dependendo do gradiente de velocidade durante a ruptura dos flocos, do tempo de agitação e do gradiente de velocidade de refloculação, raramente atingindo os resultados obtidos com as condições inicias de sedimentação, sem a quebra dos flocos.

Neste contexto, o presente trabalho pretende avaliar os efeitos da ruptura e da refloculação na remoção de cor verdadeira originada pela presença de SHA na água. Para tanto, será otimizado o tratamento por coagulação, floculação e sedimentação da água de estudo utilizando dois coagulantes. Então, será feita uma comparação da cor 
aparente remanescente para diferentes velocidades de sedimentação, em três condições: logo após a floculação; após a ruptura (para três gradientes de velocidades diferentes); e após a refloculação (por diversos tempos e gradientes de velocidades). Desta forma, esta comparação pretende avaliar os efeitos da ruptura e da refloculação nos valores de cor aparente remanescente, para as velocidades de sedimentação estudadas. 


\section{OBJETIVOS}

O objetivo geral é avaliar a ruptura de flocos e refloculação através da comparação da sedimentação dos flocos de água com baixa turbidez e cor verdadeira relativamente alta, utilizando sulfato de alumínio e cloreto férrico como coagulantes, através de ensaios em reatores estáticos (jarteste).

Para tanto, os objetivos específicos do trabalho são:

- selecionar, para a água de estudo, as condições de coagulação (pH e dosagem), as condições de mistura rápida (gradiente de velocidade médio e tempo de mistura rápida), e as condições de floculação (gradiente de velocidade médio e tempo de floculação) para os dois coagulantes;

- estudar as condições de sedimentação dos flocos para o caso da água coagulada, floculada e decantada para os dois coagulantes;

- estudar as condições de sedimentação dos flocos para o caso em que a água foi submetida à coagulação, floculação, agitação rápida (ruptura dos flocos), refloculação com diferentes tempos e decantação para os dois coagulantes. 


\section{REVISÃO DA LITERATURA}

\subsection{Substâncias Húmicas}

A matéria orgânica contém compostos que podem ser convenientemente agrupados em substâncias não húmicas e húmicas. As substâncias não húmicas incluem aquelas com características químicas definidas, como carboidratos, proteínas, aminoácidos, gorduras, graxas e ácidos orgânicos de baixo peso molecular. Elas são facilmente atacadas por microrganismos e têm vida relativamente curta. As substâncias húmicas (ácido húmico-AH, ácido fúlvico-AF e humina), em contraposição, são mais estáveis. São ácidos de coloração escura, tanto alifáticos quanto aromáticos, quimicamente complexos, hidrofílicos e têm alto peso molecular (DI BERNARDO \& DANTAS, 2005).

As SH são classificadas de acordo com suas características de solubilidade. Os ácidos húmicos, solúveis em meio alcalino diluído e insolúveis em meio ácido (precipitam em $\mathrm{pH}<2$ ); os ácidos fúlvicos são solúveis em álcali e ácido e a humina é a fração não extraída por ácido ou álcali diluído. Geralmente, 90\% das substâncias húmicas aquáticas dissolvidas em águas são constituídas de ácidos fúlvicos e o restante (10\%) correspondem aos ácidos húmicos (ROCHA \& ROSA, 2003).

Tanto as substâncias húmicas aquáticas (SHA) quanto as provenientes de solo turfoso (SHT) apresentam moléculas de massa molar variada, geralmente entre $200 \mathrm{Da}$ e $30 \mathrm{KDa}$ e entre 5 e $100 \mathrm{KDa}$, respectivamente. Por esse motivo, as condições de coagulação (tipo e dosagem de coagulante e pH de coagulação) podem resultar totalmente diferentes no tratamento de águas com a mesma coloração devido a presença de SH com propriedades estruturais distintas (CAMPOS 2004)

Thurman e Malcolm (1981) definiram substância húmica aquática como a porção não específica, amorfa, constituída de carbono orgânico dissolvido (COD) em 
pH 2 e adsorvente em coluna de resina XAD 8 com altos valores de coeficientes de distribuição. A matéria orgânica retida pela resina é eluída com solução de $\mathrm{NaOH} 0,1$ mol/L. O extrato obtido é chamado de substâncias húmicas aquáticas (SHA).

Após coleta de água bruta de manancial com elevada cor verdadeira, SLOBODA (2007) extraiu, fracionou e caracterizou as frações das SHA empregando técnicas analíticas como ressonância magnética nuclear de C13 (RMN de C13), infravermelho (IV) e ultravioleta-Visível (UV/VIS), análise elementar e teor de cinzas.

A análise elementar auxilia nas comparações entre classes e origens de diferentes materiais húmicos, uma vez que é possível fazer uma estimativa do conteúdo de grupos funcionais oxigenados, grau de condensação dos carbonos aromáticos e conteúdo de carbonos alifáticos. Os teores de C, H, N e O, apresentados na Figura 3.1, que foram obtidos para as frações SHA, aproximaram-se de dados publicados na literatura, não havendo muita diferença ente as SHA e as SHT. Para todas as frações estudadas por SLOBODA (2007) a porcentagem de oxigênio foi a maior, indicando que as SHA contêm elevado teor de grupos funcionais oxigenados, o que as torna como mais hidrofílicas e mais capazes de formar complexos com metais.

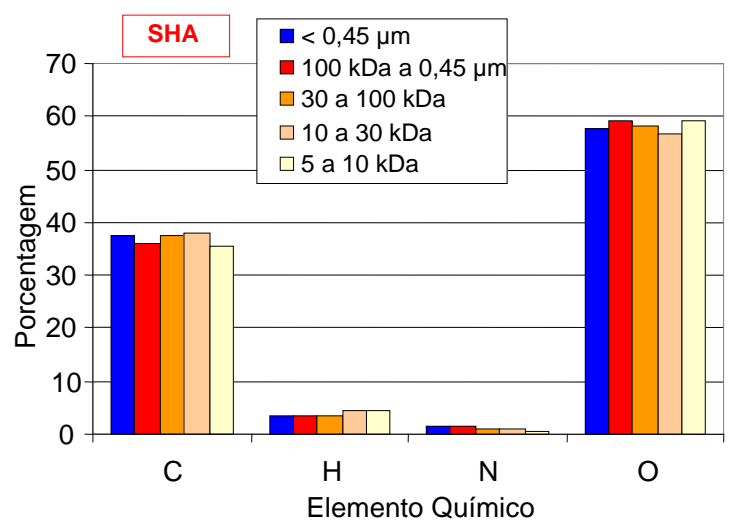

Figura 3.1 - Resultados da análise elementar para SHA Fonte - SLOBODA (2007) 
A análise espectroscópica por ultravioleta visível é utilizada na avaliação da aromaticidade, do grau de humificação das $\mathrm{SH}$ e do grau de condensação de anéis aromáticos. SLOBODA(2007) observou nas SHA estudadas a prevalência de ácidos fúlvicos em relação aos ácidos húmicos, o que torna as SHA com características mais hidrofílicas e mais ácidas. Já a análise dos espectros no IV apontou bandas largas e intensas comum nos espectros das $\mathrm{SH}$, atribuídas à superposição de absorções de bandas individuais Esses espectros confirmam a menor aromaticidade das SHA, efeito esperado já que a maior porcentagem é de ácidos fúlvicos.

SLOBODA (2007) também verificou que na fração de SHA passada na membrana de $0,45 \mu \mathrm{m}$ a maior porcentagem é de ácido fúlvico em relação aos ácidos húmicos, aproximadamente $69 \%$ formada por ácidos fúlvicos. Isso mostra que as SHA são formadas na maior parte por AF em relação em aos $\mathrm{AH}$. A fração $\mathrm{F} 2$ apresentou aproximadamente $98 \%$ de $\mathrm{AH}$ em relação aos AF. As frações menores que $30 \mathrm{kDa}$ apresentaram 100\% de AF, conforme é mostrado na Figura 3.2.

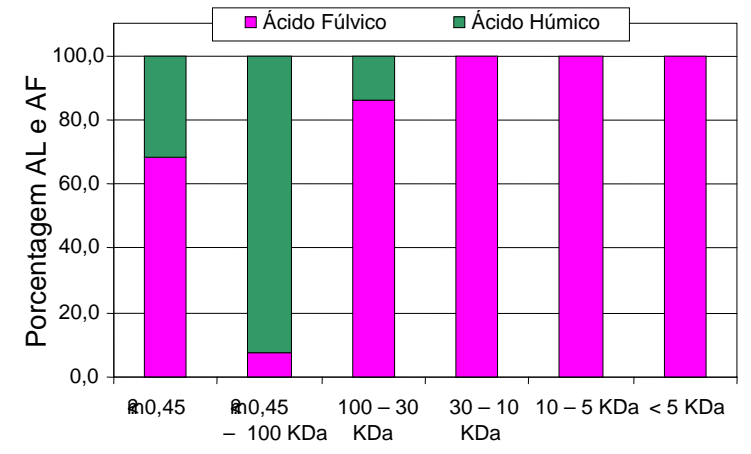

Figura 3.2 - Porcentagem de AH e AF nas diferentes frações das SHA Fonte - SLOBODA (2007)

DANTAS et al. (2007) demonstram que águas com a mesma coloração, mas com substâncias húmicas com propriedades estruturais distintas, podem resultar 
diferentes condições de coagulação. No referido trabalho, foi verificado que para a fração de menor massa molar as dosagens de coagulante requeridas foram maiores, comprovando que o aumento da fração de ácido fúlvico pode dificultar a coagulação com o sulfato de alumínio.

SLOBODA et al. (2007) compararam as características das SHA e SHT e verificaram as diferenças e semelhanças entre as mesmas. Os resultados mostraram que nas SHA a porcentagem de ácidos fúlvicos é maior que a de ácidos húmicos, ao contrário do que ocorre com as SHT. Segundo os autores, como nas SHA há maior porcentagem de ácidos fúlvicos, conseqüentemente há maior quantidade de grupos funcionais oxigenados e maior número de cadeias alifáticas, enquanto que nas SHT as cadeias são mais condensadas, predominando estruturas aromáticas. Em vista destas diferenças, o tratamento de águas com a mesma coloração pode resultar diferente, principalmente a coagulação química e a formação de subprodutos orgânicos halogenados.

SHARP et al. (2006) estudaram os impactos da variação sazonal da matéria orgânica natural na coagulação de águas. Foi verificado que ocorre um aumento significativo da fração de ácido fúlvico em função da época do ano (maior porcentagem no inverno), e que além da concentração de COT, outro fator importante que influi na coagulação é a densidade de carga da matéria orgânica. Os autores concluíram que os ácidos fúlvicos são os principais responsáveis no aumento da densidade de carga de matéria orgânica, motivo pelo qual estes exercem influência significativa na coagulação. 


\subsection{Remoção de cor por coagulação}

Segundo DI BERNARDO \& DANTAS (2005), o fenômeno da coagulação é caracterizado pela desestabilização da dispersão coloidal, obtida pela redução das forças de repulsão entre as partículas de cargas negativas, por meio da adição de produto químico apropriado. No tratamento de água, a coagulação normalmente é feita pela adição de sais de alumínio ou de ferro ou de polímeros sintéticos ou vegetais catiônicos, seguidos por agitação rápida com o intuito de homogeneizar a mistura. Considera-se a coagulação como resultado individual ou combinado da ação de quatro mecanismos de coagulação distintos. Esses mecanismos incluem: compressão de dupla camada elétrica, adsorção e neutralização de carga, varredura, adsorção e formação de pontes. O tipo de interação entre o coagulante químico e as partículas coloidais determina os mecanismos de coagulação (O’ MELIA 1972; DEMPSEY, 1984; EDWARDS \& AMIRTHARAJAH, 1985).

O mecanismo da varredura é muito utilizado nas estações de tratamento de água nas quais se tem floculação e sedimentação (ou flotação) antecedendo a filtração rápida.Uma vez que resulta em flocos de maior tamanho e com velocidades de sedimentação relativamente altas se comparados com flocos obtidos através da coagulação em outros mecanismos. Dependendo da quantidade adicionada de coagulante, do $\mathrm{pH}$ da mistura e da concentração de alguns tipos de íons na água, poderá ocorrer a formação de precipitados. As partículas coloidais presentes comportam-se como núcleos de condensação para estes precipitados.

DI BERNARDO \& DANTAS (2005) afirmam que em águas com baixa turbidez em relação à cor, inicialmente os polímeros resultantes da hidrólise do coagulante reagem com as $\mathrm{SH}$ em dispersão e formam partículas que precipitam e, em seguida reagem com as partículas coloidais. Os autores verificaram também que águas brutas 
provenientes de mananciais distintos com características semelhantes e baixa turbidez, podem apresentar resultados muito divergentes quanto às dosagens de produtos químicos. Esta ultima conclusão reforça a hipótese de que SH provenientes de diferentes substratos apresentam diferentes características e podem ocasionar diferenças nas etapas do tratamento de água.

Para a remoção de $\mathrm{SH}$, quando são utilizados sais de alumínio ou de ferro como coagulantes, estas podem ser agregadas e posteriormente removidas ou por adsorção de SH no precipitado do coagulante; ou pela formação de complexos insolúveis das substâncias com o coagulante. Geralmente o primeiro mecanismo é dominante em valores de $\mathrm{pH}$ básicos e dosagens mais elevadas de coagulante, enquanto o segundo mecanismo, neutralização de carga, prevalece sob condições de $\mathrm{pH}$ ácidos e dosagens menos elevadas de coagulante (EDWARDS \& AMIRTHARAJAH , 1985; PADUA \& DI BERNARDO, 1997). Desta forma a remoção das SH por coagulação depende da concentração do carbono orgânico dissolvido (COD), a natureza química das $\mathrm{SH}$, tipo de coagulante, dosagem de coagulante e do $\mathrm{pH}$.

BLACK \& WILLENS (1961) afirmam que o método mais comum para a remoção de cor da água natural é a coagulação-floculação com sais de alumínio ou ferro e recomendam a faixa de pH ótimo para a coagulação como sendo entre 5,2 e 5,7.

VAN BENSCHOTEN \& EDZWALD. (1990) pesquisaram a coagulação, pelo emprego de ácido fúlvico como causador da cor, com sulfato de alumínio e cloreto de polialumínio como coagulantes, variando o $\mathrm{pH}$ entre 5 e 7 . Os resultados mostraram que as maiores eficiências na remoção de COD ocorreram em maiores valores de $\mathrm{pH}$ com dosagens excessivas de coagulante. Ambos coagulantes apresentaram dosagens e eficiências semelhantes. O estudo também mostrou que a hidrólise e solubilidade dos sais de alumínio são afetadas pela temperatura da água. 
ARMITHARAJAH E MILLS (1982) propuseram se estudar a coagulação, baseada nos diagramas de solubilidade do alumínio e nas condições de coagulação, como dosagem de A12(SO4)3 x 14,3 H2O e pH da mistura. Nestes diagramas, das curvas das espécies hidrolisadas do alumínio, há a delimitação das regiões nas quais predominam os diferentes mecanismos de coagulação.

AMIRTHARAJAH (1989), em experimentos utilizando dispersões com diferentes concentrações de ácido húmico e caulinita, afirma que de acordo com através do diagrama de coagulação é possível representar as regiões otimizadas para remoção de cor e turbidez com sulfato de alumínio. A Figura 3.3 mostra regiões nas quais a dispersão preparada estava com cor verdadeira de $100 \mathrm{uH}$ e sem turbidez. Nesse diagrama são apresentados os resultados dos experimentos de coagulação, onde se obteve remoção de cor verdadeira igual ou acima de $90 \%$.. Duas regiões distintas destacam-se na Figura 3.3: uma região com pH na faixa de 6 a 8,3 com dosagens de coagulante de $12 \mathrm{mg} / \mathrm{l}$ a $55 \mathrm{mg} / \mathrm{l}$ aproximadamente, outra com $\mathrm{pH}$ na faixa de 4 a 4,8 com dosagens de coagulante acima de $10 \mathrm{mg} / \mathrm{l}$. 


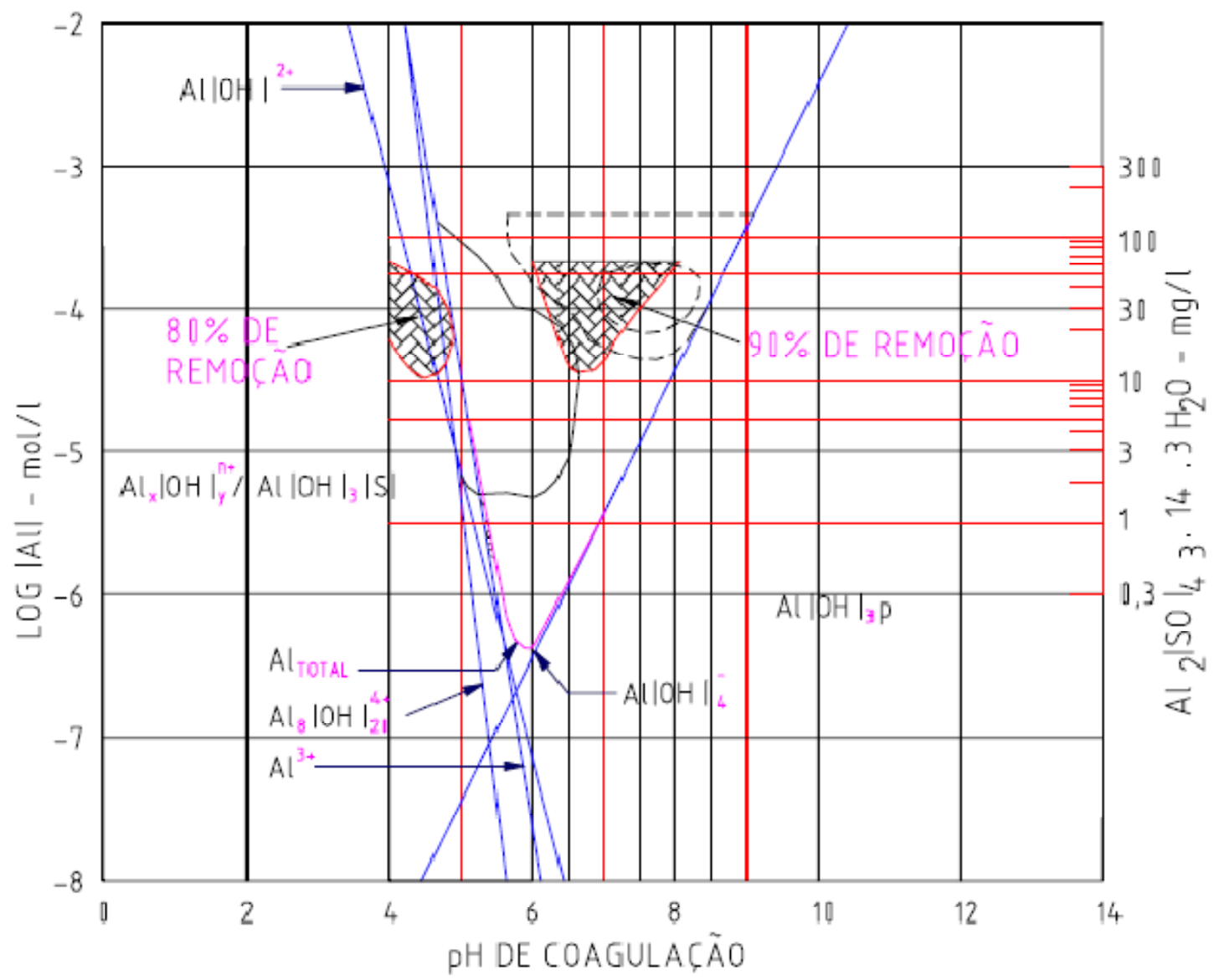

Figura 3.3 - Regiões de remoção de Cor Verdadeira (100uH), Turbidez (0uT) com Sulfato de Alumínio. Fonte - AMIRTHARAJAH (1989).

PAVANELLI (2001) investigou a eficiência de alguns tipos de coagulantes aplicados ao tratamento de água. Foram utilizados os seguintes tipos de coagulantes: sulfato de alumínio, cloreto férrico, cloreto de polialumínio e sulfato férrico. $\mathrm{O}$ autor ressalta que não há dosagem ótima de coagulante, tampouco pH de coagulação ótimo, e sim um par de valores "dosagem de coagulante x pH de coagulação" apropriado para cada situação. Para a escolha deste par de valores, o autor reforça a importância de se construir o diagrama de coagulação para cada água de estudo e, assim, definir as regiões de maiores remoção levando em conta a necessidade de utilização de acidificante ou alcalinizante, os custos dos produtos químicos e a eficiência de remoção desejada. A Figura 3.4 apresenta o diagrama de coagulação de água com cor verdadeira de $100 \mathrm{uH}$, 
coagulada com cloreto férrico, submetida a uma velocidade de sedimentação de 1 $\mathrm{cm} / \mathrm{min}$.

SLOBODA (2007) realizou ensaios de filtração direta com águas com baixa turbidez e cor verdadeira de $100 \mathrm{uH}$ causada por substâncias húmicas aquáticas, obtendo diagramas de coagulação, como o apresentado na Figura 3.5. 
|1/0」」а」 әр бш|

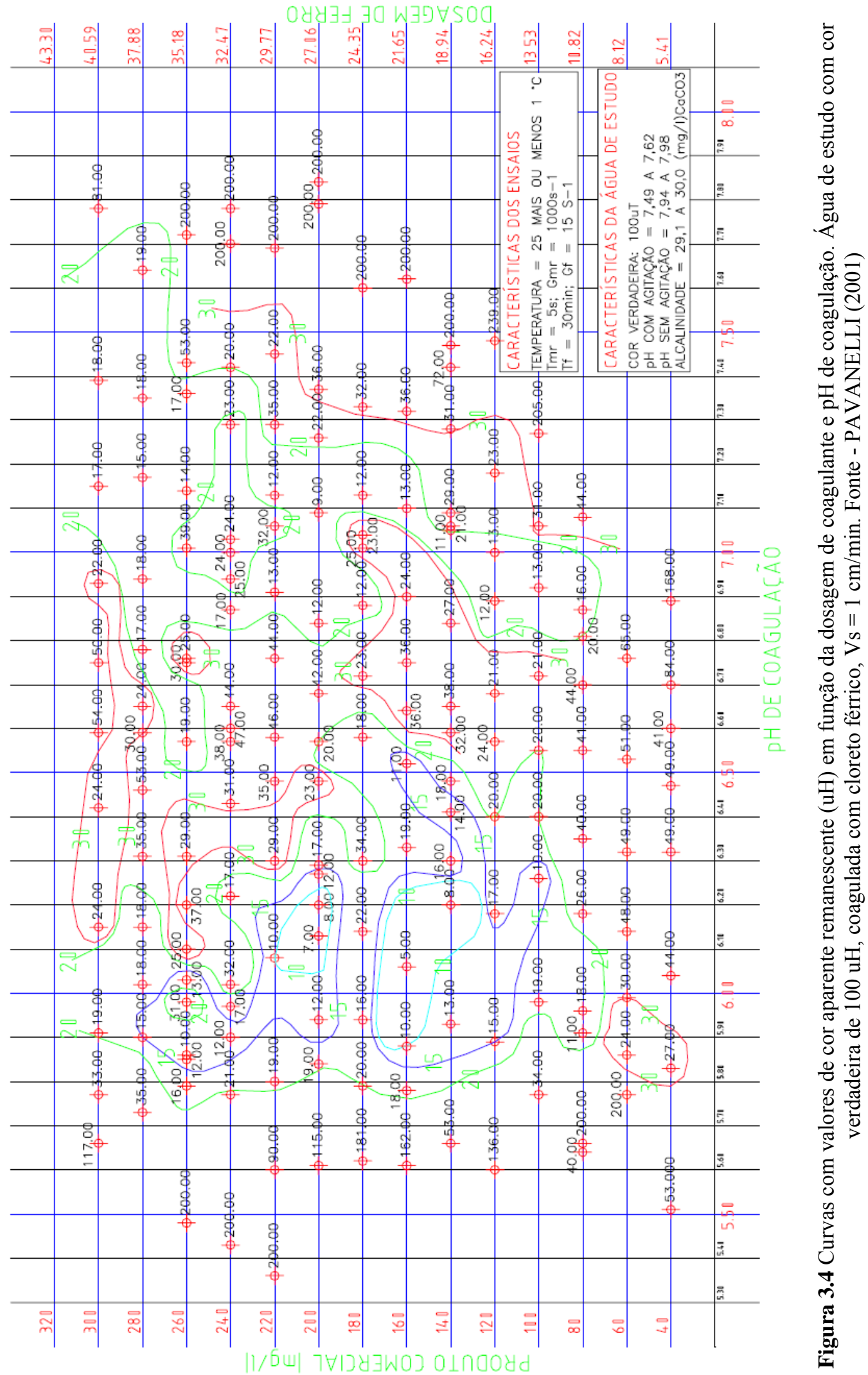

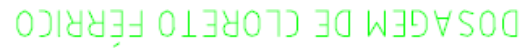




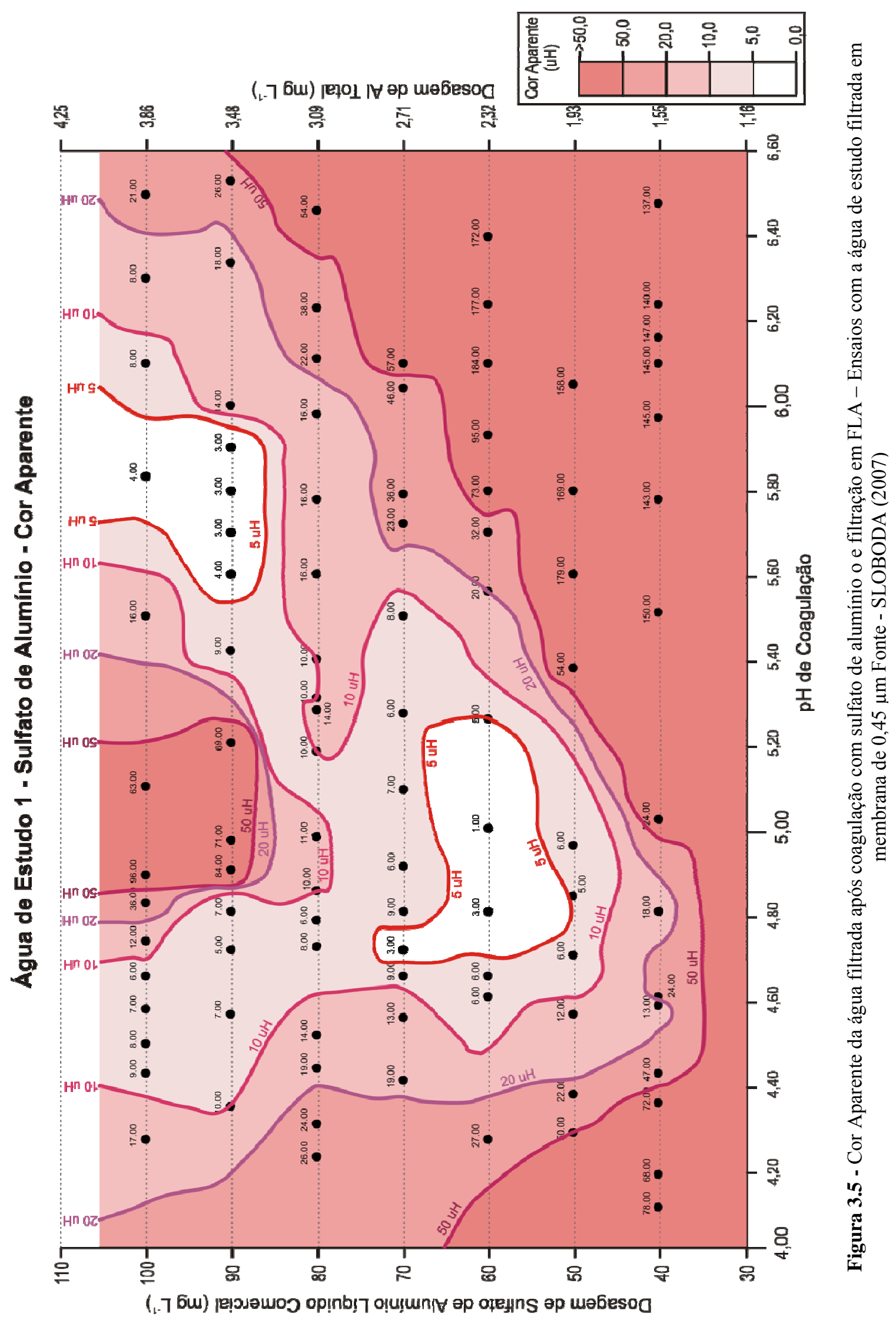




\subsection{Floculação}

Durante a floculação, as interações ocorrem entre as impurezas desestabilizadas e os precipitados de metal, formando partículas passíveis de serem removidas posteriormente por sedimentação, flotação ou filtração. A agitação lenta promove o aumento da taxa de encontros entre as partículas, que se agregam para formar partículas maiores, denominadas flocos.

As interações entre as partículas da água ocorrem devido a três mecanismos distintos: interação pericinética (movimento Browniano), onde a energia térmica causa o movimento errático das partículas; interação ortocinética, onde os encontros das partículas são decorrentes do gradiente de velocidade, tanto no escoamento laminar quanto no turbulento; sedimentação diferenciada, onde partículas com diferentes velocidades de sedimentação podem se encontrar.

A agitação lenta promovida durante a floculação aumenta a taxa de encontros entre as partículas, que se agregam para formar partículas maiores, denominadas flocos. De acordo com o tamanho dos flocos, as forças de cisalhamento geradas pela agitação podem causar a sua ruptura. Desta forma, a agregação e ruptura ocorrem simultaneamente.

Segundo BRATBY (1981), para a determinação dos coeficientes de agregação e ruptura na floculação são realizados ensaios de coagulação, floculação e sedimentação por um tempo longo para condições otimizadas da mistura rápida e diferentes tempos de agitação e de gradiente de velocidade de floculação, e construídas curvas de eficiência de remoção em função do tempo de floculação, para cada gradiente de velocidade estudado.

BRITO (1998), em estudo para a determinação dos coeficientes de agregação e de ruptura, observou que à medida que foi maior o tempo de sedimentação (menores 
Vs), os valores de agregação aumentaram e os valores de ruptura diminuíram. Assim, concluiu que tanto para mistura rápida, quanto para a floculação, a seleção dos valores do gradiente de velocidade e do tempo de agitação que otimizam tais operações é substancialmente influenciada pela velocidade de sedimentação dos flocos.

LIBÂNIO (1995) observou que diversos trabalhos experimentais mostram nítida redução da eficiência da floculação com o contínuo aumento do período de agitação. Assim, durante a floculação, os flocos atingem o seu tamanho máximo a partir do qual passa a prevalecer o mecanismo de ruptura, de forma que o aumento do tempo de floculação tende a reduzir as dimensões dos flocos e também a eficiência da floculação.

Para otimização dos parâmetros de mistura rápida e floculação, após a escolha no diagrama de coagulação de pares de valores de $\mathrm{pH}$ de coagulação versus dosagem de coagulante, fixa-se os parâmetros da floculação e posteriormente, com variação dos parâmetros de mistura rápida e velocidade de sedimentação, chega-se aos valores de otimização de mistura rápida. Com a dosagem dos coagulantes e valores de $\mathrm{pH}$ de coagulação além dos parâmetros de mistura rápida conseguidos anteriormente, procedese aos ensaios de otimização da floculação. Fazendo variações nos parâmetros Tf e Gf, chega-se a gráficos como os apresentados na Figura 3.6 e Figura 3.7. Com esses gráficos é possível determinar os parâmetros ótimos de floculação. (BRITO ,1998; DI BERNARDO \& DANTAS, 2005; VOLTAN, 2007).

Para o caso de uma unidade de floculação composta por câmaras em série, PÁDUA et al (1998) propuseram uma metodologia para determinação dos gradientes de velocidade em cada câmara. Esta metodologia é de extrema importância, porém, por não ser utilizada neste estudo, está apenas sendo citada para conhecimento. 


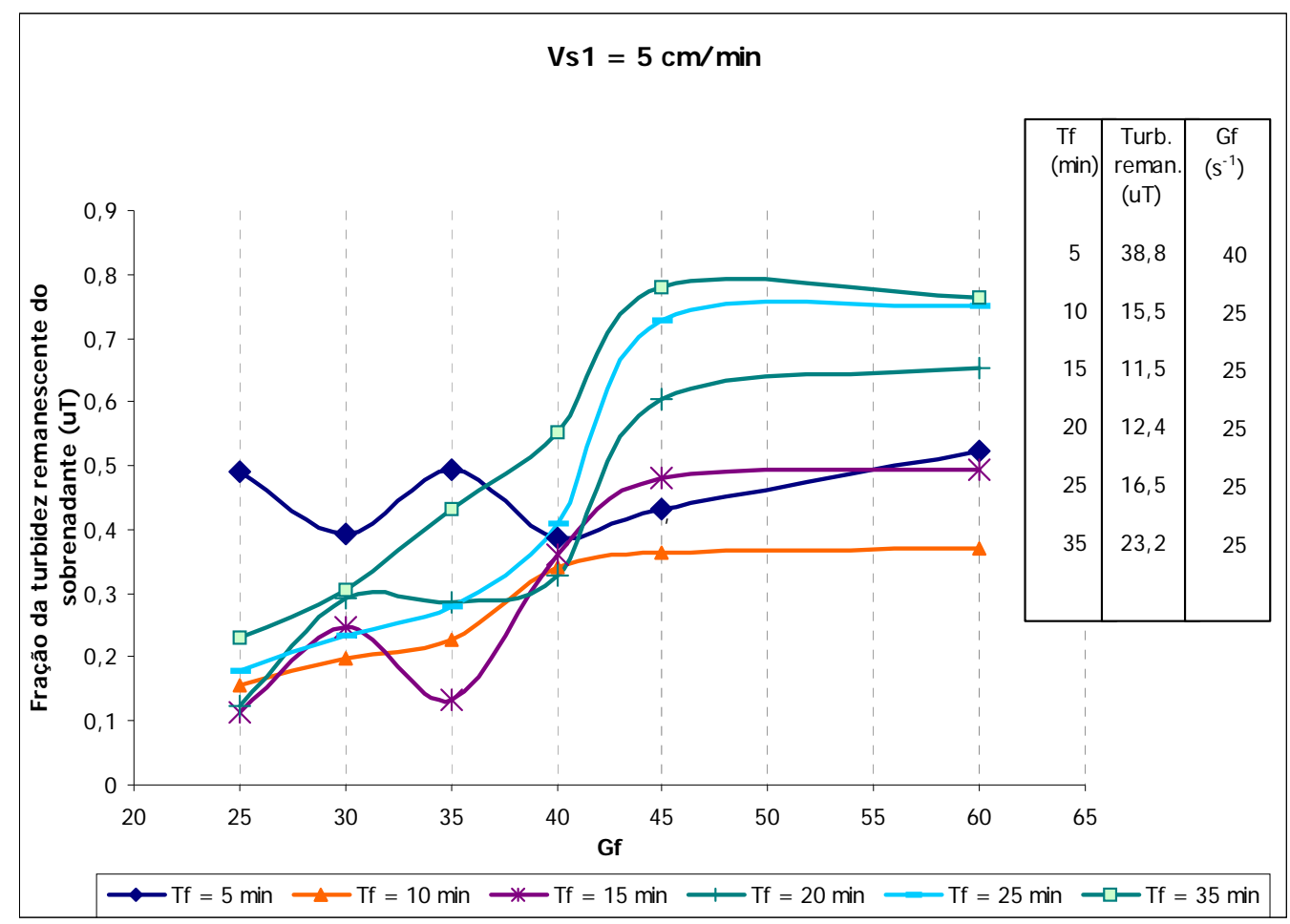

Figura 3.6 - Gráfico típico de remoção por gradiente de velocidade, para cada tempo de floculação.

Fonte - VOLTAN (2007)

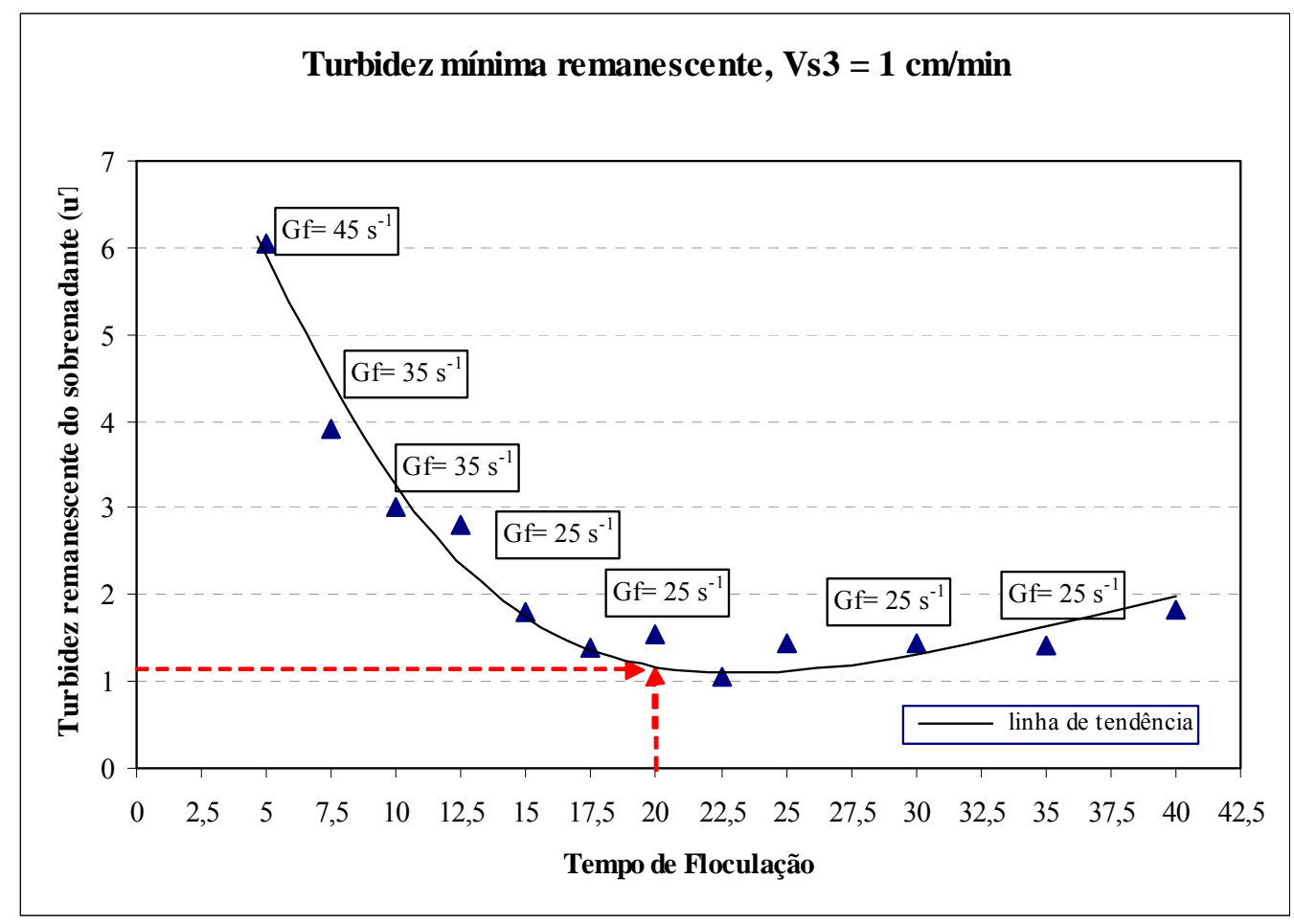

Figura 3.7 - Gráfico típico de turbidez mínima remanescente em função do tempo de floculação com os respectivos gradientes de velocidade de Floculação (Gf), Fonte - VOLTAN 2007. 


\subsection{Ruptura e recrescimento de flocos}

Com o aumento do tamanho dos flocos, as forças de cisalhamento podem causar suas rupturas. Agregação e ruptura ocorrem simultaneamente, conduzindo a uma condição única de distribuição no tamanho dos flocos.

De acordo com YUKSELEN \& GREGORY (2002), o aumento da agitação, em poucos segundos, causa a ruptura em flocos de tamanhos reduzidos. Retornando para a condição anterior de agitação, os flocos voltam a crescer. Isto acontece, pois as interações entre as partículas são fenômenos físicos (forças eletrostáticas ou de Van der Waals), e não existe nenhuma razão para os flocos não se formarem novamente após seu rompimento (YUKSELEN \& GREGORY ,2004b).

Segundo JARVIS et al (2005), os flocos quebram em seus pontos fracos, portanto quando eles se reagrupam tendem a formar estruturas mais estáveis e compactas. Essas estruturas mais estáveis e compactas são a causa do limitado tamanho dos flocos no recrescimento.

Através de um monitoramento dinâmico do tamanho dos flocos, YUKSELEN \& GREGORY $(2002,2004 a, 2004 b)$ realizaram estudos verificando que o recrescimento dos flocos levados à ruptura é limitado e constataram que a ruptura dos flocos não é totalmente reversível, pois estes não atingem o tamanho inicial quando as condições de agitação retornam àquelas da floculação. A reversibilidade da ruptura dos flocos depende da intensidade e do tempo da agitação. Diversas comparações entre os tipos de coagulantes, entre utilização de polímeros e entre diversas condições de ruptura foram realizadas.

YUKSELEN E GREGORY (2002, 2004a e 2004b) realizaram ensaios em jarteste monitorando o tamanho dos flocos através de um sensor óptico. O sistema de 
monitoramento óptico utilizado era composto de uma pequena mangueira transparente que conduzia o sobrenadante do jarro para o equipamento de leitura óptica.

YUKSELEN E GREGORY (2002) estudaram uma água coagulada, floculada por 10 minutos e, a partir deste momento, submetida à ruptura e refloculação diversas vezes. Observa-se na Figura 3.8 que: a ruptura se mostrou mais pronunciada para a maior agitação. Os autores concluíram que: flocos formados se rompem em poucos segundos quando a intensidade da agitação aumenta; retornando às condições de agitação anteriores, observa-se o recrescimento dos flocos até um tamanho limitado, menor do que o tamanho encontrado anteriormente; o recrescimento se mostrou mais limitado para agitação mais intensa; e que, desta forma, nota-se que a irreversibilidade da ruptura dos flocos é parcial.

YUKELSEN E GREGORY (2004a) estudaram a ruptura e recrescimento dos flocos para diversos coagulantes a base de alumínio e a influência do tempo de agitação relativo à ruptura dos flocos. Os resultados destes ensaios podem ser observados na Figura 3.9. Novamente foi possível observar que os flocos, durante a refloculação, não retornaram as condições iniciais.Neste trabalho, os autores concluíram que o recrescimento se mostrou mais limitado para agitação mais intensa, assim como de maior duração. 


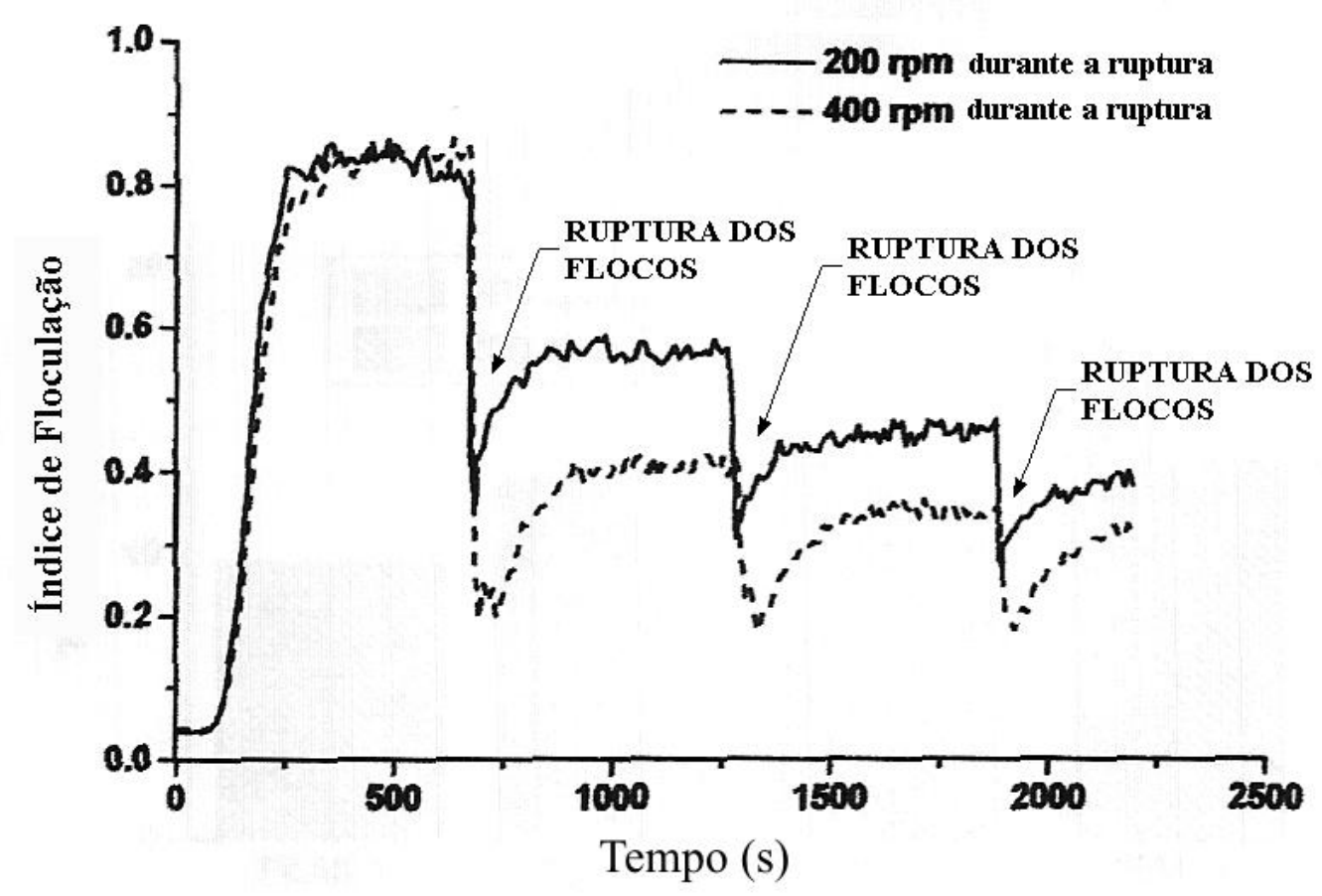

Figura. 3.8 - Desempenho da floculação, ruptura e refloculação, para diferentes rotações durante a ruptura. Fonte: YUKELSEN E GREGORY (2002).

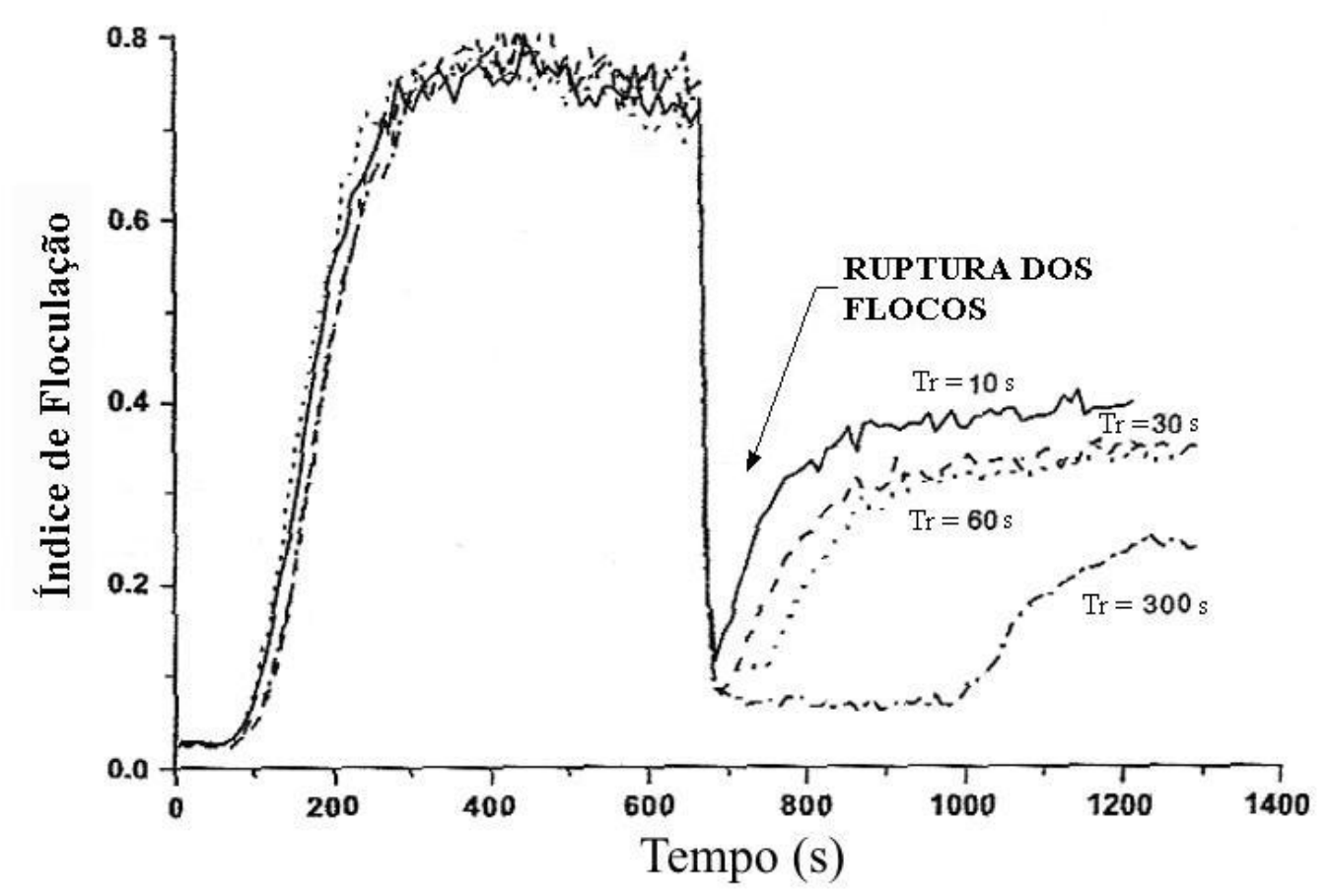

Figura 3.9 - Desempenho da floculação, ruptura e refloculação, para diferentes tempos de ruptura. A ruptura ocorreu à 400 rpm. Fonte: YUKELSEN E GREGORY (2004a).

JARVIS et al. (2005a) utilizaram em seus estudos uma água coletada em um reservatório que apresentava como características uma quantidade considerável de 
matéria orgânica natural, baixa turbidez e alcalinidade. O estudo utilizou diversos coagulantes e avaliou a ruptura e a reagregação através do tamanho dos flocos, utilizando equipamento contador de partículas por difração de laser. O comportamento para diferentes coagulantes durante a floculação, ruptura e refloculação podem ser observados na Figura 3.10.

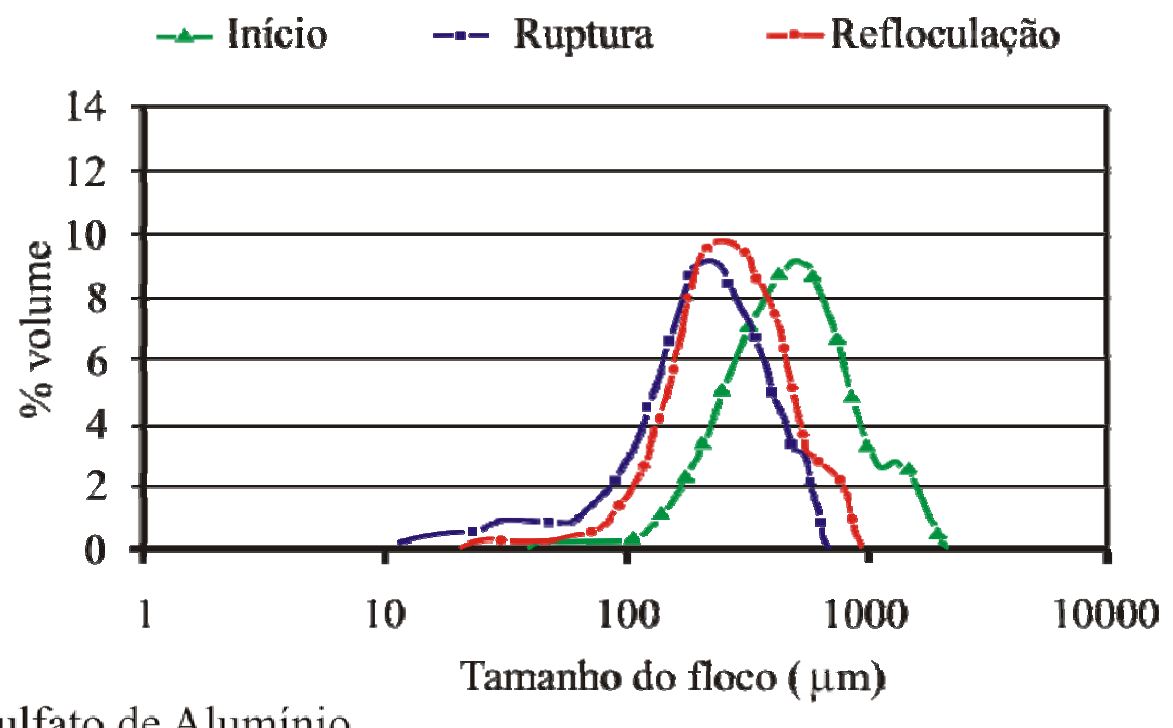

\section{Sulfato de Alumínio}

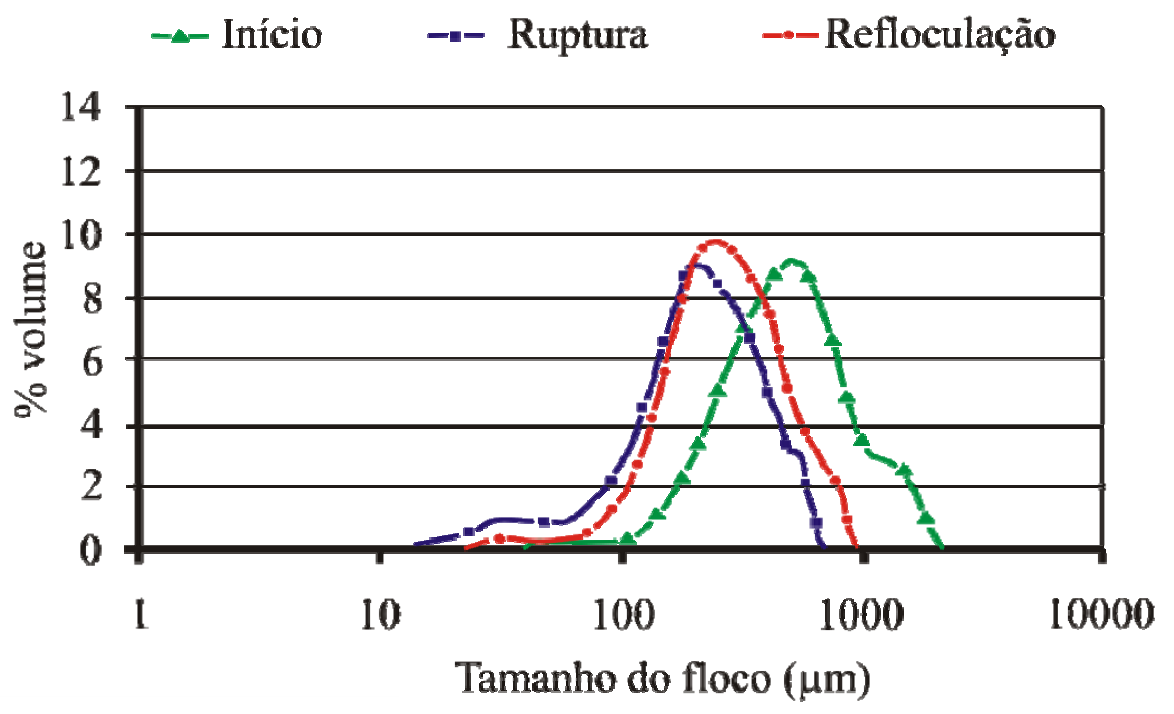

\section{Sulfato Férrico}

Figura 3.10 - Distribuição do tamanho dos flocos durante a floculação, ruptura e refloculação, para os coagulantes: Sulfato de Alumínio e Sulfato Férrico; Fonte: JARVIS et al. (2005a). 
JARVIS et al. (2006) compararam as características físicas dos flocos de água com matéria orgânica formados com a adição ou não de polímero auxiliar de floculação com flocos de água sem matéria orgânica. O sulfato férrico foi utilizado como coagulante primário e um polímero catiônico foi utilizado como auxiliar. O tamanho do floco após a floculação, na ruptura e na refloculação foi mensurado através de equipamento contador de partículas por difração de laser. No estudo, foi utilizada água bruta obtida em reservatório em Yorkshire, Inglaterra. As características da água estudada são apresentadas na Tabela 3.1 .

Tabela 3.1 - Características da água estudada por JARVIS et al.(2006)

\begin{tabular}{|c|c|}
\hline Características & Valor \\
\hline COD & $6.9 \mathrm{mg} / \mathrm{L}$ \\
\hline Turbidez & $5.0 \mathrm{uT}$ \\
\hline $\mathrm{pH}$ & 6.0 \\
\hline Alcalinidade & $<10 \mathrm{mg} / \mathrm{L} \mathrm{de} \mathrm{CaCO}_{3}$ \\
\hline Condutividade elétrica & $75 \mu \mathrm{s} / \mathrm{cm}$ \\
\hline Absorbância a $254 \mathrm{~nm}$ & $50.81 / \mathrm{m}$ \\
\hline
\end{tabular}

A capacidade de recrescimento dos flocos foi observada após os mesmos serem submetidos a um gradiente de velocidade $200 \mathrm{rpm}$ por $15 \mathrm{~min}$ para sua ruptura, seguido de um gradiente de refloculação de $30 \mathrm{rpm}$. A Figura 3.11 apresenta a evolução no tamanho das partículas com o tempo durante a experimento. Os autores concluíram que a presença de matéria orgânica na água acarreta na formação de flocos com estruturas significantemente diferentes. A adição do polímero não acarretou em fortalecimento estrutural dos flocos. Todos os flocos estudados apresentaram capacidade limitada de reformação após a ruptura dos mesmos. 


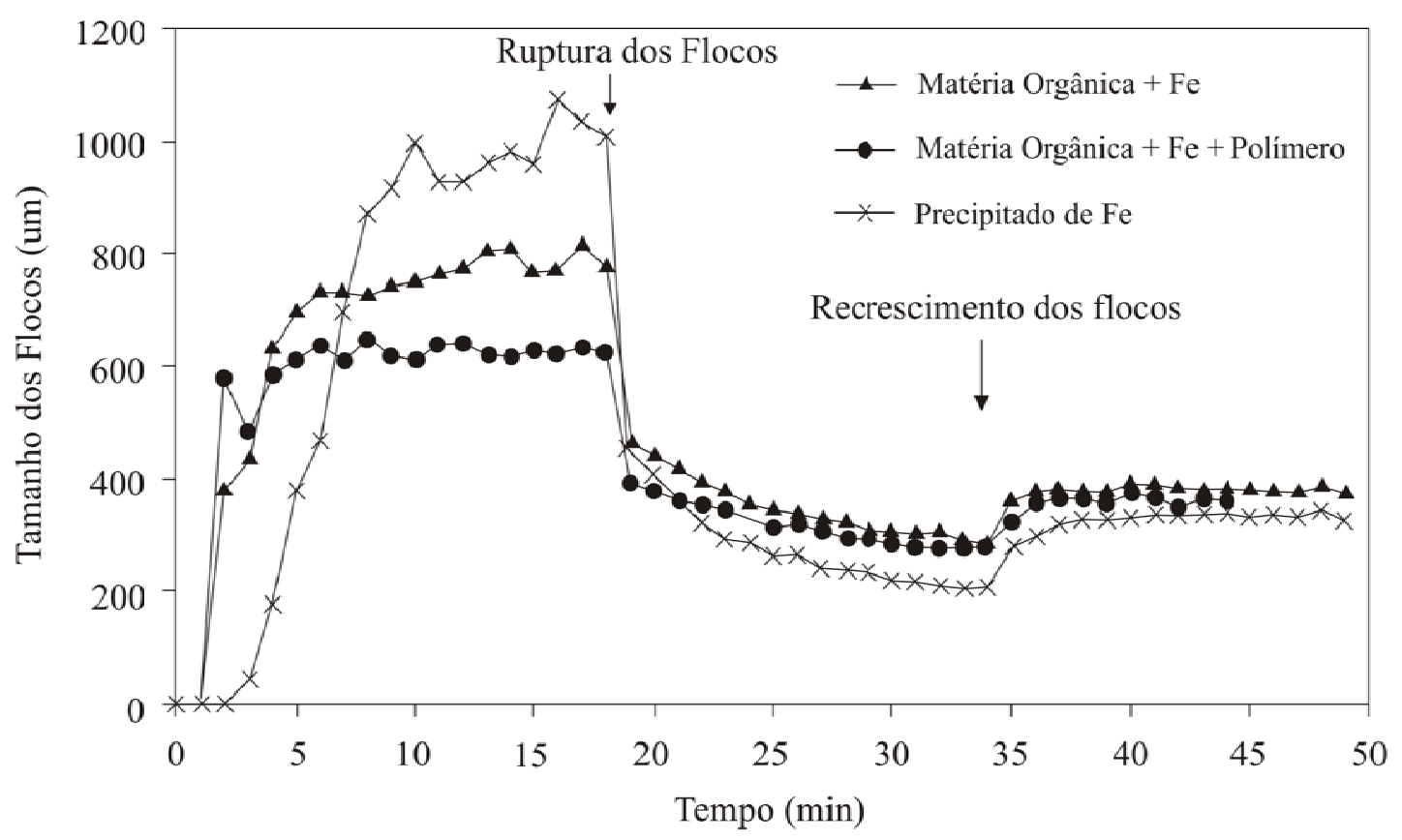

Figura 3.11.- Capacidade de recrescimento dos flocos após serem submetidos a um gradiente de ruptura

Fonte - JARVIS (2006).

JARVIS et al. (2005b) estudaram formas de calcular a resístência dos flocos, e concluíram que isso é possível relacionando o tamanho dos mesmos no final da floculação com aquele obtido no fim da ruptura. Deste modo, os flocos rompidos que permanecerem de tamanho mais próximo àquele anterior à ruptura possuem maior resistência. Os autores observaram que, geralmente, conforme o tamanho dos flocos aumenta, sua resistência ao cisalhamento diminui.

VOLTAN (2007) observou que os resultados dos trabalhos sobre o efeito da ruptura e refloculação encontrados na literatura abordam, principalmente, os tamanhos dos flocos. Raramente se observa a relação da ruptura e refloculação com a sedimentação. Os resultados sobre a sedimentação dos flocos apresentados são relativos a tempos de sedimentação muito longos (em geral maiores que $20 \mathrm{~min}$ ) conduzindo a velocidades de sedimentação extremamente baixas, menores que $0,3 \mathrm{~cm} / \mathrm{min}$. Estas 
velocidades são muito distantes das encontradas na prática em decantadores, na ordem de 1 à $5 \mathrm{~cm} / \mathrm{min}$. A sedimentação não depende só do tamanho dos flocos, mas também de características como densidade e força de ligação, entre outros.

No referido estudo, foi utilizada água com turbidez elevada (100 uT), coagulada com sulfato de alumínio. Primeiramente, foi selecionado o par de valores "dosagem de coagulante x pH de coagulação" através da construção de diagramas de coagulação. Os parâmetros de mistura rápida e floculação foram otimizados. A dosagem de sulfato de alumínio escolhida foi $55 \mathrm{mg} / \mathrm{l} \mathrm{com}$ o pH de coagulação de 6,50. O tempo de mistura rápida selecionado foi de $10 \mathrm{~s}$ com gradiente de velocidade de $600 \mathrm{~s}^{-1}$. Na floculação determinou-se o gradiente de velocidade de $25 \mathrm{~s}^{-1}$ e tempo de $20 \mathrm{~min}$. Após essa fase, foi realizado um ensaio onde foram coletadas amostras nos tempos 1, 2, 3, 4, e 6 min, possibilitando a construção de uma curva de sedimentação característica da água estudada.

Para avaliar os efeitos da ruptura dos flocos na eficiência da sedimentação foram realizados ensaios em equipamento jarteste onde, ao final da floculação, aumentou-se a rotação das paletas do equipamento até gradientes de velocidade para ruptura dos flocos (Gr) de 75,150 e $250 \mathrm{~s}^{-1}$. O tempo de ruptura (Tr) foi de $10 \mathrm{~s}$, sendo $4 \mathrm{~s}$ de aceleração da rotação do equipamento até atingir a rotação equivalente ao $\mathrm{Gr}, 5$ s de agitação nesta rotação, e 1 s para desaceleração das paletas. Segundo o autor, buscou-se trabalhar com o menor tempo de ruptura possível, reproduzindo uma situação de ruptura de flocos em passagens e comportas de uma Estação de Tratamento de Água, uma vez que resultados para grandes tempos de ruptura, da ordem de minutos, não teriam significado prático nenhum. Após o término do Tempo de ruptura, foram coletadas amostras nos tempos 1 , 2, 3, 4, e 6 min para a composição de uma curva de sedimentação após a ruptura dos flocos. 
$\mathrm{Na}$ última etapa foram realizados ensaios como os de ruptura nos quais, após a agitação intensa, os jarros retornaram as condições de floculação com os gradientes de velocidade de 25 e $20 \mathrm{~s}^{-1}$. Os tempos de refloculação estudados foram de 5, 7,5, 10, 12,5, $15,17,5,20,25,30,35$ e 40 min. Com o fim do tempo de refloculação, coletaram-se amostras nos tempos $1,2,3,4$, e 6 minutos.

Assim, através de comparação da sedimentação ocorrida nessas diferentes condições, foi possível avaliar o efeito da ruptura e refloculação na água estudada, conforme se pode observar na Figura 3.12. Os efeitos do aumento da agitação e conseqüente ruptura nos diferentes gradientes utilizados são mostrados na Figura 3.13

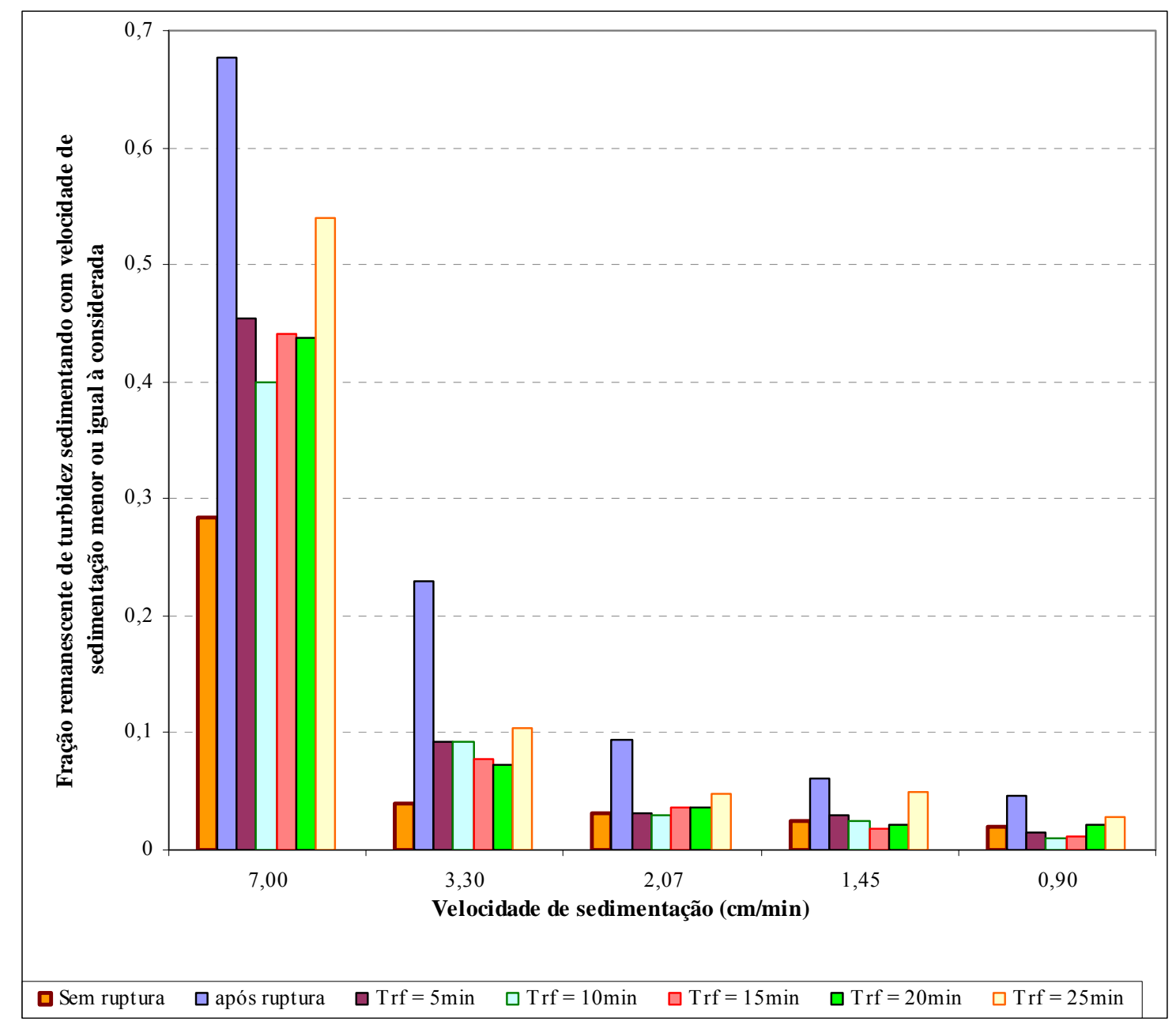

Figura 3.12 - Fração remanescente de turbidez em função da velocidade de sedimentação, para o gradiente de velocidade na ruptura de $75 \mathrm{~s}^{-1}$ e gradiente de velocidade de refloculação de $25 \mathrm{~s}^{-1}$. Fonte VOLTAN (2007) 

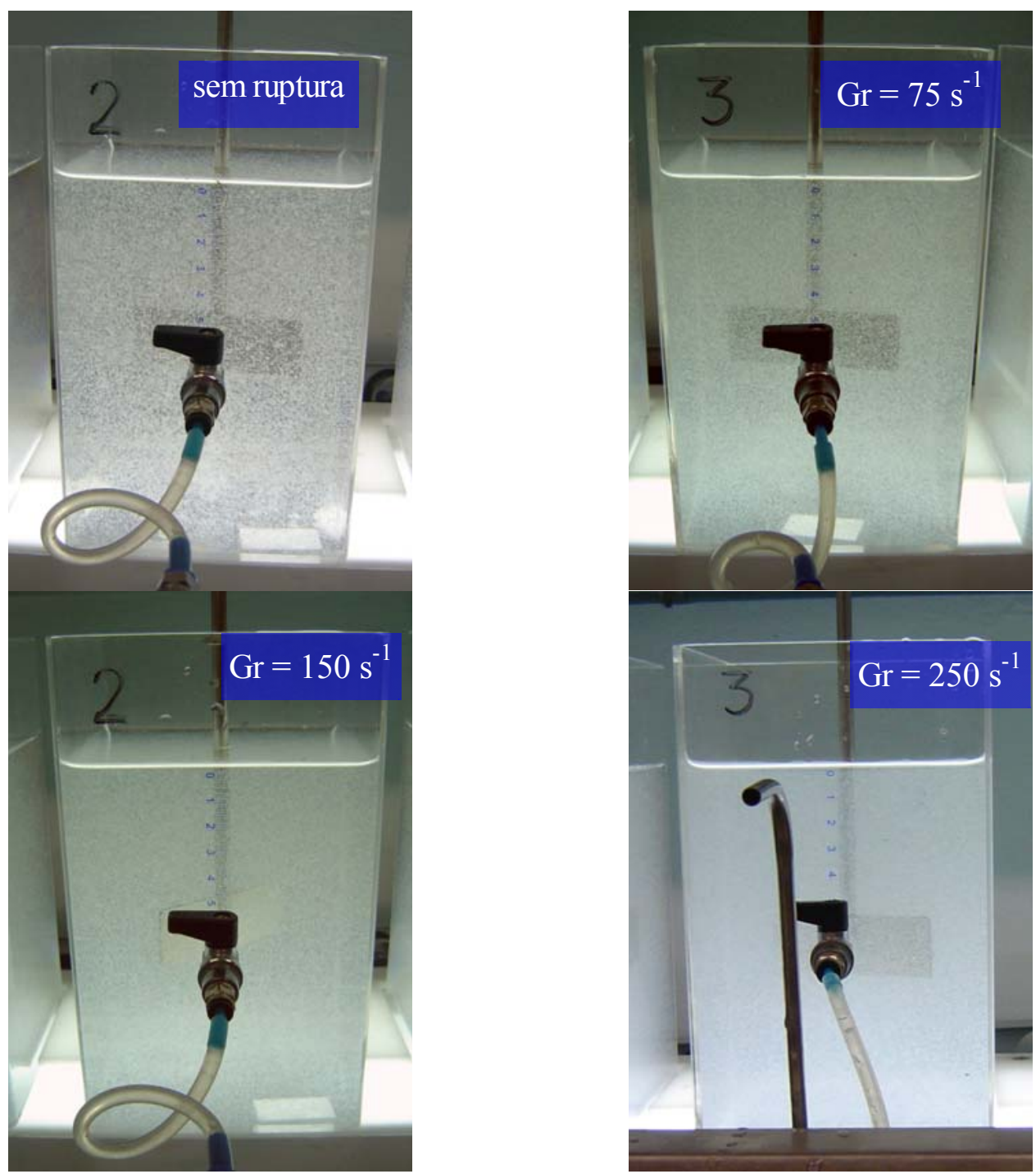

Figura 3.13 - Vista frontal do jarro mostrando os flocos ao final da floculação e após a ruptura, para os gradientes de velocidade de ruptura de 75, 150 e 250 s-1 Fonte - VOLTAN (2007)

Nesse estudo, o autor desenvolveu uma metodologia para a programação do aparelho de jarteste, com a variação da rotação das palhetas ao longo do tempo, segundo o gráfico apresentado na Figura 3.14. 


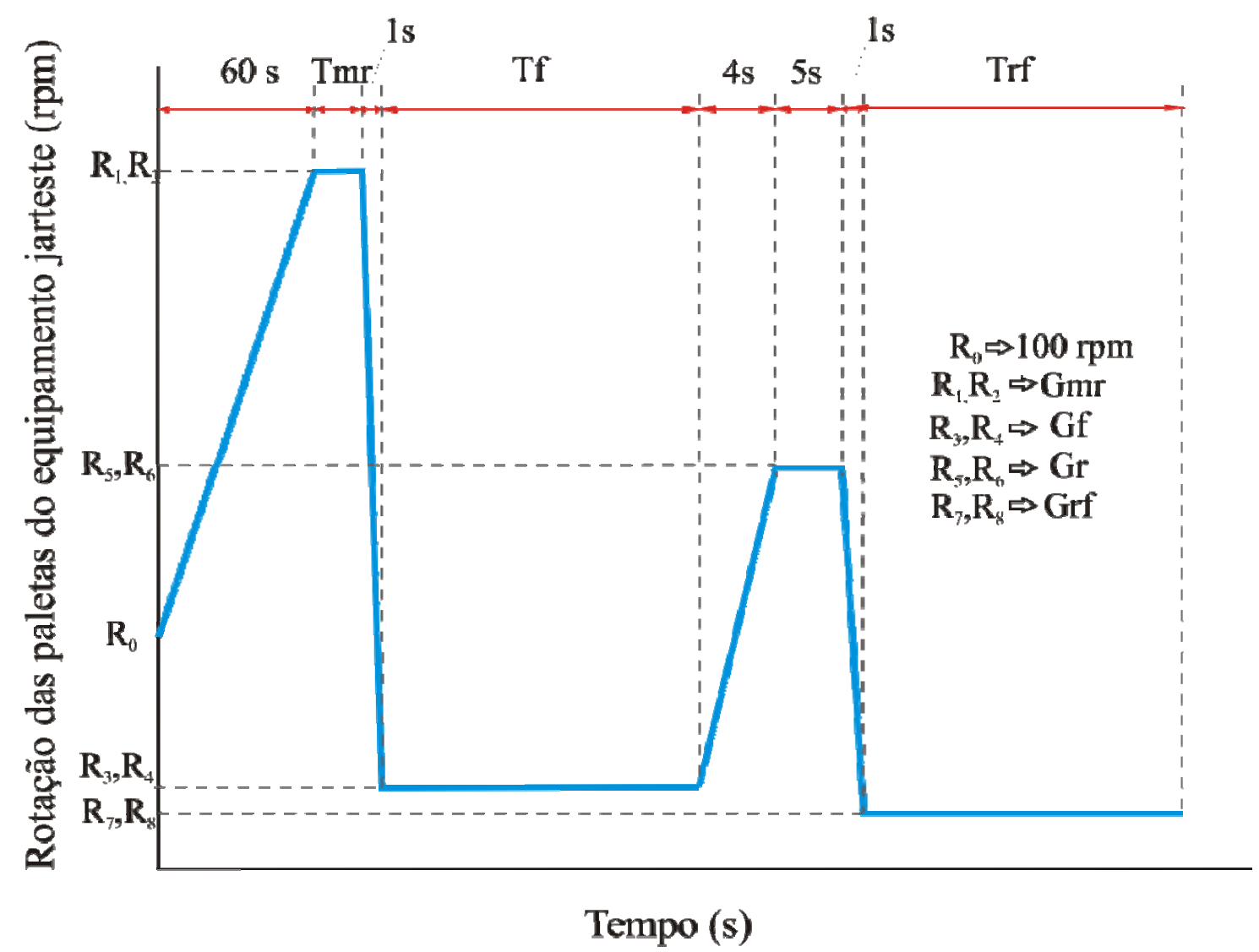

Figura 3.14 - Rotação das paletas do equipamento de Jarteste em função do tempo de ensaio e a relação entre a rotação e o respectivo gradiente de velocidade, para os ensaios realizados

Fonte - VOLTAN (2007)

Para o cálculo das velocidades de sedimentação correspondentes aos tempos 1 , 2, 3, 4, e 6 min, foi divida a distância entre a superfície da água e o ponto de coleta pelo tempo de sedimentação. Devido ao grande número de coletas, ao volume descartado e ao volume coletado, houve um rebaixamento significativo na superfície da água. Assim, fez-se necessário considerar este rebaixamento. Sendo assim, na Figura 3.15 representase graficamente a distância média em cada coleta entre o nível de água no jarro e o ponto de coleta, para poder calcular as velocidades de sedimentação correspondentes. Para os tempos de coleta estudados, as alturas médias de sedimentação encontradas foram de 7,$0 ; 6,6 ; 6,2 ; 5,8$; e 5,4 centímetros, e a partir destes valores foram calculadas 
as velocidades de sedimentação respectivas de cada coleta: 7,00;3,30;2,07; 1,45 e 0,90 $\mathrm{cm} / \mathrm{min}$

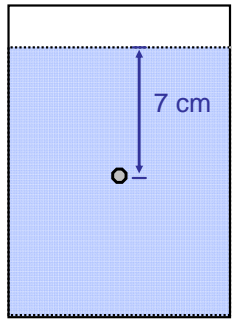

Coleta 1 altura inicial: $7,15 \mathrm{~cm}$ altura final: $6,85 \mathrm{~cm}$

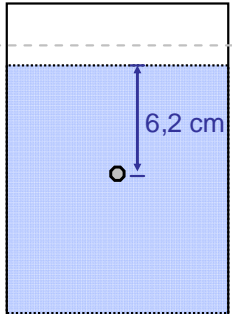

Coleta 3 altura inicial: $6,35 \mathrm{~cm}$ altura final: $6,05 \mathrm{~cm}$

altura média durante a coleta: $7,0 \mathrm{~cm}$ altura média durante a coleta: $6,6 \mathrm{~cm}$ altura média durante a coleta: $6,2 \mathrm{~cm}$

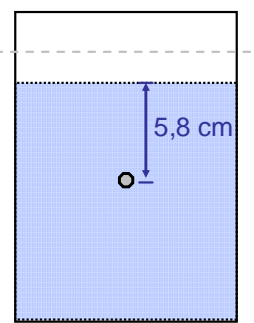

Coleta 4

altura inicial: $5,95 \mathrm{~cm}$ altura final: $5,65 \mathrm{~cm}$ altura média durante a coleta: $5,8 \mathrm{~cm}$

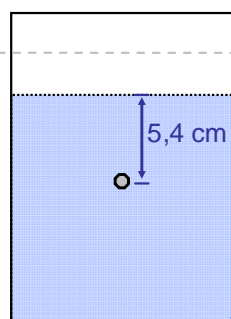

Coleta 5

altura inicial: $5,55 \mathrm{~cm}$ altura final: $5,25 \mathrm{~cm}$ altura média durante a coleta: $5,4 \mathrm{~cm}$

Figura 3.15 - Esquema dos jarros do equipamento jarteste mostrando altura de sedimentação média em cada coleta. Fonte - VOLTAN (2007)

VOLTAN (2007) concluiu que a ruptura, em poucos segundos, prejudicou a remoção dos flocos por sedimentação. Quanto maior o gradiente de velocidade na ruptura, pior foi a eficiência de remoção, mesmo após a refloculação. A refloculação, mesmo nos primeiros minutos, melhora a eficiência de remoção se comparada com logo após a ruptura. Quanto menor o gradiente de velocidade durante a refloculação, menores foram os valores da turbidez remanescente do sobrenadante. Apenas para velocidades de sedimentação mais baixas e gradientes de velocidade de ruptura e gradientes de velocidade de refloculação $75 \mathrm{~s}^{-1}$ e $15 \mathrm{~s}^{-1}$, respectivamente, foi possível obter sobrenadante com eficiência de remoção similar à encontrada inicialmente, sem ruptura. 


\section{MATERIAIS E MÉTODOS}

Neste capítulo são apresentados os materiais, os equipamentos e a metodologia utilizados para a realização do trabalho.

\subsection{MATERIAIS E EQUIPAMENTOS}

Como coagulantes, foram utilizados o sulfato de alumínio líquido comercial $\mathrm{Al}_{2}\left(\mathrm{SO}_{4}\right)_{3} \times 14,3 \mathrm{H}_{2} \mathrm{O}$ (50 \% do valor de massa em água) isento de ferro com 7,3\% de $\mathrm{Al}_{2} \mathrm{O}_{3}$ e o cloreto férrico líquido comercial $\mathrm{FeCl}_{3} \times 6 \mathrm{H}_{2} \mathrm{O}$ com $38 \%$ de cloreto férrico da Nheel Química Ltda. Os coagulantes foram preparados em soluções com concentração final de $20 \mathrm{mg} / \mathrm{L}$ dos produtos comerciais.

Para correção de $\mathrm{pH}$, foram utilizadas soluções de Hidróxido de Sódio, $\mathrm{NaOH}$, com concentração de $1 \mathrm{mg} / \mathrm{L}$. As soluções foram preparadas semanalmente, com água deionizada. Para conferir turbidez à água de estudo foi utilizada caulinita, com nome comercial de caulim micronizado. Os equipamentos utilizados para a execução dos ensaios e para medir os parâmetros, estão descritos a seguir:

- Potenciômetro modelo $420 \mathrm{~A}$ da marca ORION com eletrodo combinado para medição do $\mathrm{pH}$;

- turbidímetro modelo $2100 \mathrm{P}$ da marca HACH e cubeta para medição da turbidez;

- espectofotômetro de leitura digital, modelo DR4000 da marca HACH, com duas cubetas (mostrados na Figura ) para medição da cor verdadeira e cor aparente;

- reatores estáticos de bancada, jarteste, da marca NOVA ÉTICA, com seis jarros com capacidade de $2 \mathrm{~L}$ cada, provido de eixos com paletas e rotações de variação programável entre 20 e 600 rpm. (Figura 4.2) Destaca-se que as 
rotações das paletas neste equipamento são ajustadas por um controlador digital com capacidade para seis programações diferentes;

- Equipamentos diversos: Cronômetro digital; Termômetro de bulbo; Balança eletrônica da marca METTLER, vidrarias variadas, e copos descartáveis de $50 \mathrm{ml}$ de volume para efetuar as coletas.

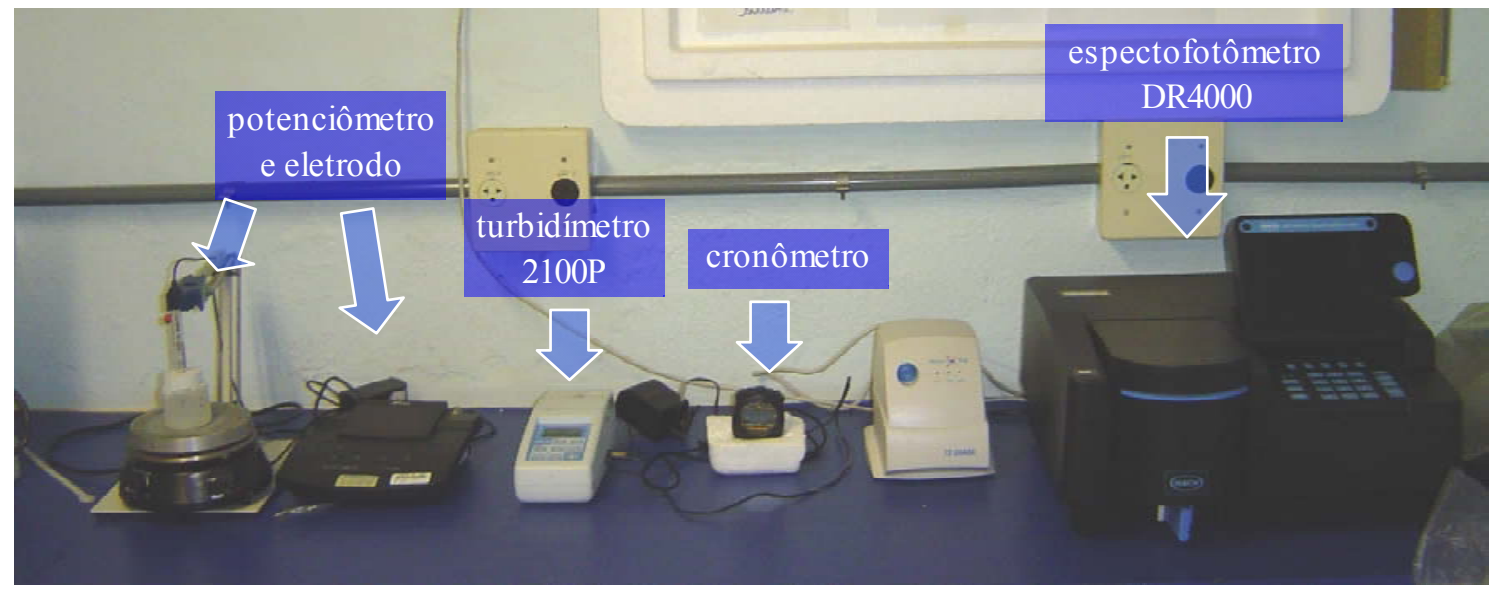

Figura 4.1 - Foto dos equipamentos utilizados nos ensaios de bancada.

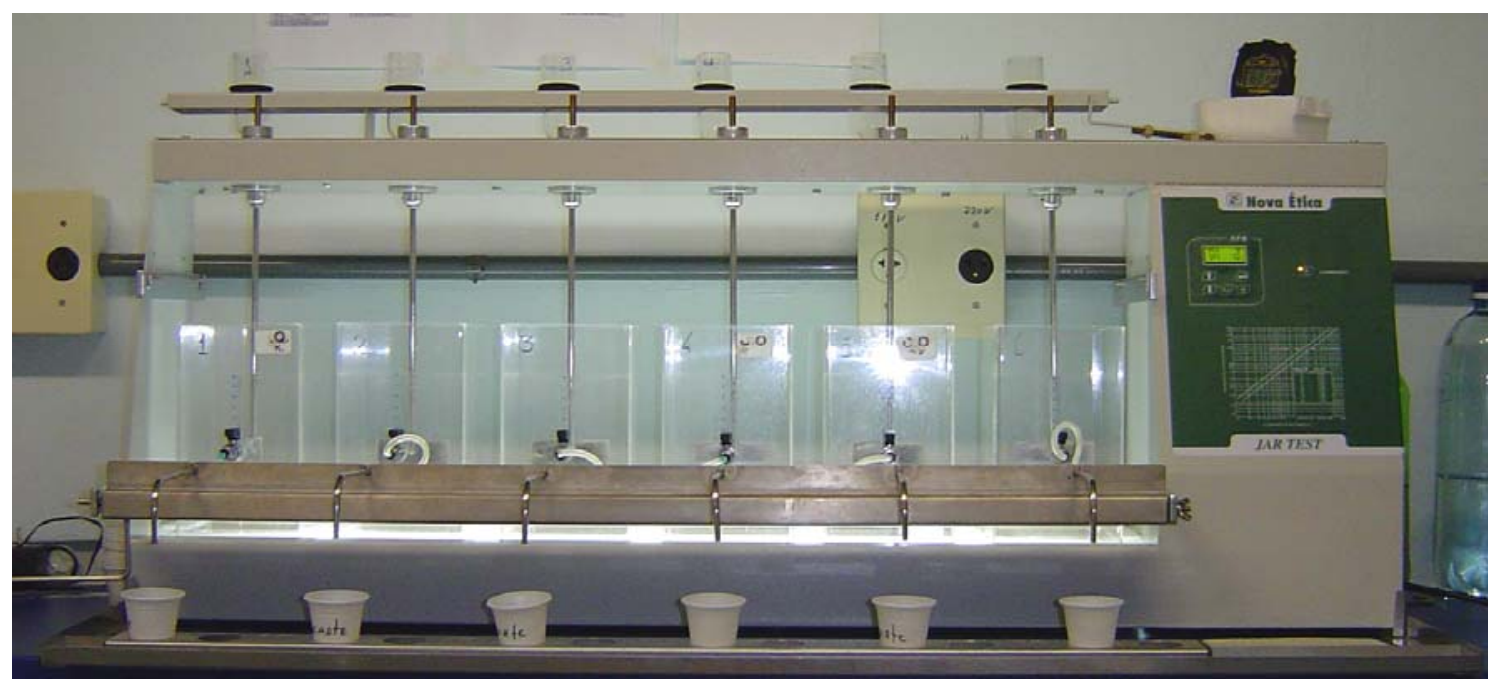

Figura 4.2 - Foto do equipamento Jarteste (reator estático de bancada). 


\subsection{METODOLOGIA}

O trabalho foi realizado com o sulfato de alumínio líquido comercial e o cloreto férrico líquido comercial como coagulantes e uma única água de estudo, preparada com características semelhantes às encontradas no estudo pela HIDROSAN ENGENHARIA (2000) com a água afluente à da ETA Principal de Salvador, conforme parâmetros da Tabela 4.1. A água de estudo será apresentada em detalhes mais adiante.

Tabela.4.1 - Faixa de valores dos parâmetros da água de estudo.

$\begin{array}{cc}\text { Parâmetro } & \text { Valor } \\ \text { Turbidez } & 4 \text { a } 6 \mathrm{uT} \\ \text { Cor Aparente } & 100 \mathrm{a} 150 \mathrm{uH} \\ \text { Cor Verdadeira } & 90 \mathrm{a} 110 \mathrm{uH} \\ \text { pH } & 5,8 \text { a } 6,2 \\ \text { Temperatura } & 25 \pm 1{ }^{\circ} \mathrm{C}\end{array}$

Foram realizados o preparo e caracterização da água de estudo, incluindo a extração de SHA para conferir a cor à água. Na seqüência, os ensaios foram realizados em jarteste nas etapas descritas a seguir: determinação da dosagem de coagulante e $\mathrm{pH}$ de coagulação; determinação dos parâmetros da mistura rápida; determinação dos parâmetros de floculação; construção de curva de sedimentação; e ruptura dos flocos, refloculação e construção de nova curva de sedimentação. Essas etapas estão ilustradas no fluxograma apresentado na Figura 4.3. 


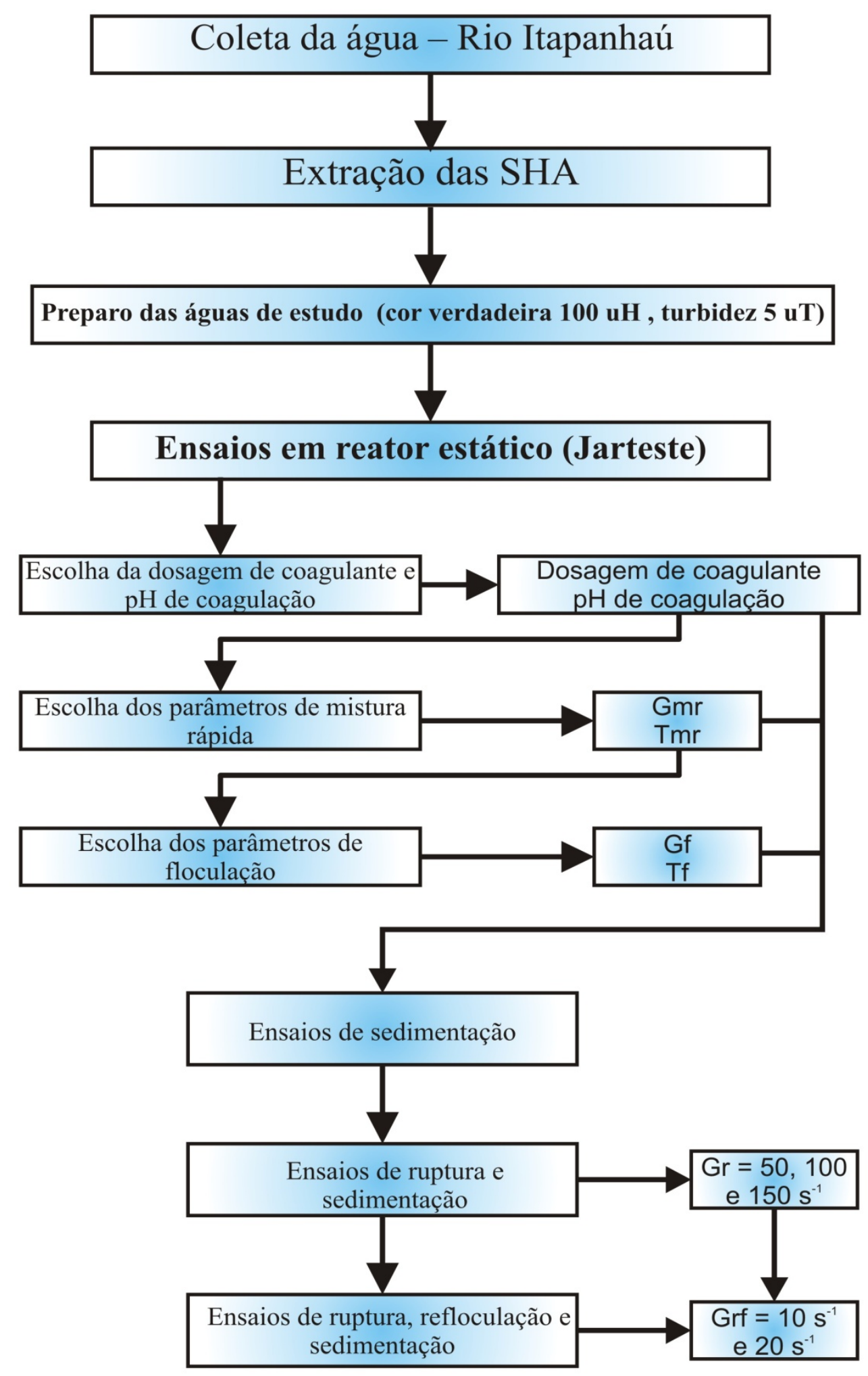

Figura 4.3 - Fluxograma dos procedimentos realizados para cada coagulante. 


\subsection{Coleta da água bruta e extração das substâncias húmicas aquáticas}

A água contendo as SHA foi coletada no rio Itapanhaú (Figura 4.4), localizado no município de Bertioga no Estado de São Paulo, próximo ao cruzamento da Rodovia Rio - Santos e pertence ao Parque Estadual da Serra do Mar. A água bruta foi acidificada a pH 2,5, com ácido clorídrico concentrado, a fim de prevenir a precipitação de hidróxidos metálicos, e armazenada em recipientes plásticos.
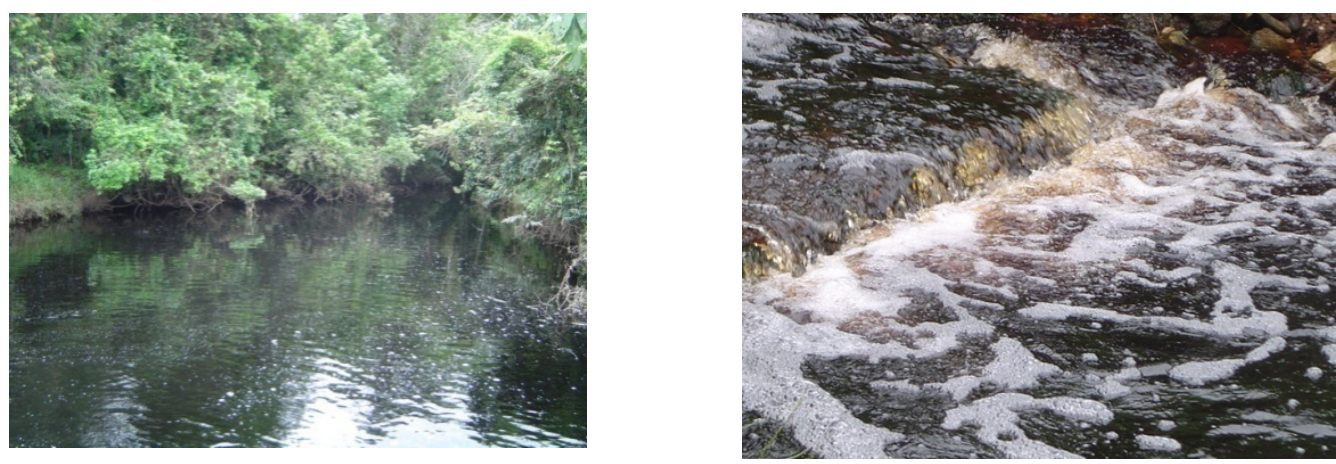

Figura 4.4 - Rio Itapanhaú

O Rio Itapanhaú vem sendo estudado na Escola de Engenharia de São Carlos da Universidade de São Paulo (EESC-USP), na Universidade Estadual Paulista (UNESP) de Araraquara-SP e na Universidade de Ribeirão Preto (UNAERP) devido ao elevado teor de SHA, o qual apresenta cor verdadeira da ordem de $400 \mathrm{uH}$.

Conforme metodologia proposta por SLOBODA (2007), foi montado um sistema para a extração substâncias húmicas aquáticas por adsorção em coluna com fluxo descendente por gravidade com a resina macroporosa não iônica de éster acrílico (XAD 8). A resina foi suspensa em água deionizada e adicionada em uma coluna de vidro, formando um leito trocador de diâmetro de $31 \mathrm{~mm}$ de diâmetro e $30 \mathrm{~cm}$ de altura. A água bruta era bombeada para a coluna com fluxo descendente por gravidade. A instalação usada para extração das SHA é mostrada na Figuras 4.5 e 4.6. 


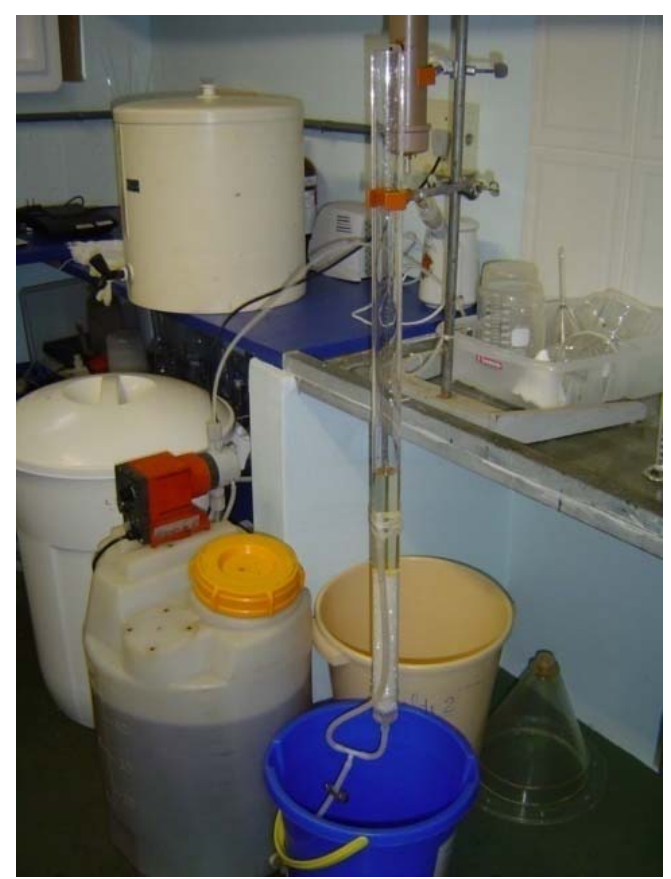

Figura 4.5 - Foto da Instalação de Extração das SHA

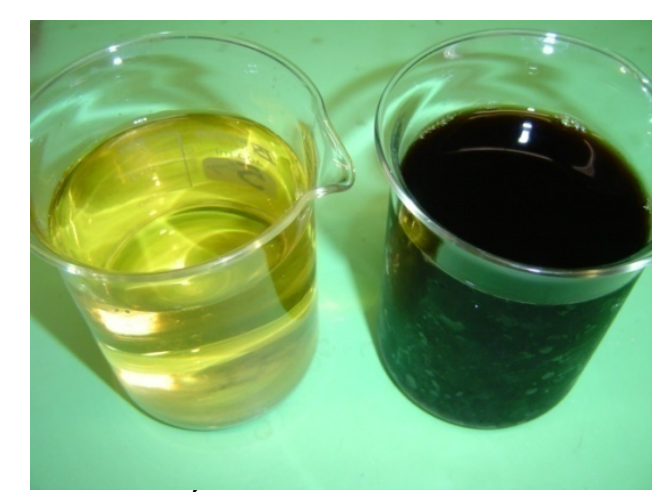

Figura 4.6 - Água bruta e extrato de SHA após a eluição

O líquido efluente da coluna de extração foi monitorado por leituras de absorvância a $254 \mathrm{~nm}$ com o objetivo de estimar a saturação da resina. Quando o valor da absorvância do efluente apresentava aproximadamente metade do valor da absorvância da amostra bruta, o processo de extração era interrompido.

Após a saturação da resina, era feita a eluição com solução de $\mathrm{NaOH} 0,1 \mathrm{~mol} \mathrm{~L}^{-1}$ ( $\mathrm{pH}=13)$, com vazão de $1,0 \mathrm{~mL} \min ^{-1}$. O eluato era recolhido na base da coluna e armazenado em frasco de polietileno e mantido sob refrigeração a $4{ }^{\circ} \mathrm{C}$. 
O extrato alcalino de SHA era coletado e acondicionado em embalagens duplas de papel celofane para a realização da diálise. Essas embalagens eram então imersas em banho com solução de ácido clorídrico para redução do pH. Posteriormente, as mesmas eram lavadas com água do poço não clorada até teste de ausência de cloretos por titrimetria, com auxílio de solução padronizada de nitrato de prata.

O extrato após a diálise era diluído na proporção de 1 para 3 com água deionizada e em seguida filtrado à vácuo em membrana com poros $0,45 \mu \mathrm{m}$ (membrana da Millipore em HA em éster de celulose, $90 \mathrm{~mm}$ de diâmetro, branca) para remoção de partículas grosseiras, para que, conforme as regras da AFA presentes no Standard Methods for the Examination of Water and Wastewater (1998), resultassem apenas substâncias em solução.

\subsection{Preparo da água de estudo}

Após a filtração na membrana, os extratos foram utilizados para obtenção da cor verdadeira de $100 \mathrm{uH}$ em água retirada do poço artesiano da EESC-USP. Para conferir turbidez a água de estudo, foi empregada caulinita.

Para reduzir erros na preparação da turbidez da água e remover as partículas de maior tamanho, foi utilizada a metodologia proposta por DI BERNARDO (2004), sendo necessária a preparação de uma suspensão-mãe de argila. Para o preparo dela, foram misturadas 1.000 gramas de caulinita a 50 litros de água. A água com caulinita foi agitada por 2 horas, seguido por 10 horas de repouso dessa solução. O sobrenadante foi coletado e adicionado na água do poço da EESC/USP para conferir turbidez no valor de $5 \mathrm{uT}$ 


\subsection{Ensaios no equipamento estático}

Os ensaios no equipamento estático foram feitos de acordo com a seqüência e procedimentos descritos por VOLTAN (2007):

- colocar porções de água bruta, mantida a temperatura constante, em cada um dos 6 jarros em seqüência até completar 2 litros, de forma a homogeneizar a água em todos os 6 jarros;

- colocar os volumes correspondentes às dosagens do coagulante nas cubetas do equipamento. Colocar, com o auxílio de pipetas, os volumes correspondentes ao acidificante ou alcalinizante dentro dos jarros. Ligar o aparelho, com as paletas abaixadas, com a rotação de $100 \mathrm{rpm}$, agitando a água dos jarros para misturar o acidificante ou alcalinizante antes de adicionar o coagulante;

- ajustar a rotação para obter, de acordo com curva de calibração do aparelho, o gradiente de velocidade médio da mistura rápida (Gmr), e acionar o cronômetro ao mesmo tempo em que é adicionado o coagulante. Logo após o tempo de mistura rápida, foi realizada a leitura do valor de pH de coagulação da água de cada jarro;

- após o tempo estabelecido para a mistura rápida (Tmr), era reduzida a rotação do aparelho para o valor correspondente ao gradiente de velocidade médio de floculação (Gf). Decorrido o tempo de floculação, Tf, desligar o aparelho;

- $\quad$ se for o caso, (item 5.3.5), ajustar a rotação do equipamento para obter o gradiente médio de velocidade de ruptura (Gr), e após o tempo de 5 segundos, voltar à rotação do aparelho, para obter o $\mathrm{Gf}_{2}$, e desligar o aparelho após o segundo tempo de floculação; 
- com o aparelho desligado, coletar amostras nos tempos de coletas, para representar as velocidades de sedimentação (Vs). Medir os parâmetros desejados, $\mathrm{pH}$, cor aparente e turbidez nas amostras coletadas.

\subsubsection{Ensaios para determinação das dosagens de coagulante e de correção de pH}

O mecanismo de coagulação para este estudo foi o da varredura, apropriado para a sedimentação dos flocos. Como o objetivo desse ensaio foi a determinação do $\mathrm{pH}$ de coagulação e da dosagem do coagulante, os seguintes parâmetros foram adotados com referência ao trabalho feito por CAMPOS (2004), o qual utilizou uma água com características semelhantes à água de estudo deste trabalho: tempo de mistura rápida (Tmr) igual à $10 \mathrm{~s}$; gradiente de velocidade médio da mistura rápida $(\mathrm{Gmr})$ igual a 1000 $\mathrm{s}^{-1}$, o tempo de floculação (Tf) igual à 30 minutos; gradiente de velocidade médio na floculação (Gf) igual a $15 \mathrm{~s}^{-1}$; e coletadas amostras correspondentes as velocidades de sedimentação de $0,5,1,5$ e $3,0 \mathrm{~cm} / \mathrm{min}$.

Em cada jarro de cada ensaio foi feita uma variação da dosagem de coagulante e da dosagem de acidificante ou alcalinizante visando obter diversos valores de $\mathrm{pH}$ de coagulação e dosagem de coagulante. Com esses pares de valores, foram construídos os diagramas de coagulação para remoção de cor para cada velocidade de sedimentação estudada.

Com o diagrama construído foram traçadas curvas de mesma cor aparente remanescente. Desta forma, foram obtidos pares de valores de $\mathrm{pH}$ de coagulação (dosagem de acidificante ou alcalinizante) e de dosagem de coagulante apropriados para a água de estudo para as velocidades de sedimentação de $0,5,1,5$ e 3,0 cm/min. 


\subsubsection{Ensaios para a determinação dos parâmetros da Mistura Rápida}

Com a dosagem de coagulante e acidificante/alcalinizante selecionados na etapa anterior, foi feita a seleção dos parâmetros de mistura rápida (Tmr e Gmr). Foram fixados: tempo de floculação (Tf) em 30 minutos; gradiente de velocidade médio da floculação (Gf) em $15 \mathrm{~s}^{-1}$; e coletadas amostras correspondentes às velocidades de sedimentação de $0,5,1,0$ e $1,5 \mathrm{~cm} / \mathrm{min}$.

Foram variados os dois parâmetros da mistura rápida: tempo de mistura rápida (Tmr) e gradiente de velocidade médio de mistura rápida (Gmr). Os tempos de mistura rápida foram $5,10,20,30,60$ e $90 \mathrm{~s}$. Os gradientes de velocidade médios de mistura rápida foram 400, 600, 800, 1000 e $1200 \mathrm{~s}^{-1}$. Nos ensaios com o cloreto férrico foi necessário testar o gradiente de velocidade de $300 \mathrm{~s}^{-1}$, uma vez que os resultados obtidos com os gradientes mais baixos foram mais efetivos com esse coagulante.

Gráficos foram construídos para cada velocidade de sedimentação, com o valor de cor aparente remanescente para cada par de valores Tmr e Gmr e foi escolhido o par de valores que apresentou a melhor remoção de cor aparente.

\subsubsection{Ensaios para a determinação dos parâmetros de Floculação}

Nesta série de ensaios foi feita a seleção dos parâmetros de floculação (Tf e Gf), fixando as coletadas amostras correspondentes às velocidades de sedimentação de 0,5 , 1,0 e $1,5 \mathrm{~cm} / \mathrm{min}$.

Foram variados os dois parâmetros de floculação: tempo de floculação (Tf) e gradiente de velocidade médio de floculação (Gf). Os tempos de floculação foram 5, 10 , $15,20,25,30,35,40,45,50,55$ e $60 \mathrm{~min}$. Os gradientes de velocidade médios de

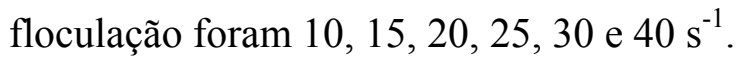


Com obtenção dos valores de cor aparente remanescente para o par de valores $\mathrm{Tf}$ e Gf, para cada tempo de floculação foi selecionado um gradiente de velocidade médio, que apresentou o menor valor de cor remanescente. E, em seguida foram construídos gráficos semelhantes aos das Figuras 2.6 e 2.7, para cada velocidade de sedimentação. A partir da análise desses gráficos foi selecionado o tempo de floculação e gradiente de velocidade médio de floculação que forneceu os menores valores de cor aparente remanescente após a sedimentação.

\subsubsection{Ensaios para a caracterização da Sedimentação}

Para a caracterização da sedimentação foi realizado ensaio em jarteste com os parâmetros selecionados nos itens 4.5.1, 4.5.2 e 4.5.3 (dosagem de coagulante e acidificante/alcalinizante, Tmr e Gmr, Tf e Gf).

Foram coletadas amostras da água decantada nos tempos 1,5 , 3, 4,5 , 6, 9, e 12 min e relacionadas às velocidades de sedimentação (Vs) correspondentes. Os ensaios realizados nessa etapa foram feitos em tréplica, ou seja, serão utilizados três jarros submetidos às mesmas condições de coagulação, floculação e sedimentação.

Devido ao rebaixamento no nível de água nos jarros de cerca de $0,4 \mathrm{~cm}$ a cada coleta, as alturas médias de sedimentação encontradas foram de 7,0;6,6;6,2; 5,8;5,4 e $5,0 \mathrm{~cm}$. Assim os tempos de sedimentação estudados equivalem às velocidades de sedimentação de 4,67;2,20;1,38;0,97, 0,60 e 0,42 cm/min, respectivamente.

\subsubsection{Ensaios de ruptura dos flocos}

Para esta etapa foi realizado um ensaio em jarteste com os parâmetros selecionados de acordo com os itens 4.5.1, 4.5.2 e 4.5.3 (dosagem de coagulante e acidificante/alcalinizante, Tmr e Gmr, Tf e Gf). 
Em seguida foi executado o procedimento de ruptura dos flocos, com gradientes de velocidade médios de ruptura dos flocos de $\mathrm{Gr}=50,100$ e $150 \mathrm{~s}^{-1}$. O tempo de ruptura (Tr) foi de $5 \mathrm{~s}$. Foram coletadas amostras de água decantada nos tempos 1,5 , 3, $4,5,6,9$ e 12 minutos e relacionadas às velocidades de sedimentação (Vs) correspondentes. Com os resultados, foram comparadas as eficiências de remoção de cor aparente com a condição inicial (itens 3.5.4) para cada velocidade de sedimentação.

\subsubsection{Ensaios de refloculação}

Nesta etapa os procedimentos do item 4.5.5 foram repetidos, executando-se o procedimento de ruptura dos flocos, com gradientes de velocidade médios de ruptura dos flocos de $\mathrm{Gr}=50,100$ e $150 \mathrm{~s}^{-1}$. O tempo de ruptura $(\mathrm{Tr})$ foi de $5 \mathrm{~s}$. Após o tempo de ruptura, a água foi submetida novamente à condição de floculação, com dois gradientes de velocidade médios, um determinado no item 4.5.3 e outro um pouco superior, e tempos de refloculação de 5, 10, 15, 20 e 25 min.

Foram coletadas amostras nos tempos $1,5,3,4,5,6,9$ e 12 min e relacionadas às velocidades de sedimentação (Vs) correspondentes. As eficiências de remoção de cor aparente foram comparadas com a condição inicial (item 4.5.4) para cada velocidade de sedimentação. 


\section{RESULTADOS E DISCUSSÕES}

Neste capítulo são apresentados os resultados obtidos nos ensaios bem como a discussão dos mesmos.

\subsection{Caracterização da água de estudo}

$\mathrm{Na}$ tabela 5.1, apresentam-se as principais características da água de estudo obtidas em uma caracterização geral da água realizada após o seu preparo. Durante o período de execução dos ensaios, os parâmetros turbidez, cor aparente, cor verdadeira, absorvância, alcalinidade total, $\mathrm{pH}$ e temperatura foram medidos diariamente para avaliar variações nas características da água de estudo. A tabela 5.2 apresenta a faixa de valores utilizada das características da água medidas diariamente.

Tabela 5.1- Caracterização da água de estudo.

\begin{tabular}{cccc} 
Parâmetro & Valor & Parâmetro & Valor \\
\hline Absorbância $(254 \mathrm{~nm})$ & 0,357 & Carbono Orgânico Dissolvido $(\mathrm{mg} / \mathrm{L})$ & 10,55 \\
Condutividade Elétrica $(\mu \mathrm{s} / \mathrm{cm})$ & 78,5 & Cálcio $(\mathrm{mg} / \mathrm{L})$ & 0,15 \\
Cor Verdadeira $(\mathrm{uH})$ & 98 & Magnésio $(\mathrm{mg} / \mathrm{L})$ & 0,71 \\
Cor Aparente $(\mathrm{uH})$ & 144 & Zinco - amostra não digerida $(\mathrm{mg} / \mathrm{L})$ & ND \\
pH & 6,3 & Zinco - amostra digerida $(\mathrm{mg} / \mathrm{L})$ & 0,02 \\
Turbidez $(\mathrm{uT})$ & 4,95 & Chumbo - amostra não digerida $(\mathrm{mg} / \mathrm{L})$ & 0,08 \\
Alcalinidade Total $(\mathrm{mg} / \mathrm{L} \mathrm{CaCO} 3)$ & 15,2 & Chumbo - amostra digerida $(\mathrm{mg} / \mathrm{L})$ & ND \\
Dureza Total $(\mathrm{mg} / \mathrm{L} \mathrm{CaCO})_{3}$ & 23,0 & Cádmio - amostra não digerida $(\mathrm{mg} / \mathrm{L})$ & ND \\
Fosfato total $(\mathrm{mg} / \mathrm{L})$ & 0,14 & Cádmio - amostra digerida $(\mathrm{mg} / \mathrm{L})$ & ND \\
Fluoreto $(\mathrm{mg} / \mathrm{L})$ & 0,17 & Níquel - amostra não digerida $(\mathrm{mg} / \mathrm{L})$ & ND \\
Sódio $(\mathrm{mg} / \mathrm{L})$ & 2,0 & Níquel - amostra digerida $(\mathrm{mg} / \mathrm{L})$ & ND \\
Potássio $(\mathrm{mg} / \mathrm{L})$ & 4,6 & Ferro - amostra não digerida $(\mathrm{mg} / \mathrm{L})$ & ND \\
Sulfatos $(\mathrm{mg} / \mathrm{L})$ & ND & Ferro - amostra digerida $(\mathrm{mg} / \mathrm{L})$ & 0,11 \\
Nitrogênio Amoniacal $(\mathrm{mg} / \mathrm{L})$ & 0,36 & Manganês - amostra não digerida $(\mathrm{mg} / \mathrm{L})$ & ND \\
Nitrogênio Nitrato $(\mathrm{mg} / \mathrm{L})$ & 0,026 & Manganês - amostra digerida $(\mathrm{mg} / \mathrm{L})$ & ND \\
Nitrogênio Nitrito $(\mathrm{mg} / \mathrm{L})$ & ND & Cobre - amostra não digerida $(\mathrm{mg} / \mathrm{L})$ & ND \\
Sólidos Totais $(\mathrm{mg} / \mathrm{L})$ & 96,0 & Cobre - amostra digerida $(\mathrm{mg} / \mathrm{L})$ & ND \\
Sólidos Totais Suspensos $(\mathrm{mg} / \mathrm{L})$ & 4,0 & Cromo - amostra não digerida $(\mathrm{mg} / \mathrm{L})$ & ND \\
Totais Dissolvidos $(\mathrm{mg} / \mathrm{L})$ & 92,0 & Cromo - amostra digerida $(\mathrm{mg} / \mathrm{L})$ & ND
\end{tabular}


Tabela 5.2- Faixa de valores dos parâmetros da água de estudo monitorados diariamente.

\begin{tabular}{|c|c|}
\hline Características da água de estudo - Faixa de valores \\
\hline Parâmetros & Valores \\
\hline Absorvância & 0,34 a 0,38 \\
\hline Cor Verdadeira $(\mathrm{uH})$ & 95 a 105 \\
\hline Cor Aparente $(\mathrm{uH})$ & 140 a 160 \\
\hline $\mathrm{pH}$ & 6,2 a 6,8 \\
\hline Turbidez $(\mathrm{uT})$ & 4 a 6 \\
\hline Alcalinidade Total $(\mathrm{mg} / \mathrm{L} \mathrm{CaCO3})$ & 14 a 18 \\
\hline Temperatura $\left({ }^{\circ} \mathrm{C}\right)$ & 24 a 26 \\
\hline
\end{tabular}

\subsection{Ensaios utilizando o Sulfato de Alumínio como coagulante}

Primeiramente serão apresentados os resultados dos ensaios utilizando o sulfato de alumínio como coagulante, seguindo a metodologia descrita no Item 5.

\subsubsection{Escolha da dosagem de coagulante e pH de coagulação}

Para a obtenção dos parâmetros dosagem de coagulante e pH de coagulação foram realizados ensaios segundo a metodologia descrita no item 4.5.1 com os gradientes de velocidade e tempo de agitação tanto para a mistura rápida quanto para a floculação obtidos no trabalho de Campos (2004). Os ensaios foram feitos para três velocidades de sedimentação a fim de evitar a influência desta na escolha correta dos parâmetros de coagulação.

Foram realizados ensaios com dosagens entre 40 e $400 \mathrm{mg} / \mathrm{L}$ de coagulante, variando o pH de coagulação, buscando as regiões em que fossem observadas remoção de cor. Verificou-se que ao se adicionar o coagulante sem a utilização de alcalinizante, o pH de coagulação tornava-se muito baixo para a ocorrência da coagulação da água de estudo (abaixo de 5). Assim, em nenhum ensaio foi utilizado acidificante para a 
variação de $\mathrm{pH}$. A variação do $\mathrm{pH}$ de coagulação com a utilização de alcalinizante foi realizada para o preenchimento de todas as regiões dos gráficos de "dosagem de coagulante versus $\mathrm{pH}$ de coagulação" com os valores de cor aparente remanescente dos ensaios.

Ao final, foram realizados 19 ensaios, totalizando 114 pontos do diagrama para cada velocidade de sedimentação. Os resultados dos ensaios desta etapa estão mostrados nas Tabelas do Anexo A, A.1 a A.19. Nelas, encontram-se: as dosagens de Sulfato de Alumínio Líquido Comercial (50\% do valor de massa em água) adicionado nos jarros; as dosagens de alcalinizante adicionadas para variação do $\mathrm{pH}$; o $\mathrm{pH}$ medido ao final da coagulação; a cor aparente e a turbidez remanescentes para os diferentes tempos de sedimentação.

De posse destes resultados, foi possível a construção dos diagramas de coagulação (“dosagem de coagulante versus pH de coagulação”). Nestes diagramas foram traçadas as curvas de mesma cor aparente remanescente. Assim, foram determinadas as regiões de maior eficiência de remoção de cor para cada velocidade de sedimentação. Estes diagramas estão mostrados na Figura 5.1 para a Vs de $3,0 \mathrm{~cm} / \mathrm{min}$, na Figura 5.2 para a Vs de $1,5 \mathrm{~cm} / \mathrm{min}$ e na Figura 5.3 para a Vs de $0,5 \mathrm{~cm} / \mathrm{min}$. 


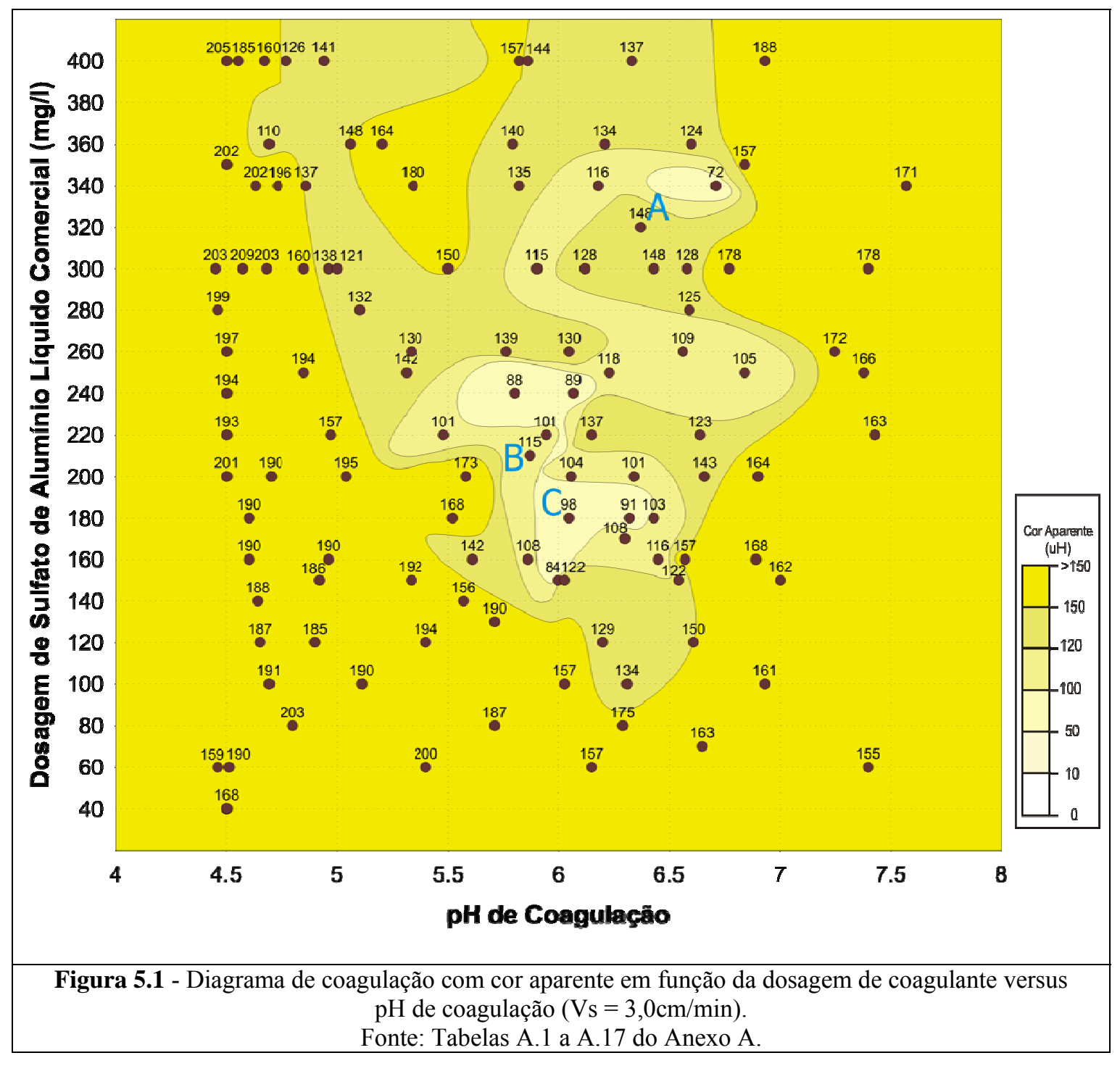




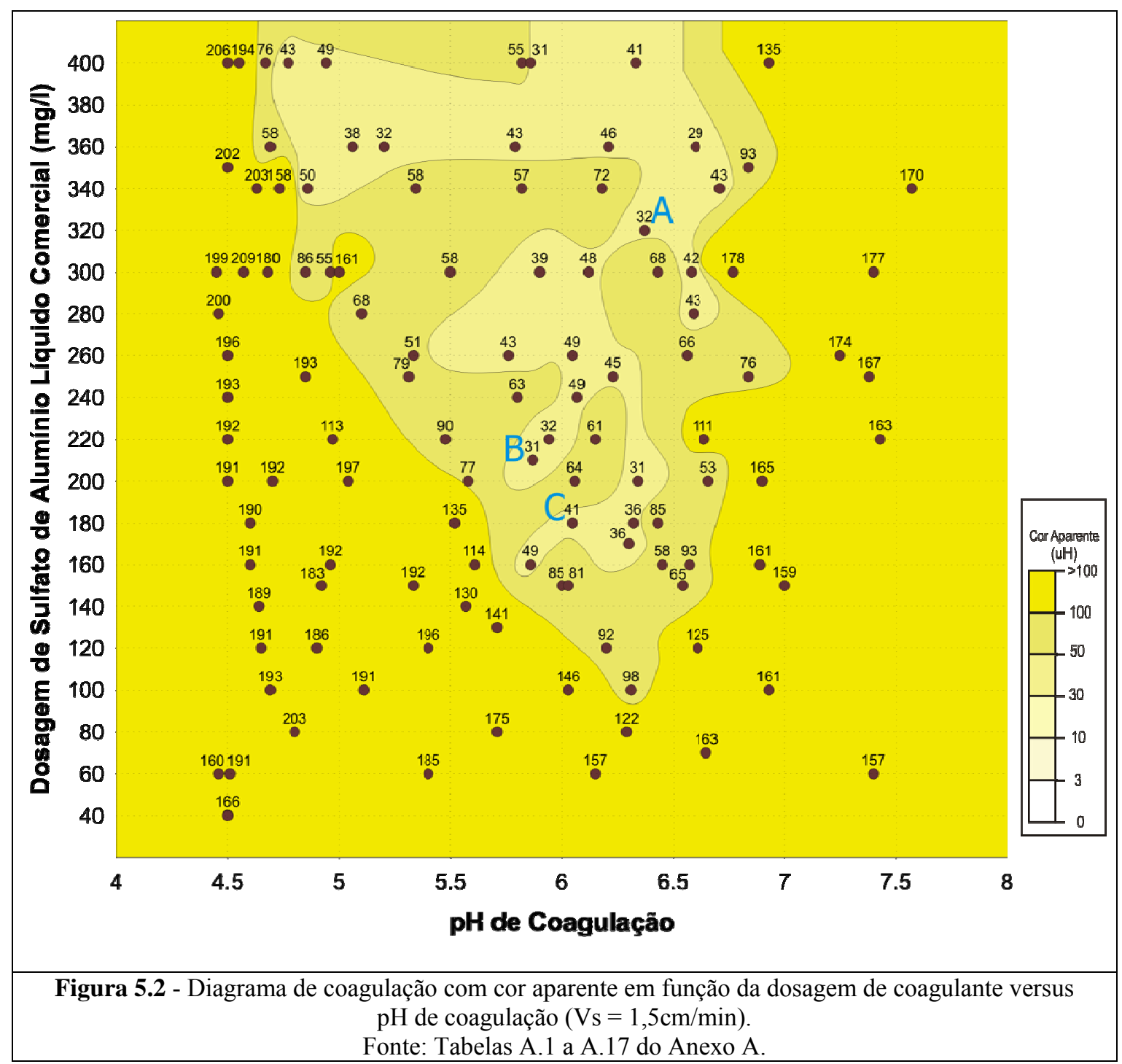




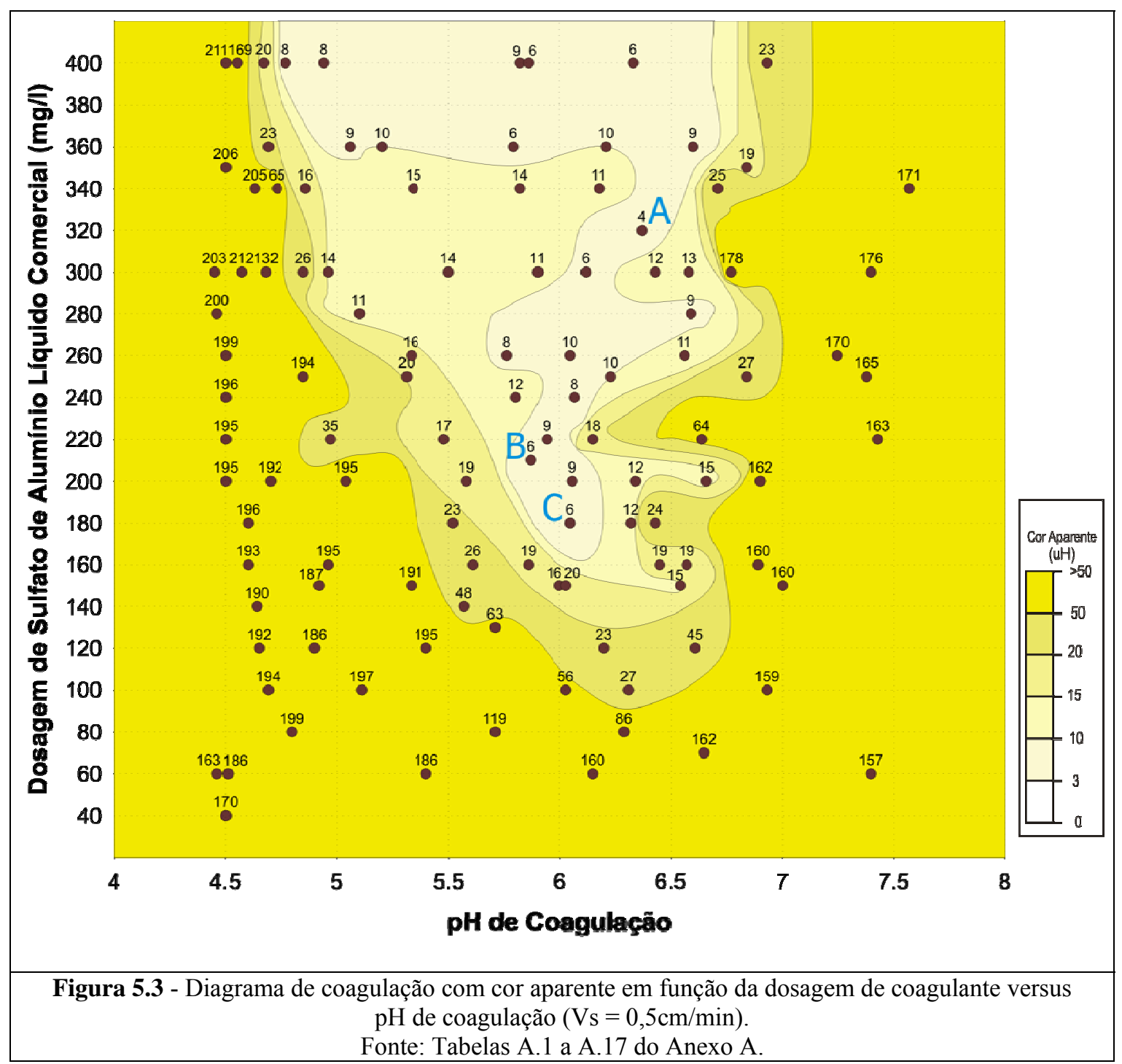

Devido à diferença nas regiões com maior remoção de cor nos três diagramas de coagulação, para a escolha do par de valores "dosagem de coagulante e pH de coagulação" adequado para esta água de estudo, foram escolhidos três pontos do diagrama de coagulação e reproduzidos ensaios em jarteste para validação da eficiência de remoção de cor aparente dos mesmos. A diferença entre os diagramas evidencia a influência da velocidade de sedimentação remoção de cor. Os pontos escolhidos foram: A, com dosagem de coagulante de $320 \mathrm{mg} / \mathrm{L}$ e pH de coagulação de 6,35; B, com dosagem de coagulante de $180 \mathrm{mg} / \mathrm{L}$ e pH de coagulação de 5,95; C, com dosagem de coagulante de $210 \mathrm{mg} / \mathrm{L}$ e pH de coagulação de 6,05 . 
Os resultados do ensaio de validação estão disponíveis na Tabela 5.3. De acordo com os dados apresentados, o ponto que produziu os melhores resultados foi o ponto B, com dosagem de coagulante de $180 \mathrm{mg} / \mathrm{L} \mathrm{e} \mathrm{pH}$ de coagulação de 5,96. Este par de valores foi o escolhido para a realização dos ensaios seguintes.

Tabela 5.3 - Resultados do ensaio de reprodução dos pontos selecionados.

\begin{tabular}{|c|c|c|c|c|c|c|c|c|c|}
\hline \multirow{3}{*}{$\begin{array}{c}\text { Jarro } \\
\text { (Ponto) }\end{array}$} & \multicolumn{2}{|c|}{ Produtos químicos } & \multirow{3}{*}{$\begin{array}{c}\text { pH de } \\
\text { Coagulação }\end{array}$} & \multicolumn{2}{|c|}{$\mathrm{Vs} 1=3,0 \mathrm{~cm} / \mathrm{min}$} & \multicolumn{2}{|c|}{$\begin{array}{l}\mathrm{Vs} 2=1,5 \\
\mathrm{~cm} / \mathrm{min}\end{array}$} & \multicolumn{2}{|c|}{$\begin{array}{c}\mathrm{Vs} 3=0,5 \\
\mathrm{~cm} / \mathrm{min}\end{array}$} \\
\hline & $\begin{array}{l}\text { Sulfato de } \\
\text { Alumínio } \\
\text { Líquido } \\
\text { Comercial }\end{array}$ & $\begin{array}{l}\text { Hidróxido } \\
\text { de Sódio }\end{array}$ & & $\begin{array}{l}\text { Turb. } \\
\text { (uT) }\end{array}$ & $\begin{array}{l}\text { Cor } \\
\text { Apar. } \\
(\mathrm{uH})\end{array}$ & $\begin{array}{l}\text { Turb. } \\
\text { (uT) }\end{array}$ & $\begin{array}{c}\text { Cor } \\
\text { Apar. } \\
(\mathrm{uH})\end{array}$ & $\begin{array}{l}\text { Turb. } \\
\text { (uT) }\end{array}$ & $\begin{array}{l}\text { Cor } \\
\text { Apar } \\
(\mathrm{uH})\end{array}$ \\
\hline & $(\mathrm{mg} / \mathrm{L})$ & $(\mathrm{mg} / \mathrm{L})$ & & & & & & & \\
\hline $1(\mathrm{~A})$ & 320 & 55 & 6,33 & 6,83 & 126 & 4,07 & 74 & 0,93 & 11 \\
\hline 2 (B) & 180 & 27 & 5,96 & 5,52 & 104 & 3,81 & 72 & 0,87 & 10 \\
\hline $3(\mathrm{C})$ & 210 & 30 & 5,67 & 6,21 & 123 & 3,88 & 73 & 1,06 & 13 \\
\hline
\end{tabular}

\subsubsection{Escolha dos parâmetros da Mistura Rápida}

Seguindo a metodologia apresentada no item 4.5.2, foram realizados os ensaios para escolha dos parâmetros da mistura rápida, a dosagem de coagulante e o $\mathrm{pH}$ de coagulação utilizados durante esta etapa de ensaios foram os selecionados no item 5.2.1: Dosagem de Sulfato de Alumino de $180 \mathrm{mg} / \mathrm{L}$; e pH coagulação de 5,96. As condições de floculação foram as mesmas utilizadas anteriormente, ou seja, gradiente médio de velocidade durante a floculação de $15 \mathrm{~s}^{-1}$ e tempo de floculação de 30 minutos.

Foram testados os gradientes de velocidade de mistura rápida (Gmr) de 400, 600, 800, 1000 e $1200 \mathrm{~s}^{-1}$, e os tempos de mistura (Tmr) de 5, 10, 20, 30, 60 e 90s. A cada ensaio, o equipamento jarteste foi ajustado na rotação referente ao $\mathrm{Gmr}$, e foram adicionados os volumes da solução de coagulante em tempos diferentes buscando obter, em cada jarro, um tempo de mistura diferente para um mesmo gradiente de velocidade. 
Como os resultados para velocidades de sedimentação mais elevadas mostraramse muito ruins, a velocidade de sedimentação de $3 \mathrm{~cm} / \mathrm{min}$ não foi usada nos ensaios otimização da mistura rápida e floculação. Nesses ensaios, as velocidades de sedimentação de 1,5 e $0,5 \mathrm{~cm} / \mathrm{min}$ foram mantidas, enquanto que a velocidade de sedimentação de $1 \mathrm{~cm} / \mathrm{min}$ substituiu a de $3 \mathrm{~cm} / \mathrm{min}$

Os resultados dos ensaios para as três velocidades de sedimentação são apresentados no Anexo B, Tabelas B.1 a B.5. No total, realizaram-se 5 ensaios, um para cada gradiente de velocidade. Os resultados são expostos em gráficos tridimensionais, com os gradientes de velocidade um dos eixos, o tempo de mistura no outro eixo e a cor aparente remanescente no terceiro eixo. A Figura 5.4 mostra os resultados para a Vs de 1,5 cm/min, na Figura 5.5 para a Vs de $1,0 \mathrm{~cm} / \mathrm{min}$ e na Figura 5.6 para a Vs de 0,5 $\mathrm{cm} / \mathrm{min}$. 


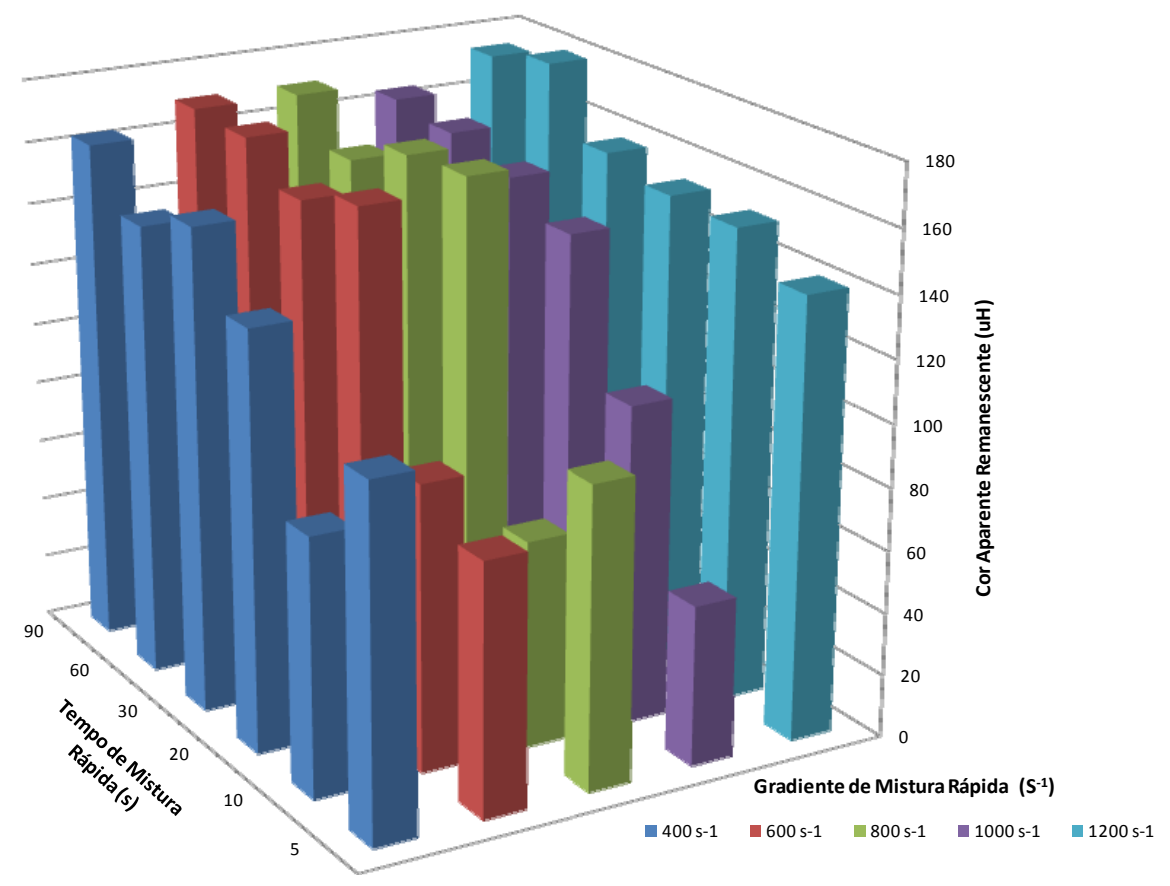

Figura 5.4- Cor aparente remanescente em função do gradiente de mistura rápida (Gmr) versus tempo de mistura rápida (Tmr) para a velocidade de sedimentação $V s 1=1,5 \mathrm{~cm} / \mathrm{min}$

Fonte: Tabelas B.1 a B.5 do Anexo B.

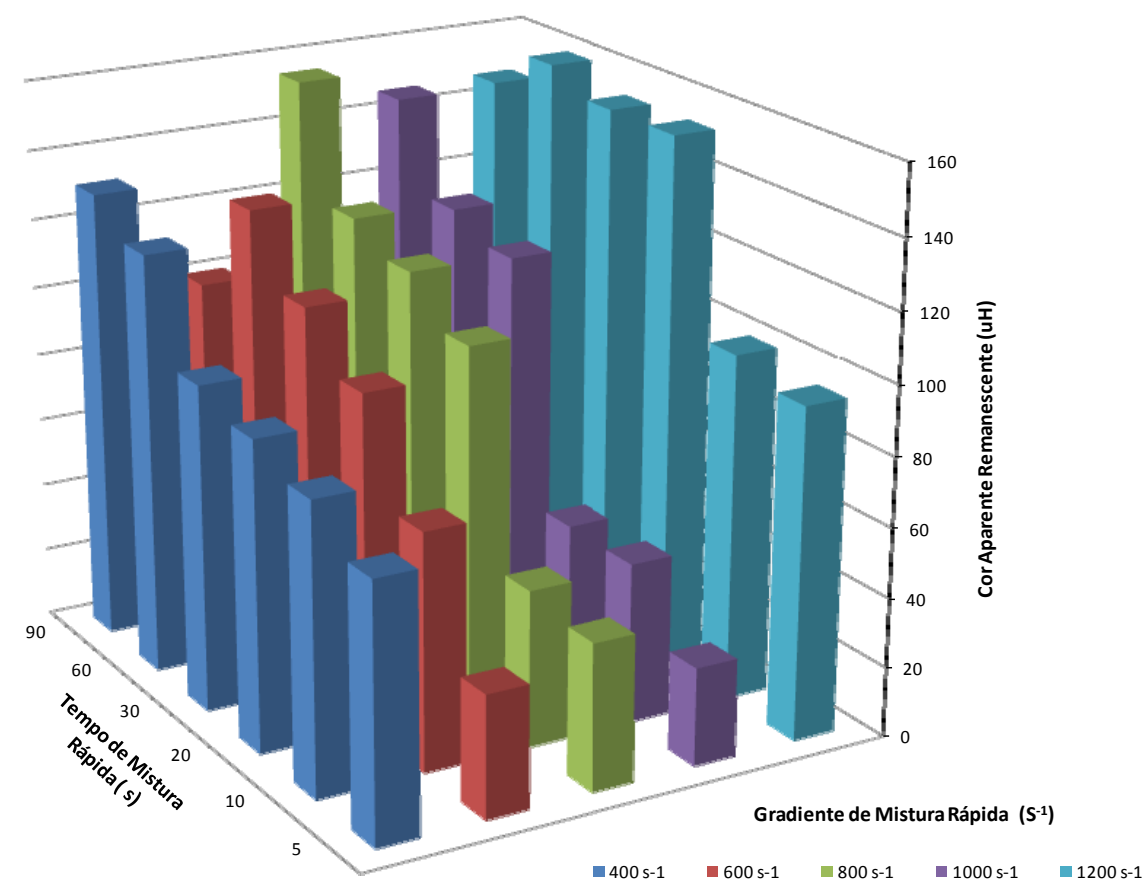

Figura 5.5- Cor aparente remanescente em função do gradiente de mistura rápida (Gmr) versus tempo de mistura rápida (Tmr) para a velocidade de sedimentação $\mathrm{Vs} 2=1,0 \mathrm{~cm} / \mathrm{min}$

Fonte: Tabelas B.1 a B.5 do Anexo B. 


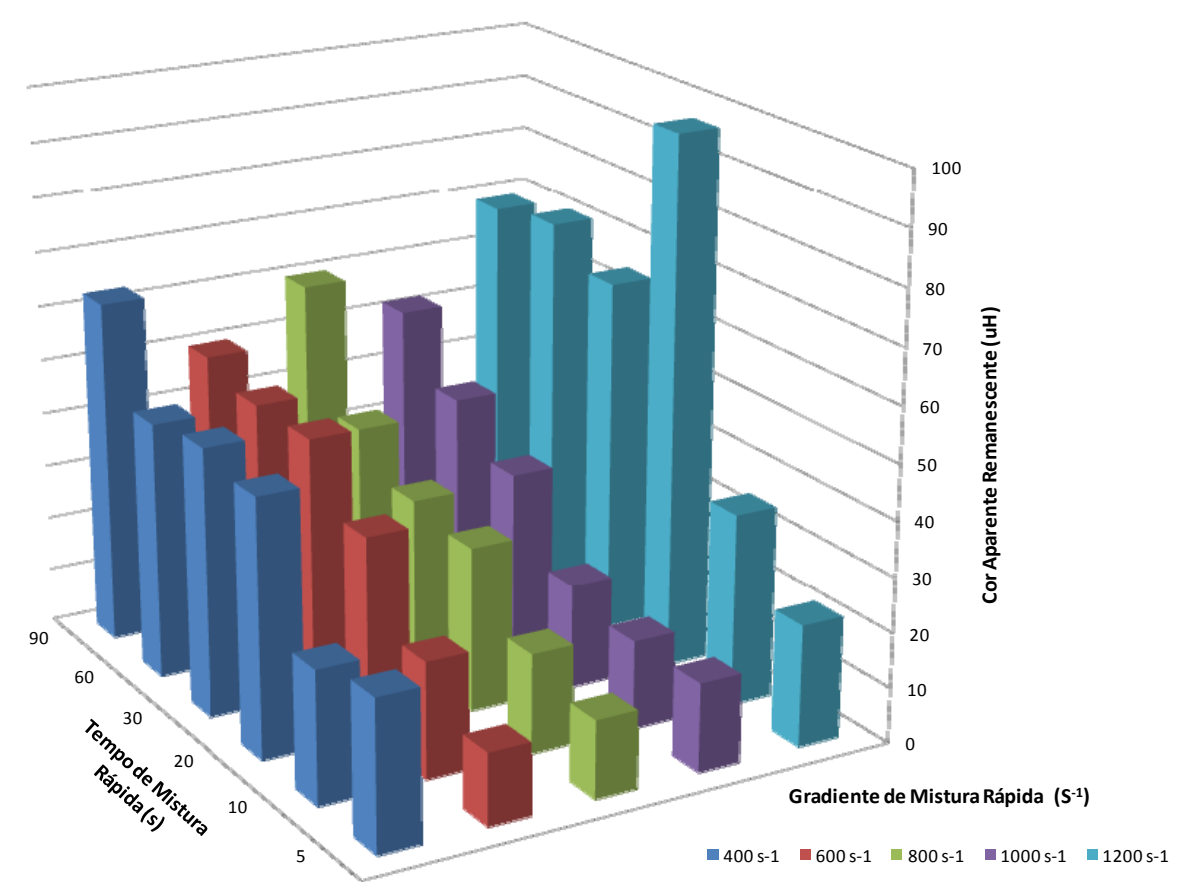

Figura 5.6- Cor aparente remanescente em função do gradiente de mistura rápida (Gmr) versus tempo de mistura rápida (Tmr) para a velocidade de sedimentação $\mathrm{Vs} 3=0,5 \mathrm{~cm} / \mathrm{min}$ Fonte: Tabelas B.1 a B.5 do Anexo B.

A análise dos gráficos mostra que a eficiência é maior quando a mistura rápida é realizada em tempos menores, e que tanto os gradientes de velocidade mais elevados quanto os menores tem pior eficiência que os gradientes intermediários. A análise conjunta dos resultados para as três velocidades de sedimentação evidencia a maior eficiência do gradiente de velocidade de $1000 \mathrm{~s}^{-1}$. Assim, o par de valores escolhido nas próximas etapas foi o gradiente de velocidade de $1000 \mathrm{~s}^{-1} \mathrm{e}$ o tempo de $5 \mathrm{~s}$.

\subsubsection{Escolha dos parâmetros de Floculação}

Os ensaios foram realizados conforme descrição do item 4.5.3. De acordo com os resultados obtidos anteriormente, os parâmetros adotados para os ensaios desta série foram: dosagem de sulfato de alumínio de $180 \mathrm{mg} / \mathrm{L}, \mathrm{pH}$ coagulação de 5,96, Gmr de $1000 \mathrm{~s}^{-1}$ e Tmr de $5 \mathrm{~s}^{-1}$. 
Foram testados os gradientes de velocidade de floculação (Gf) de 10, 15, 20, 25, 30 e $40 \mathrm{~s}^{-1}$, e os tempos de floculação (Tf) de 5, 10, 15, 20, 25, 30, 35, 40 , 45, 50, 55 e 60 minutos. Assim foram necessários dois ensaios para cada gradiente de velocidade a ser testado. Para submeter cada jarro do aparelho de jarteste a um tempo de floculação diferente, a paleta correspondente foi erguida no tempo de floculação desejado. Deste modo, enquanto no jarro em questão tinha-se início a sedimentação, nos demais a floculação continuava. As velocidades de sedimentação foram mantidas as mesmas utilizadas na escolha dos parâmetros de mistura rápida: $1,5,1,0$, e $0,5 \mathrm{~cm} / \mathrm{min}$. Os valores de cor aparente remanescente para as três velocidades de sedimentação, estão mostrados no Anexo C, nas Tabelas C.1 a C.12.

Os resultados para cada tempo de floculação foram plotados em gráficos de cor aparente remanescente do em função do gradiente de velocidade. Ao se observar as curvas foi possível determinar qual gradiente de velocidade que produziu melhor resultado na remoção de cor. Os gráficos mostrados nas Figuras 5.7, 5.8 e 5.9 referemse à remoção de cor aparente nas velocidades de sedimentação de 1,5, 1,0 e 0,5 cm/min, respectivamente. 


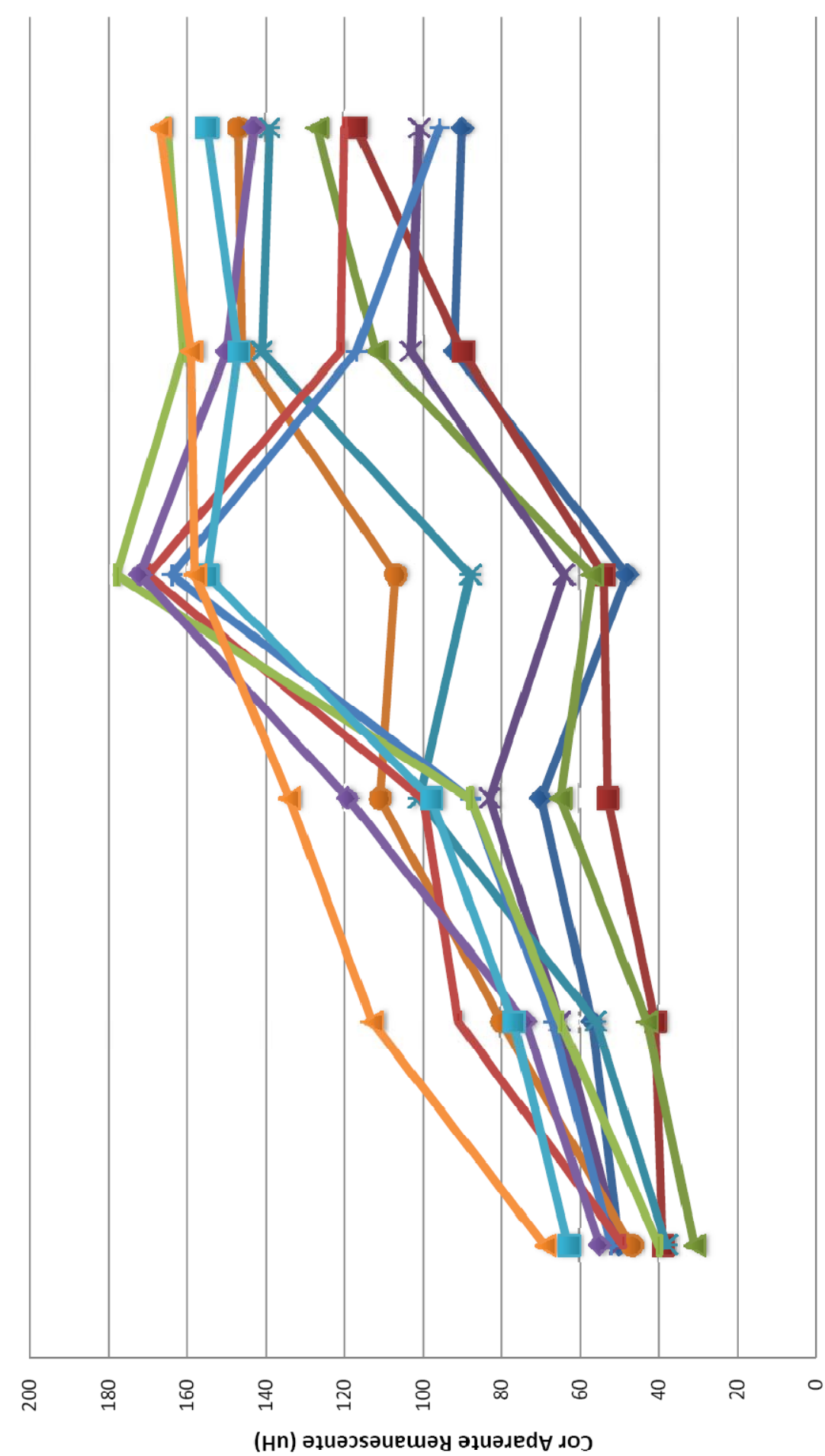

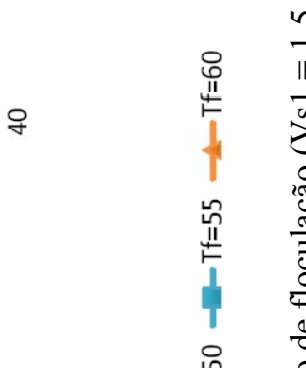

요

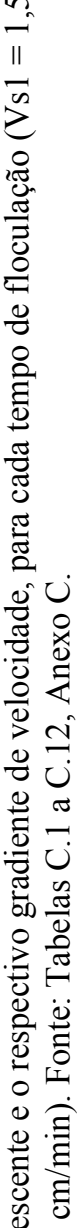

는

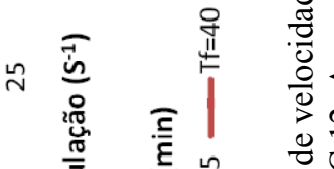

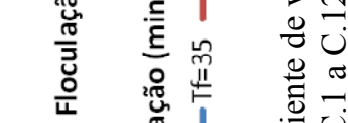

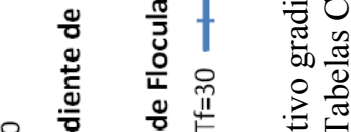

人

II 0

* 导 ह

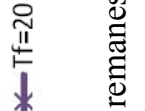

욱

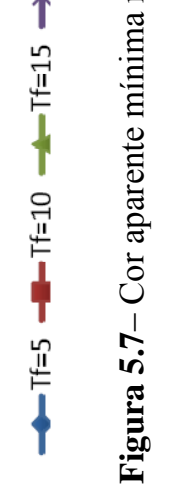




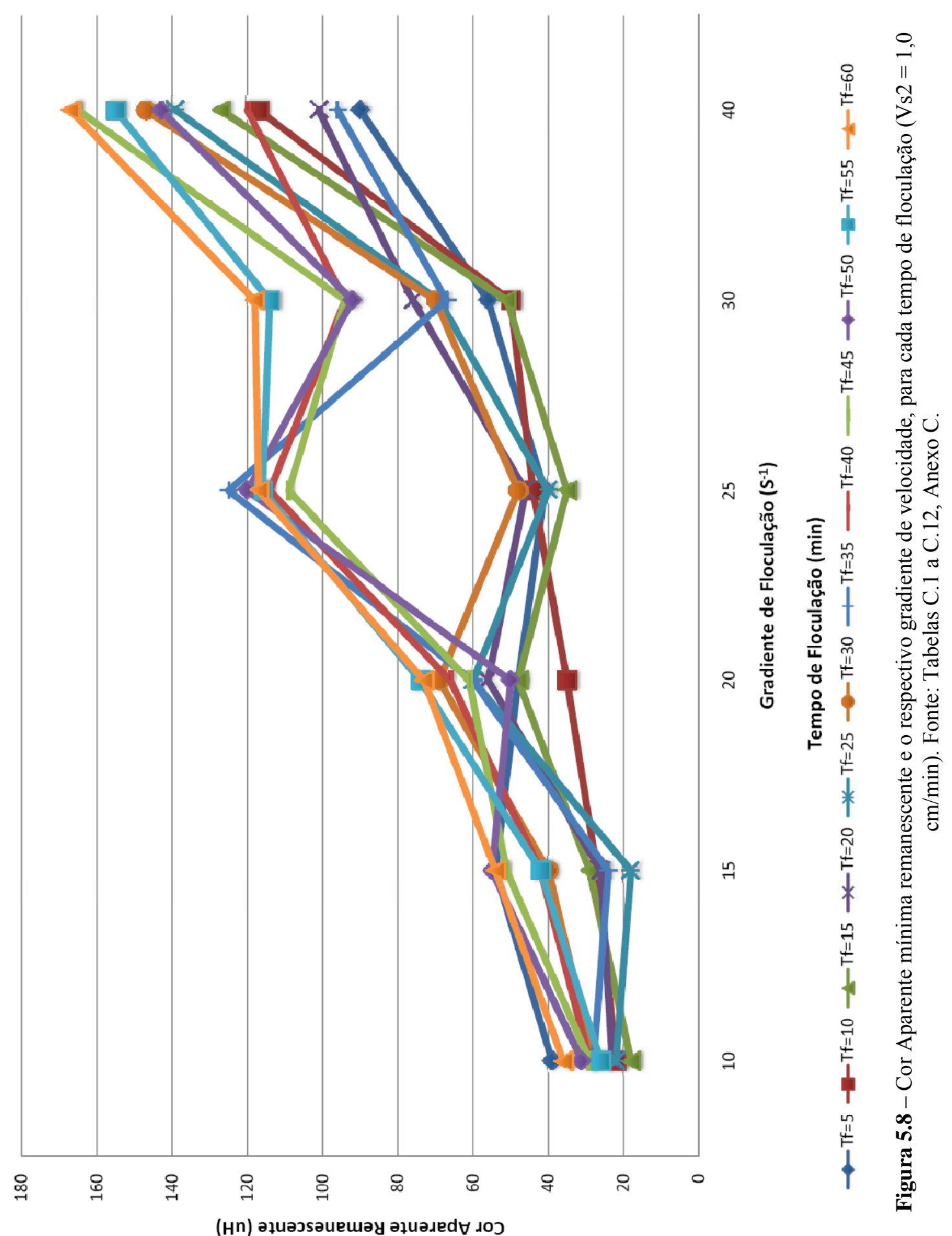



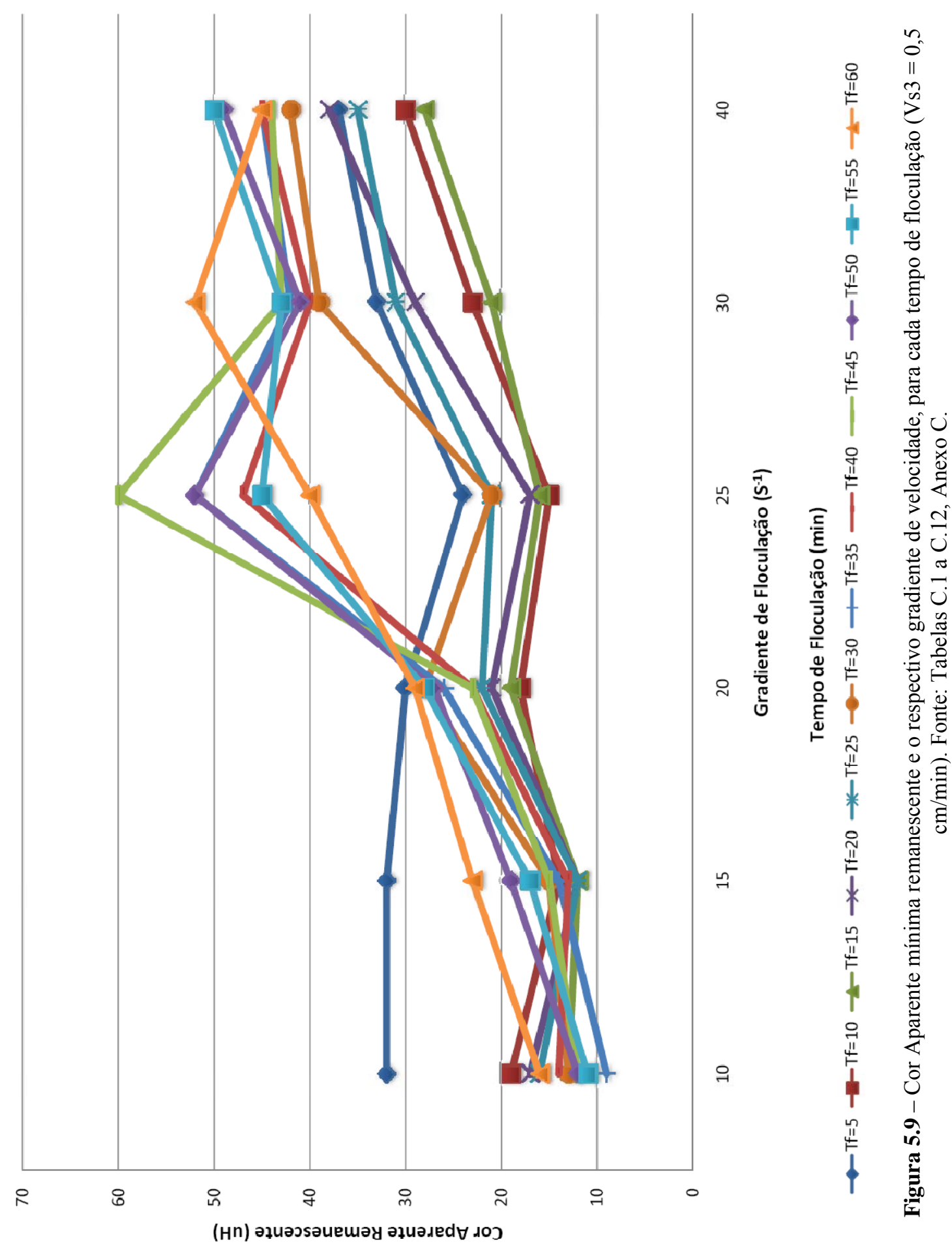
Observando os gráficos das Figuras 5.7, 5.8 e 5.9, selecionou-se o resultado referente ao gradiente de velocidade que obteve a menor cor aparente remanescente para cada tempo de floculação. Estes resultados foram plotados em gráficos de "cor aparente versus tempo de floculação", um para cada velocidade de sedimentação. Foram traçadas também linhas de tendência dos pontos para melhor avaliação dos resultados. As Figuras 5.10, 5.11 e 5.12 apresentam estes gráficos de mínima cor remanescente.

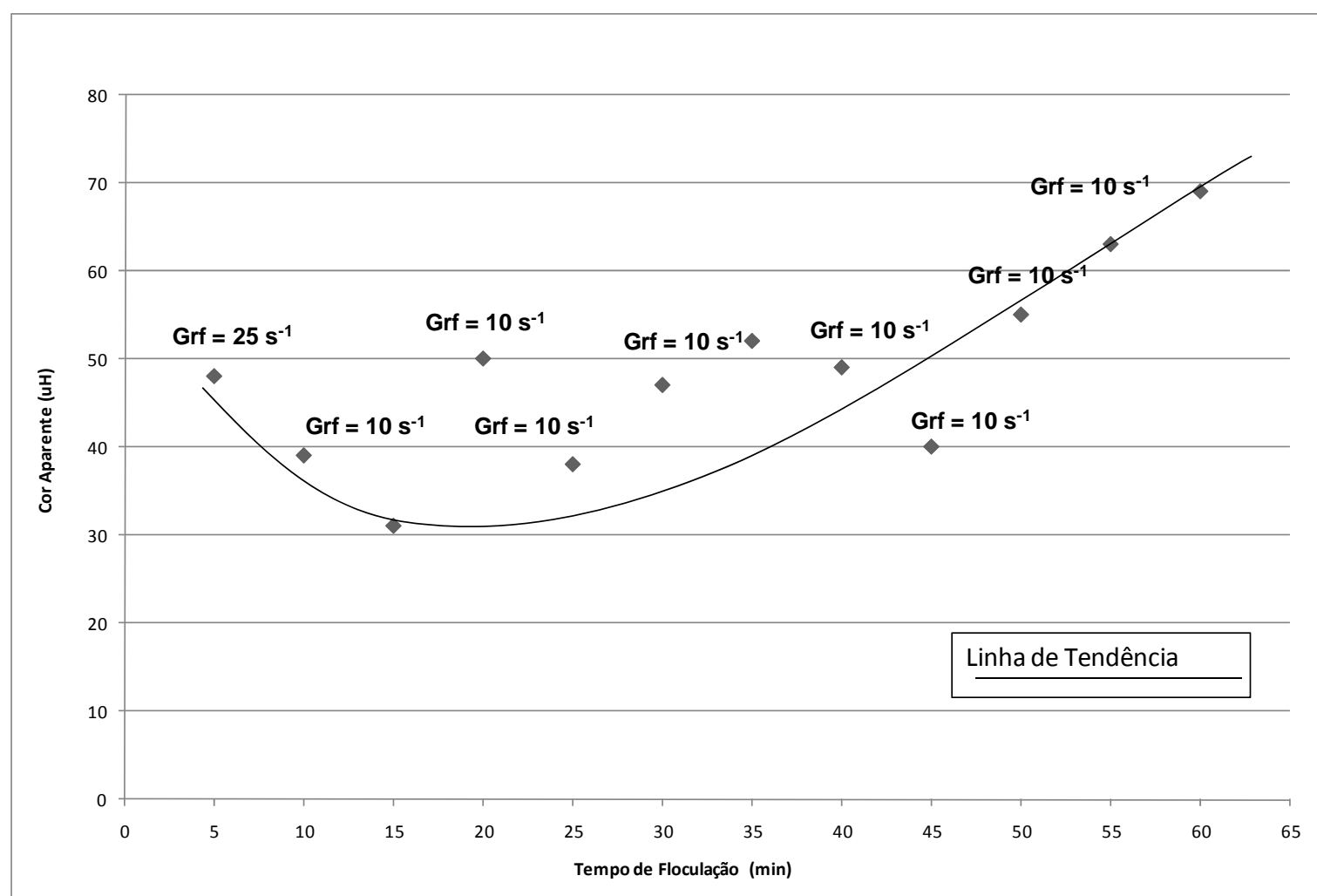

Figura 5.10 - Cor Aparente mínima remanescente em função do tempo de floculação com os respectivos gradientes de velocidade de Floculação (Gf), para a velocidade de sedimentação Vs1 = 1,5 cm/min Fonte: Tabelas C.1 a C.12, Anexo C. 


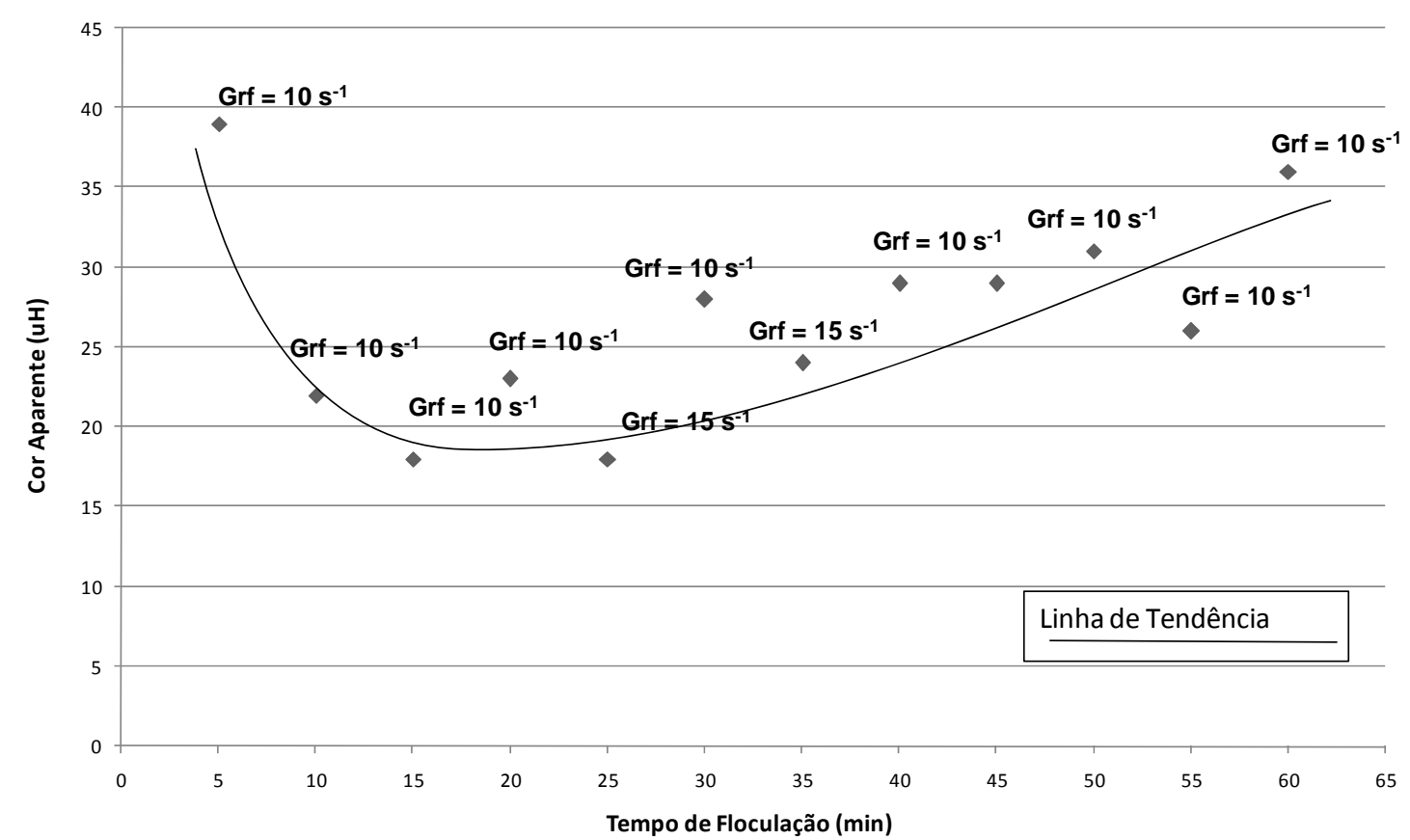

Figura 5.11 - Cor Aparente mínima remanescente em função do tempo de floculação com os respectivos gradientes de velocidade de Floculação (Gf), para a velocidade de sedimentação Vs $2=1,0$ $\mathrm{cm} / \mathrm{min}$ Fonte: Tabelas C.1 a C.12, Anexo C.

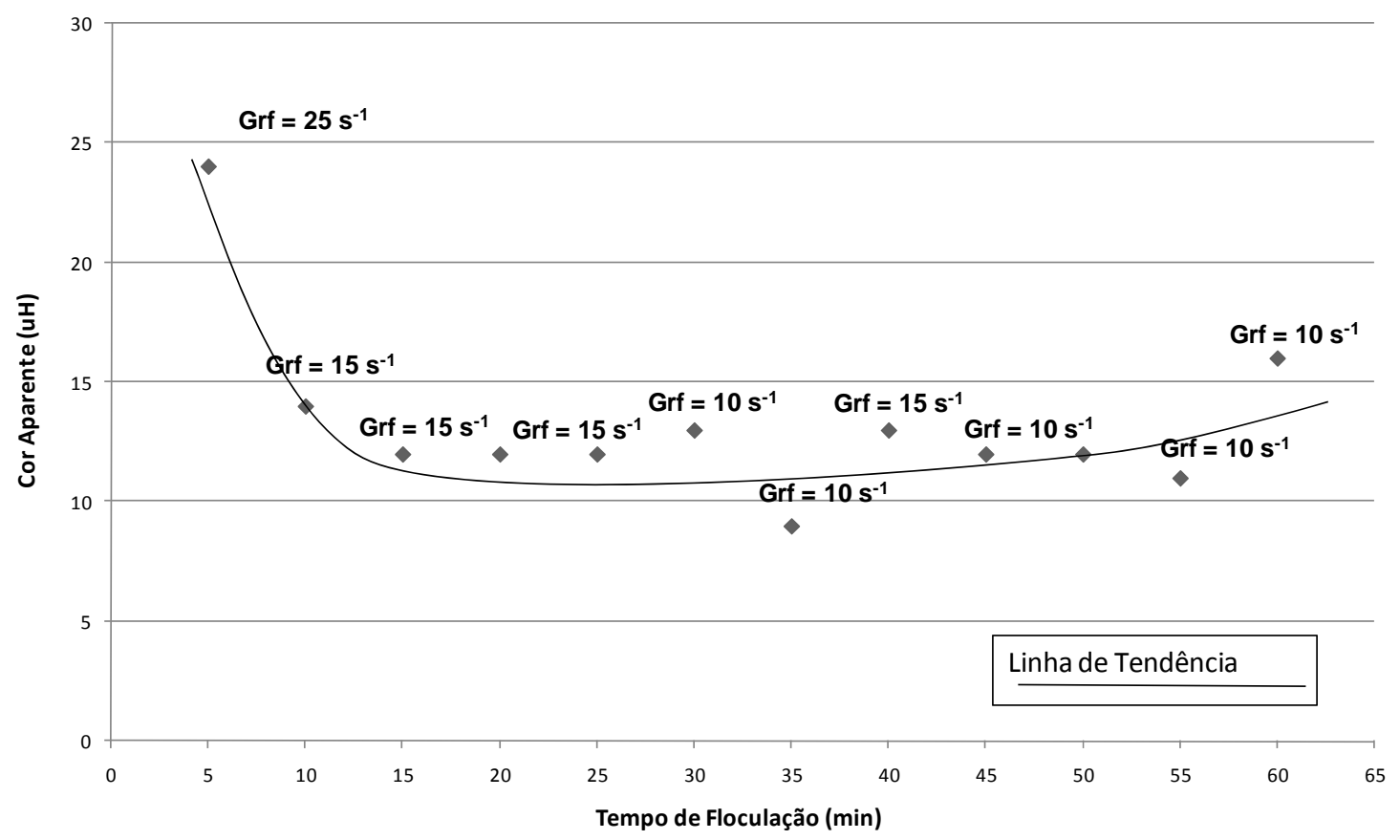

Figura 5.12 - Cor Aparente mínima remanescente em função do tempo de floculação com os respectivos gradientes de velocidade de Floculação (Gf), para a velocidade de sedimentação Vs3 = 0,5 $\mathrm{cm} / \mathrm{min}$ Fonte: Tabelas C.1 a C.12, Anexo C. 
A análise dos gráficos das Figuras 5.10, 5.11 e 5.12 mostra que a partir do tempo de 15 minutos a linha de tendência dos pontos faz uma curva, passando por um mínimo em que o aumento de tempo de floculação não implica no aumento de remoção de cor por sedimentação. Nas três velocidades de sedimentação os tempos de floculação superiores a 15 minutos apresentaram aumento na cor aparente remanescente.

Na Tabela 5.4 estão mostrados os valores de cor aparente mínima para cada tempo de floculação e o correspondente gradiente de velocidade de floculação. Observase que para valores de Tf entre 15 e 25 min a cor aparente mínima resulta nos menores valores de cor aparente para as três velocidades de sedimentação. Com o tempo de 35 min foi obtido o melhor resultado na remoção de cor em Vs3, porém neste tempo de floculação, os resultados de mínima cor remanescente para as outras velocidades foram piores do que os demais.

Apesar de no tempo de floculação de 15 min não se ter observado a menor cor aparente, ao se observar em conjunto os resultados obtidos com este tempo e com o gradiente de floculação de $10 \mathrm{~s}^{-1}$ para as três velocidades de sedimentação, observa-se que ele apresenta melhor conjunto de valores que os valores obtidos com outros tempos de floculação. Assim, foram escolhidos o gradiente de velocidade de $10 \mathrm{~s}^{-1}$ e tempo de floculação de 15 min como parâmetros de floculação adequados para esta água de estudo, os quais foram utilizados nas etapas subseqüentes deste trabalho. 
Tabela 5.4 - Resultados dos ensaios de escolha dos parâmetros de floculação.

\begin{tabular}{|c|c|c|c|c|c|c|}
\hline \multirow{7}{*}{$\begin{array}{l}\text { Tempo de } \\
\text { Floculação }\end{array}$} & \multicolumn{2}{|c|}{$\mathrm{Vs}_{\mathrm{s}}=1.5 \mathrm{~cm} / \mathrm{min}$} & \multicolumn{2}{|c|}{$\mathrm{Vs} 2=1.0 \mathrm{~cm} / \mathrm{min}$} & \multicolumn{2}{|c|}{$\mathrm{Vs}_{\mathrm{s}}=0.5 \mathrm{~cm} / \mathrm{min}$} \\
\hline & Gradiente & & Gradiente & & Gradiente & \\
\hline & de & Cor & de & Cor & de & Cor \\
\hline & velocidade & Aparente & velocidade & Aparente & velocidade & Aparente \\
\hline & na & mínima & na & mínima & na & mínima \\
\hline & floculação & $(\mathrm{uH})$ & floculação & $(\mathrm{uH})$ & floculação & $(\mathrm{uH})$ \\
\hline & $\operatorname{Gf}\left(s^{-1}\right)$ & & $\operatorname{Gf}\left(s^{-1}\right)$ & & $\operatorname{Gf}\left(s^{-1}\right)$ & \\
\hline 5 & 25 & 48 & 10 & 39 & 25 & 24 \\
\hline 10 & 10 & 39 & 10 & 22 & 15 & 14 \\
\hline 15 & 10 & 31 & 10 & 18 & 15 & 12 \\
\hline 20 & 10 & 50 & 10 & 23 & 15 & 12 \\
\hline 25 & 10 & 38 & 15 & 18 & 15 & 12 \\
\hline 30 & 10 & 47 & 10 & 28 & 10 & 13 \\
\hline 35 & 10 & 52 & 15 & 24 & 10 & 9 \\
\hline 40 & 10 & 49 & 10 & 29 & 15 & 13 \\
\hline 45 & 10 & 40 & 10 & 29 & 10 & 12 \\
\hline 50 & 10 & 55 & 10 & 31 & 10 & 12 \\
\hline 55 & 10 & 63 & 10 & 26 & 10 & 11 \\
\hline 60 & 10 & 69 & 10 & 36 & 10 & 16 \\
\hline
\end{tabular}

\subsubsection{Ensaios de Coagulação, Floculação e Sedimentação}

Determinados os parâmetros de coagulação, mistura rápida e floculação, foram executados ensaios de coagulação, floculação e sedimentação Os ensaios foram realizados conforme descrição do item 4.5.4. O objetivo dessa etapa foi obter dados que servissem como base para comparação com o efeito da ruptura e da refloculação As coletas foram feitas para as velocidades de sedimentação foram de 4,67;2,20;1,38; $0,97,0,60$ e $0,42 \mathrm{~cm} / \mathrm{min}$. Os ensaios dessa etapa foram realizados em tréplica. Observase na Tabela 5.5 os resultados dos ensaios desta etapa. 
Tabela 5.5 - Resultados do ensaio de coagulação, floculação e sedimentação.

\begin{tabular}{|c|c|c|c|c|c|c|c|c|c|c|c|c|c|c|c|}
\hline \multirow{2}{*}{ Jarro } & \multicolumn{2}{|c|}{$\begin{array}{l}\text { Dosagem } \\
\text { (mg/L) * }\end{array}$} & \multirow{2}{*}{$\begin{array}{l}\text { pH de } \\
\text { Coagu } \\
\text { lação }\end{array}$} & \multicolumn{2}{|c|}{$\begin{array}{c}\text { Vs1 } \\
4,67 \\
\text { (cm/min) }\end{array}$} & \multicolumn{2}{|c|}{$\begin{array}{c}\text { Vs2 } \\
2,2 \\
\text { (cm/min) }\end{array}$} & \multicolumn{2}{|c|}{$\begin{array}{c}\text { Vs3 } \\
1,38 \\
\text { (cm/min) }\end{array}$} & \multicolumn{2}{|c|}{$\begin{array}{c}\text { Vs4 } \\
0,97 \\
\text { (cm/min) }\end{array}$} & \multicolumn{2}{|c|}{$\begin{array}{c}\text { Vs5 } \\
0,60 \\
\text { (cm/min) } \\
\end{array}$} & \multicolumn{2}{|c|}{$\begin{array}{c}\text { Vs6 } \\
0,42 \\
\text { (cm/min) }\end{array}$} \\
\hline & $\begin{array}{c}\text { Sulfato } \\
\text { de } \\
\text { Alumínio }\end{array}$ & $\begin{array}{l}\text { Hidróxido } \\
\text { de Sódio }\end{array}$ & & $\begin{array}{l}\text { Turb. } \\
\text { (UT) }\end{array}$ & $\begin{array}{l}\text { Cor } \\
\text { Ap. } \\
\text { (uH) }\end{array}$ & $\begin{array}{l}\text { Turb. } \\
\text { (uT) }\end{array}$ & $\begin{array}{l}\text { Cor } \\
\text { Ap. } \\
\text { (uH) }\end{array}$ & $\begin{array}{l}\text { Turb. } \\
\text { (uT) }\end{array}$ & $\begin{array}{l}\text { Cor } \\
\text { Ap. } \\
\text { (uH) }\end{array}$ & $\begin{array}{l}\text { Turb. } \\
\text { (uT) }\end{array}$ & $\begin{array}{l}\text { Cor } \\
\text { Ap. } \\
\text { (uH) }\end{array}$ & $\begin{array}{l}\text { Turb. } \\
\text { (uT) }\end{array}$ & $\begin{array}{l}\text { Cor } \\
\text { Ap. } \\
\text { (uH) }\end{array}$ & $\begin{array}{l}\text { Turb. } \\
\text { (uT) }\end{array}$ & $\begin{array}{l}\text { Cor } \\
\text { Ap. } \\
\text { (uH) }\end{array}$ \\
\hline 1 & 180 & 27 & 6,15 & 3,28 & 143 & 3,25 & 66 & 2,83 & 51 & 1,86 & 29 & 1,31 & 15 & 0,83 & 9 \\
\hline 2 & 180 & 27 & 6,09 & 7,44 & 156 & 3,86 & 70 & 2,4 & 43 & 1,96 & 32 & 1,07 & 14 & 0,78 & 8 \\
\hline 3 & 180 & 27 & 6,07 & 7,62 & 149 & 2,59 & 47 & 2,06 & 27 & 1,51 & 20 & 1,11 & 13 & 0,76 & 8 \\
\hline
\end{tabular}

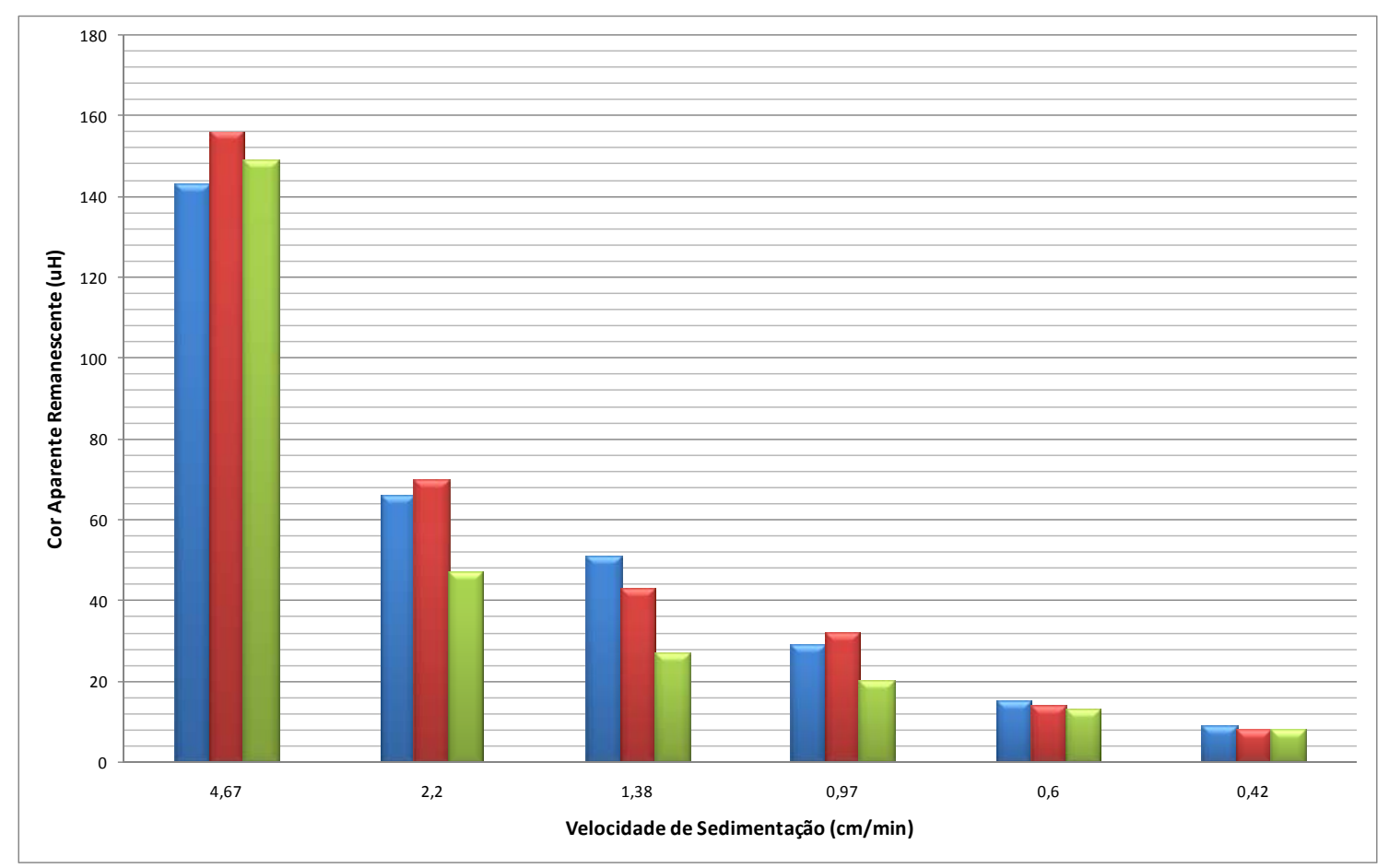

Figura 5.13 - Cor aparente remanescente em função da velocidade de sedimentação

Na Figura 5.14 é apresentada uma foto dos jarros deste ensaio ao final da floculação, antes de parar a rotação das paletas. Neste instante, o gradiente de velocidade era de $10 \mathrm{~s}^{-1}$ e o tempo de floculação por volta de $15 \mathrm{~min}$. Os flocos estavam formados e imediatamente se iniciaria a sedimentação. 


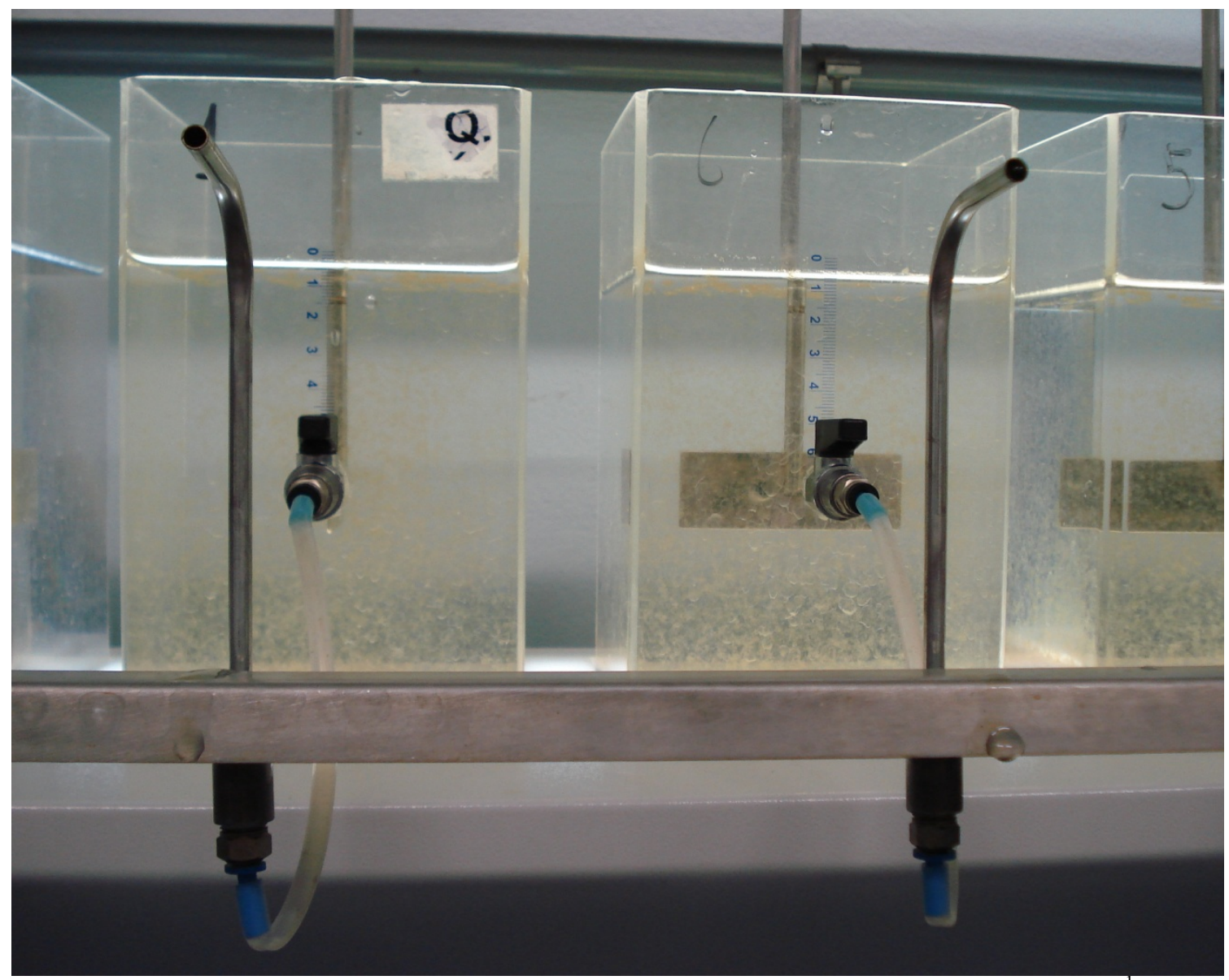

Figura 5.14 - Jarros com flocos formados, ao final da floculação, para $\mathrm{Tf}=15 \mathrm{~min}$ e $\mathrm{Gf}=10 \mathrm{~s}^{-1}$. 


\subsubsection{Ensaios de Ruptura}

Os ensaios de ruptura e sedimentação foram executados conforme descrito no item 4.5.5. Foram utilizados três gradientes de velocidade para ruptura, partindo do gradiente de (Gr) de $50 \mathrm{~s}^{-1}$, valor muito próximo aos valores testados na escolha dos parâmetros de floculação, até um gradiente mais elevado de $150 \mathrm{~s}^{-1}$, passando pelo valor intermediário de $100 \mathrm{~s}^{-1}$. Devido ao pequeno tamanho dos flocos formados, a diferença visual no tamanho dos flocos é pequena, como se pode observar nas Figuras 5.15 a 5.18, porém é possível perceber uma diferença gradual na cor e turbidez da água conforme o aumento do gradiente de velocidade de ruptura.

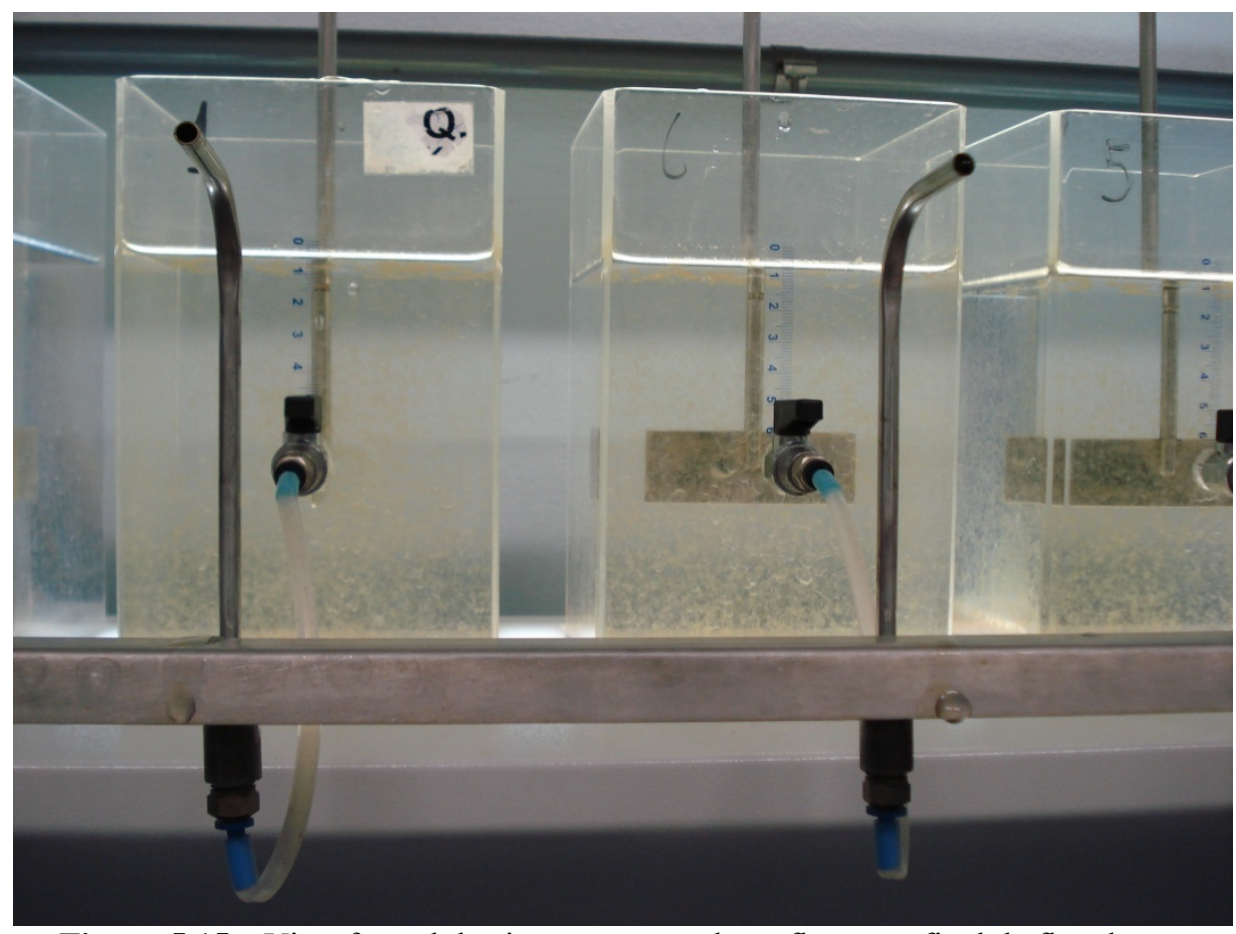

Figura 5.15 - Vista frontal dos jarros mostrando os flocos ao final da floculação 


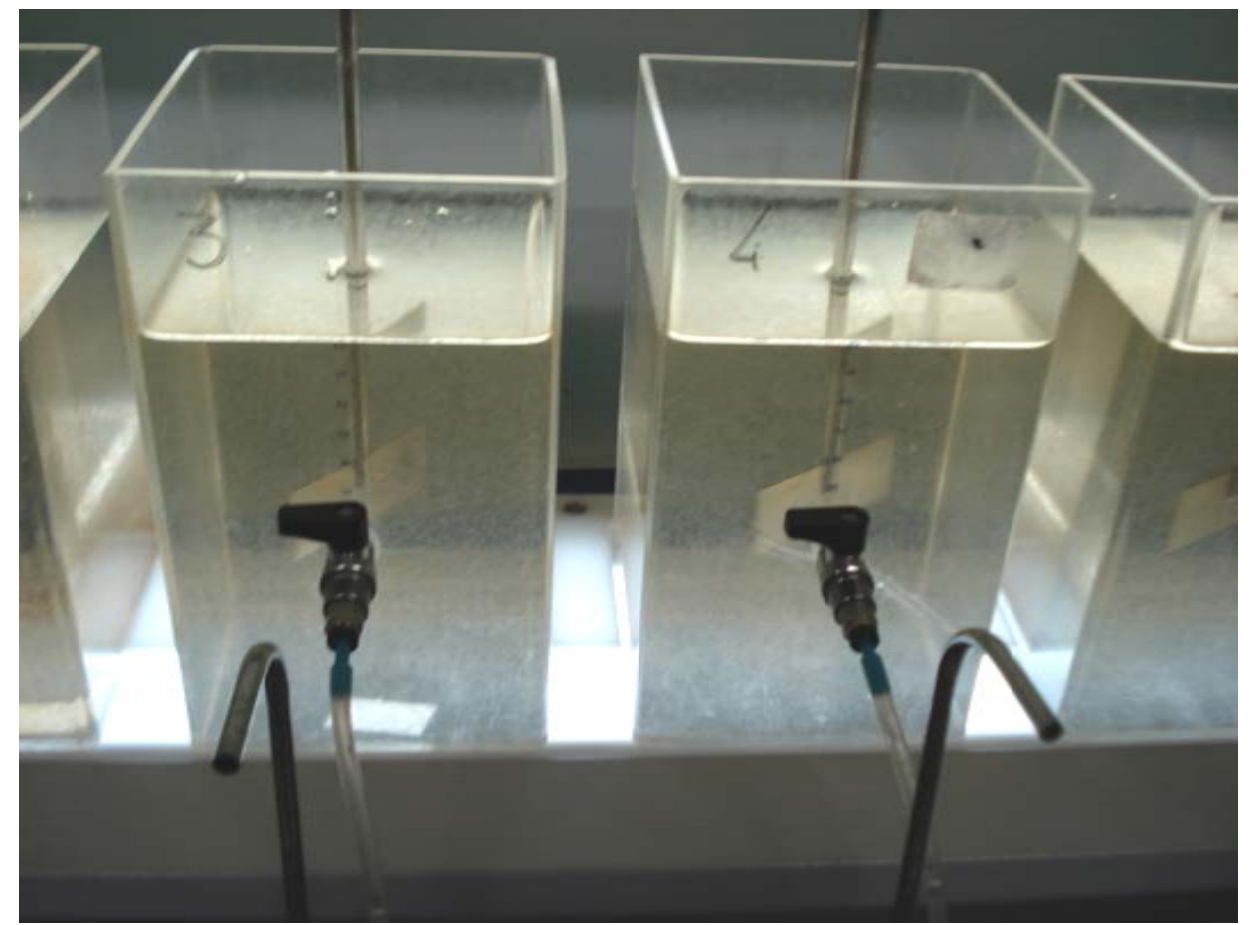

Figura 5.16 - Vista frontal dos jarros mostrando os flocos ao após a ruptura, para o gradiente de velocidade de ruptura de $50 \mathrm{~s}^{-1}$

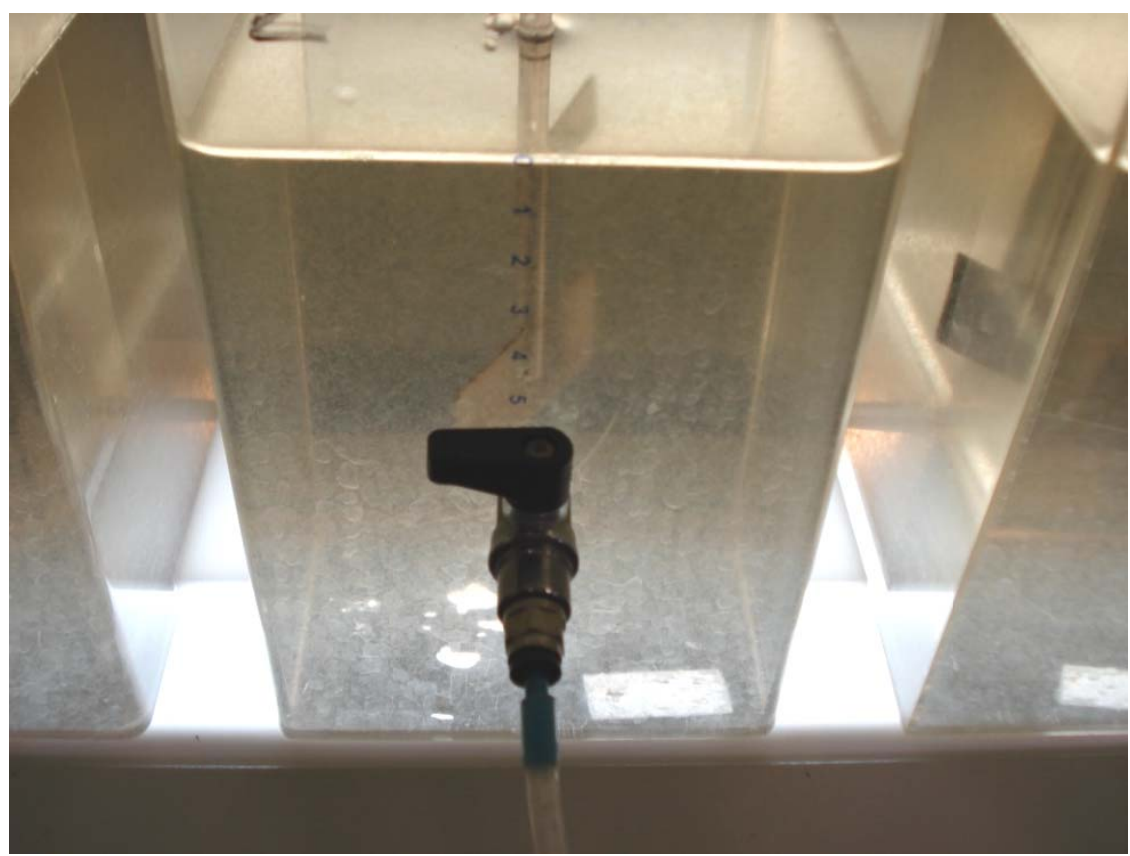

Figura 5.17 - Vista frontal dos jarros mostrando os flocos após a ruptura, para o gradiente de velocidade de ruptura de $100 \mathrm{~s}^{-1}$ 


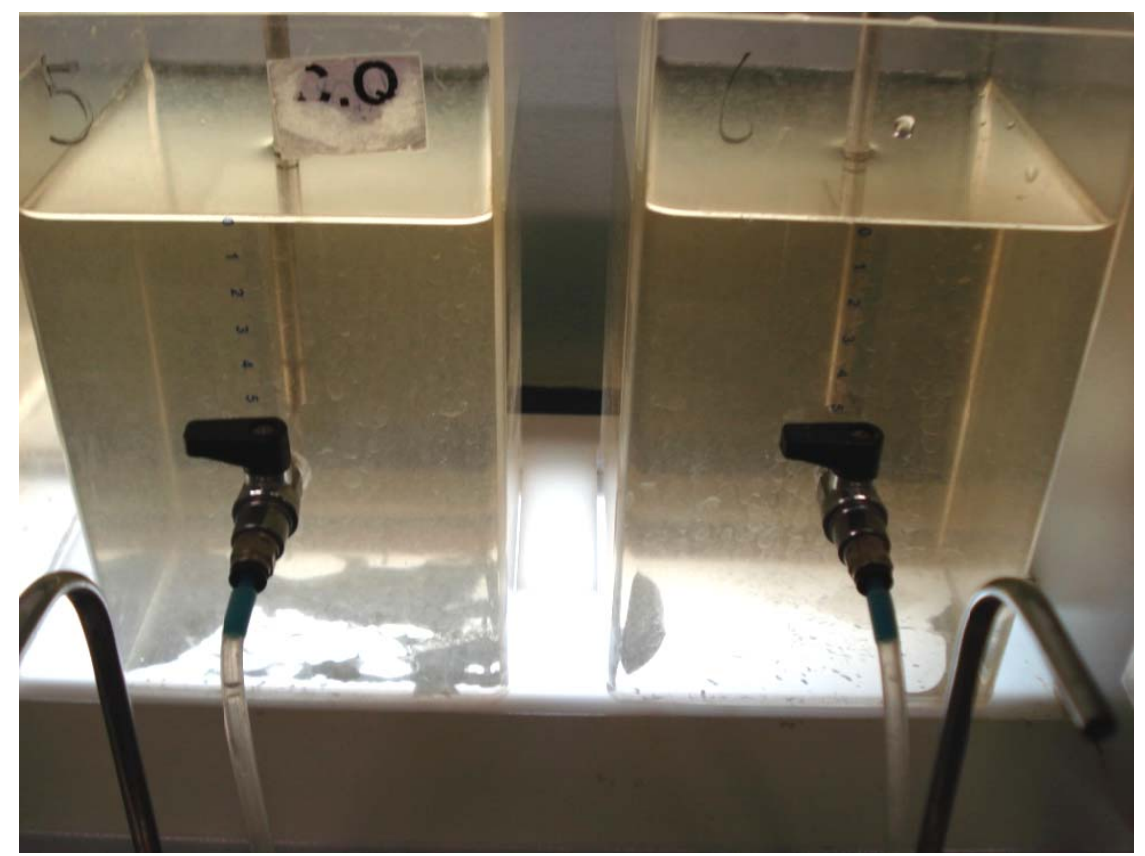

Figura 5.18 - Vista frontal dos jarros mostrando os flocos após a ruptura, para o gradiente de velocidade de ruptura de $150 \mathrm{~s}^{-1}$

Os resultados desta série de ensaios para os gradientes de velocidade de ruptura de 50, 100 e $150 \mathrm{~s}^{-1}$ estão mostrados na Tabela 5.6. Para efeito comparativo, estes resultados foram dispostos em gráficos juntamente com a condição inicial sem ruptura, ilustrados na Figura 5.19. O gráfico com os resultados de cor aparente remanescente demonstra a perda de eficiência na remoção de cor causada pela ruptura, mesmo quando ocorrida com gradientes de velocidade mais baixos.Também é possível observar que no caso de velocidades de sedimentação mais baixas a influência da ruptura foi ainda maior.

Tabela 5.6 - Resultados do ensaio de ruptura, para diferentes gradientes de velocidade durante a ruptura.

\begin{tabular}{|c|c|c|c|c|c|c|c|}
\hline \multirow{2}{*}{ Amostra } & \multirow{2}{*}{$\begin{array}{c}\text { Gradiente } \\
\text { de Ruptura }\end{array}$} & \multicolumn{6}{|c|}{ Cor Aparente (uH) para as velocidades de sedimentação (cm/min) } \\
\cline { 3 - 8 } & & $\begin{array}{c}\text { Vs1 } \\
\mathbf{4 , 6 7} \\
\mathbf{c m} / \mathbf{m i n}\end{array}$ & $\begin{array}{c}\text { Vs2 } \\
\mathbf{2 , 2 0} \\
\mathbf{c m} / \mathbf{m i n}\end{array}$ & $\begin{array}{c}\text { Vs3 } \\
\mathbf{1 , 3 8} \\
\mathbf{c m} / \mathbf{m i n}\end{array}$ & $\begin{array}{c}\mathbf{V} \mathbf{3} \\
\mathbf{0 , 9 7} \\
\mathbf{c m} / \mathbf{m i n}\end{array}$ & $\begin{array}{c}\text { Vs5 } \\
\mathbf{0 , 6 0} \\
\mathbf{c m} / \mathbf{m i n}\end{array}$ & $\begin{array}{c}\text { Vs6 } \\
\mathbf{0 , 4 2} \\
\mathbf{c m} / \mathbf{~ m i n}\end{array}$ \\
\hline 1 & $\begin{array}{c}\text { sem } \\
\text { ruptura }\end{array}$ & 149 & 61 & 40 & 27 & 14 & 8 \\
\hline 2 & 50 & 168 & 110 & 84 & 53 & 31 & 25 \\
\hline 3 & 100 & 174 & 145 & 122 & 77 & 56 & 38 \\
\hline 4 & 150 & 192 & 166 & 150 & 96 & 66 & 53 \\
\hline
\end{tabular}




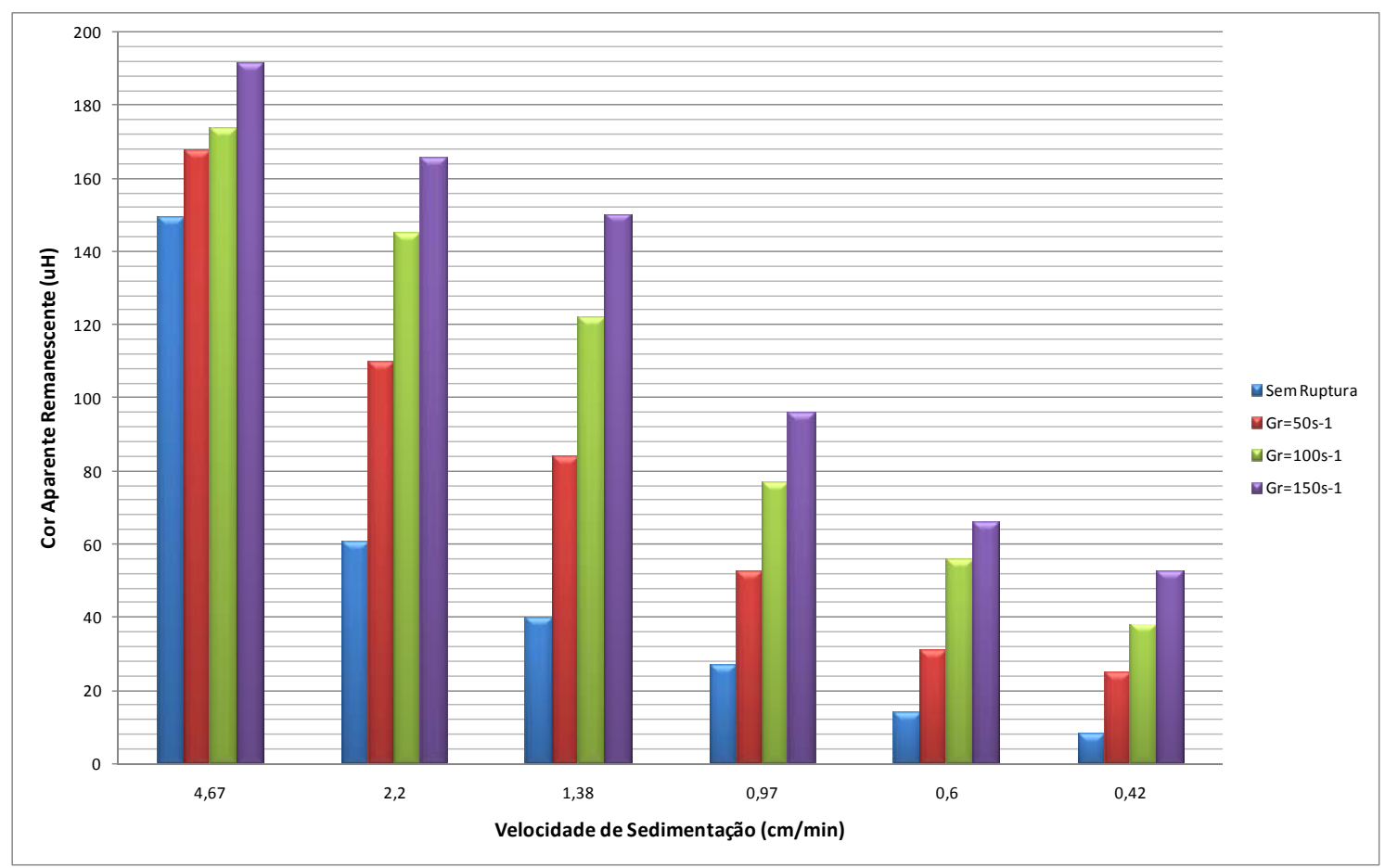

Figura 5.19 - Cor Aparente remanescente em função da velocidade de sedimentação, para diferentes gradientes de velocidade de ruptura.

\subsubsection{Ensaios de refloculação}

Neste item são mostrados os resultados dos ensaios de ruptura seguida de refloculação. Foram utilizados nestes ensaios os mesmos parâmetros de coagulação, floculação e ruptura do item anterior, seguindo a metodologia descrita no item 4.5.6. Os ensaios deste item foram divididos pelo gradiente de velocidade de ruptura utilizado (Gr): $50 ; 100$ e $150 \mathrm{~s}^{-1}$. A princípio o gradiente de velocidade de refloculação (Grf) utilizado foi igual ao de floculação, $10 \mathrm{~s}^{-1}$. Esse gradiente de velocidade é considerado muito baixo, uma vez que gradientes dessa magnitude normalmente permitem a formação de depósitos nas câmaras de floculação. Como equipamento de jarteste utilizado nos ensaios tem neste valor como sua limitação mínima, ele é o menor gradiente de velocidade possível de ser testado Desta forma, o segundo gradiente de velocidade de refloculação selecionado a ser utilizado nos ensaios foi o de $20 \mathrm{~s}^{-1}$. Os tempos de refloculação (Trf) foram variados de 5 a 25 minutos. Tempos maiores que 25 
minutos não foram testados uma vez que em todos os ensaios os tempos mais altos de refloculação foram os que apresentaram piores resultados.

Nos itens 5.2.6.1, 5.2.6.2 e 5.2.6.3 disponibilizam-se os resultados e a discussão dos ensaios para os Gr de 50, 100 e $150 \mathrm{~s}^{-1}$, respectivamente. Para efeito de comparação, apresentam-se os resultados para as condições sem ruptura (item 5.2.4) e com ruptura sem refloculação (item 5.2.5).

\subsubsection{Ensaios de refloculação para $\mathrm{Gr} 50 \mathrm{~s}^{-1}$}

Os resultados dos ensaios de refloculação para o gradiente de velocidade de ruptura (Gr) de $50 \mathrm{~s}^{-1}$ encontram-se no Anexo D, Tabelas D.1 e D.2. A foto da Figura 5.20 mostra os jarros do equipamento de jarteste durante um ensaio. Foram construídos gráficos dos resultados apresentados na Figura 5.21, para o valor de Grf de $10 \mathrm{~s}^{-1}$ e na Figura 5.22 para o de $20 \mathrm{~s}^{-1}$. Observa-se que a refloculação é pouco efetiva para a recuperação dos flocos, principalmente no caso do gradiente de refloculação de $20 \mathrm{~s}^{-1}$, onde os resultados foram em sua maioria piores que os resultados após a ruptura, sem floculação. Para ambos os Grf, observa-se que na refloculação, nos primeiros 5 minutos, houve diminuição da cor aparente remanescente se comparada com as amostras obtidas logo após a ruptura. Para tempos maiores de refloculação, na maioria das velocidades de sedimentação, os resultados foram próximos à condição de ruptura, com os piores resultados obtidos para as velocidades de sedimentação mais altas.

A grande diferença entre os resultados obtidos demonstra que a refloculação após a ruptura com $\mathrm{Gr}=50 \mathrm{~s}^{-1}$ não é eficiente se comparada com a condição sem a ruptura para a água de estudo coagulada com sulfato de alumínio. 


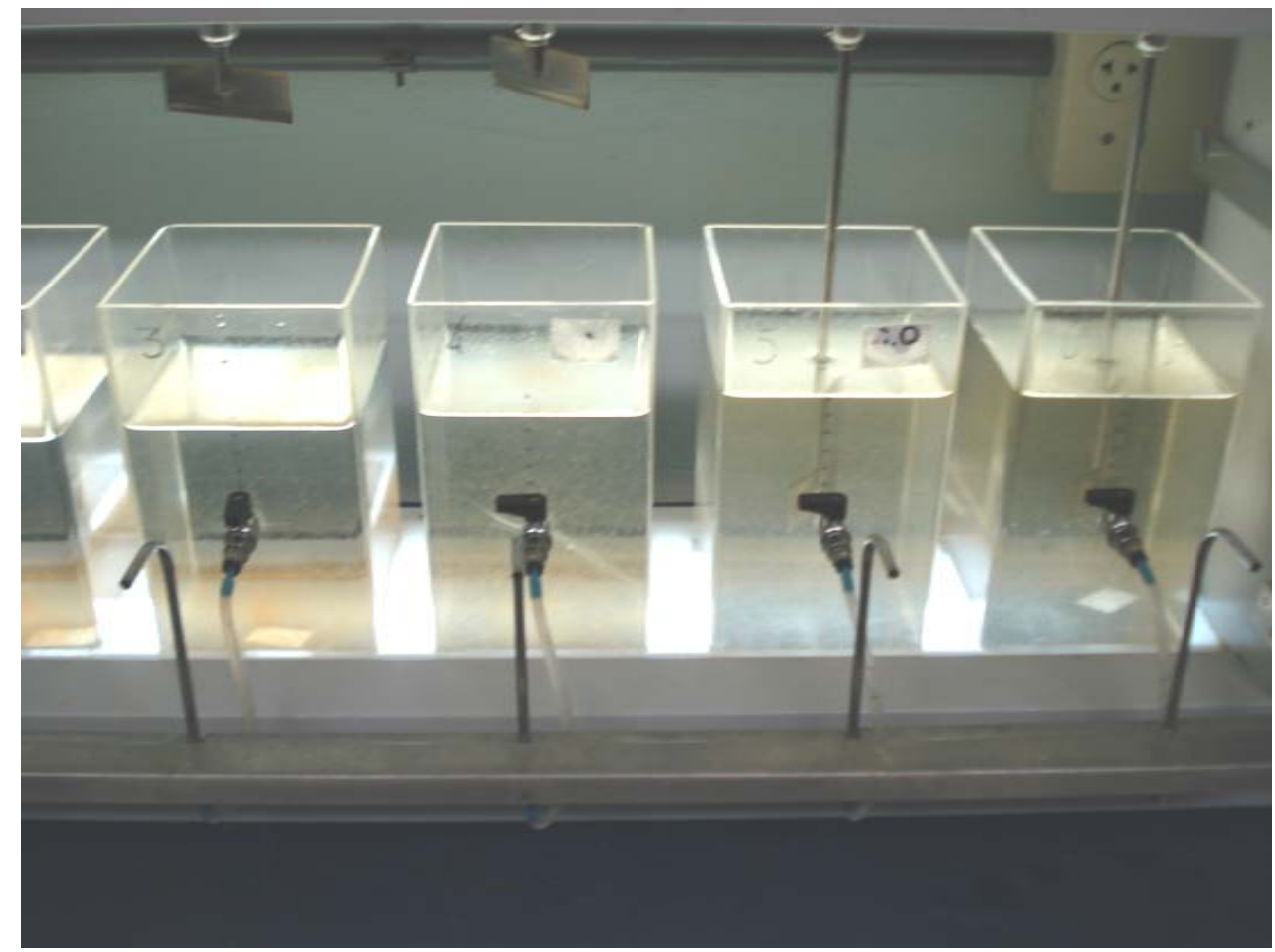

Figura 5.20 - Vista frontal dos jarros durante o ensaio para Gr igual a 50 s-1 e Grf igual a 10 s-1. Observa-se os dois primeiro jarro ao final da sedimentação, o segundo no inicio da sedimentação e o terceiro e quarto ainda refloculando. 


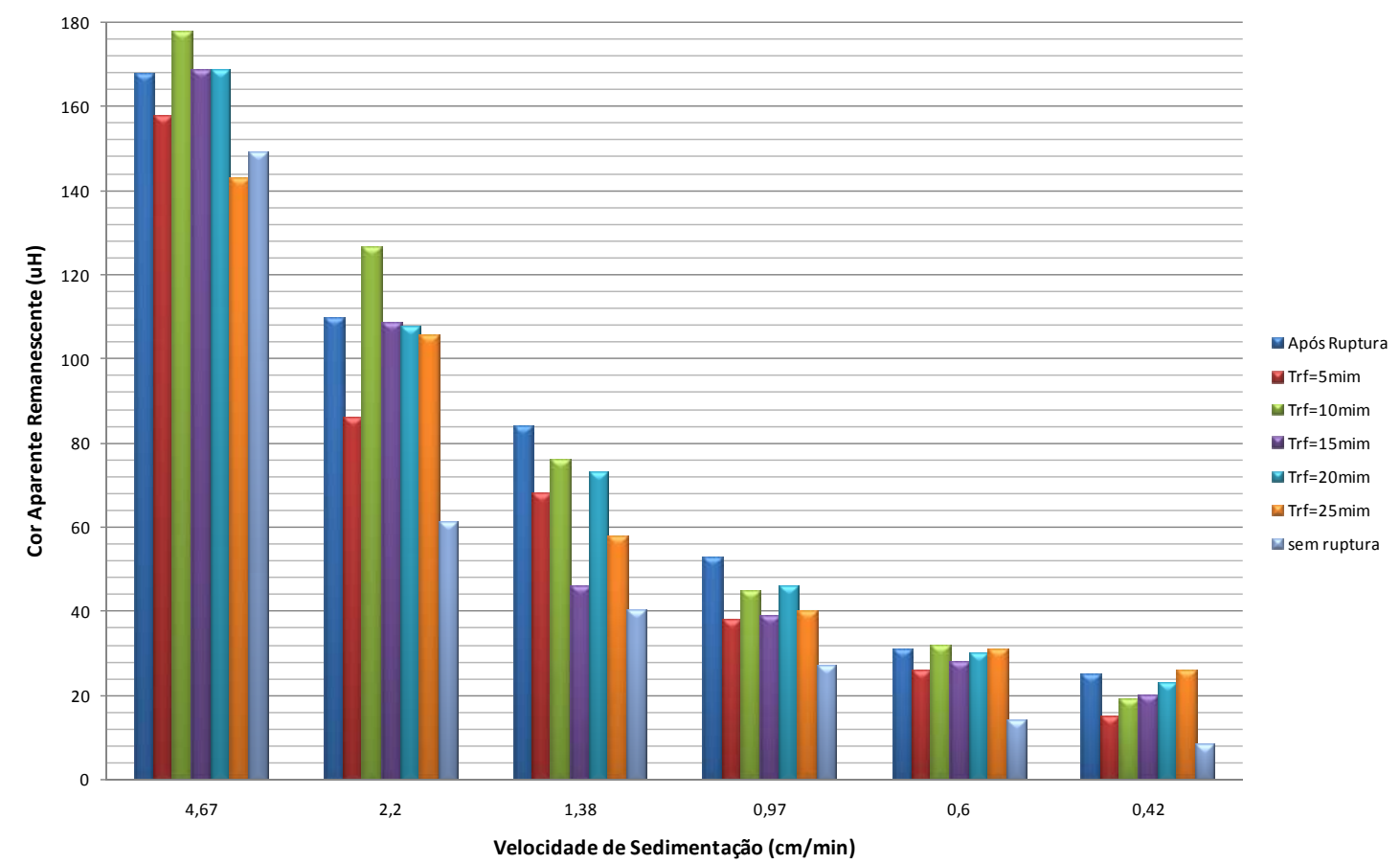

Figura 5.21- Cor Aparente remanescente em função da velocidade de sedimentação, para o gradiente de velocidade na ruptura de $50 \mathrm{~s}^{-1}$ e gradiente de velocidade de refloculação de $10 \mathrm{~s}^{-1}$. Fonte: Tabela D.1, Anexo D.

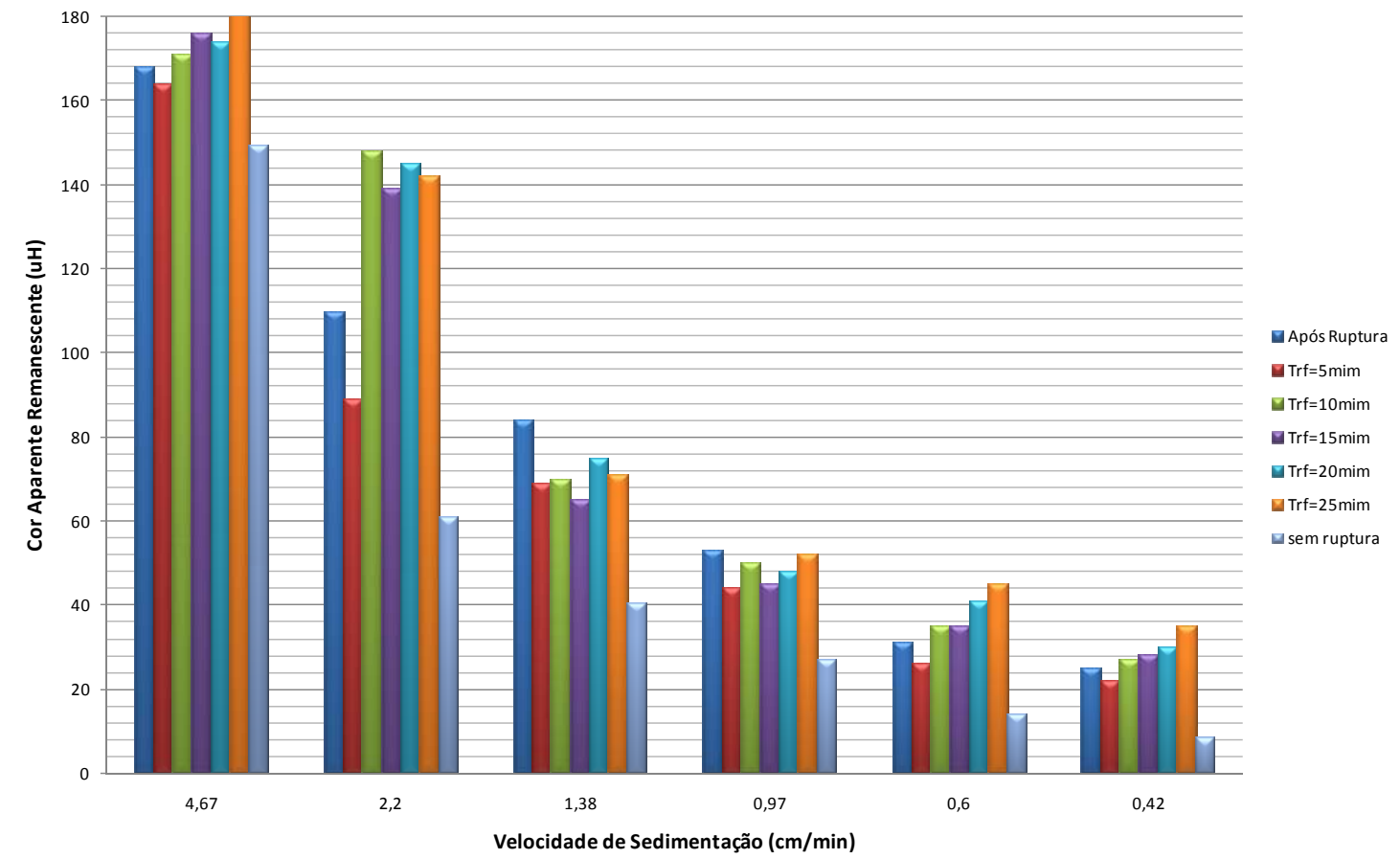

Figura 5.22 - Cor Aparente remanescente em função da velocidade de sedimentação, para o gradiente de velocidade na ruptura de $50 \mathrm{~s}^{-1}$ e gradiente de velocidade de refloculação de $20 \mathrm{~s}^{-1}$.

Fonte: Tabela D.2, Anexo D. 


\subsubsection{Ensaios de Refloculação para Gr $100 \mathrm{~s}^{-1}$}

Os resultados dos ensaios de refloculação para o gradiente de velocidade de ruptura (Gr) de $100 \mathrm{~s}^{-1}$ encontram-se no Anexo D, Tabelas D.3 e D.4. Foram construídos gráficos dos resultados apresentados na Figura 5.23, para o valor de Grf de $10 \mathrm{~s}^{-1}$ e na Figura 5.24 para o de $20 \mathrm{~s}^{-1}$. Com eles é possível observar que a refloculação é pouco efetiva para a recuperação dos flocos, principalmente no caso do gradiente de refloculação de $20 \mathrm{~s}^{-1}$, onde os resultados de cor aparente remanescente foram ainda piores que os resultados após a ruptura com o gradiente de ruptura de $50 \mathrm{~s}^{-1}$. Para ambos os Grf, observa-se que a refloculação combinada com baixas velocidades de sedimentação apresentou resultados melhores do que os resultados de logo após a ruptura.

No caso do gradiente de refloculação de $10 \mathrm{~s}^{-1}$, os resultados de cor aparente remanescente para a velocidade de sedimentação do $0,42 \mathrm{~cm} / \mathrm{min}$ foram muito próximos aos resultados obtidos sem ruptura. Contudo, esses valores nunca foram inferiores aos sem ruptura. A grande diferença entre os resultados obtidos nas outras velocidades de sedimentação demonstra que a refloculação não é eficiente se comparada com a condição sem a ruptura para a água de estudo coagulada com sulfato de alumínio e gradiente de ruptura de $100 \mathrm{~s}^{-1}$. 


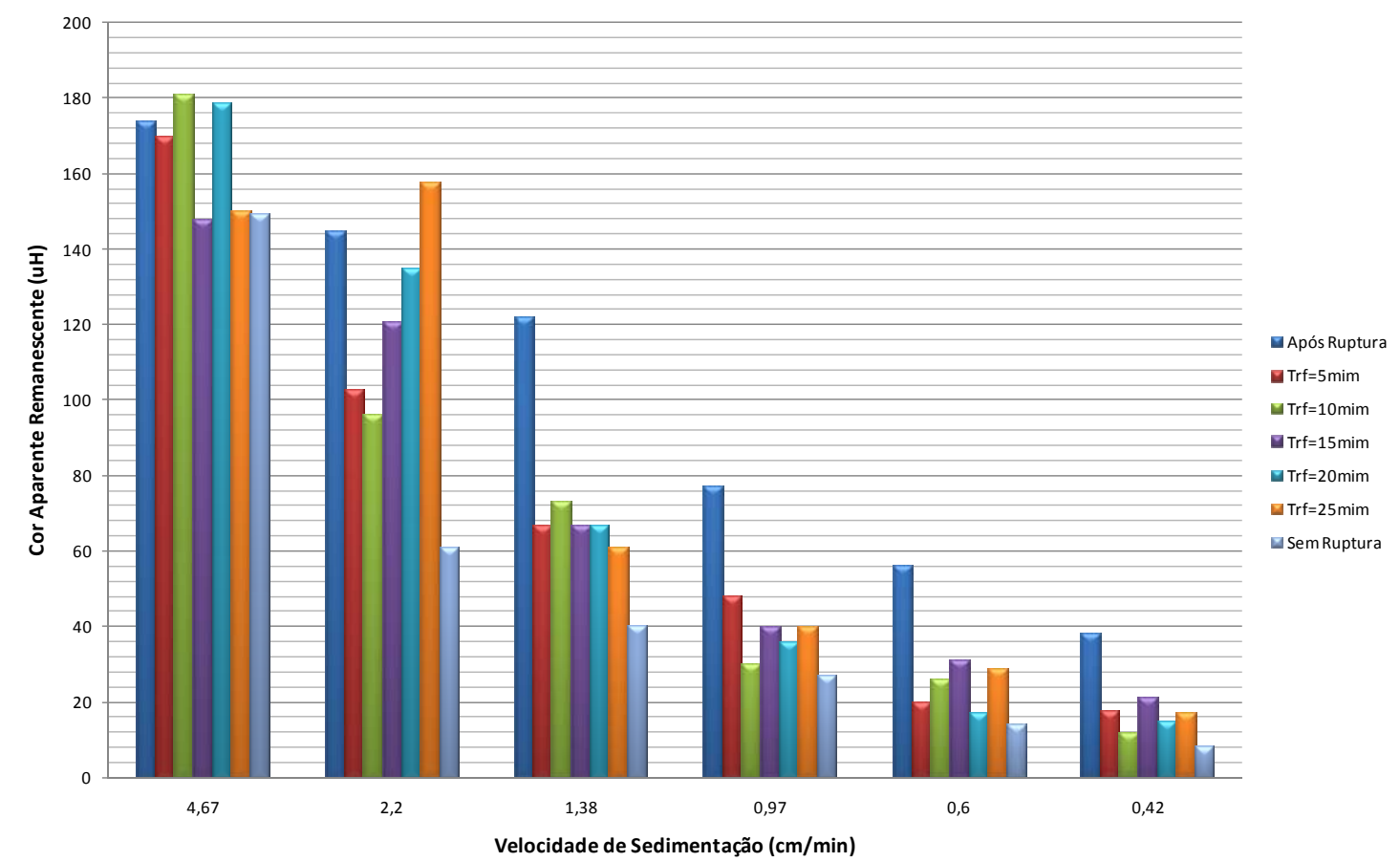

Figura 5.23- Cor Aparente remanescente em função da velocidade de sedimentação, para o gradiente de velocidade na ruptura de $100 \mathrm{~s}^{-1}$ e gradiente de velocidade de refloculação de $10 \mathrm{~s}^{-1}$. Fonte: Tabela D.1, Anexo D.

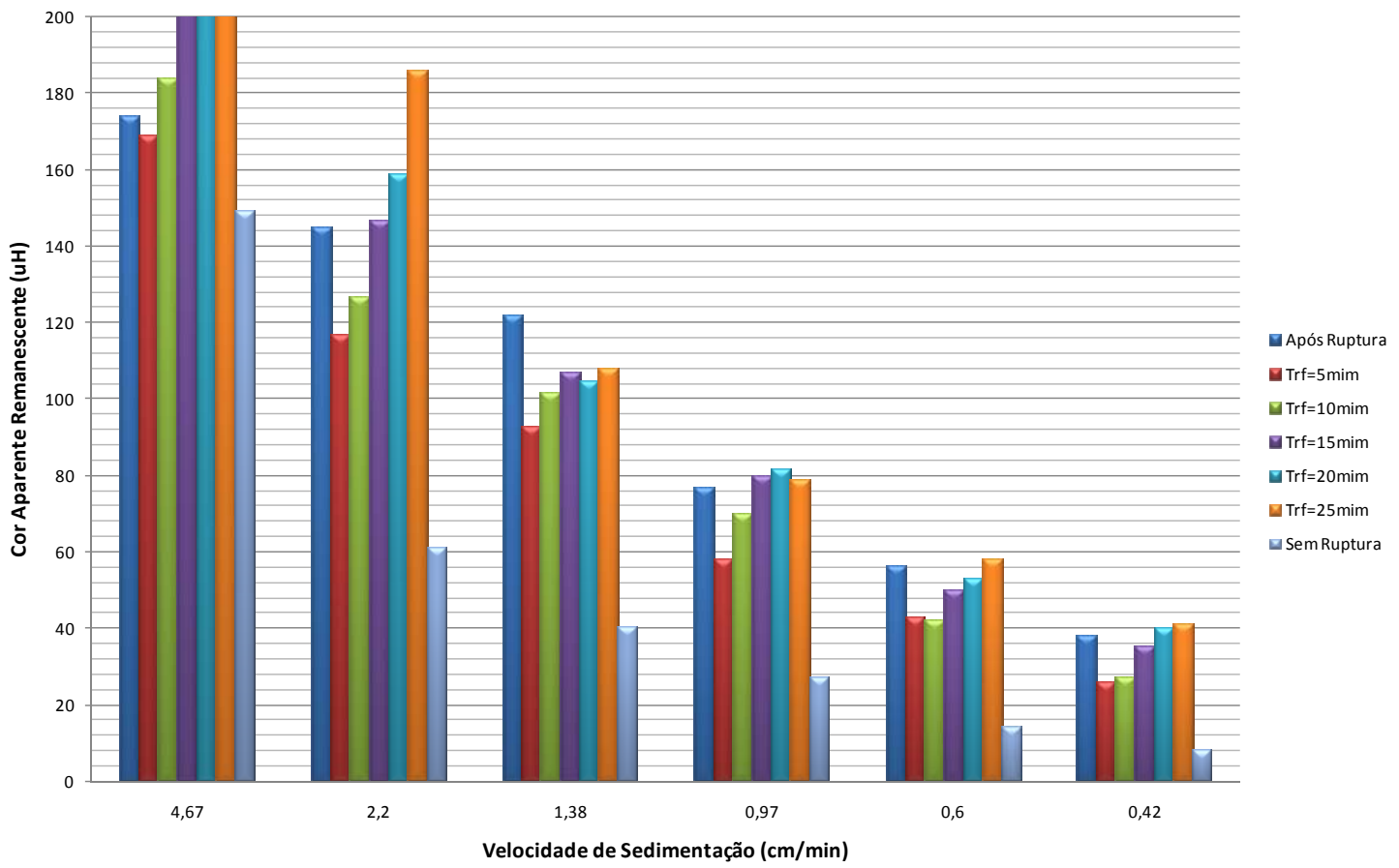

Figura 5.24 - Cor Aparente remanescente em função da velocidade de sedimentação, para o gradiente de velocidade na ruptura de $100 \mathrm{~s}^{-1}$ e gradiente de velocidade de refloculação de $20 \mathrm{~s}^{-1}$.

Fonte: Tabela D.2, Anexo D. 


\subsubsection{Ensaios de Refloculação para Gr de $150 \mathrm{~s}^{-1}$}

Os ensaios de refloculação para o gradiente de ruptura de $150 \mathrm{~s}^{-1}$ foram realizados conforme a metodologia descrita no item 4.5.6. Os gradientes de velocidade de refloculação utilizados foram 10 e $20 \mathrm{~s}^{-1}$. Os resultados dos ensaios desta série são explicitados no Anexo D, Tabelas D.5 e D.6, referentes aos Grf de 10 e $20 \mathrm{~s}^{-1}$ respectivamente. Na Figura 5.25, é possível observar os jarros do equipamento jarteste durante um ensaio.

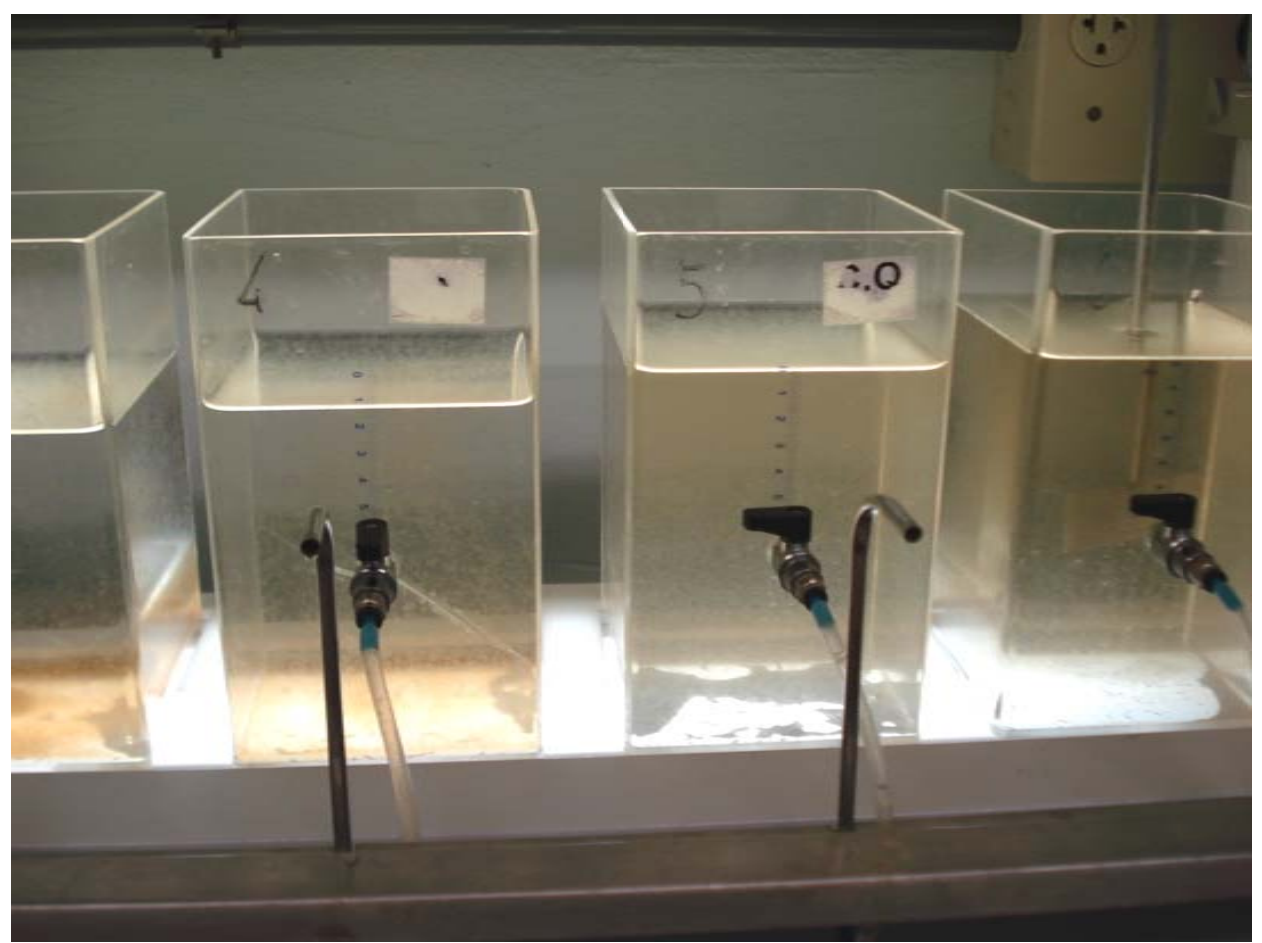

Figura 5.25- Vista frontal dos jarros durante um ensaio. Observa-se o primeiro jarro ao final da sedimentação, o segundo no inicio da sedimentação e o terceiro ainda refloculando.

Na Figura 5.26 e na Figura 5.27, referentes aos gradientes de refloculação de 10 e $20 \mathrm{~s}^{-1}$ respectivamente, são apresentados os resultados dos ensaios realizados. Como no caso dos gradientes de ruptura mais baixos, os resultados foram bem inferiores ao caso sem ruptura de flocos. Porém, ao se comparar os resultados de após a ruptura com 
os resultados dos ensaios com baixo tempo de refloculação é possível perceber uma melhora significativa na eficiência da remoção de cor aparente por sedimentação.

Essa melhora, que também ocorreu os outros gradientes de ruptura, é evidenciada devido à péssima condição da água de estudo após a ruptura com o gradiente de velocidade de $150 \mathrm{~s}^{-1}$. Como o ocorrido com os gradientes de ruptura menores, ao se utilizar o gradiente de refloculação de $10 \mathrm{~s}^{-1}$, os resultados apresentados são muito mais próximos das condições sem a ruptura do que os resultados do ensaio com a refloculação com o gradiente de velocidade de $20 \mathrm{~s}^{-1}$. 


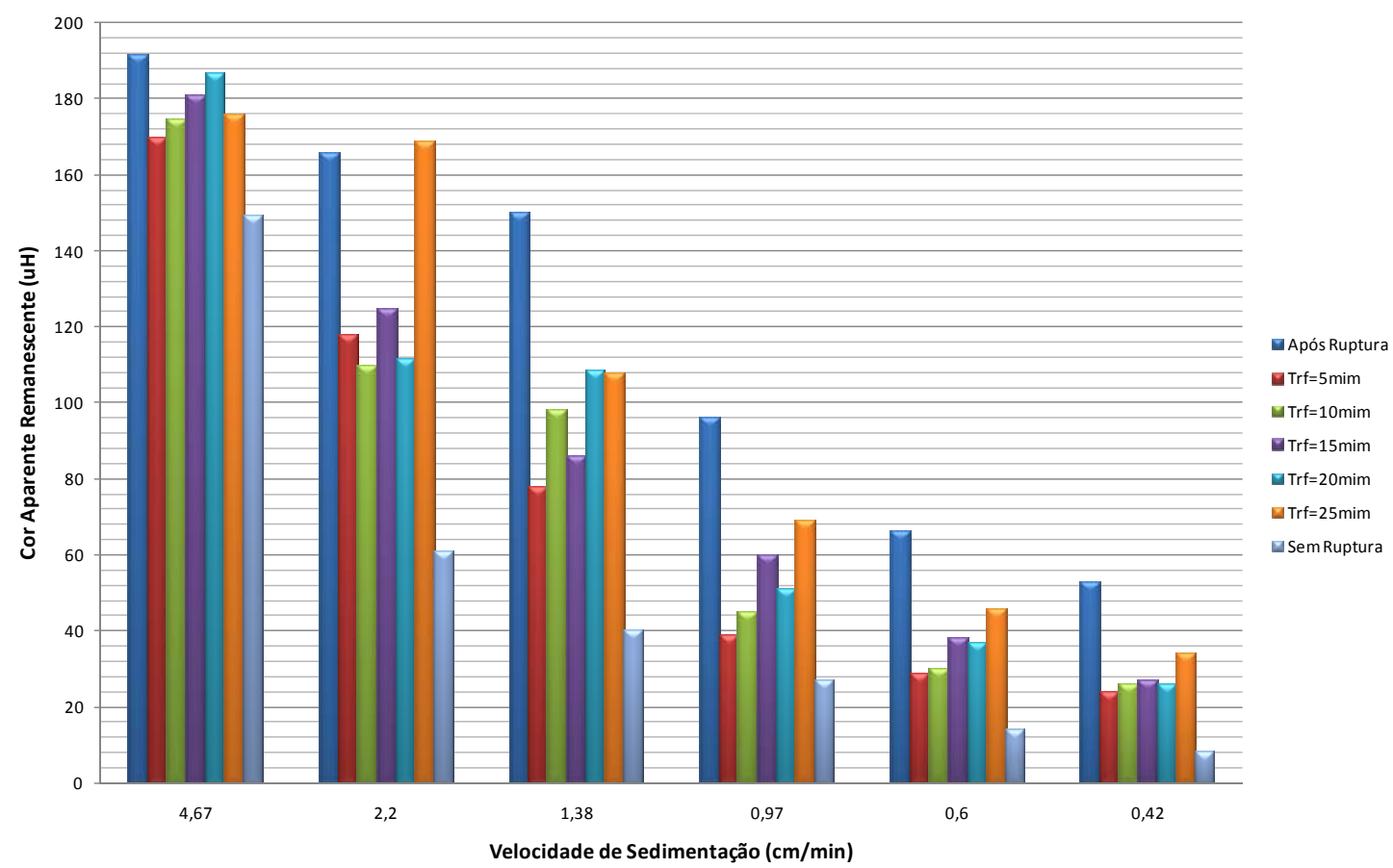

Figura 5.26 - Cor Aparente remanescente em função da velocidade de sedimentação, para o gradiente de velocidade na ruptura de $150 \mathrm{~s}^{-1}$ e gradiente de velocidade de refloculação de $10 \mathrm{~s}^{-1}$. Fonte: Tabela D.1, Anexo D.

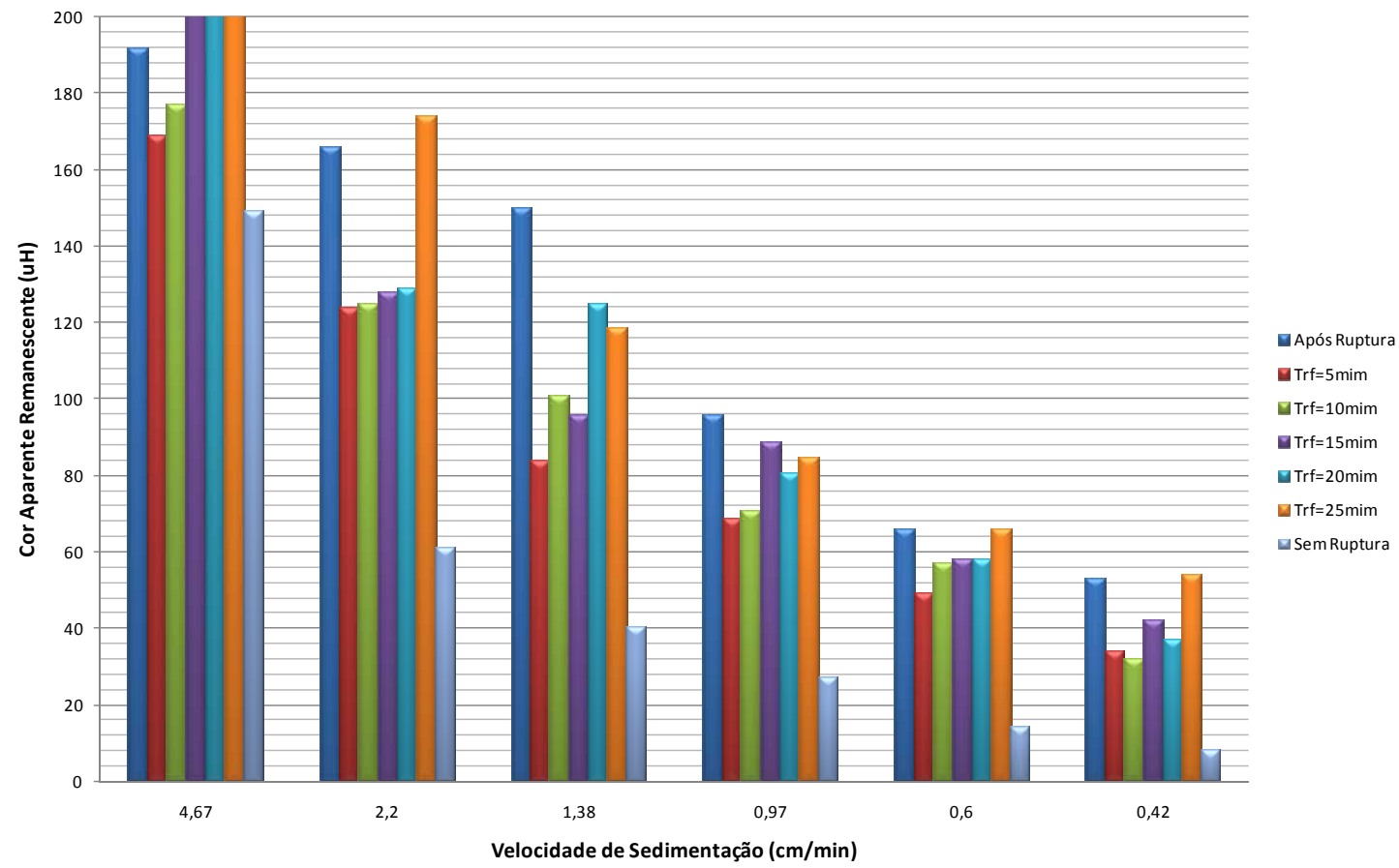

Figura 5.27 - Cor Aparente remanescente em função da velocidade de sedimentação, para o gradiente de velocidade na ruptura de $150 \mathrm{~s}^{-1}$ e gradiente de velocidade de refloculação de $20 \mathrm{~s}^{-1}$.

Fonte: Tabela D.2, Anexo D. 


\subsubsection{Comentários gerais sobre os ensaios de refloculação com o sulfato de alumínio como coagulante}

Foi possível observar que a refloculação diminuiu o valor da cor aparente quando comparada com os resultados obtidos logo após a ruptura. Em geral, a refloculação foi mais eficiente para tempos de até $10 \mathrm{~min}$, e após esses tempos, houve aumento na cor aparente. Para o gradiente de refloculação de $10 \mathrm{~s}^{-1}$ os resultados aproximaram-se mais dos valores obtidos sem ruptura. Apenas para a velocidade de sedimentação de $4,67 \mathrm{~cm} / \mathrm{min}$ e Grf de $10 \mathrm{~s}^{-1}$, foi possível observar resultados com cor aparente remanescente no mesmo patamar dos resultados sem ruptura. Este fato tem pouco significado, uma vez que esta velocidade de sedimentação não apresentou nenhuma eficiência na remoção de cor quando a água de estudo foi coagulada com o sulfato de alumínio.

Para o gradiente de refloculação de $20 \mathrm{~s}^{-1}$, os resultados foram de uma pior remoção quando comparados com os resultados do gradiente de $10 \mathrm{~s}^{-1}$. De modo geral, a ruptura se mostrou irreversível, praticamente para todos os casos., uma vez que os patamares de remoção atingidos pela refloculação não atingiram aqueles obtidos nos ensaios sem a ruptura dos flocos. Desta forma, fica claro que os flocos formados depois da ruptura têm comportamento diferente daquele em que os flocos foram formados inicialmente. Durante a ruptura, os flocos se rompem em pedaços, com características que não retornam às condições iniciais, como densidade, tamanho e capacidade de se aglutinar com outros fragmentos de flocos, influenciando, portanto, também a sua sedimentação. 


\subsection{Ensaios utilizando o Cloreto Férrico como coagulante}

Nesse item são apresentados os resultados dos ensaios utilizando o cloreto férrico como coagulante, seguindo a metodologia descrita no item 4 e utilizada no item 5.2

\subsubsection{Escolha da dosagem de coagulante e pH de coagulação}

Para a obtenção dos parâmetros dosagem de coagulante e pH de coagulação foram realizados ensaios segundo a metodologia descrita no item 4.5.1 com os gradientes de velocidade e tempo de agitação tanto para a mistura rápida quanto para a floculação utilizados nos ensaios com o sulfato de alumínio (item 5.2).

Foram realizados ensaios com dosagens entre 40 e $320 \mathrm{mg} / \mathrm{L}$ de coagulante, variando o pH de coagulação, buscando as regiões em que fossem observados remoção de cor aparente da água de estudo. Da mesma maneira que havia acontecido nos ensaios com o sulfato de alumínio, verificou-se que ao se adicionar o coagulante sem a utilização de alcalinizante, o pH de coagulação tornava-se muito baixo para a ocorrência da coagulação da água de estudo (abaixo de 4). Assim, em nenhum ensaio foi utilizado acidificante para a variação de $\mathrm{pH}$. Com a variação do $\mathrm{pH}$ de coagulação com a utilização de alcalinizante procurou-se preencher todas as regiões de gráficos com "dosagem de coagulante versus $\mathrm{pH}$ de coagulação" com os valores de cor aparente remanescente dos ensaios. 
Foram realizados 24 ensaios, totalizando 140 pontos do diagrama para cada velocidade de sedimentação. Os resultados dos ensaios desta etapa estão mostrados nas Tabelas do Anexo E, E.1 a E.24. Nelas, encontram-se: as dosagens de cloreto férrico líquido Comercial (50\% do valor de massa em água) adicionado nos jarros; as dosagens de alcalinizante ou de acidificante adicionadas para variação do $\mathrm{pH}$; o $\mathrm{pH}$ medido ao final da coagulação; a cor aparente remanescente para os diferentes tempos de sedimentação.

De posse destes resultados, foi possível a construção de diagramas de coagulação (“dosagem de coagulante versus pH de coagulação"). Nestes diagramas foram traçadas curvas de mesma cor aparente remanescente. Assim, foram determinadas as regiões de maior eficiência de remoção de cor aparente para cada velocidade de sedimentação. Os diagramas são mostrados na Figura 5.28 para a Vs de $3,0 \mathrm{~cm} / \mathrm{min}$, na Figura 5.29 para a Vs de $1,5 \mathrm{~cm} / \mathrm{min}$ e na 5.30 para a Vs de $0,5 \mathrm{~cm} / \mathrm{min}$. 


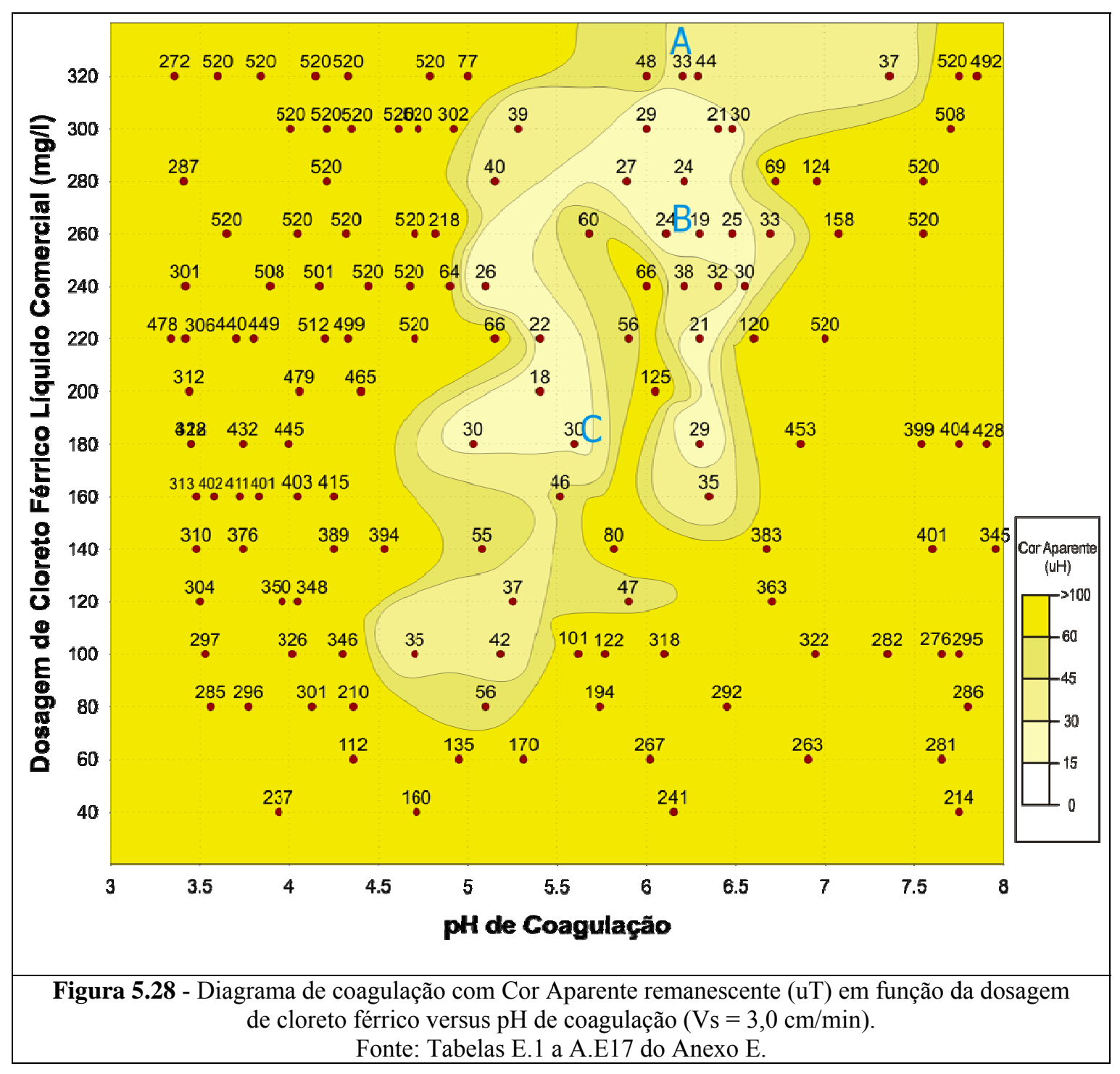




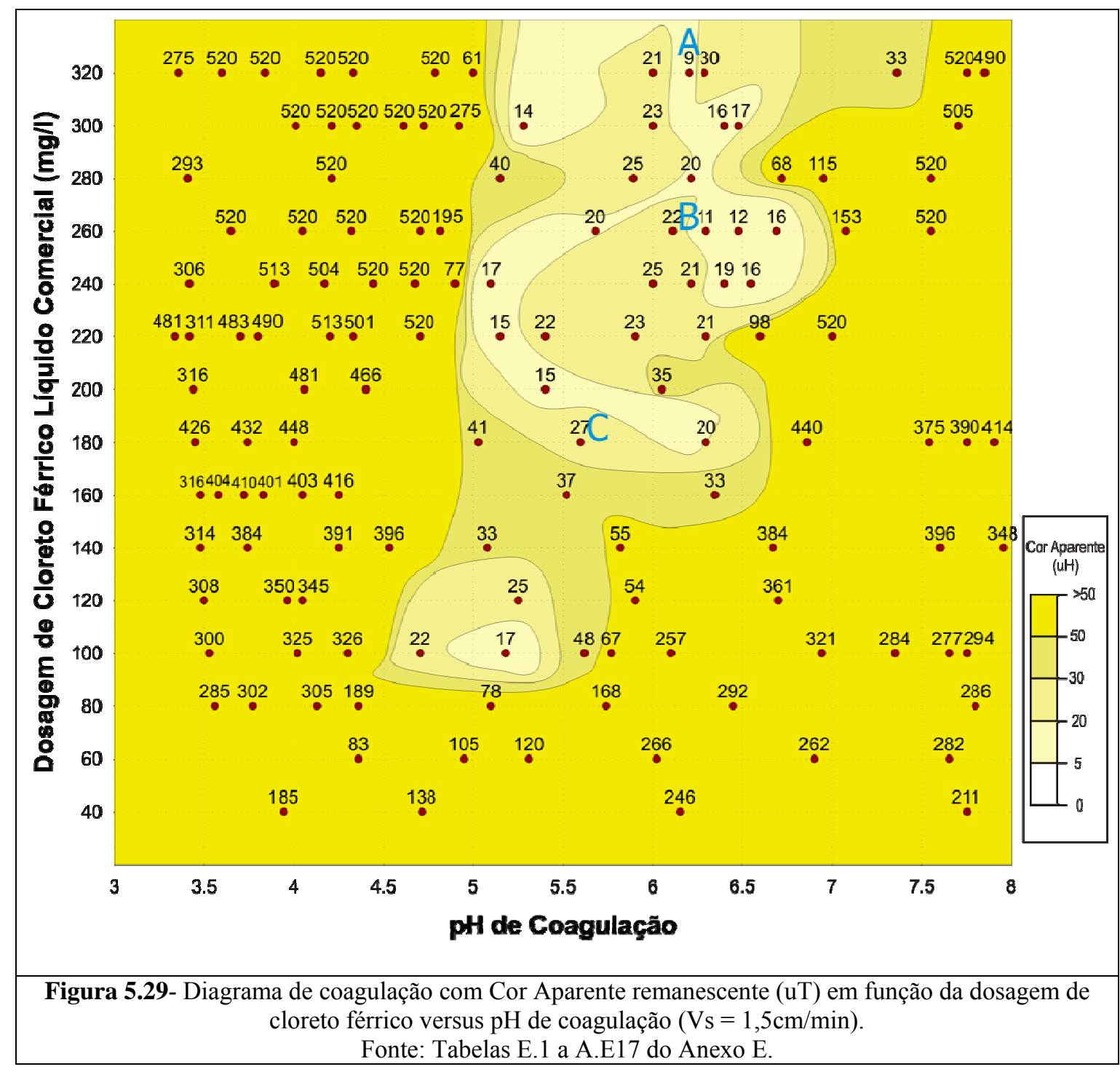




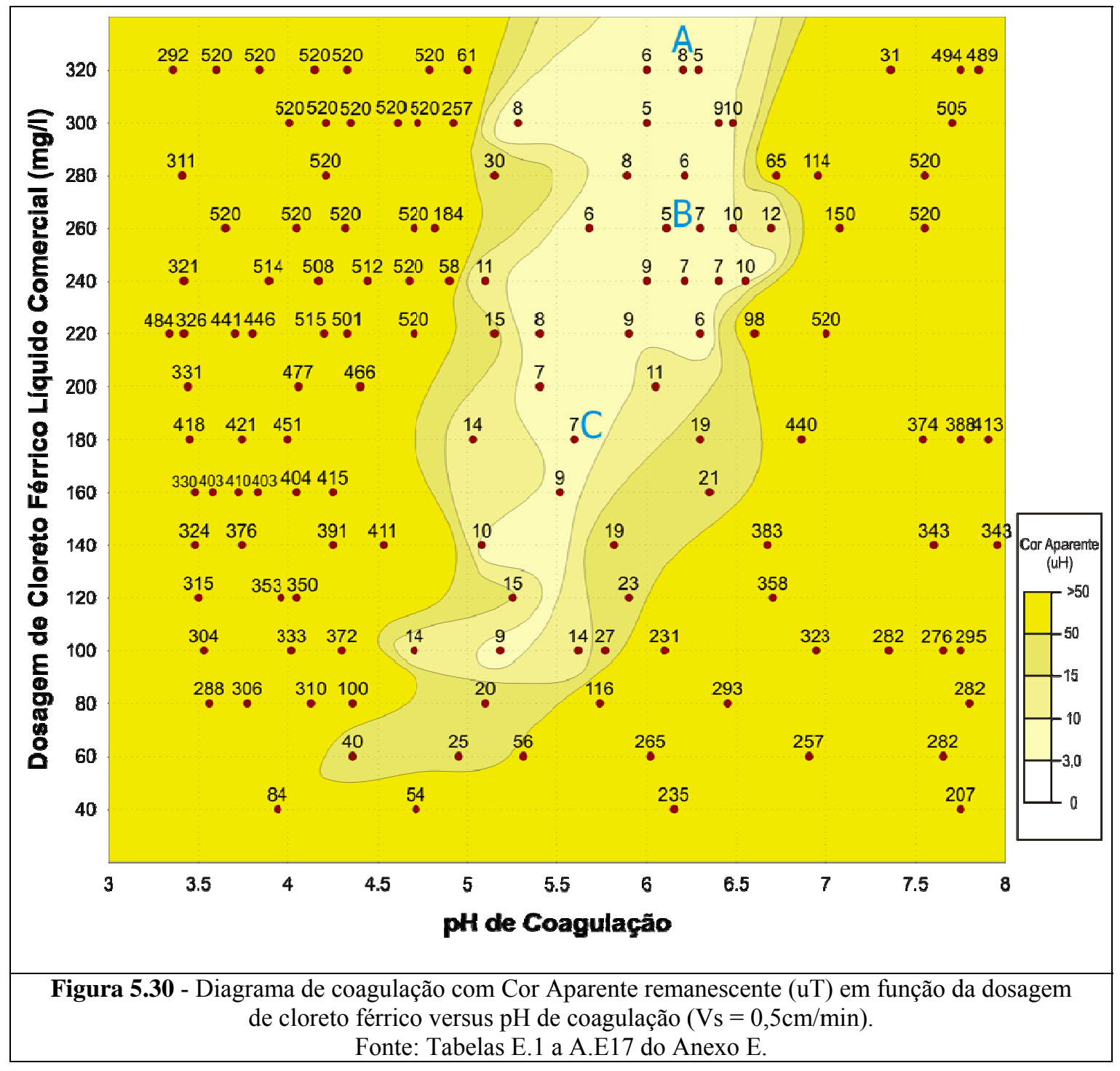

A escolha de um único ponto nos diagramas como o ponto de melhor coagulação foi feita a partir de um novo ensaio, onde três pontos que apresentaram bons resultados foram escolhidos para serem novamente reproduzidos com a finalidade de se escolher o par de valores “dosagem de coagulante e pH de coagulação" adequado para esta água de estudo utilizando cloreto férrico como coagulante. Os pontos escolhidos foram: A, com dosagem de coagulante de $320 \mathrm{mg} / \mathrm{L}$ e pH de coagulação de 6,35; B, com dosagem de coagulante de 260 mg/L e pH de coagulação de 6,15; C, com dosagem de coagulante de 200 mg/L e pH de coagulação de 5,45. 
Assim, foi realizado um ensaio com as mesmas características dos anteriores para a validação dos três pontos escolhidos. Os resultados estão disponíveis na Tabela 5.7. De acordo com os dados apresentados, o ponto que produziu os melhores resultados foi o ponto B, com dosagem de coagulante de $260 \mathrm{mg} / \mathrm{L}$ e pH de coagulação de 6,49. Este par de valores foi o escolhido para a realização dos ensaios seguintes.

Tabela 5.7 - Resultados do ensaio de reprodução dos pontos selecionados.

\begin{tabular}{|c|c|c|c|c|c|c|c|c|c|}
\hline \multirow{3}{*}{$\begin{array}{c}\text { Jarro } \\
\text { (Ponto) }\end{array}$} & \multicolumn{2}{|c|}{ Produtos químicos } & \multirow{3}{*}{$\begin{array}{c}\text { pH de } \\
\text { Coagulação }\end{array}$} & \multicolumn{2}{|c|}{$V s 1=3,0 \mathrm{~cm} / \mathrm{min}$} & \multicolumn{2}{|c|}{$\begin{array}{l}\mathrm{Vs} 2=1,5 \\
\mathrm{~cm} / \mathrm{min}\end{array}$} & \multicolumn{2}{|c|}{$\begin{array}{l}\mathrm{Vs} 3=0,5 \\
\mathrm{~cm} / \mathrm{min}\end{array}$} \\
\hline & $\begin{array}{l}\text { Cloreto } \\
\text { Férrico }\end{array}$ & $\begin{array}{l}\text { Hidróxido } \\
\text { de Sódio }\end{array}$ & & $\begin{array}{c}\text { Turb. } \\
\text { (uT) }\end{array}$ & $\begin{array}{l}\text { Cor } \\
\text { Apar. } \\
\text { (uH) }\end{array}$ & $\begin{array}{c}\text { Turb. } \\
\text { (uT) }\end{array}$ & $\begin{array}{l}\text { Cor } \\
\text { Apar. } \\
\text { (uH) }\end{array}$ & $\begin{array}{c}\text { Turb. } \\
\text { (uT) }\end{array}$ & $\begin{array}{c}\text { Cor } \\
\text { Apar. } \\
\text { (uH) }\end{array}$ \\
\hline & (mg/L) & $(\mathrm{mg} / \mathrm{L})$ & & & & & & & \\
\hline $1(\mathrm{~A})$ & 320 & 100 & 6,52 & 1,48 & 35 & 1,1 & 18 & 1,03 & 12 \\
\hline 2 (B) & 260 & 80 & 6,49 & 1,99 & 27 & 0,99 & 16 & 1,02 & 10 \\
\hline $3(\mathrm{C})$ & 200 & 57 & 6 & 3,3 & 110 & 1,57 & 34 & 1,24 & 14 \\
\hline
\end{tabular}

\subsubsection{Escolha dos parâmetros da Mistura Rápida}

Seguindo a metodologia apresentada no item 4.5.2, foram realizados os ensaios para escolha dos parâmetros da Mistura Rápida. A dosagem de coagulante e o $\mathrm{pH}$ de coagulação utilizados durante esta etapa de ensaios foram os selecionados no item 5.2.1: Dosagem de cloreto férrico de $260 \mathrm{mg} / \mathrm{L}$; e pH coagulação de 6,49. As condições de floculação foram as mesmas utilizadas anteriormente, ou seja, gradiente médio de velocidade durante a floculação de $15 \mathrm{~s}^{-1}$ e tempo de floculação de 30 minutos.

Foram testados os gradientes de velocidade de mistura rápida $(\mathrm{Gmr})$ de 300, 400, 600, 800, 1000 e $1200 \mathrm{~s}^{-1}$, e os tempos de mistura (Tmr) de 5, 10, 20, 30, 60 e $90 \mathrm{~s}$. A cada ensaio, o equipamento jarteste foi ajustado na rotação referente ao $\mathrm{Gmr}$, e foram adicionados o volume da solução de coagulante em tempos diferentes buscando obter, em cada jarro, um tempo de mistura diferente para um mesmo gradiente de velocidade. 
Diferentemente dos ensaios com o Sulfato de Alumínio, foi testado o gradiente de velocidade de $300 \mathrm{~s}^{-1}$, uma vez que após os testes dos gradientes de 400 a $1200 \mathrm{~s}^{-1}$, o gradiente de $400 \mathrm{~s}^{-1}$ foi o que apresentava os melhores resultados. Desse modo foi necessário verificar se um gradiente ainda menor teria resultados ainda melhores.

Os resultados dos ensaios para as três velocidades de sedimentação são apresentados no Anexo F, Tabelas F.1 a F.6. No total, realizaram-se 6 ensaios, um para cada gradiente de velocidade. Os resultados são expostos em gráficos tridimensionais, com os gradientes de velocidade um dos eixos, o tempo de mistura no outro eixo e a cor aparente remanescente no terceiro eixo. três gráficos foram produzidos, um para cada velocidade de sedimentação. A Figura 5.31 mostra os resultados para a Vs de 1,5 $\mathrm{cm} / \mathrm{min}$, na Figura 5.32 para a Vs de $1,0 \mathrm{~cm} / \mathrm{min}$ e na Figura 5.33 para a Vs de 0,5 $\mathrm{cm} / \mathrm{min}$.

Como no caso do sulfato de alumínio, a velocidade de sedimentação de 3 cm/min não foi usada nos ensaios otimização da mistura rápida e floculação. Nesses ensaios, as velocidades de sedimentação de 1,5 e $0,5 \mathrm{~cm} / \mathrm{min}$ foram mantidas, enquanto que a velocidade de sedimentação de $1 \mathrm{~cm} / \mathrm{min}$ substituiu a de $3 \mathrm{~cm} / \mathrm{min}$ 


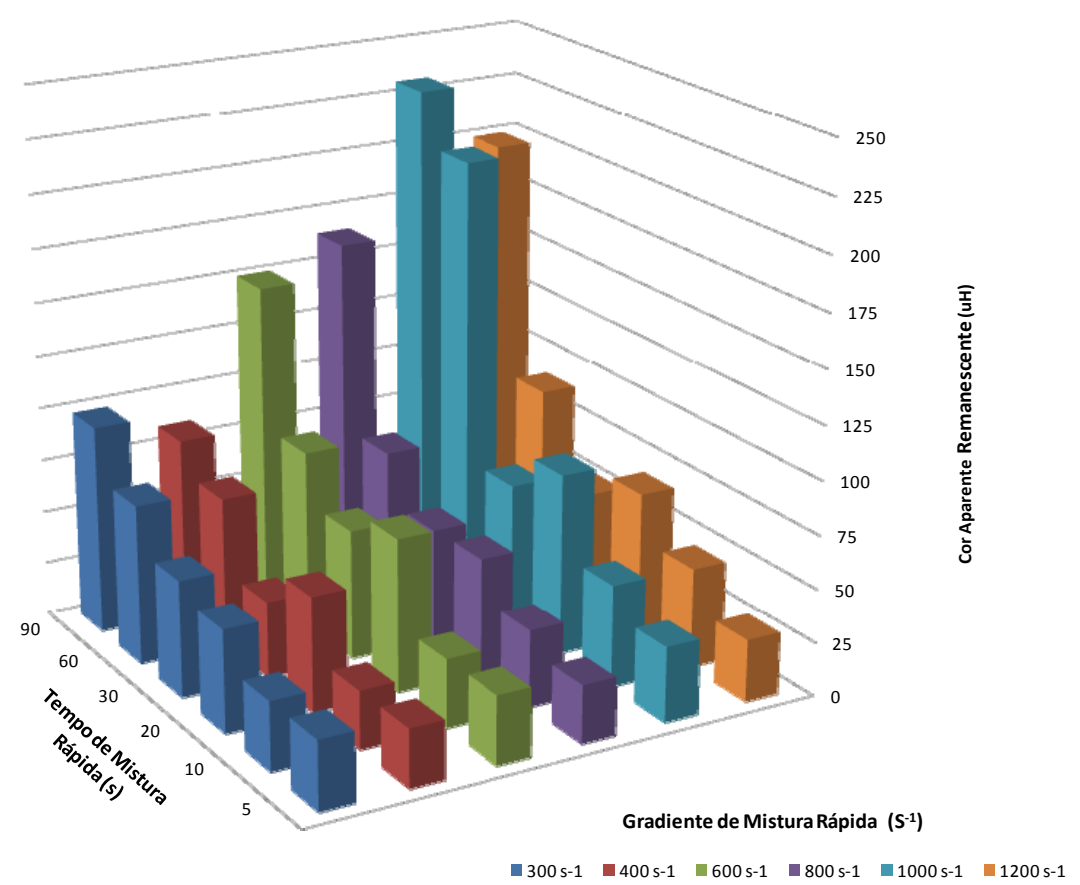

Figura 5.31 - Cor aparente remanescente em função do gradiente de mistura rápida (Gmr) versus tempo de mistura rápida (Tmr) para a velocidade de sedimentação Vs1 $=1,5 \mathrm{~cm} / \mathrm{min}$ Fonte: Tabelas F.1 a F.6 do Anexo F.

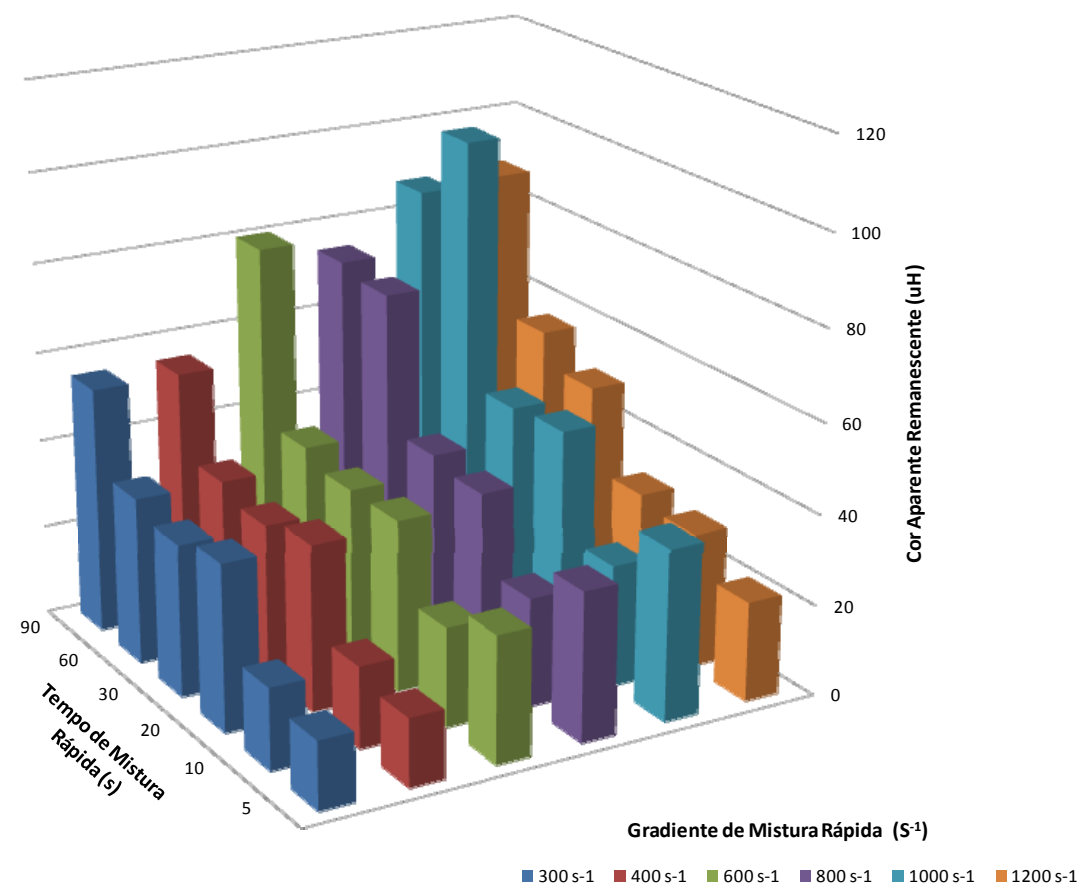

Figura 5.32 - Cor aparente remanescente em função do gradiente de mistura rápida (Gmr) versus tempo de mistura rápida $(\mathrm{Tmr})$ para a velocidade de sedimentação Vs1 $=1,0 \mathrm{~cm} / \mathrm{min}$ Fonte: Tabelas F.1 a F.6 do Anexo F. 


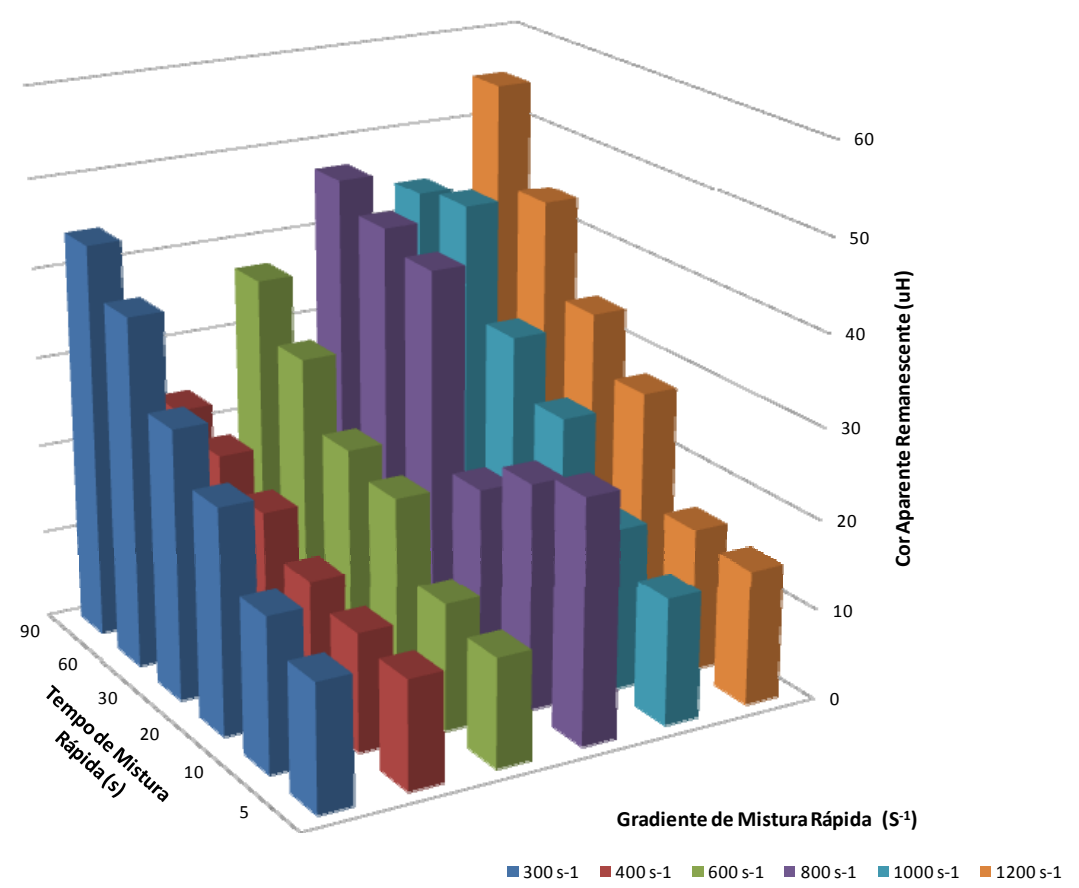

Figura 5.33 - Cor aparente remanescente em função do gradiente de mistura rápida (Gmr) versus tempo de mistura rápida (Tmr) para a velocidade de sedimentação $\mathrm{Vs} 1=0,5 \mathrm{~cm} / \mathrm{min}$ Fonte: Tabelas F.1 a F.6 do Anexo F.

A análise dos gráficos mostra que, como quando utilizado o cloreto férrico como coagulante, a eficiência na remoção de cor aparente é maior quando a mistura rápida é realizada em tempos menores. Por outro lado, com os gradientes de velocidade mais elevados a eficiência piorou. A análise conjunta dos resultados para as três velocidades de sedimentação evidencia a maior eficiência do gradiente de velocidade de $400 \mathrm{~s}^{-1}$. Assim, o par de valores escolhido para as próximas etapas foi gradiente de velocidade de $400 \mathrm{~s}^{-1}$ e tempo de $5 \mathrm{~s}$.

\subsubsection{Escolha dos parâmetros de Floculação}

Os ensaios foram realizados conforme descrição do item 4.5.3. De acordo com os resultados obtidos anteriormente, os parâmetros adotados para os ensaios desta série foram: dosagem de cloreto férrico de $260 \mathrm{mg} / \mathrm{L}, \mathrm{pH}$ coagulação de $6,49, \mathrm{Gmr}$ de $400 \mathrm{~s}^{-1}$ e Tmr de $5 \mathrm{~s}^{1}$. 
Como nos ensaios com o sulfato de alumínio, foram testados os gradientes de velocidade de floculação (Gf) de 10, 15, 20, 25, 30 e $40 \mathrm{~s}^{-1}$, e os tempos de floculação (Tf) de 5, 10, 15, 20, 25, 30, 35, 40, 45, 50, 55 e 60 minutos. Assim foram necessários dois ensaios para cada gradiente de velocidade a ser testado. Para submeter cada jarro do aparelho de jarteste a um tempo de floculação diferente, a paleta correspondente foi erguida no tempo de floculação desejado. Deste modo, enquanto no jarro em questão tinha-se inicio a sedimentação os demais a floculação continuava. As velocidades de sedimentação foram mantidas as mesmas utilizadas na escolha dos parâmetros de mistura rápida: $1,5,1,0$, e $0,5 \mathrm{~cm} / \mathrm{min}$. Os valores de cor aparente e turbidez remanescente, para as três velocidades de sedimentação, estão no Anexo G, nas Tabelas G.1 a G.12.

Os resultados para cada tempo de floculação foram plotados em gráficos de cor aparente em função do gradiente de velocidade. Ao se observar as curvas é possível determinar qual gradiente de velocidade que produz melhor resultado na remoção de cor. Os gráficos mostrados nas Figuras 5.34, 5.35 e 5.36, referem-se à remoção de cor aparente nas velocidades de sedimentação de 1,5,1,0 e $0,5 \mathrm{~cm} / \mathrm{min}$, respectivamente. 


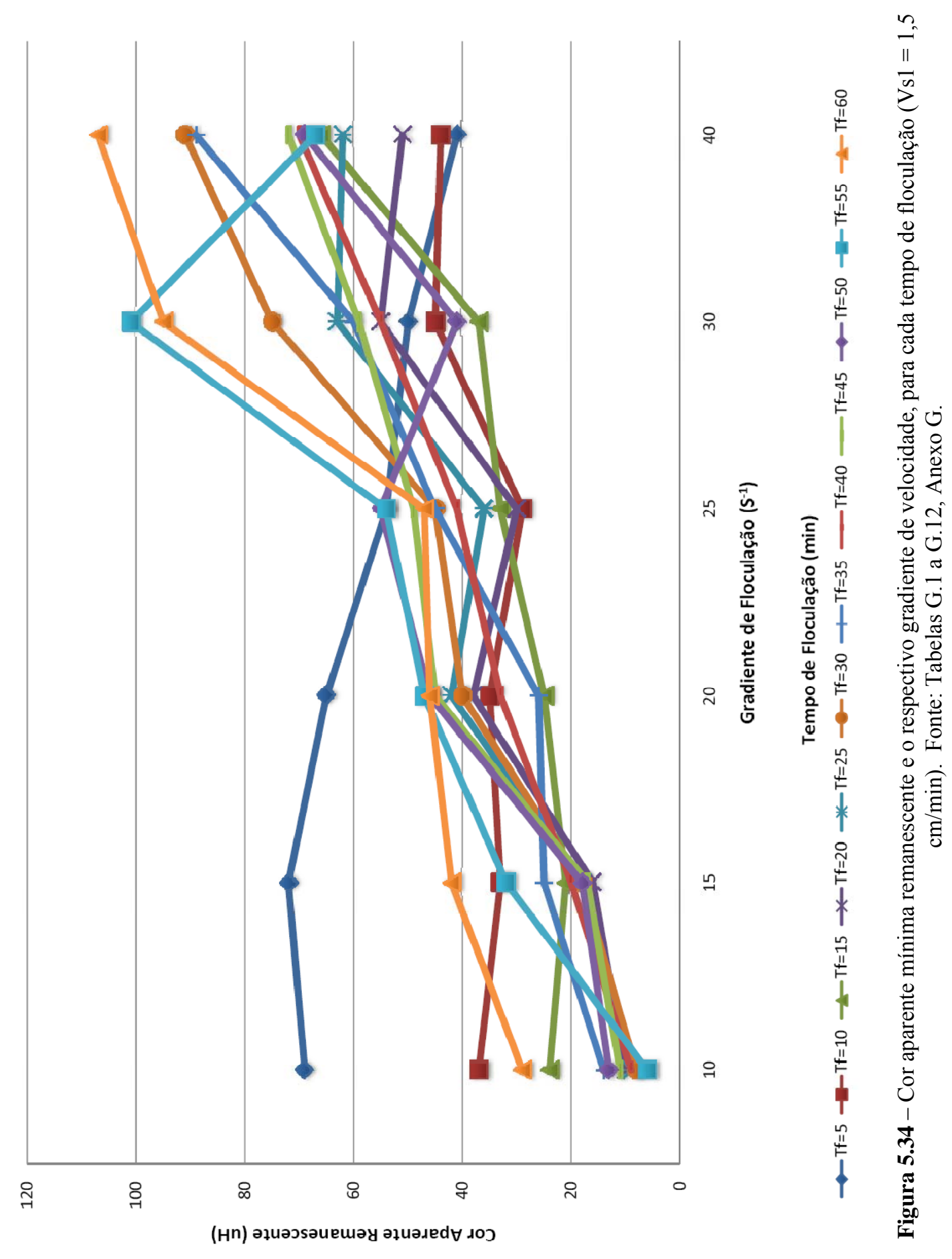




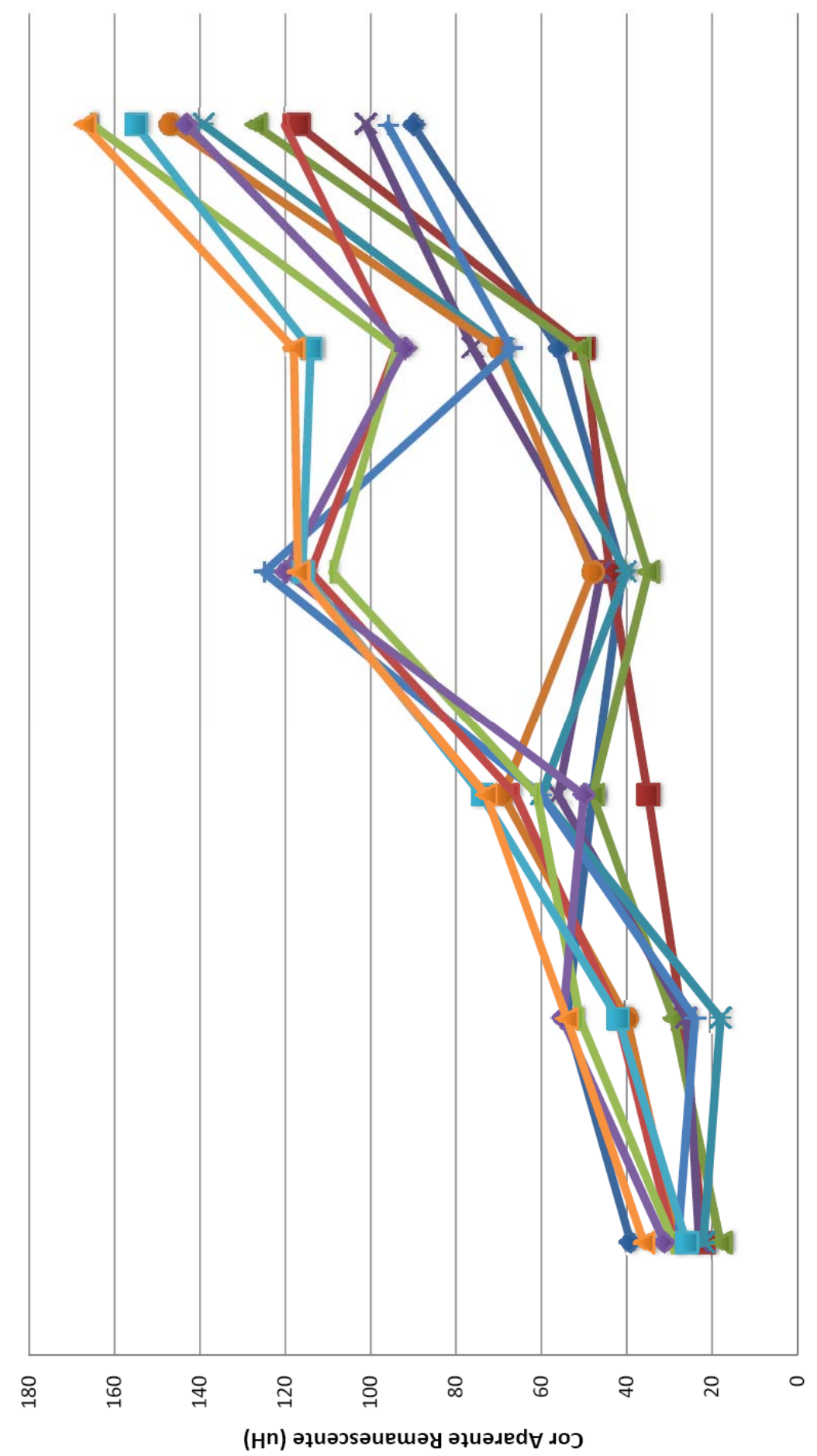

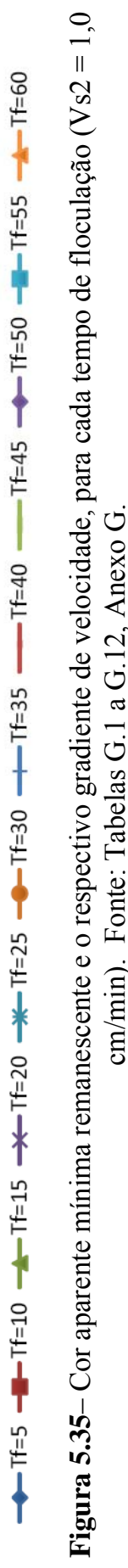




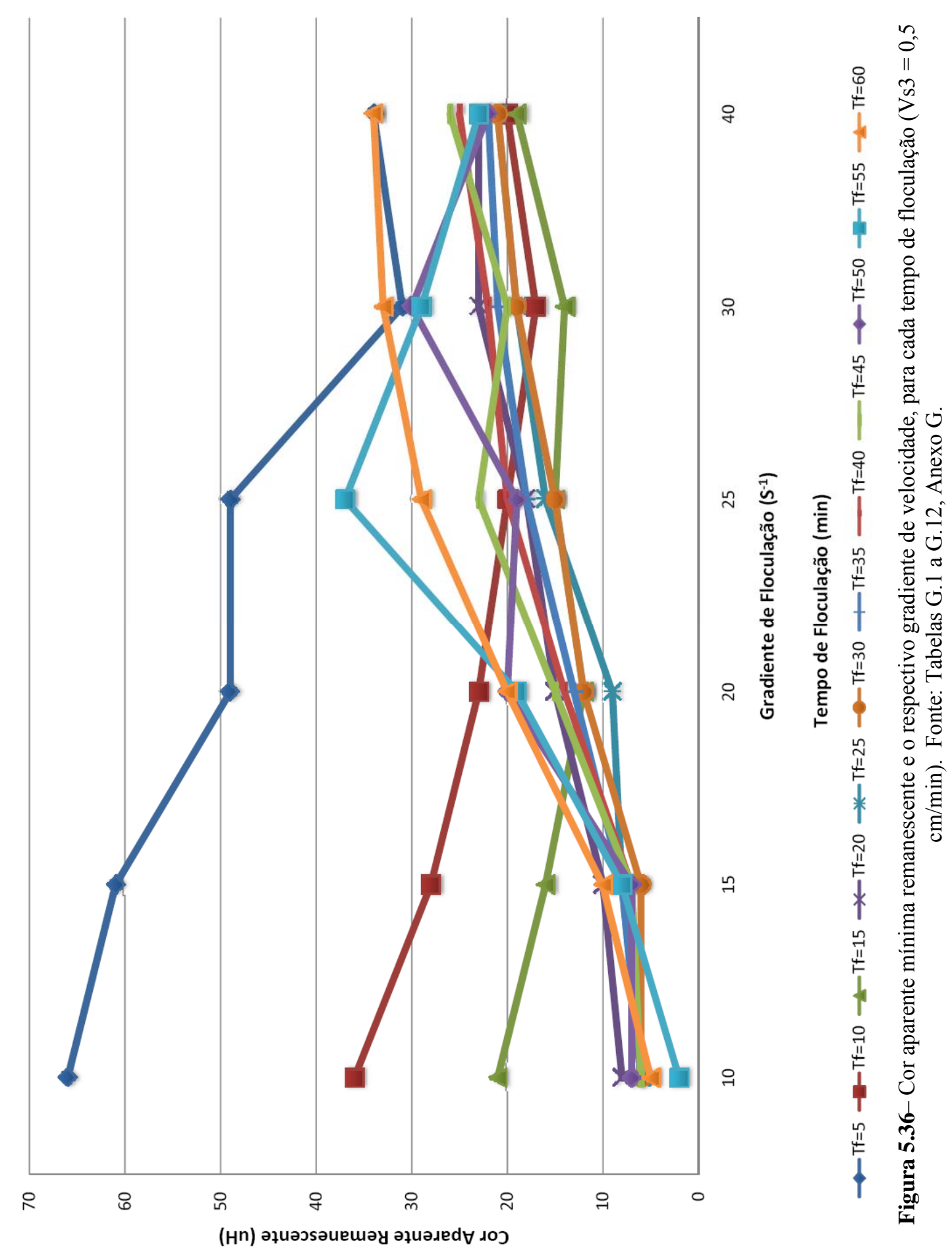


Observando os gráficos das Figuras 5.34, 5.35 e 5.36, selecionou-se o resultado referente ao gradiente de velocidade que obteve a menor cor aparente remanescente para cada tempo de floculação. Estes resultados foram plotados em gráficos de "cor aparente versus tempo de floculação", um para cada velocidade de sedimentação. Foram traçadas também linhas de tendência dos pontos para uma melhor avaliação dos resultados. As Figuras 5.37, 5.38 e 5.39 apresentam estes gráficos de mínima cor remanescente.

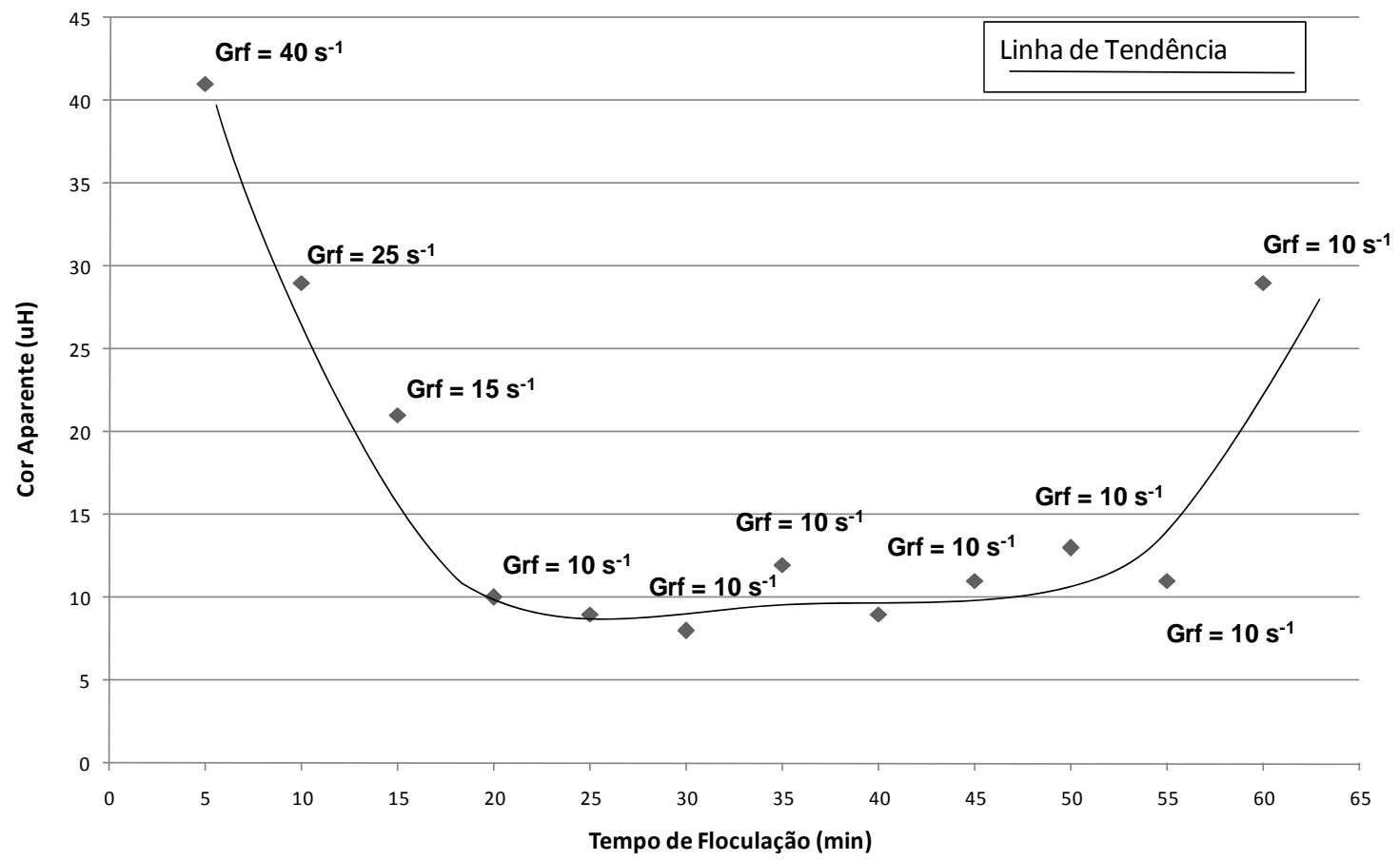

Figura 5.37 - Cor Aparente mínima remanescente em função do tempo de floculação com os respectivos gradientes de velocidade de Floculação (Gf), para a velocidade de sedimentação Vs1 $=1,5$ cm/min Fonte: Tabelas G.1 a G.12, Anexo G. 


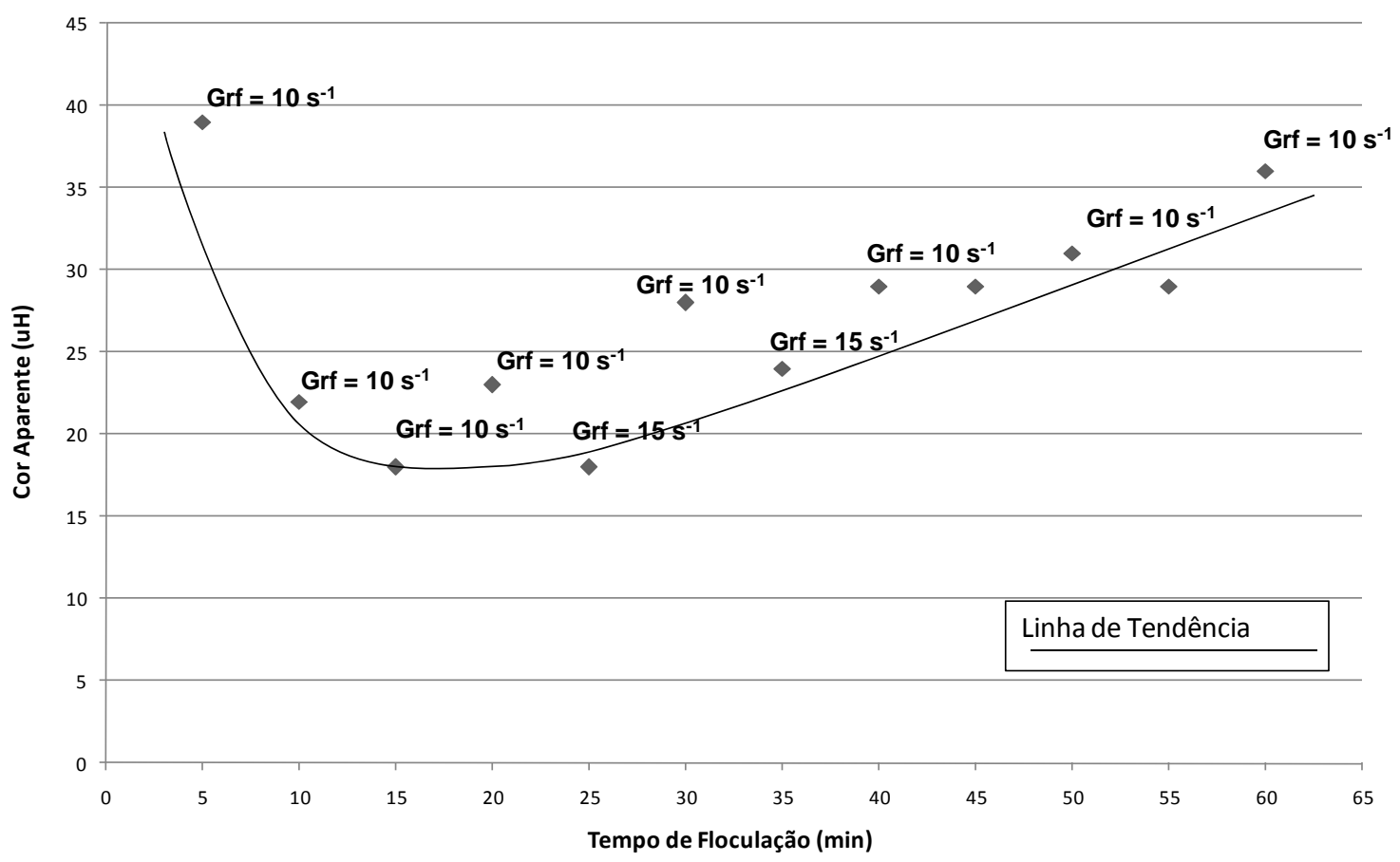

Figura 5.38 - Cor aparente mínima remanescente em função do tempo de floculação com os respectivos gradientes de velocidade de Floculação (Gf), para a velocidade de sedimentação Vs2 = 1,0 $\mathrm{cm} / \mathrm{min}$ Fonte: Tabelas G.1 a G.12, Anexo G.

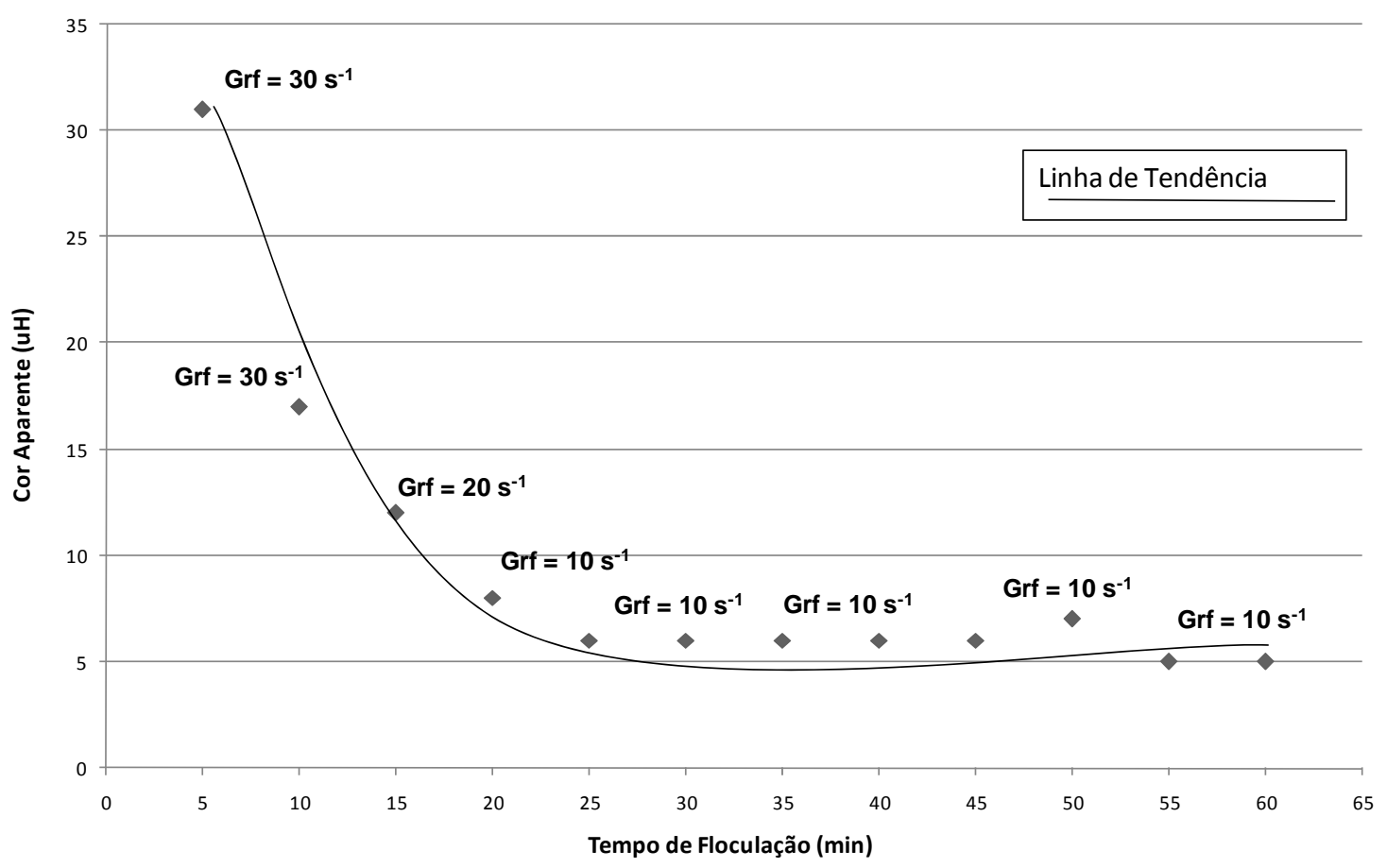

Figura 5.39 - Cor aparente mínima remanescente em função do tempo de floculação com os respectivos gradientes de velocidade de Floculação (Gf), para a velocidade de sedimentação Vs3 = 0,5 cm/min Fonte: Tabelas G.1 a G.12, Anexo G. 
A análise dos gráficos das Figuras 5.37, 5.38 e 5.39 mostra que a partir do tempo de 20 min a linha de tendência dos pontos faz uma curva, passando por um mínimo em que o aumento de tempo de floculação não implica no aumento de remoção de cor por sedimentação. Dependendo da velocidade de sedimentação, para os tempos de floculação superiores a 20 minutos, houve aumento na cor aparente remanescente.

Na Tabela 5.8 estão mostrados os valores de cor aparente mínima para cada tempo de floculação e o correspondente gradiente de velocidade de floculação. Observase que para valores de Tf entre 20 e 30 min a cor aparente mínima resultou menor valor. Com o tempo de $25 \mathrm{~min}$ foram obtidos os melhores resultados de remoção de cor. Apesar de nesse tempo de floculação o menor valor de cor aparente para a velocidade de sedimentação de $1,0 \mathrm{~cm} / \mathrm{min}$ ter sido obtido no gradiente de $15 \mathrm{~s}^{-1}$, o valor obtido com o gradiente de $10 \mathrm{~s}^{-1}$ também é inferior aos valores obtidos com outros tempos de floculação. Assim, foram escolhidos o gradiente de velocidade de $10 \mathrm{~s}^{-1}$ e tempo de floculação de 25 min como parâmetros de floculação adequados para esta água de estudo, os quais foram utilizados nas etapas subseqüentes deste trabalho. 
Tabela 5.8 - Resultados dos ensaios de escolha dos parâmetros de floculação.

\begin{tabular}{|c|c|c|c|c|c|c|}
\hline \multirow{7}{*}{$\begin{array}{l}\text { Tempo de } \\
\text { Floculação } \\
\text { Tf (min) }\end{array}$} & \multirow{2}{*}{\multicolumn{2}{|c|}{$V s 1=1.5 \mathrm{~cm} / \mathrm{min}$}} & \multicolumn{2}{|c|}{$\mathrm{Vs} 2=1.0 \mathrm{~cm} / \mathrm{min}$} & \multicolumn{2}{|c|}{$\mathrm{Vs} 3=0.5 \mathrm{~cm} / \mathrm{min}$} \\
\hline & & & Gradiente & & Gradiente & \\
\hline & de & Cor & de & Cor & de & Cor \\
\hline & velocidade & Aparente & velocidade & Aparente & velocidade & Aparente \\
\hline & na & mínima & na & mínima & na & mínima \\
\hline & floculação & (uH) & floculação & (uH) & floculação & (uH) \\
\hline & $G f\left(s^{-1}\right)$ & & $G f\left(s^{-1}\right)$ & & $G f\left(s^{-1}\right)$ & \\
\hline 5 & 40 & 41 & 10 & 39 & 30 & 31 \\
\hline 10 & 25 & 29 & 10 & 22 & 30 & 17 \\
\hline 15 & 15 & 21 & 10 & 18 & 20 & 12 \\
\hline 20 & 10 & 10 & 10 & 23 & 10 & 8 \\
\hline 25 & 10 & 9 & 15 & 18 & 10 & 6 \\
\hline 30 & 10 & 8 & 10 & 28 & 10 & 7 \\
\hline 35 & 10 & 14 & 15 & 24 & 10 & 6 \\
\hline 40 & 10 & 9 & 10 & 29 & 10 & 6 \\
\hline 45 & 10 & 11 & 10 & 29 & 10 & 6 \\
\hline 50 & 10 & 13 & 10 & 31 & 10 & 7 \\
\hline 55 & 10 & 6 & 10 & 26 & 10 & 2 \\
\hline 60 & 10 & 29 & 10 & 36 & 10 & 5 \\
\hline
\end{tabular}

\subsubsection{Ensaios de coagulação, floculação e sedimentação}

Determinados os parâmetros de coagulação, mistura rápida e floculação, foram executados ensaios de coagulação, floculação e sedimentação Os ensaios foram realizados conforme descrição do item 4.5.4. O objetivo dessa etapa foi obter dados que servissem como base para comparação com o efeito da ruptura e da refloculação As coletas foram feitas para as velocidades de sedimentação foram de 4,67; 2,20; 1,38; 0,97, 0,60 e 0,42 cm/min. . Os ensaios dessa etapa foram realizados em tréplica. Observa-se na Tabela 5.9 os resultados dos ensaios desta etapa. 
Tabela 5.9 - Resultados do ensaio de coagulação, floculação e sedimentação.

\begin{tabular}{|c|c|c|c|c|c|c|c|c|c|c|c|c|c|c|c|}
\hline \multirow{2}{*}{ Jarro } & \multicolumn{2}{|c|}{$\begin{array}{l}\text { Dosagem } \\
(\mathrm{mg} / \mathrm{L}) \text { * }\end{array}$} & \multirow{2}{*}{$\begin{array}{l}\text { pH de } \\
\text { Coagu } \\
\text { lação }\end{array}$} & \multicolumn{2}{|c|}{$\begin{array}{c}\text { Vs1 } \\
4,67 \\
\text { (cm/min) }\end{array}$} & \multicolumn{2}{|c|}{$\begin{array}{c}\text { Vs2 } \\
2,2 \\
\text { (cm/min) }\end{array}$} & \multicolumn{2}{|c|}{$\begin{array}{c}\text { Vs3 } \\
1,38 \\
\text { (cm/min) }\end{array}$} & \multicolumn{2}{|c|}{$\begin{array}{c}\text { Vs4 } \\
0,97 \\
\text { (cm/min) }\end{array}$} & \multicolumn{2}{|c|}{$\begin{array}{c}\text { Vs5 } \\
0,60 \\
\text { (cm/min) }\end{array}$} & \multicolumn{2}{|c|}{$\begin{array}{c}\text { Vs6 } \\
0,42 \\
\text { (cm/min) }\end{array}$} \\
\hline & $\begin{array}{l}\text { Cloreto } \\
\text { Férrico }\end{array}$ & $\begin{array}{l}\text { Hidróxido } \\
\text { de Sódio }\end{array}$ & & $\begin{array}{l}\text { Turb. } \\
\text { (UT) }\end{array}$ & $\begin{array}{l}\text { Cor } \\
\text { Ap. } \\
\text { (uH) }\end{array}$ & $\begin{array}{l}\text { Turb. } \\
\text { (uT) }\end{array}$ & $\begin{array}{l}\text { Cor } \\
\text { Ap. } \\
\text { (uH) }\end{array}$ & $\begin{array}{l}\text { Turb. } \\
\text { (uT) }\end{array}$ & $\begin{array}{l}\text { Cor } \\
\text { Ap. } \\
\text { (uH) }\end{array}$ & $\begin{array}{l}\text { Turb. } \\
\text { (uT) }\end{array}$ & $\begin{array}{l}\text { Cor } \\
\text { Ap. } \\
\text { (uH) }\end{array}$ & $\begin{array}{l}\text { Turb. } \\
\text { (UT) }\end{array}$ & $\begin{array}{l}\text { Cor } \\
\text { Ap. } \\
\text { (uH) }\end{array}$ & $\begin{array}{l}\text { Turb. } \\
\text { (UT) }\end{array}$ & $\begin{array}{l}\text { Cor } \\
\text { Ap. } \\
\text { (uH) }\end{array}$ \\
\hline 1 & 260 & 80 & 6,41 & 0,88 & 24 & 0,72 & 20 & 0,63 & 15 & 0,59 & 15 & 0,62 & 13 & 0,61 & 10 \\
\hline 2 & 260 & 80 & 6,24 & 0,93 & 23 & 0,61 & 15 & 0,68 & 12 & 0,59 & 12 & 0,55 & 10 & 0,61 & 9 \\
\hline 3 & 260 & 80 & 6,31 & 0,7 & 20 & 0,67 & 14 & 0,63 & 12 & 0,65 & 10 & 0,59 & 8 & 0,49 & 6 \\
\hline
\end{tabular}

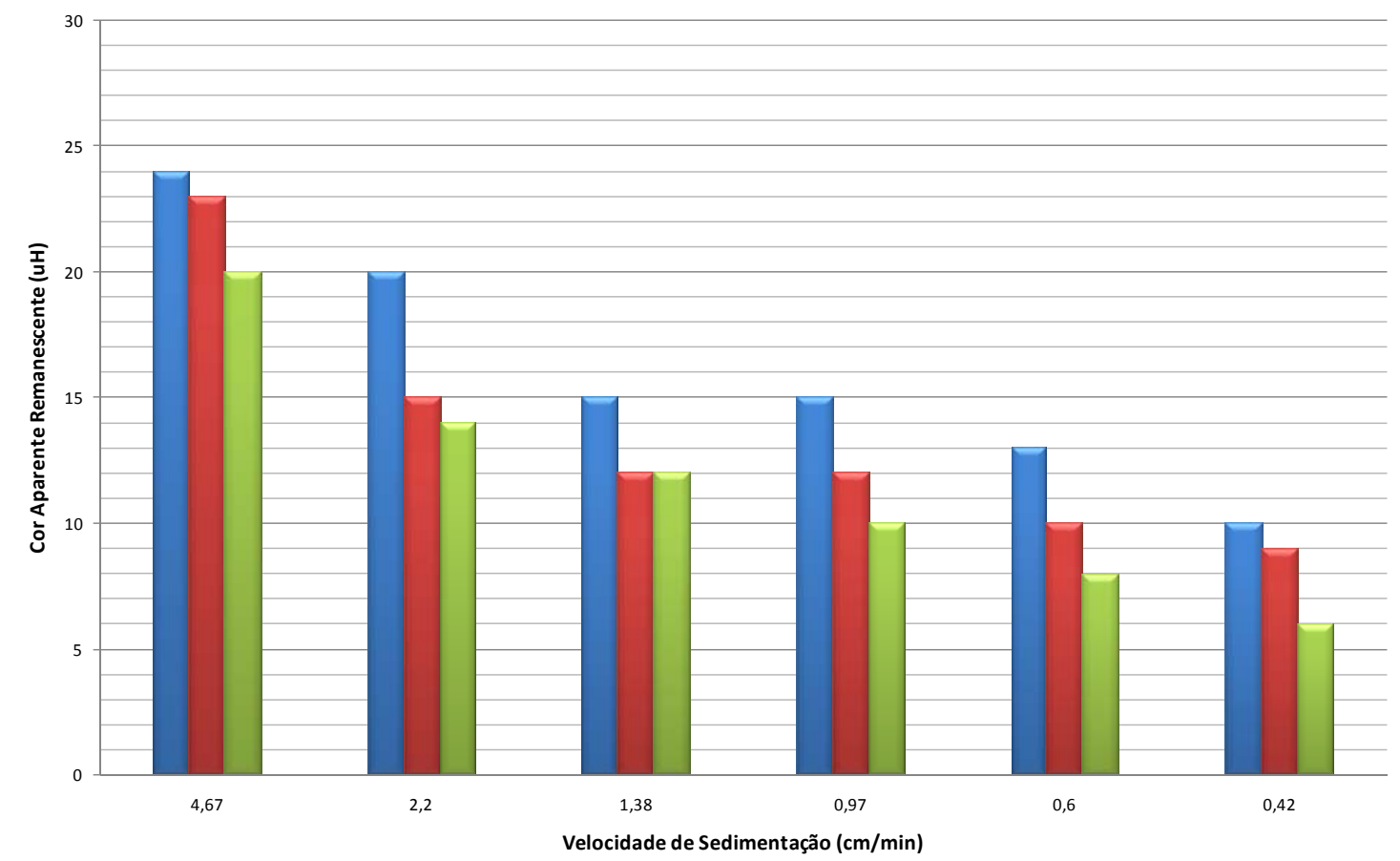

Figura 5.40 - Cor aparente remanescente em função da velocidade de sedimentação

Na Figura 5.41 é mostrada foto dos jarros deste ensaio ao final da floculação, momentos após parar a rotação das paletas. O gradiente de velocidade era de $10 \mathrm{~s}^{-1}$ e o tempo de floculação de 25 min. 


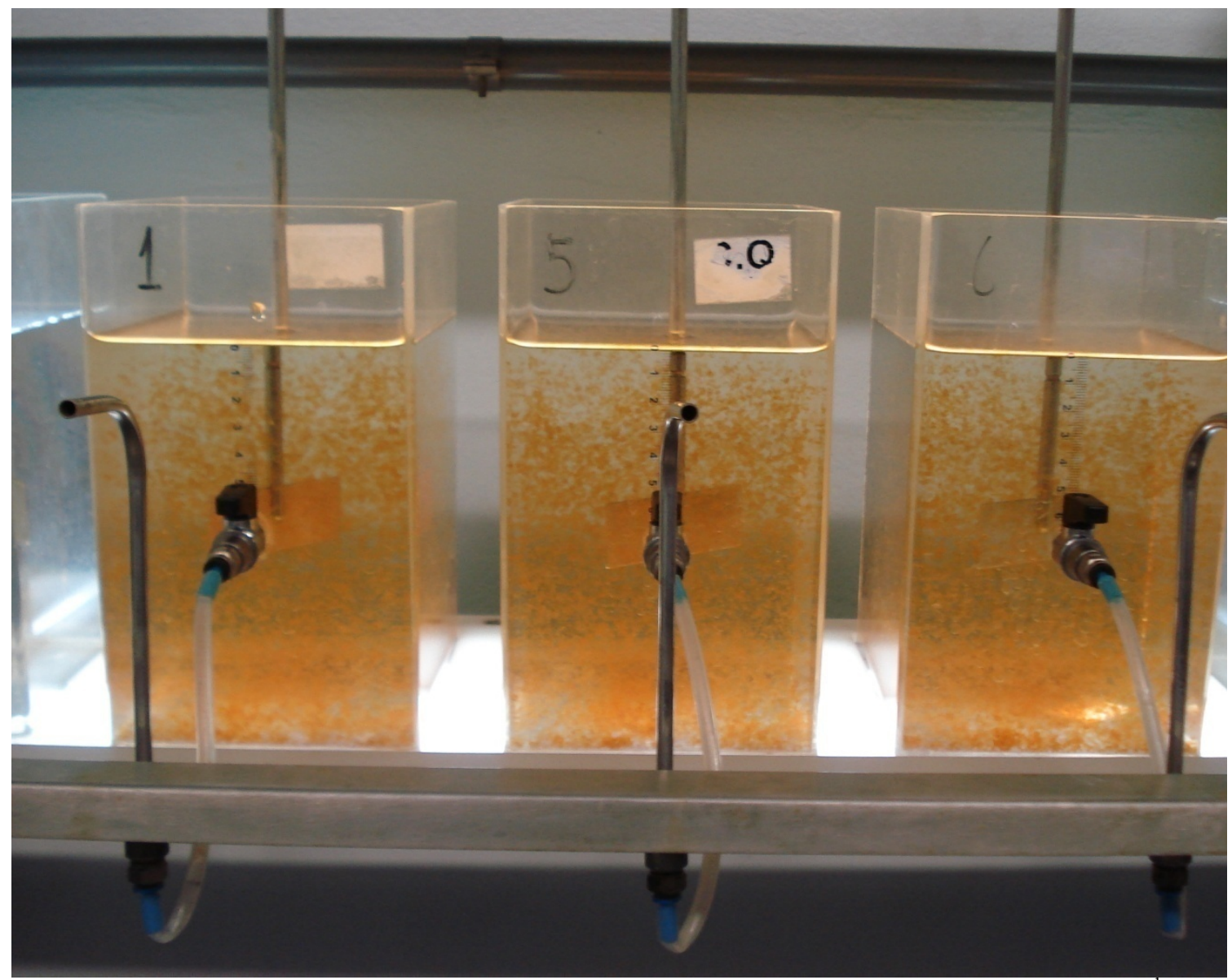

Figura 5.41 - Jarros com flocos formados, no inicio da sedimentação, para $\mathrm{Tf}=25 \mathrm{~min}$ e Gf $=10 \mathrm{~s}^{-1}$.

\subsubsection{Ensaios de ruptura}

Os ensaios de ruptura e sedimentação foram executados conforme descrito no item4.5.5. Foram utilizados três gradientes de velocidade para ruptura, partindo do gradiente de $(\mathrm{Gr})$ de $50 \mathrm{~s}^{-1}$, valor muito próximo aos valores testados na escolha dos parâmetros de floculação, até um gradiente mais elevado de $150 \mathrm{~s}^{-1}$, passando pelo valor intermediário de 100s-1. Nas fotos das Figuras 5.42 a 5.45 são apresentados fotos onde pode-se perceber a diferença no tamanho dos flocos conforme é mudado o gradiente de velocidade de ruptura. 


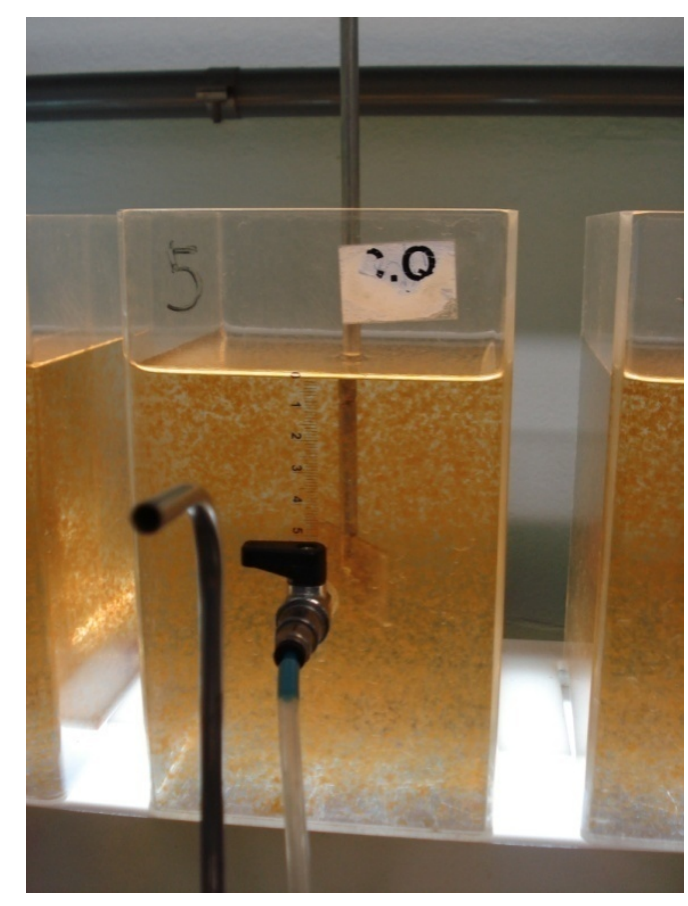

Figura 5.42 - Vista frontal dos jarros mostrando os flocos ao final da floculação sem ruptura

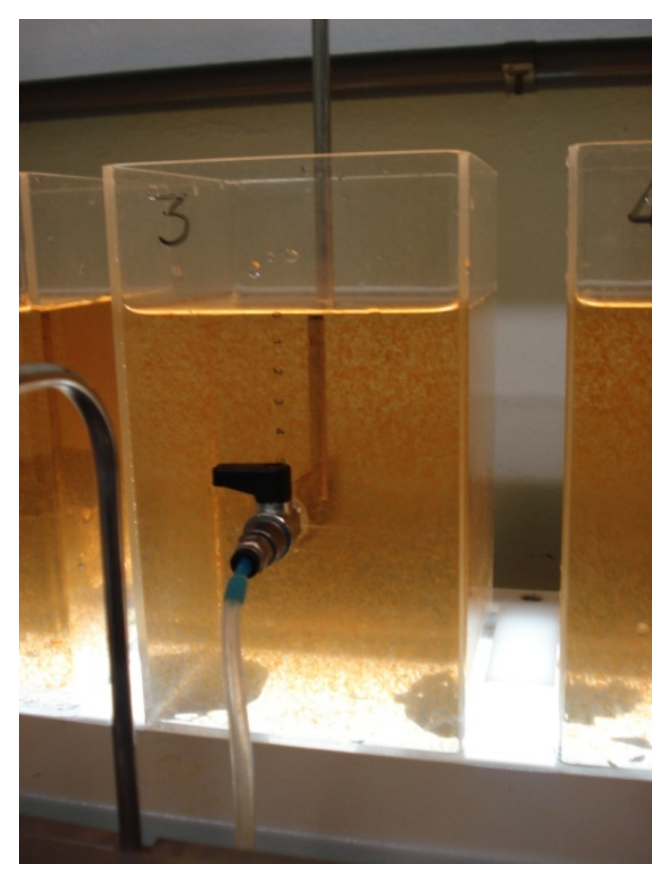

Figura 5.44 - Vista frontal dos jarros mostrando os flocos ao após a ruptura, para o gradiente de velocidade de ruptura de $100 \mathrm{~s}^{-1}$

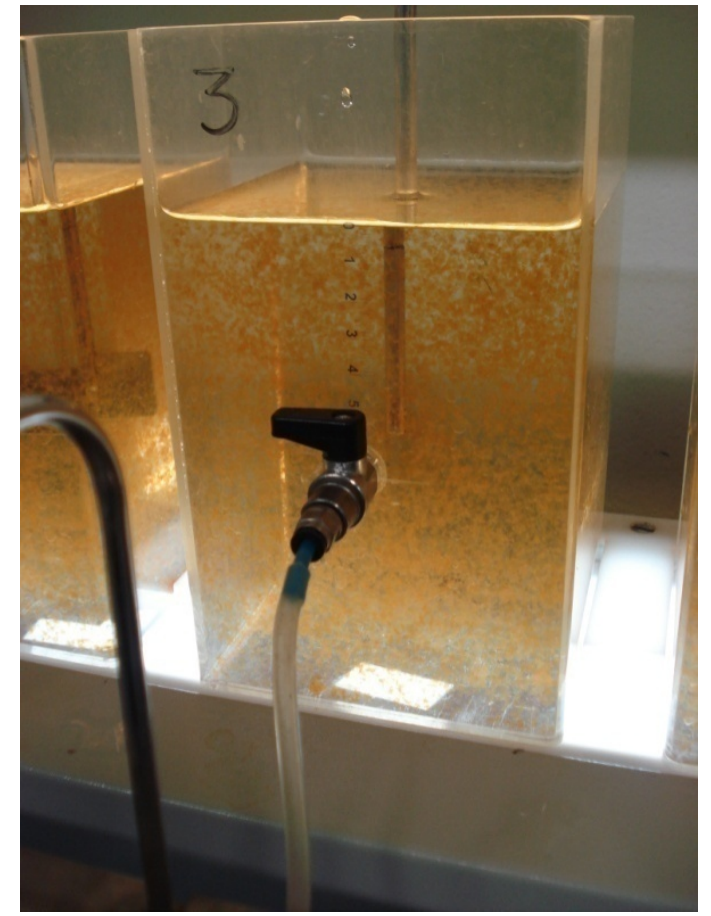

Figura 5.43 - Vista frontal dos jarros mostrando os flocos ao após a ruptura, para o gradiente de velocidade de ruptura de $50 \mathrm{~s}^{-1}$

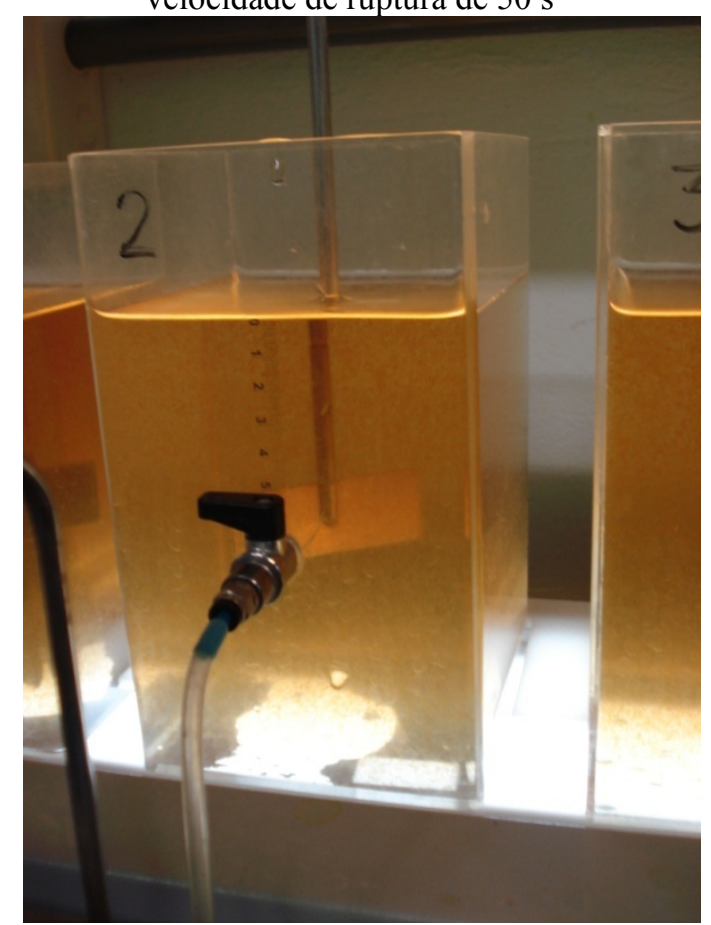

Figura 5.45 - Vista frontal dos jarros mostrando os flocos ao após a ruptura, para o gradiente de velocidade de ruptura de $150 \mathrm{~s}^{-1}$

Os resultados desta série de ensaios para os gradientes de velocidade de ruptura de 50, 100 e $150 \mathrm{~s}^{-1}$ estão mostrados na Tabela 5.10. Para efeito comparativo, estes resultados foram dispostos em gráficos juntamente com a condição inicial sem ruptura, 
ilustrados na Figura 5.46. O gráfico com os resultados de cor aparente remanescente demonstra a perda de eficiência na remoção de cor causada pela ruptura, mesmo quando ocorrida com gradientes de velocidade de ruptura mais baixos.

Tabela 5.10 - Resultados do ensaio de ruptura, para diferentes gradientes de velocidade durante a ruptura.

\begin{tabular}{|c|c|c|c|c|c|c|c|}
\hline \multirow{2}{*}{ Amostra } & \multirow{2}{*}{$\begin{array}{l}\text { Gradiente } \\
\text { de Ruptura }\end{array}$} & \multicolumn{6}{|c|}{$\begin{array}{l}\text { Cor Aparente remanescente (uH) para as velocidades de sedimentação } \\
\text { (cm/min) }\end{array}$} \\
\hline & & $\begin{array}{c}\text { Vs1 } \\
4,67 \\
\mathrm{~cm} / \mathrm{min} \\
\end{array}$ & $\begin{array}{c}\text { Vs2 } \\
2,2 \mathrm{~cm} / \mathrm{min} \\
\end{array}$ & $\begin{array}{c}\text { Vs3 } \\
1,38 \\
\mathrm{~cm} / \mathrm{min}\end{array}$ & $\begin{array}{c}\text { Vs4 } \\
0,97 \\
\mathrm{~cm} / \mathrm{min} \\
\end{array}$ & $\begin{array}{c}\text { Vs5 } \\
0,6 \mathrm{~cm} / \mathrm{min}\end{array}$ & $\begin{array}{c}\text { Vs6 } \\
0,42 \\
\mathrm{~cm} / \mathrm{min}\end{array}$ \\
\hline 1 & $\begin{array}{c}\text { sem } \\
\text { ruptura }\end{array}$ & 22 & 16 & 13 & 12 & 10 & 8 \\
\hline 2 & 50 & 121 & 46 & 35 & 33 & 30 & 30 \\
\hline 3 & 100 & 178 & 67 & 50 & 44 & 34 & 31 \\
\hline 4 & 150 & 335 & 104 & 90 & 84 & 60 & 44 \\
\hline
\end{tabular}

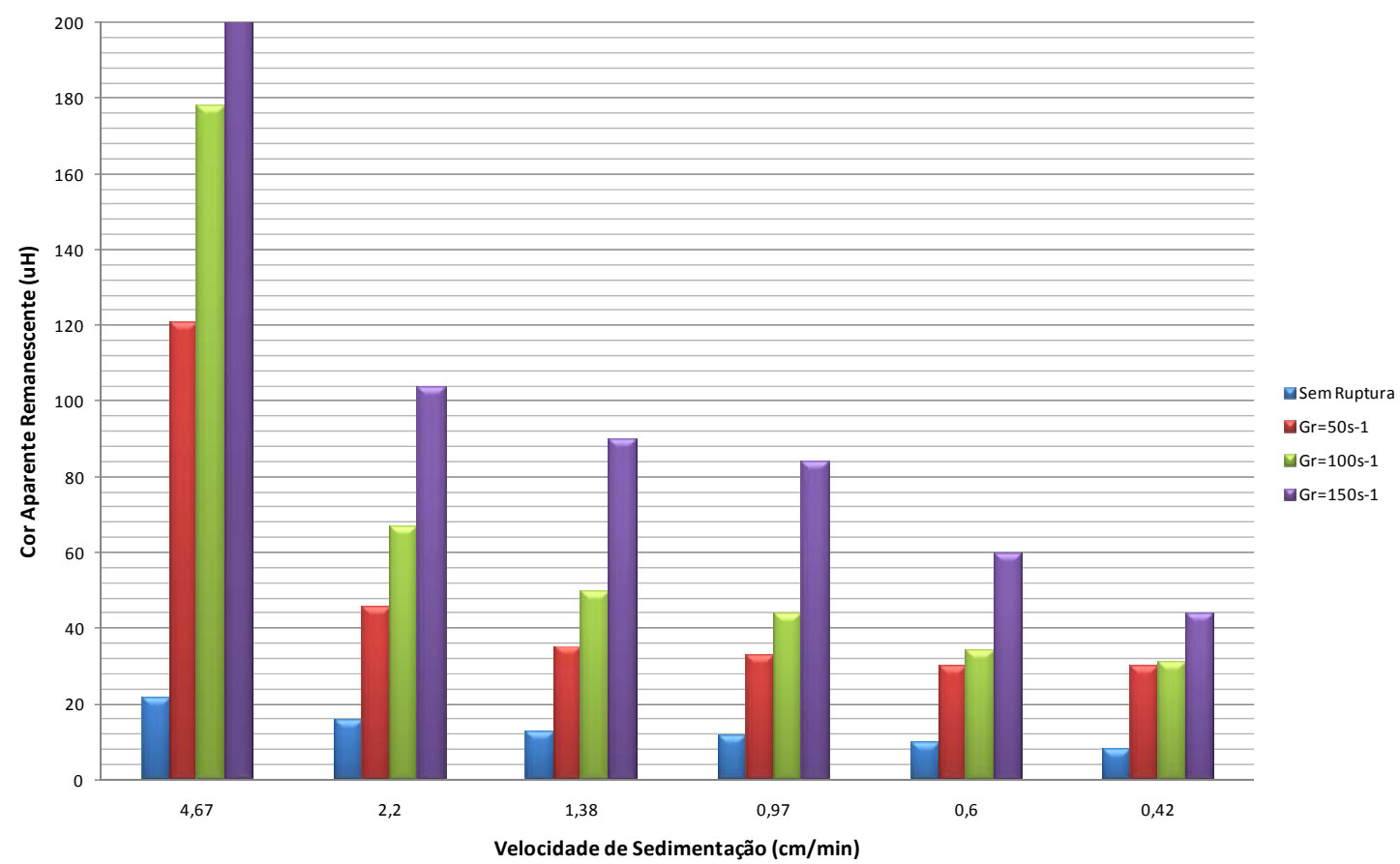

Figura 5.46 - Cor aparente remanescente em função da velocidade de sedimentação, para diferentes gradientes de velocidade de ruptura.

\subsubsection{Ensaios de refloculação}

Neste item são mostrados os resultados dos ensaios de ruptura seguida de refloculação. Foram utilizados nestes ensaios os mesmos parâmetros de coagulação, 
floculação e ruptura do item anterior, seguindo a metodologia descrita no item 4.5.6. Os ensaios deste item foram divididos pelo gradiente de velocidade de ruptura utilizado (Gr): $50 ; 100$ e $150 \mathrm{~s}^{-1}$. A princípio, o gradiente de velocidade de refloculação (Grf) utilizado foi igual ao de floculação definido para o coagulante, que da mesma maneira do caso da utilização do sulfato de alumínio como coagulante, foi de $10 \mathrm{~s}^{-1}$. Como equipamento de jarteste utilizado nos ensaios tem esse valor como sua limitação mínima, também foi testado um gradiente de velocidade maior. Desta forma, novamente os gradientes de velocidade de refloculação utilizados nos ensaios foram de 10 e $20 \mathrm{~s}^{-1}$. Os tempos de refloculação (Trf) foram variados de 5 a 25 minutos. Tempos maiores que 25 minutos não foram testados uma vez que em todos os ensaios os tempos mais altos de refloculação foram os que apresentaram piores resultados.

Nos itens 5.2.6.1, 5.2.6.2 e 5.2.6.3 disponibilizam-se os resultados e a discussão dos ensaios para os Gr de 50, 100 e $150 \mathrm{~s}^{-1}$, respectivamente. Para efeito de comparação, apresentam-se os resultados para as condições sem ruptura (item 5.3.4) e com ruptura sem refloculação (item 5.2.5).

\subsubsection{Ensaios de refloculação para Gr $50 \mathrm{~s}^{-1}$}

Os resultados dos ensaios de refloculação para o gradiente de velocidade de ruptura de $50 \mathrm{~s}^{-1}$ encontram-se no Anexo H, Tabelas H.1 e H.2. As fotos da Figura 5.47 mostram os jarros do equipamento de jarteste durante um ensaio. Na Figura 5.48 são apresentados os resultados para Grf de $10 \mathrm{~s}^{-1}$ e na Figura 5.49 para o de $20 \mathrm{~s}^{-1}$. Os resultados indicam que a refloculação é pouco efetiva para a recuperação do tamanho dos flocos, principalmente no caso do gradiente de refloculação de $20 \mathrm{~s}^{-1}$, onde os resultados foram piores, principalmente com altos tempos de refloculação. Para ambos os Grf, observa-se que a refloculação com menores tempos, acarreta em diminuição da 96 
cor aparente remanescente se comparada com após a ruptura. Para tempos maiores de refloculação, na maioria das velocidades de sedimentação, o resultado foi próximo à condição após a ruptura, com os piores resultados obtidos com altas velocidades de sedimentação.

Os resultados obtidos demonstram que a refloculação não é eficiente se comparada com a condição sem a ruptura para a água de estudo coagulada com cloreto férrico e gradiente de ruptura de $50 \mathrm{~s}^{-1}$.

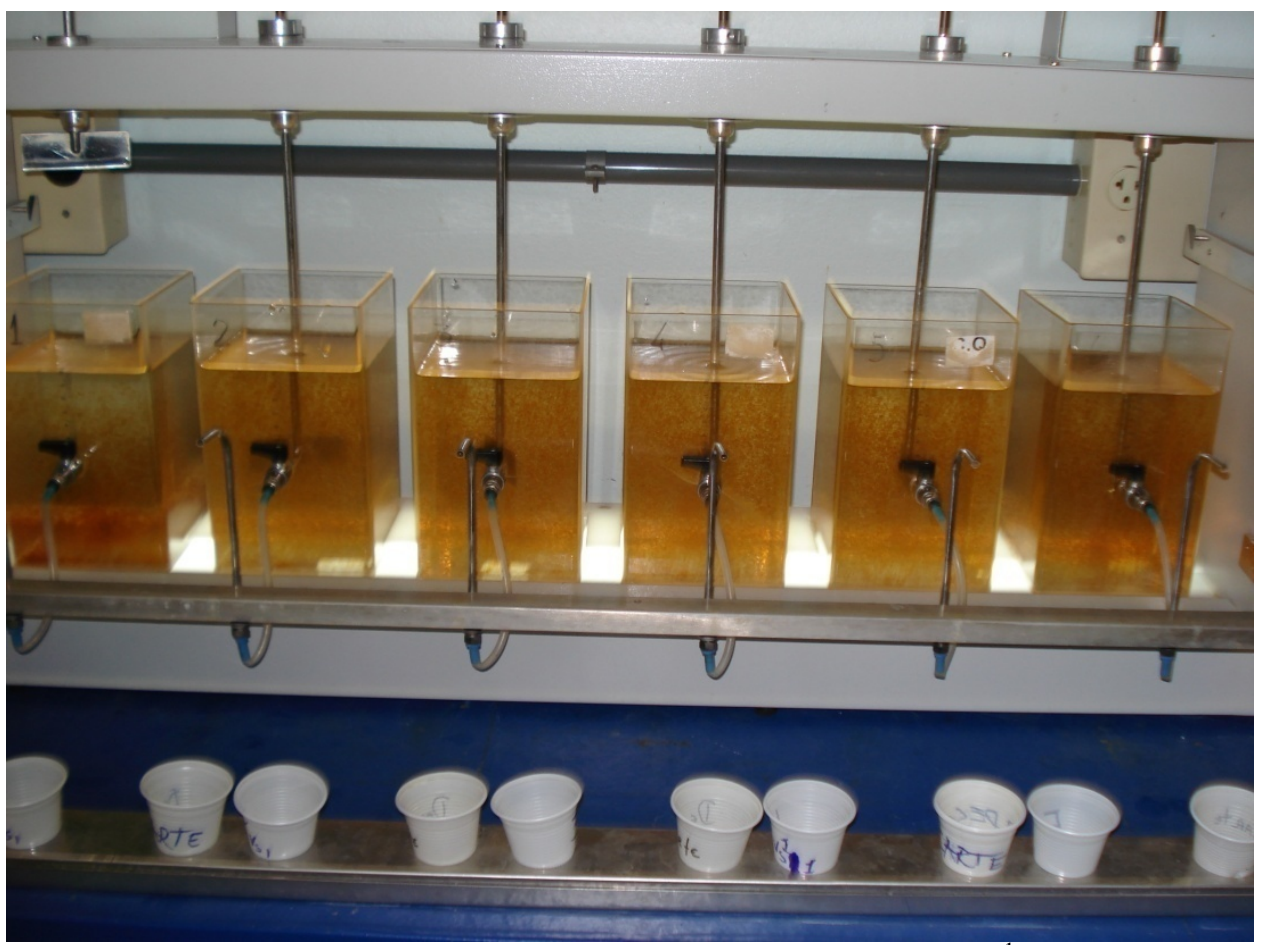

Figura 5.47- Vista frontal dos jarros durante o ensaio para Gr igual a $50 \mathrm{~s}^{-1}$ e Grf igual a $10 \mathrm{~s}^{-1}$. Observa-se o jarro da esquerda no inicio da sedimentação e os demais ainda refloculando. 


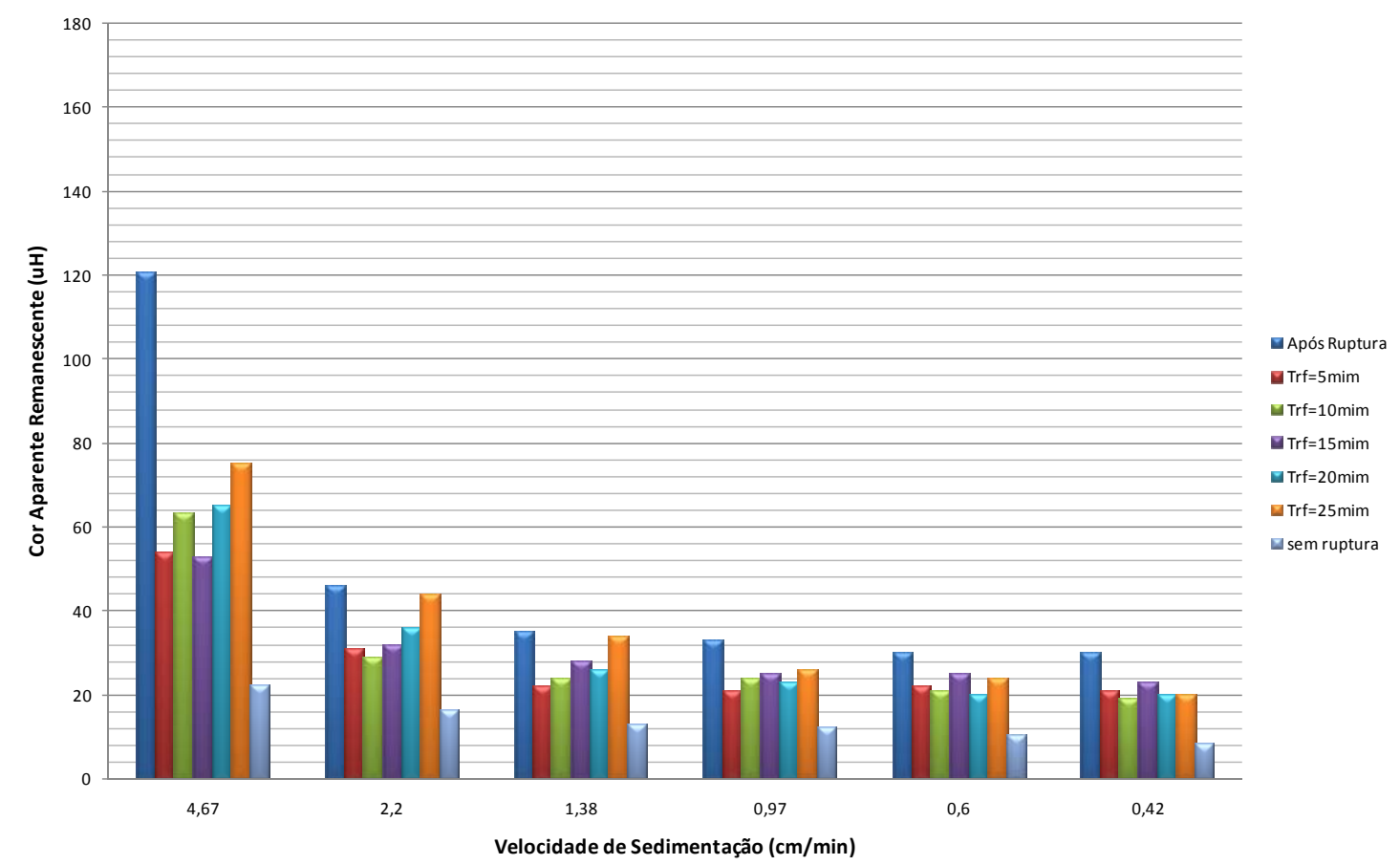

Figura 5.48 - Cor aparente remanescente em função da velocidade de sedimentação, para o gradiente de velocidade na ruptura de $50 \mathrm{~s}^{-1}$ e gradiente de velocidade de refloculação de $10 \mathrm{~s}^{-1}$. Fonte: Tabela H.1, Anexo H.

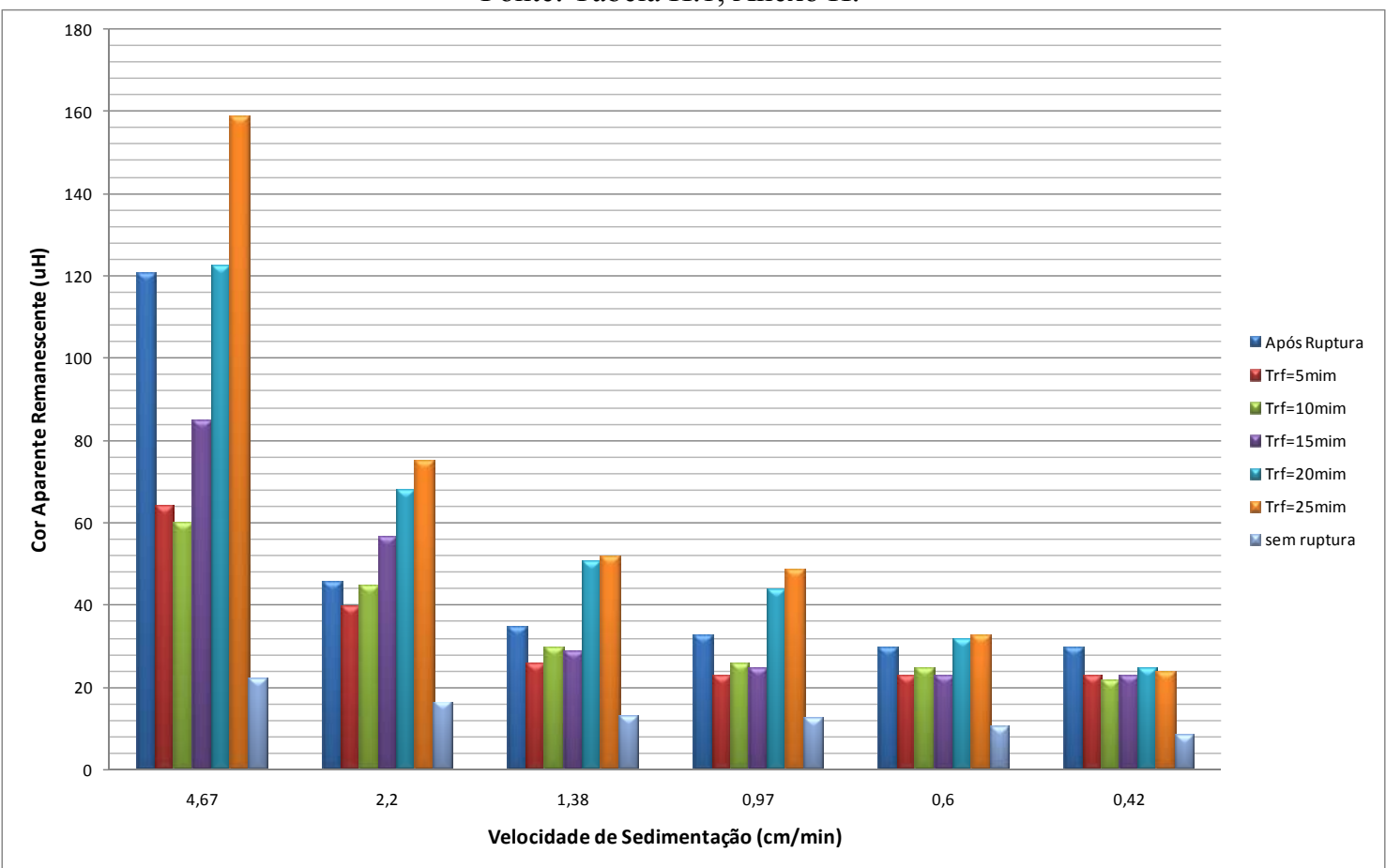

Figura 5.49 - Cor aparente remanescente em função da velocidade de sedimentação, para o gradiente de velocidade na ruptura de $50 \mathrm{~s}^{-1}$ e gradiente de velocidade de refloculação de $20 \mathrm{~s}^{-1}$.

Fonte: Tabela H.2, Anexo H. 


\subsubsection{Ensaios de refloculação para $\operatorname{Gr} 100 \mathrm{~s}^{-1}$}

Os resultados dos ensaios de refloculação para o gradiente de velocidade de ruptura de $100 \mathrm{~s}^{-1}$ encontram-se no Anexo H, Tabelas H.3 e H.4. Foram construídos gráficos dos resultados, os quais são apresentados na Figura 5.50 para o valor de Grf de $10 \mathrm{~s}^{-1}$ e na Figura 5.51 para o Grf de $20 \mathrm{~s}^{-1}$. Para ambos os Grf, observa-se que a refloculação para as baixas velocidades de sedimentação apresentou resultados que se aproximaram dos resultados sem ruptura, porém sem nunca chegar à mesma eficiência na remoção de cor. 


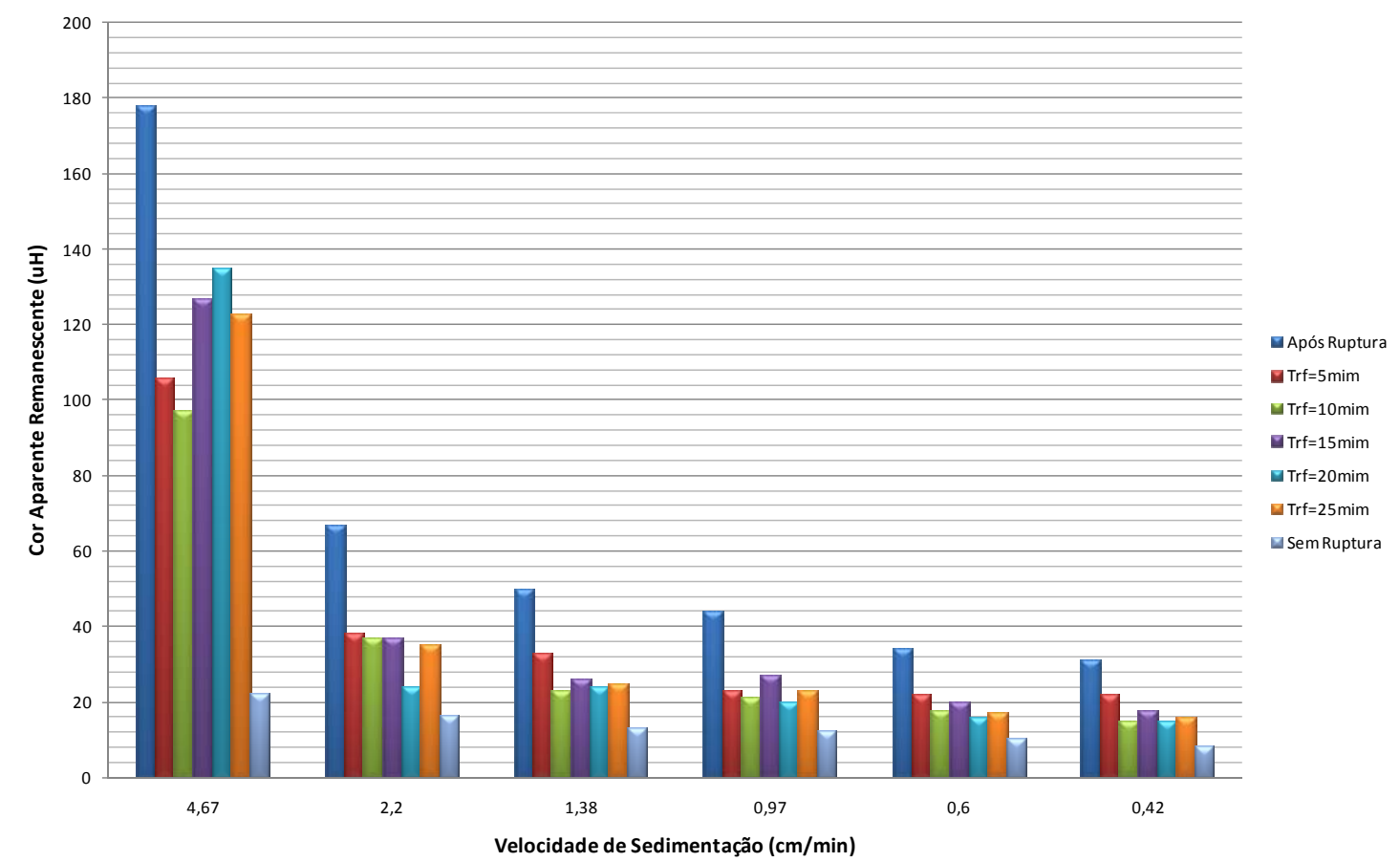

Figura 5.50 - Cor aparente remanescente em função da velocidade de sedimentação, para o gradiente de velocidade na ruptura de $100 \mathrm{~s}-1$ e gradiente de velocidade de refloculação de $10 \mathrm{~s}-1$. Fonte: Tabela H.3, Anexo H.

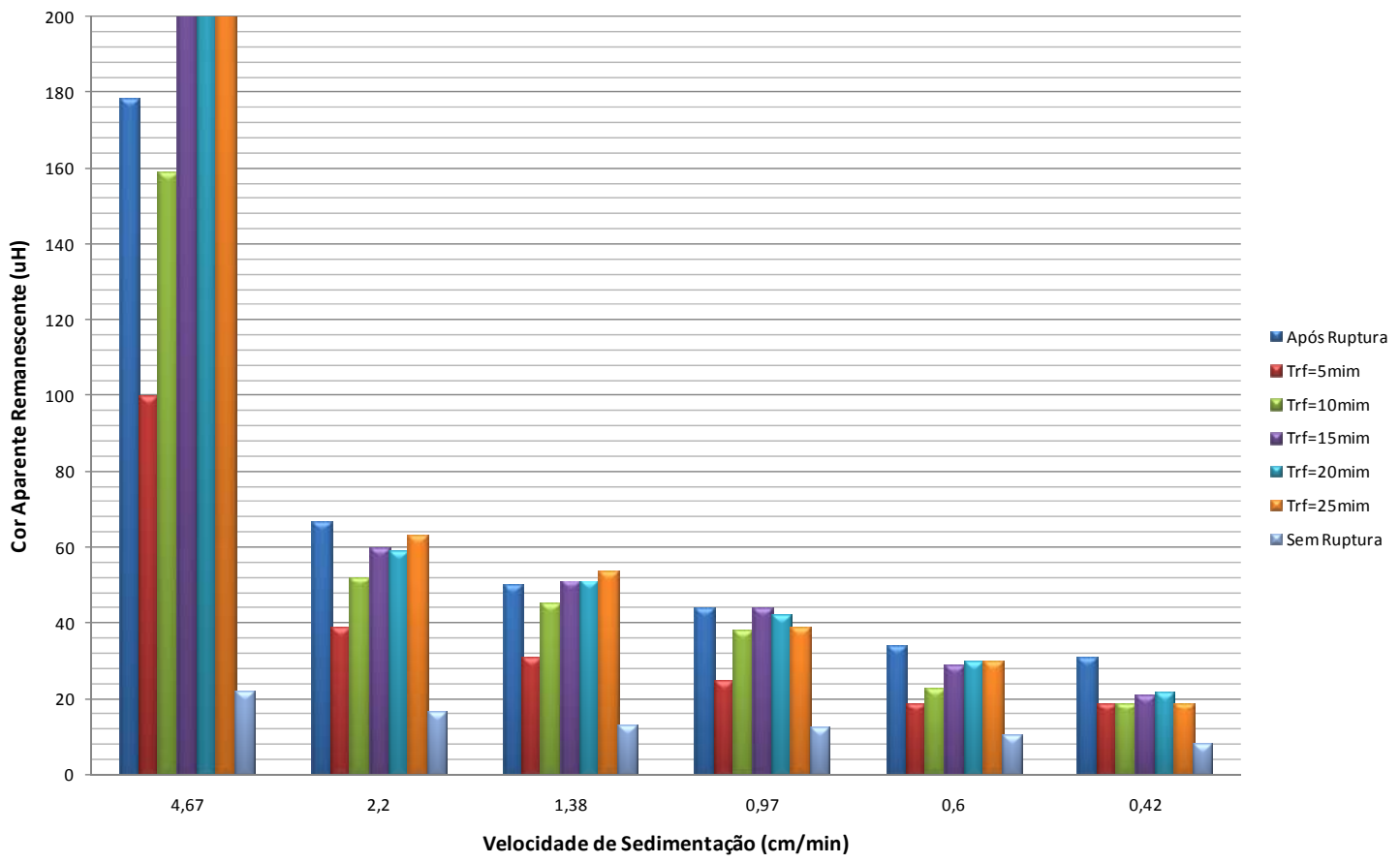

Figura 5.51 - Cor aparente remanescente em função da velocidade de sedimentação, para o gradiente de velocidade na ruptura de $100 \mathrm{~s}-1$ e gradiente de velocidade de refloculação de $20 \mathrm{~s}-1$.

Fonte: Tabela H.4, Anexo H. 


\subsubsection{Ensaios de refloculação para Gr de $150 \mathrm{~s}^{-1}$}

Os ensaios de refloculação para o gradiente de ruptura de $150 \mathrm{~s}^{-1}$ foram realizados conforme a metodologia descrita no item 4.5.6 Os gradientes de velocidade de refloculação utilizados foram 10 e $20 \mathrm{~s}^{-1}$. Os resultados dos ensaios desta série são explicitados no Anexo H, Tabelas H.5 e H.6, referentes aos Grf de 10 e $20 \mathrm{~s}^{-1}$ respectivamente. Na Figura 5.52 é possível observar os jarros do equipamento jarteste durante um ensaio.

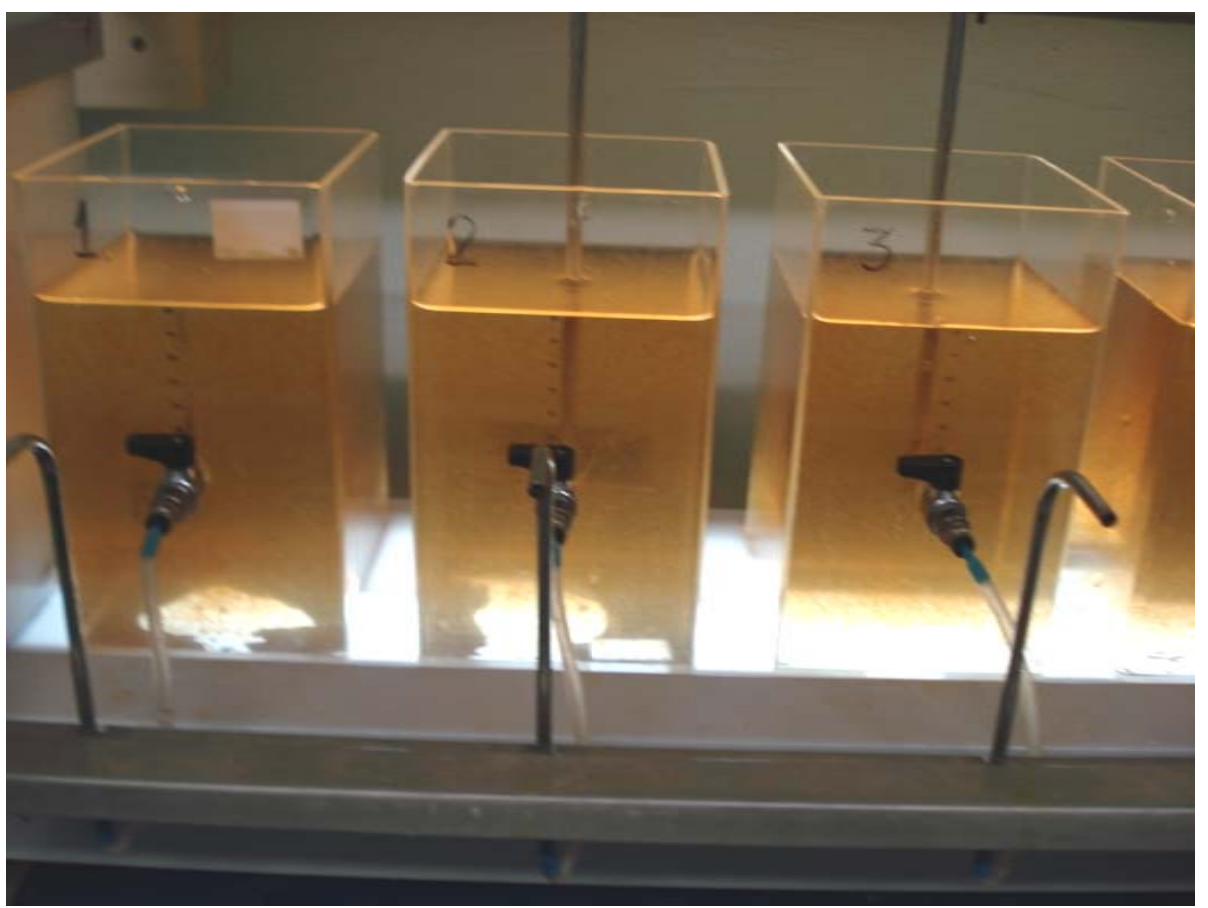

Figura 5.52 - Vista frontal dos jarros durante um ensaio.

$\mathrm{Na}$ Figura 5.53 e na Figura 5.54, referentes aos gradientes de refloculação de 10 e $20 \mathrm{~s}^{-1}$ respectivamente, são apresentados os resultados dos ensaios realizados. Como no caso dos gradientes de ruptura mais baixos, os resultados foram novamente piores do que no caso sem ruptura de flocos.

Ao se comparar os resultados dos ensaios de ruptura com os resultados dos ensaios com baixo tempo de refloculação, é possível perceber uma melhora significativa 
na eficiência da remoção por sedimentação. Essa melhora é evidenciada devido à péssima condição da água de estudo após a ruptura com o gradiente de velocidade de $150 \mathrm{~s}^{-1}$. Como no caso dos gradientes de ruptura mais baixos, ao se utilizar o gradiente de refloculação de $10 \mathrm{~s}^{-1}$ os resultados apresentados são muito mais próximos das condições sem a ruptura do que os resultados do ensaio com a refloculação com o gradiente de velocidade de $20 \mathrm{~s}^{-1}$. 


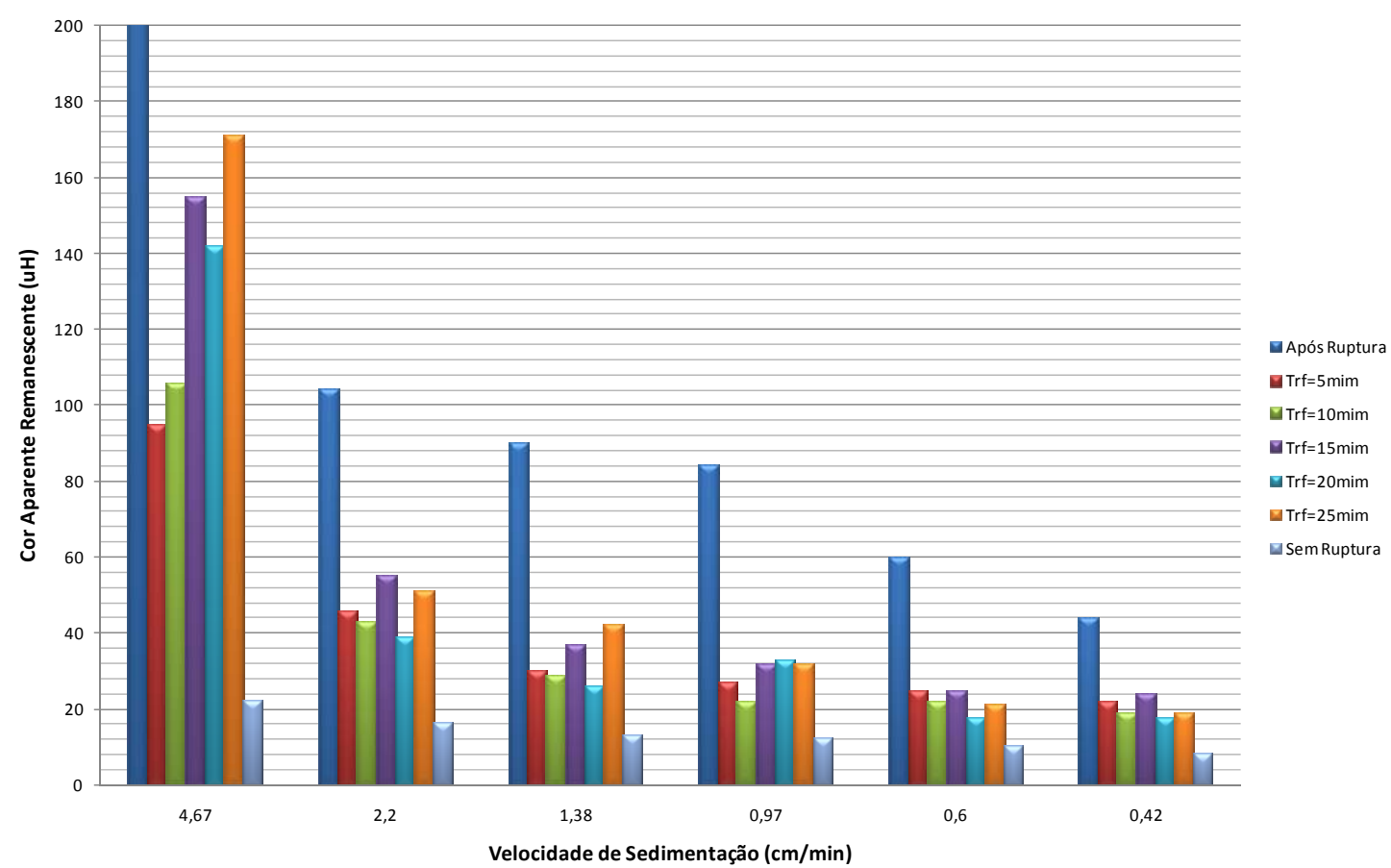

Figura 5.53- Cor aparente remanescente em função da velocidade de sedimentação, para o gradiente de velocidade na ruptura de 150 s-1 e gradiente de velocidade de refloculação de 10 s-1. Fonte: Tabela H.5, Anexo H.

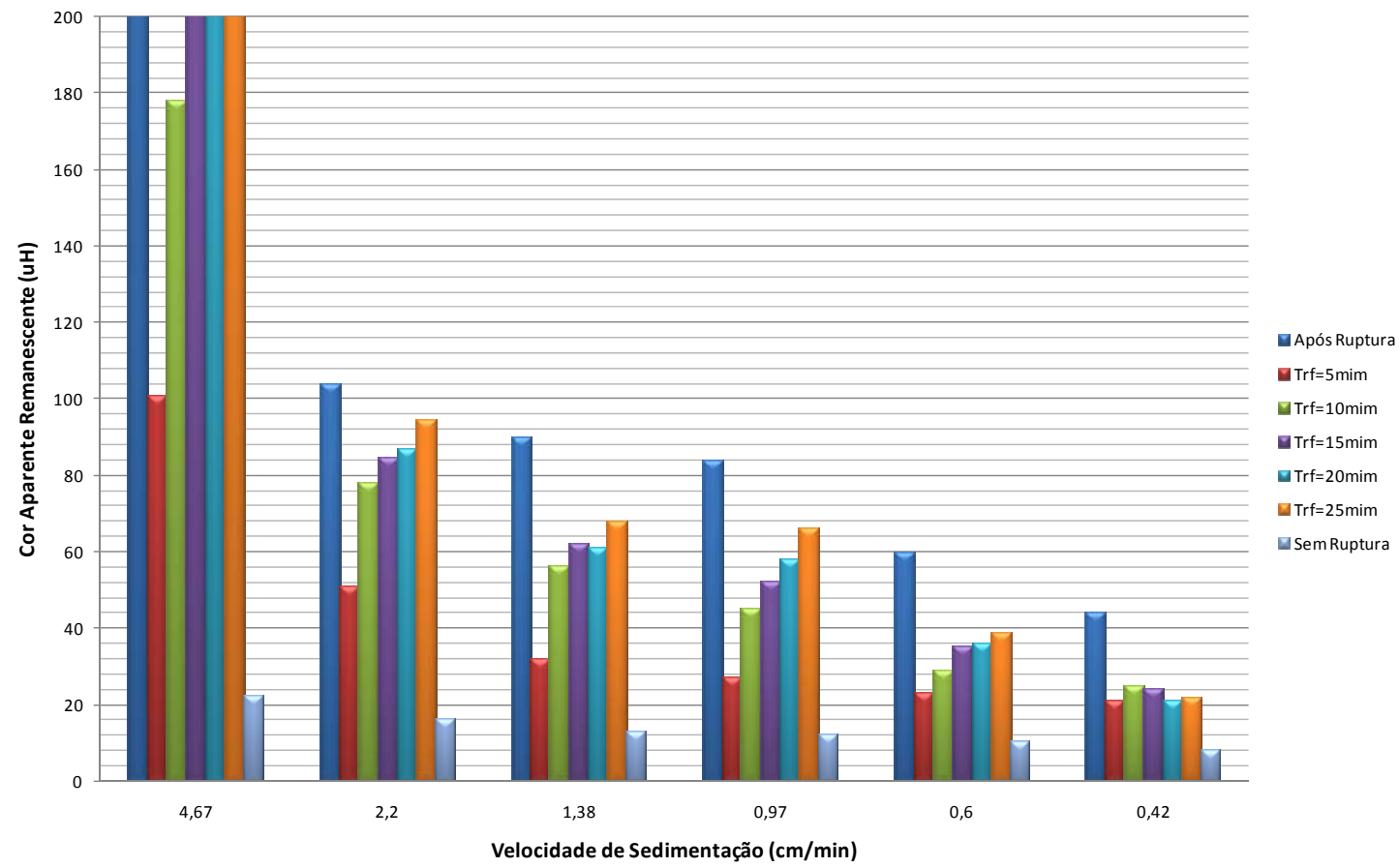

Figura 5.54- Cor aparente remanescente em função da velocidade de sedimentação, para o gradiente de velocidade na ruptura de 150 s-1 e gradiente de velocidade de refloculação de 20 s-1.

Fonte: Tabela H.6, Anexo H. 


\subsubsection{Comentários gerais sobre os ensaios de refloculação com o cloreto férrico como coagulante}

Como ocorrido nos ensaios utilizando o sulfato de alumínio como coagulante, foi possível observar que a refloculação, logo nos primeiros minutos, diminuiu o valor de cor aparente remanescente quando comparada com os resultados obtidos após a ruptura. Porém, em nenhuma situação de refloculação, a cor aparente remanescente atingiu os valores obtidos sem a ruptura. Para o gradiente de refloculação de $20 \mathrm{~s}^{-1}$ os resultados foram piores quando comparado com o gradiente de $10 \mathrm{~s}^{-1}$.

A refloculação foi mais eficiente para o tempo de 5 min e após esse intervalo de tempo a cor aparente remanescente aumentou consideravelmente. Para o gradiente de refloculação de 20 s-1 muitas vezes os resultados foram ainda piores do que os valores obtidos logo após a ruptura, sendo que quanto maior o tempo de refloculação, piores foram os resultados obtidos para esse gradiente. Estes fatos, evidenciam que a cor aparente remanescente aumenta a partir de um certo tempo de floculação para um mesmo gradiente de velocidade.

Em todos os ensaios, pode-se notar que os resultados se aproximaram dos obtidos sem ruptura para as velocidades de sedimentação menores, porém sem nunca atingir os mesmos patamares. Assim, a ruptura se mostrou irreversível em todas as situações ensaiadas. 


\subsection{Comparações entre os ensaios com os diferentes coagulantes}

O cloreto férrico teve um desempenho superior ao sulfato de alumínio, principalmente nas velocidades de sedimentação mais altas, mais próximas às velocidades utilizadas em decantadores em escala real. Isso se deve ao fato da floculação da água coagulada com o cloreto férrico ter gerado flocos de tamanho muito superior aos flocos gerados com o sulfato de alumínio.

Por outro lado, houve maior dificuldade para se encontrar os parâmetros de coagulação do cloreto férrico, uma vez que foi necessária a realização de 24 ensaios para a composição de um diagrama de coagulação do coreto férrico contra 19 ensaios no diagrama do sulfato de alumínio. A coagulação com o cloreto férrico apresentou-se mais sensível a variações no $\mathrm{pH}$ e necessitou de dosagens maiores de alcalinizante quando comparada com o sulfato de alumínio.

A Figura 5.55 compara acurva de sedimentação dos dois coagulantes, cada um com seus os parâmetros otimizados definidos nos ensaios anteriores. Para a água de estudo, fica evidente a maior eficiência de remoção de cor com cloreto férrico principalmente nas maiores velocidades de sedimentação. 


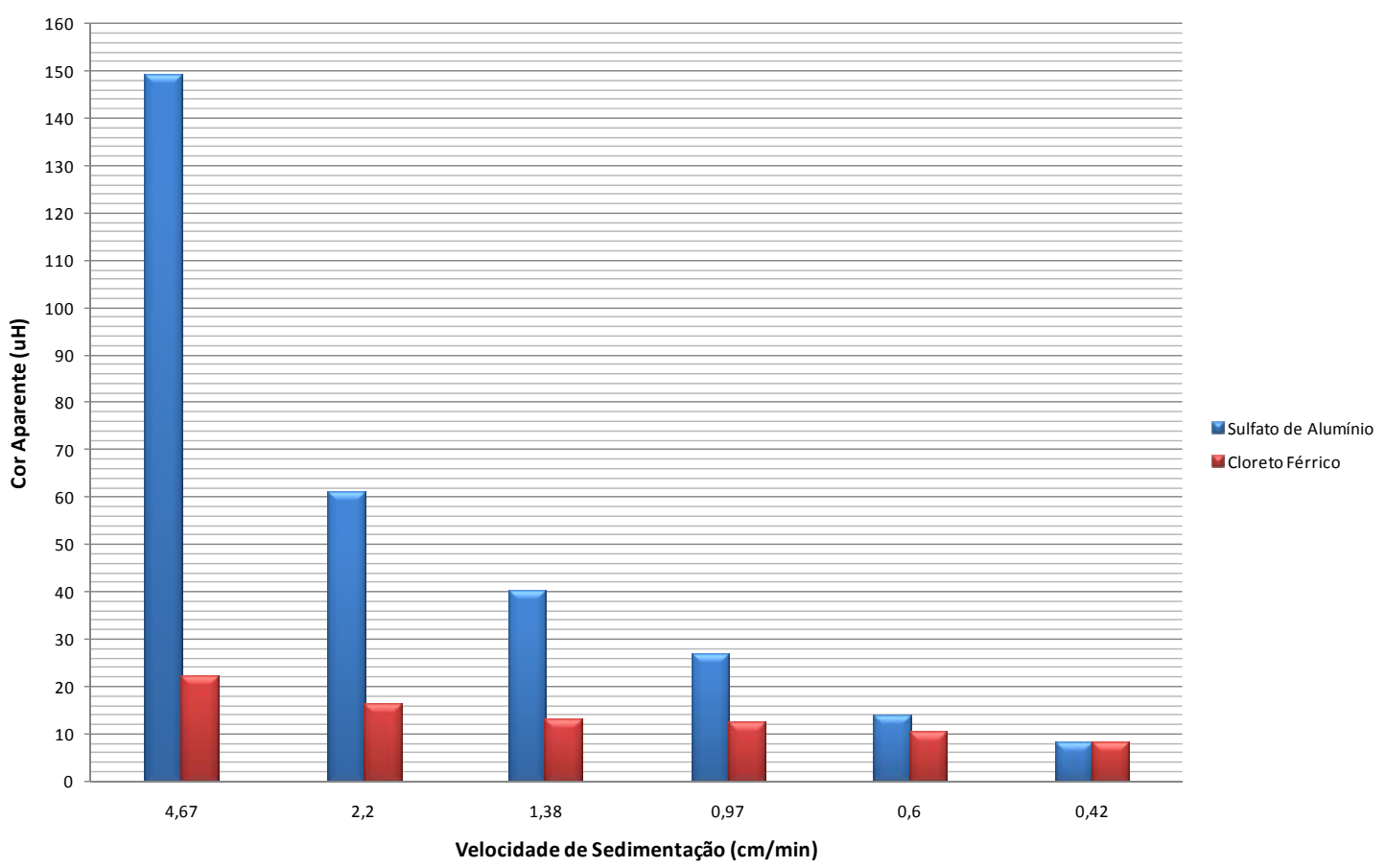

Figura 5.55- Comparação entre a sedimentação com cloreto férrico e com sulfato de alumínio

A ruptura, ocorrida com qualquer gradiente, afetou significativamente os resultados de ambos os coagulantes. Seu efeito é mais acentuado em altas velocidades de sedimentação (maiores que $2 \mathrm{~cm} / \mathrm{min}$ ) na água coagulada com o cloreto férrico, uma vez que os flocos formados com o cloreto férrico antes da ruptura apresentaram boa capacidade de sedimentação, sendo assim, mais afetados pela ruptura. A comparação do efeito da ruptura na sedimentação é percebida nas Figuras 5.56 e 5.57, que apresentam novamente os efeitos dos diferentes gradientes testados na sedimentação. 


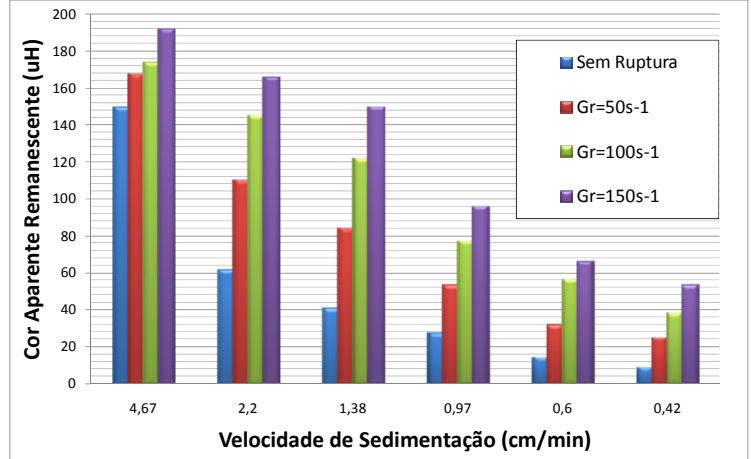

Figura 5.56 - Sedimentação para diferentes gradientes de velocidade de ruptura em água coagulada com sulfato de alumínio

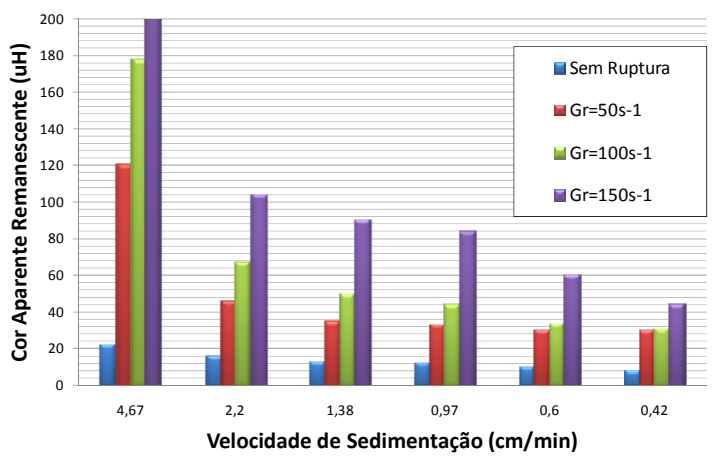

Figura 5.57 - Sedimentação para diferentes gradientes de velocidade de ruptura em água coagulada com cloreto férrico

Tanto na água coagulada com o sulfato de alumínio quanto na água coagulada com o cloreto férrico a refloculação se comportou de modo semelhante, havendo recuperação na eficiência de remoção de cor sem porém, atingir os resultados obtidos antes da ruptura. Não é possível afirmar que os coagulantes ocasionaram diferentes efeitos na reformação de flocos. Produtos auxiliares de floculação possivelmente teriam mais influência, uma vez que influenciam o tamanho e densidade dos flocos formados, porém os mesmos não foram testados. 


\section{CONCLUSÕES E RECOMENDAÇÕES}

Com base nos resultados obtidos no trabalho realizado, conclui-se que:

- a comparação dos ensaios de coagulação, floculação e sedimentação realizados com diferentes coagulantes mostra que o comportamento dos flocos formados é muito diferente conforme o coagulante utilizado;

- os flocos formados na água coagulada com o sulfato de alumínio, visivelmente menores, apresentaram baixas velocidades de sedimentação, limitando a aplicabilidade deste coagulante na água de estudo em situações ocorridas na prática;

- a água de estudo coagulada, com ambos os coagulantes, foi afetada significativamente pela ruptura e apresentou comportamento semelhante quando submetida a refloculação;

- nos ensaios em que os flocos são rompidos e submetidos à refloculação, os valores de cor aparente remanescente raramente são similares aos obtidos inicialmente (sem a ruptura);

- a refloculação, mesmo aos primeiros cinco minutos, diminuiu a cor aparente remanescente, quando comparada com as coletas efetuadas logo após a ruptura (sem refloculação); 
- tempos de refloculação relativamente longos, se mostraram com pior eficiência de remoção de cor aparente quando comparado com tempos menores de refloculação. Foi possível observar este mesmo comportamento durante a floculação - tempos de floculação maiores que 25 minutos tiveram pior eficiência de remoção de cor se comparado a tempos menores, entre 15 a 20 minutos;

- quanto maior o valor do gradiente de velocidade durante a ruptura, maiores os valores de cor aparente remanescente após a refloculação, distanciando-se dos valores obtidos inicialmente, sem a ruptura. Desta forma, este gradiente tem grande influência na velocidade de sedimentação dos flocos, mesmo após a refloculação;

- para os valores menores do gradiente de velocidade, durante a refloculação, os resultados da cor aparente remanescente do sobrenadante foram menores.

Finalizando o presente trabalho, são feitas as seguintes recomendações:

a) a realização de pesquisas sobre a ruptura e refloculação com águas de estudo com outras características, como por exemplo a utilização de águas de mananciais de abastecimento. Além da realização de ensaios de ruptura e refloculação com objetivo de avaliar o comportamento de flocos formados por outros coagulantes, como o sulfato férrico e o cloreto de polialumínio (PAC);

b) a realização de ensaios em reatores estáticos com o objetivo de estudar alternativas para melhorar a eficiência de remoção de impurezas por sedimentação, em casos que ocorrem a ruptura; sugere-se que seja estudada a adição de polímeros sintéticos ou naturais, principalmente após da ruptura, como forma de auxiliar a refloculação; 
c) a realização de pesquisas para estudar outras características dos flocos durante a ruptura e refloculação, como o controle do tamanho dos flocos através de métodos fotográficos e a realização de ensaios de contagem de partículas. Nestes casos deve-se tomar muito cuidado para o não comprometimento das amostras do sobrenadante coletado, pois estas amostras tendem a iniciar a sedimentação se ficarem paradas ou continuar a floculação se forem agitadas, mudando suas características;

d) a realização de pesquisas sobre ruptura e refloculação com o objetivo de relacionar os resultados encontrados em escala de bancada, nos reatores estáticos, com os de escala piloto, de escoamento contínuo;

e) a realização de ensaios de coagulação, floculação e sedimentação visando otimizar os parâmetros do tratamento de água contendo SHA fracionada para verificação da influência do tamanho molecular das SHA no tratamento de águas com altos valores de cor verdadeira;

f) é importante a realização de ensaios em reatores estáticos para escolher a dosagem de coagulante, $\mathrm{pH}$ de coagulação, tempo e gradiente de velocidade de mistura rápida, tempo e gradiente de velocidade de floculação, adequados para a água de estudo em questão, pois podem apresentar diferenças significativas quando comparado com valores encontrados na literatura para água de características parecidas;

g) é importante também a padronização dos procedimentos de preparo da água de estudo, principalmente no que se diz respeito à extração das SHA. 


\section{REFERÊNCIAS BIBLIOGRÁFICAS}

AMIRTHARAJAH, A.; MILLS, K.L. (1982). Rapid-mix design for mechanisms of alum coagulation. Journal AWWA, v. 74, n. 4, p. 210-216.

AMIRTHARAJAH, A. (1989). The mechanisms of coagulation. In: SEMINÁRIO NACIONAL SOBRE COAGULAÇÃO E FILTRAÇÃO DIRETA, 1., São Carlos. Anais... São Carlos: [s. n.], 1989. 1v.

AMERICAN WATER WORKS ASSOCIATION (AWWA). (1998). Standards Methods for the examination of water and wastewater. 20 ed. New Yok, APHA, AWWA, AWPCF. CD ROM.

BLACK, A. P.; WILLENS, D. G. (1961). Electrophoretic studies of coagulation for removal of organic color. J. Am. Wat. Works Assoc. v.53, p.589-605.

BRATBY, J.R. (1981) Interpreting laboratory results for the design of rapid mix and flocculation systems. . Journal of the American Water Works Association, v. 73, n. 6 , p. $318-325$, Jun.

BRITO, S.A. (1998.). Influência da velocidade de sedimentação na determinação dos coeficientes de agregação e ruptura durante a floculação São Carlos. Dissertação (Mestrado). Escola de Engenharia de São Carlos, Universidade de São Paulo.

CAMPOS, S. X. (2004). Influência das Substâncias Húmicas de Diferentes Massas Molares na Coagulação, Floculação e Sedimentação no Tratamento de Água. São Carlos. Tese (Doutorado) - Instituto de Química de São Carlos, Universidade de São Paulo. 
DANTAS, A. D. B, SLOBODA, E, DI BERNARDO, L, VIEIRA, E. M, TROFINO, J, C. (2007). Influência da massa molar de substâncias húmicas aquáticas na coagulação com sulfato de alumínio. In: Congresso Brasileiro de Engenharia Sanitária e Ambiental - ABES, 24., 2007, Belo Horizonte. Anais... Minas Gerais, 1 CD-ROM.

DEMPSEY, B. A. (1984). Removal of naturally occuring compounds by coagulation and sedimentation. CRC Critical Reviews in Environmental Control, v. 14, n. 4, p. 311331.

DI BERNARDO, L., BRITO, S.A., MOREIRA, A.M.R. (1999) Importância da velocidade de sedimentação dos flocos na otimização do gradiente de velocidade na sedimentação. In: Congresso Brasileiro de Engenharia Sanitária e Ambiental ABES, 20., 1999, Rio de Janeiro. Anais... Rio de Janeiro, 1 CD-ROM.

DI BERNARDO, A.S. (2004). Desempenho de sistemas de dupla filtração no tratamento de água com turbidez elevada. São Carlos. 281p. Dissertação (Doutorado). Escola de Engenharia de São Carlos, Universidade de São Paulo.

DI BERNARDO, L. ; DANTAS, A.D.B. (2005) Métodos e técnicas de tratamento de água, 2.ed. v.1. São Carlos: RIMA.

EDWARDS, A. G.; AMIRTHARAJAH, A. (19850. Removing color caused by humic acids. Research and Technology. Journal AWWA, v. 77, n. 3, p. 50-57.

EDZWALD, J.K. (1993.). Coagulation in drinking water treatment: particles, organics and coagulants. Water Science and Technology, v. 27, n. 11, p. 21-35.

HIDROSAN ENGENHARIA S/S LTDA (2000) Avaliação do desempenho da ETA principal de salvador e execução de ensaios de otimização do processo de tratamento. Relatório final Junho e Julho de 2000. São Carlos. 
JARVIS, P. ; JEFFERSON, B. ; PARSONS, S.A. (2005a) Breakage, regrowth, and fractal nature of natural organic matter flocs. Environmental Science \& Technology,. UK, n.7, v.39, p.2307-2314.

JARVIS, P. ; GREGORY, J. ; JEFFERSON, B. ; PARSONS, S.A (2005b) A review of floc strength and breakage. Water Research, n.39, p. 3121-3137.

JARVIS, P. ; JEFFERSON, B. ; PARSONS, S.A. (2006) Floc structural characteristics using conventional coagulation for a high doc, low alkalinity surface water source. Water Research, Volume 40, Issue 14, August 2006, p 2727-2737.

LIBÂNIO, M. (1995) Avaliação da floculação em reatores estáticos e de escoamento continuo com gradientes de velocidade constante e variável. São Carlos. 136p. Tese (Doutorado). Escola de Engenharia de São Carlos, Universidade de São Paulo.

O’ MELIA, C. R. (1972). Coagulation e Flocculation,. In: Seminário Nacional Sobre Coagulação e Filtração Direta, 1., 1989, São Carlos. Anais...São Carlos: Escola de Engenharia de São Carlos, Universidade de São Paulo, São Carlos, 1989. 1v.

PÁDUA, V.L.; DI BERNARDO, L. (1997) Emprego da mantas sintéticas no estudos de tratabilidade de água quimicamente coagulada. In: Congresso Brasileiro de Engenharia Sanitária e Ambiental, 19, Foz do Iguaçu, Anais. Rio de Janeiro, ABES

PÁDUA, V. L; DI BERNARDO, L; LIBÂNIO, M. (1998). Optimización de Gradientes de Velocidad en la Floculación. In: Seminario sobre Optimización de Plantas de Potabilización. Lima, Peru.

PÁDUA, V.L.(1994). Metodologia para determinação dos gradientes de velocidade médios em unidades de floculação de mistura completa com câmaras em serie e escoamento continuo a partir de ensaios em reatores estáticos . São Carlos. 74p. Dissertação (Mestrado). Escola de Engenharia de São Carlos, Universidade de São Paulo. 
PASCHOALATO, C.F.P.R. (2005) Efeitos da pré-oxidação, coagulação, filtração e pós-cloração na formação de subprodutos orgânicos halogenados em águas contendo substâncias húmicas. 154p. Tese (Doutorado). Escola de Engenharia de São Carlos, Universidade de São Paulo.

PAVANELLI, G. (2001). Eficiência de diferentes tipos de coagulantes na coagulação, floculação e sedimentação de água com cor ou turbidez elevada. São Carlos. 205p. Dissertação (Mestrado). Escola de Engenharia de São Carlos, Universidade de São Paulo.

ROCHA, J. C., ROSA, A. H. (2003). Substâncias Húmicas Aquáticas - Interação com Espécies Metálicas. Ed. UNESP, São Paulo.

SHARP, E. L.; PARSONS, S. A.; JEFFERSON, B. ( 2006). Seasonal variations in natural organic matter and its impact on coagulation in water treatment. Science of the Total Environment, v. 363, p. 183 -194,.

SLOBODA, E. (2007). Influência do tamanho molecular aparente das substâncias húmicas aquáticas na eficiência da coagulação com sulfato de alumínio e cloreto férrico. São Carlos. 225 p. Dissertação (Mestrado) Instituto de Química de São Carlos, Universidade de São Paulo

SLOBODA, E, DANTAS, A. D. B, VIEIRA, E. M, DI BERNARDO, L. (2007) Caracterização das substâncias húmicas aquáticas e comparação com as substâncias húmicas de turfa . In: Congresso Brasileiro de Engenharia Sanitária e Ambiental ABES, 24, 2007, Belo Horizonte - MG.

THURMAN, E. M. \& MALCOLM, R. L. (1981). Preparative Isolation of Aquatic Humic Substances. vol. 15, n. 4, p. 463 - 466. American Chemical Society. 
VAN BENSCHOTEN, J. E.; EDZWALD, J. K. (1990). Chemical aspects of coagulation using aluminum salts-I. Hydrolytic reactions of alum and polyaluminun chloride. Water Research, v. 24, n. 12, p. 519-1526.

VOLTAN, P.E.N. (2007) Avaliação da Ruptura e recrescimento de flocos em água com turbidez elevada. São Carlos. Dissertação (Mestrado). Escola de Engenharia de São Carlos, Universidade de São Paulo.

YUKSELEN, M.A. ; GREGORY, J. (2002) Breakage and re-formation of alum flocs. Environmental Engineering Science, n.4, v.19, p.229-236.

. (2004a) The reversibly of floc breakage. International Journal of Mineral Processing, v.73, p.251-259.

. (2004b) The effect of rapid mixing on the break-up and re-formation of flocs. Journal of Chemical Technology and Biotechnology, v.79, p.782-788. 


\section{ANEXO A}

Resultados dos ensaios para construção dos diagramas

de coagulação como o Sulfato de Alumínio como coagulante 
Tabela A.1 - Resultados dos ensaios para construção do diagrama de coagulação

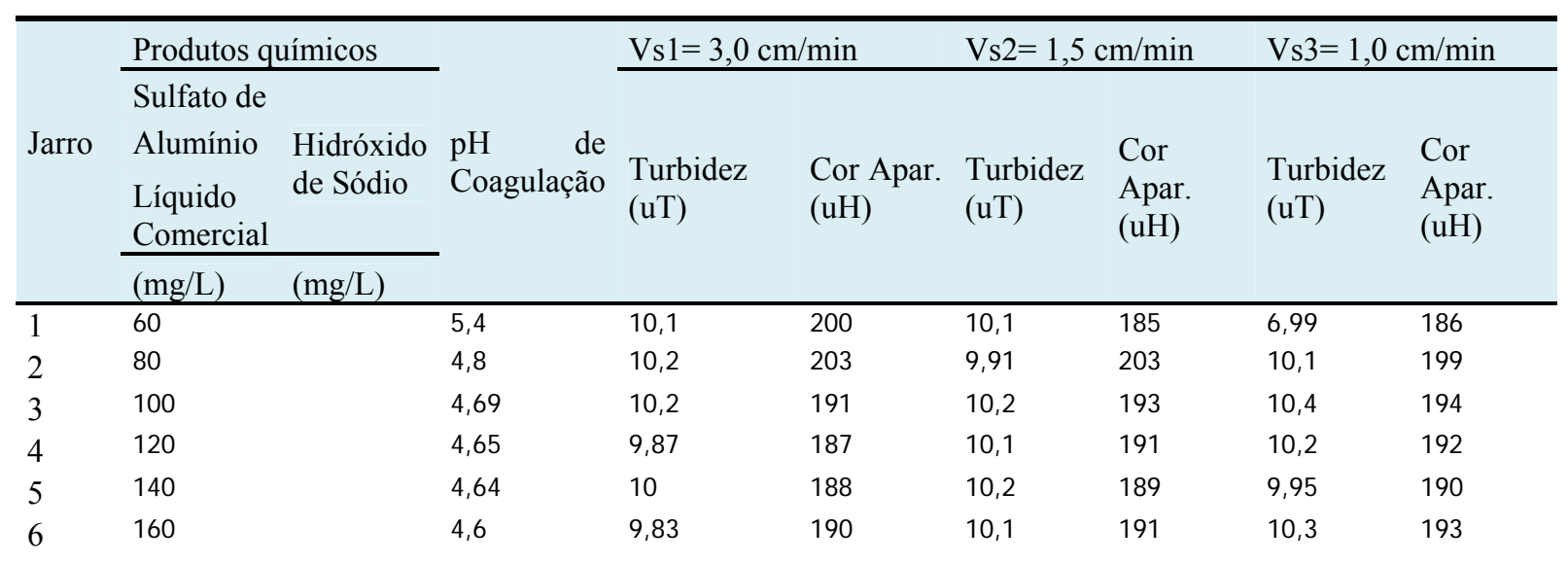

Tabela A.2 - Resultados dos ensaios para construção do diagrama de coagulação

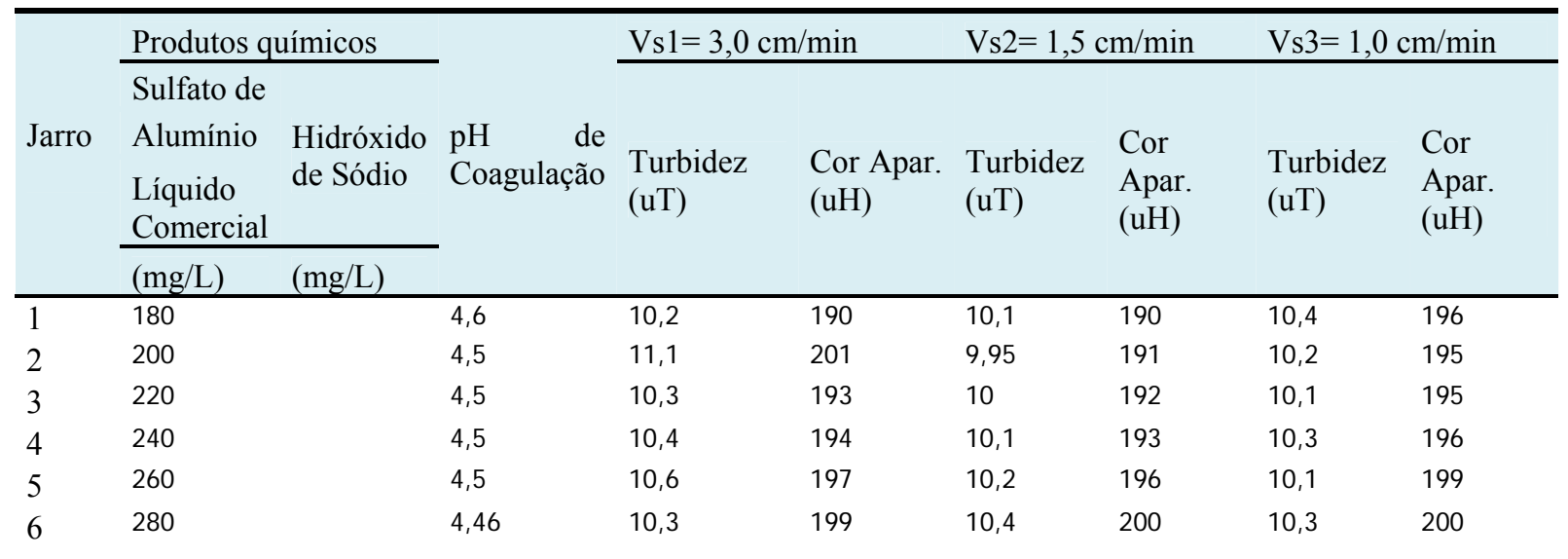

Tabela A.3 - Resultados dos ensaios para construção do diagrama de coagulação

\begin{tabular}{|c|c|c|c|c|c|c|c|c|c|}
\hline \multirow{3}{*}{ Jarro } & \multicolumn{2}{|c|}{ Produtos químicos } & \multirow{3}{*}{$\begin{array}{l}\text { pH de } \\
\text { Coagulação }\end{array}$} & \multicolumn{2}{|c|}{$\mathrm{Vs} 1=3,0 \mathrm{~cm} / \mathrm{min}$} & \multicolumn{2}{|c|}{$\mathrm{Vs} 2=1,5 \mathrm{~cm} / \mathrm{min}$} & \multicolumn{2}{|c|}{$\mathrm{Vs} 3=1,0 \mathrm{~cm} / \mathrm{min}$} \\
\hline & $\begin{array}{l}\text { Sulfato de } \\
\text { Alumínio } \\
\text { Líquido } \\
\text { Comercial } \\
\end{array}$ & $\begin{array}{l}\text { Hidróxido } \\
\text { de Sódio }\end{array}$ & & $\begin{array}{l}\text { Turbidez } \\
\text { (uT) }\end{array}$ & $\begin{array}{l}\text { Cor Apar. } \\
(\mathrm{uH})\end{array}$ & $\begin{array}{l}\text { Turbidez } \\
\text { (uT) }\end{array}$ & $\begin{array}{l}\text { Cor } \\
\text { Apar. } \\
(\mathrm{uH})\end{array}$ & $\begin{array}{l}\text { Turbidez } \\
\text { (uT) }\end{array}$ & $\begin{array}{l}\text { Cor } \\
\text { Apar. } \\
(\mathrm{uH})\end{array}$ \\
\hline & $(\mathrm{mg} / \mathrm{L})$ & $(\mathrm{mg} / \mathrm{L})$ & & & & & & & \\
\hline 1 & 300 & & 4,45 & 10,9 & 203 & 11,2 & 199 & 10,9 & 203 \\
\hline 2 & 350 & & 4,5 & 10,7 & 202 & 10,8 & 202 & 10,9 & 206 \\
\hline 3 & 400 & & 4,5 & 11,3 & 205 & 10,9 & 206 & 11,5 & 211 \\
\hline 4 & 40 & & 4,5 & 9,62 & 168 & 9,07 & 166 & 8,99 & 170 \\
\hline 5 & 60 & 5 & 4,51 & 9,38 & 190 & 9,45 & 191 & 8,91 & 186 \\
\hline 6 & 60 & 10 & 4,46 & 6,27 & 159 & 6,32 & 160 & 6,33 & 163 \\
\hline
\end{tabular}


Tabela A.4 - Resultados dos ensaios para construção do diagrama de coagulação

\begin{tabular}{|c|c|c|c|c|c|c|c|c|c|}
\hline \multirow{3}{*}{ Jarro } & Produtos qu & límicos & \multirow{3}{*}{$\begin{array}{l}\text { pH de } \\
\text { Coagulação }\end{array}$} & \multicolumn{2}{|c|}{$\mathrm{Vs} 1=3,0 \mathrm{~cm} / \mathrm{min}$} & \multicolumn{2}{|c|}{$\mathrm{Vs} 2=1,5 \mathrm{~cm} / \mathrm{min}$} & \multicolumn{2}{|c|}{$\mathrm{Vs} 3=1,0 \mathrm{~cm} / \mathrm{min}$} \\
\hline & $\begin{array}{l}\text { Sulfato de } \\
\text { Alumínio } \\
\text { Líquido } \\
\text { Comercial } \\
\end{array}$ & $\begin{array}{l}\text { Hidróxido } \\
\text { de Sódio }\end{array}$ & & $\begin{array}{l}\text { Turbidez } \\
\text { (uT) }\end{array}$ & $\begin{array}{l}\text { Cor Apar. } \\
(\mathrm{uH})\end{array}$ & $\begin{array}{l}\text { Turbidez } \\
\text { (uT) }\end{array}$ & $\begin{array}{l}\text { Cor } \\
\text { Apar. } \\
(\mathrm{uH})\end{array}$ & $\begin{array}{l}\text { Turbidez } \\
\text { (uT) }\end{array}$ & $\begin{array}{l}\text { Cor } \\
\text { Apar. } \\
\text { (uH) }\end{array}$ \\
\hline & $(\mathrm{mg} / \mathrm{L})$ & $(\mathrm{mg} / \mathrm{L})$ & & & & & & & \\
\hline 1 & 80 & 5 & 5,71 & 10,3 & 187 & 9,46 & 175 & 6,33 & 119 \\
\hline 2 & 80 & 10 & 6,29 & 8,48 & 175 & 9,4 & 122 & 3,92 & 86 \\
\hline 3 & 100 & 5 & 5,11 & 10,2 & 190 & 10,3 & 191 & 10,3 & 197 \\
\hline 4 & 100 & 10 & 6,03 & 10,2 & 157 & 6,98 & 146 & 3,06 & 56 \\
\hline 5 & 120 & 5 & 4,9 & 10,2 & 185 & 10,1 & 186 & 8,97 & 186 \\
\hline 6 & 120 & 10 & 5,4 & 9,61 & 194 & 9,71 & 196 & 9,5 & 195 \\
\hline
\end{tabular}

Tabela A.5 - Resultados dos ensaios para construção do diagrama de coagulação

\begin{tabular}{|c|c|c|c|c|c|c|c|c|c|}
\hline \multirow{3}{*}{ Jarro } & Produtos qu & límicos & \multirow{3}{*}{$\begin{array}{l}\text { pH de } \\
\text { Coagulação }\end{array}$} & \multicolumn{2}{|c|}{$\mathrm{Vs} 1=3,0 \mathrm{~cm} / \mathrm{min}$} & \multicolumn{2}{|c|}{$\mathrm{Vs} 2=1,5 \mathrm{~cm} / \mathrm{min}$} & \multicolumn{2}{|c|}{$\mathrm{Vs} 3=1,0 \mathrm{~cm} / \mathrm{min}$} \\
\hline & $\begin{array}{l}\text { Sultato de } \\
\text { Alumínio } \\
\text { Líquido } \\
\text { Comercial } \\
\end{array}$ & $\begin{array}{l}\text { Hidróxido } \\
\text { de Sódio }\end{array}$ & & $\begin{array}{l}\text { Turbidez } \\
\text { (uT) }\end{array}$ & $\begin{array}{l}\text { Cor Apar. } \\
(\mathrm{uH})\end{array}$ & $\begin{array}{l}\text { Turbidez } \\
\text { (uT) }\end{array}$ & $\begin{array}{l}\text { Cor } \\
\text { Apar. } \\
\text { (uH) }\end{array}$ & $\begin{array}{l}\text { Turbidez } \\
\text { (uT) }\end{array}$ & $\begin{array}{l}\text { Cor } \\
\text { Apar. } \\
\text { (uH) }\end{array}$ \\
\hline & $(\mathrm{mg} / \mathrm{L})$ & $(\mathrm{mg} / \mathrm{L})$ & & & & & & & \\
\hline 1 & 300 & 10 & 4,57 & 9,99 & 209 & 11,3 & 209 & 11,3 & 212 \\
\hline 2 & 300 & 20 & 4,68 & 9,83 & 203 & 8,57 & 180 & 6,06 & 132 \\
\hline 3 & 300 & 30 & 4,85 & 9,2 & 160 & 4,02 & 86 & 1,6 & 26 \\
\hline 4 & 300 & 40 & 5,5 & 7,45 & 150 & 3,4 & 58 & 1,04 & 14 \\
\hline 5 & 300 & 50 & 6,43 & 7,3 & 148 & 3,22 & 68 & 0,97 & 12 \\
\hline 6 & 300 & 60 & 7,4 & 7,87 & 178 & 7,96 & 177 & 7,71 & 176 \\
\hline
\end{tabular}

Tabela A.6 - Resultados dos ensaios para construção do diagrama de coagulação

\begin{tabular}{|c|c|c|c|c|c|c|c|c|c|}
\hline \multirow{3}{*}{ Jarro } & \multicolumn{2}{|c|}{ Produtos químicos } & \multirow{3}{*}{$\begin{array}{l}\text { pH de } \\
\text { Coagulação }\end{array}$} & \multicolumn{2}{|c|}{$\mathrm{Vs} 1=3,0 \mathrm{~cm} / \mathrm{min}$} & \multicolumn{2}{|c|}{$\mathrm{Vs} 2=1,5 \mathrm{~cm} / \mathrm{min}$} & \multicolumn{2}{|c|}{$\mathrm{Vs} 3=1,0 \mathrm{~cm} / \mathrm{min}$} \\
\hline & $\begin{array}{l}\text { Sulfato de } \\
\text { Alumínio } \\
\text { Líquido } \\
\text { Comercial } \\
\end{array}$ & $\begin{array}{l}\text { Hidróxido } \\
\text { de Sódio }\end{array}$ & & $\begin{array}{l}\text { Turbidez } \\
\text { (uT) }\end{array}$ & $\begin{array}{l}\text { Cor Apar. } \\
(\mathrm{uH})\end{array}$ & $\begin{array}{l}\text { Turbidez } \\
\text { (uT) }\end{array}$ & $\begin{array}{l}\text { Cor } \\
\text { Apar. } \\
(\mathrm{uH})\end{array}$ & $\begin{array}{l}\text { Turbidez } \\
\text { (uT) }\end{array}$ & $\begin{array}{l}\text { Cor } \\
\text { Apar. } \\
\text { (uH) }\end{array}$ \\
\hline & $(\mathrm{mg} / \mathrm{L})$ & $(\mathrm{mg} / \mathrm{L})$ & & & & & & & \\
\hline 1 & 100 & 15 & 6,31 & 6,7 & 134 & 7,33 & 98 & 1,6 & 27 \\
\hline 2 & 100 & 20 & 6,93 & 6,59 & 161 & 6,34 & 161 & 5,7 & 159 \\
\hline 3 & 200 & 10 & 4,7 & 11,1 & 190 & 10,9 & 192 & 10,9 & 192 \\
\hline 4 & 200 & 20 & 5,04 & 9,88 & 195 & 9,48 & 197 & 9,86 & 195 \\
\hline 5 & 200 & 30 & 6,06 & 5,32 & 104 & 3,4 & 64 & 1,04 & 9 \\
\hline 6 & 200 & 40 & 6,9 & 7,32 & 164 & 6,97 & 165 & 7,5 & 162 \\
\hline
\end{tabular}


Tabela A.7 - Resultados dos ensaios para construção do diagrama de coagulação

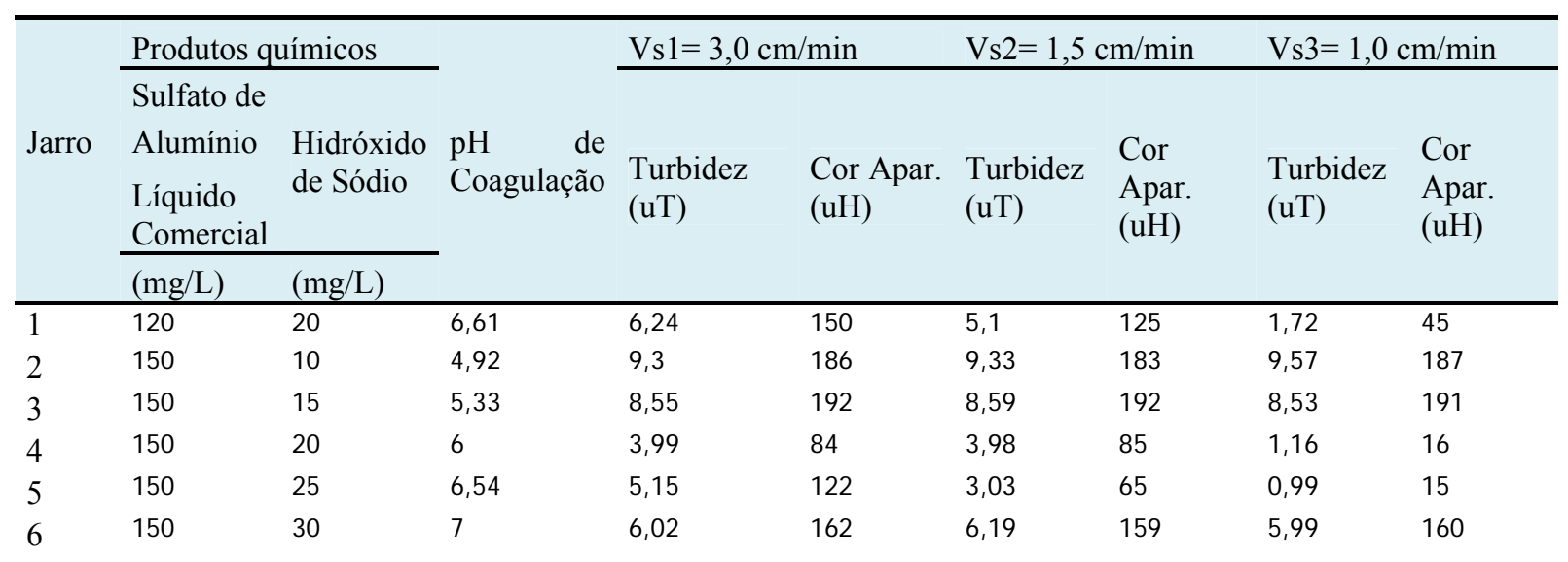

Tabela A.8 - Resultados dos ensaios para construção do diagrama de coagulação

\begin{tabular}{|c|c|c|c|c|c|c|c|c|c|}
\hline \multirow{3}{*}{ Jarro } & Produtos q & límicos & \multirow{3}{*}{$\begin{array}{l}\mathrm{pH} \quad \mathrm{de} \\
\text { Coagulação }\end{array}$} & \multicolumn{2}{|c|}{$\mathrm{Vs} 1=3,0 \mathrm{~cm} / \mathrm{min}$} & \multicolumn{2}{|c|}{$\mathrm{Vs} 2=1,5 \mathrm{~cm} / \mathrm{min}$} & \multicolumn{2}{|c|}{$\mathrm{Vs} 3=1,0 \mathrm{~cm} / \mathrm{min}$} \\
\hline & $\begin{array}{l}\text { Alumínio } \\
\text { Líquido } \\
\text { Comercial }\end{array}$ & $\begin{array}{l}\text { Hidróxido } \\
\text { de Sódio }\end{array}$ & & \multirow[t]{2}{*}{$\begin{array}{l}\text { Turbidez } \\
\text { (uT) }\end{array}$} & \multirow[t]{2}{*}{$\begin{array}{l}\text { Cor Apar. } \\
(\mathrm{uH})\end{array}$} & \multirow[t]{2}{*}{$\begin{array}{l}\text { Turbidez } \\
\text { (uT) }\end{array}$} & \multirow[t]{2}{*}{$\begin{array}{l}\text { Cor } \\
\text { Apar. } \\
(\mathrm{uH})\end{array}$} & \multirow[t]{2}{*}{$\begin{array}{l}\text { Turbidez } \\
\text { (uT) }\end{array}$} & \multirow[t]{2}{*}{$\begin{array}{l}\text { Cor } \\
\text { Apar. } \\
\text { (uH) }\end{array}$} \\
\hline & $(\mathrm{mg} / \mathrm{L})$ & $(\mathrm{mg} / \mathrm{L})$ & & & & & & & \\
\hline 1 & 120 & 15 & 6,2 & 5,75 & 129 & 4,12 & 92 & 1,36 & 23 \\
\hline 2 & 200 & 25 & 5,58 & 8,14 & 173 & 3,63 & 77 & 1,1 & 19 \\
\hline 3 & 200 & 35 & 6,66 & 6,48 & 143 & 2,48 & 53 & 0,88 & 15 \\
\hline 4 & 250 & 20 & 4,85 & 9,3 & 194 & 9,17 & 193 & 9,03 & 194 \\
\hline 5 & 250 & 30 & 5,31 & 7,1 & 142 & 4,03 & 79 & 1,25 & 20 \\
\hline 6 & 250 & 40 & 6,23 & 5,58 & 118 & 2,29 & 45 & 0,8 & 10 \\
\hline
\end{tabular}

Tabela A.9 - Resultados dos ensaios para construção do diagrama de coagulação

\begin{tabular}{|c|c|c|c|c|c|c|c|c|c|}
\hline \multirow{3}{*}{ Jarro } & Produtos q & límicos & \multirow{3}{*}{$\begin{array}{l}\text { pH de } \\
\text { Coagulação }\end{array}$} & \multicolumn{2}{|c|}{$\mathrm{Vs} 1=3,0 \mathrm{~cm} / \mathrm{min}$} & \multicolumn{2}{|c|}{$\mathrm{Vs} 2=1,5 \mathrm{~cm} / \mathrm{min}$} & \multicolumn{2}{|c|}{$\mathrm{Vs} 3=1,0 \mathrm{~cm} / \mathrm{min}$} \\
\hline & $\begin{array}{l}\text { Alumínio } \\
\text { Líquido } \\
\text { Comercial }\end{array}$ & $\begin{array}{l}\text { Hidróxido } \\
\text { de Sódio }\end{array}$ & & \multirow[t]{2}{*}{$\begin{array}{l}\text { Turbidez } \\
\text { (uT) }\end{array}$} & \multirow[t]{2}{*}{$\begin{array}{l}\text { Cor Apar. } \\
\text { (uH) }\end{array}$} & \multirow[t]{2}{*}{$\begin{array}{l}\text { Turbidez } \\
\text { (uT) }\end{array}$} & \multirow[t]{2}{*}{$\begin{array}{l}\text { Cor } \\
\text { Apar. } \\
\text { (uH) }\end{array}$} & \multirow[t]{2}{*}{$\begin{array}{l}\text { Turbidez } \\
\text { (uT) }\end{array}$} & \multirow[t]{2}{*}{$\begin{array}{l}\text { Cor } \\
\text { Apar. } \\
\text { (uH) }\end{array}$} \\
\hline & $(\mathrm{mg} / \mathrm{L})$ & $(\mathrm{mg} / \mathrm{L})$ & & & & & & & \\
\hline 1 & 300 & 45 & 5,9 & 5,07 & 115 & 1,97 & 39 & 0,93 & 11 \\
\hline 2 & 300 & 55 & 6,58 & 5,81 & 128 & 2,02 & 42 & 0,75 & 13 \\
\hline 3 & 340 & 15 & 4,63 & 9,95 & 202 & 9,79 & 203 & 9,59 & 205 \\
\hline 4 & 340 & 25 & 4,73 & 9,54 & 196 & 7,63 & 158 & 3,08 & 65 \\
\hline 5 & 340 & 35 & 4,86 & 6,88 & 137 & 2,58 & 50 & 1 & 16 \\
\hline 6 & 340 & 45 & 5,34 & 8,71 & 180 & 2,98 & 58 & 1,07 & 15 \\
\hline
\end{tabular}


Tabela A.10 - Resultados dos ensaios para construção do diagrama de coagulação

\begin{tabular}{|c|c|c|c|c|c|c|c|c|c|}
\hline \multirow{3}{*}{ Jarro } & Produtos qu & límicos & \multirow{3}{*}{$\begin{array}{l}\text { pH de } \\
\text { Coagulação }\end{array}$} & \multicolumn{2}{|c|}{$\mathrm{Vs} 1=3,0 \mathrm{~cm} / \mathrm{min}$} & \multicolumn{2}{|c|}{$\mathrm{Vs} 2=1,5 \mathrm{~cm} / \mathrm{min}$} & \multicolumn{2}{|c|}{$\mathrm{Vs} 3=1,0 \mathrm{~cm} / \mathrm{min}$} \\
\hline & $\begin{array}{l}\text { Sulfato de } \\
\text { Alumínio } \\
\text { Líquido } \\
\text { Comercial } \\
\end{array}$ & $\begin{array}{l}\text { Hidróxido } \\
\text { de Sódio }\end{array}$ & & $\begin{array}{l}\text { Turbidez } \\
\text { (uT) }\end{array}$ & $\begin{array}{l}\text { Cor Apar. } \\
(\mathrm{uH})\end{array}$ & $\begin{array}{l}\text { Turbidez } \\
\text { (uT) }\end{array}$ & $\begin{array}{l}\text { Cor } \\
\text { Apar. } \\
(\mathrm{uH})\end{array}$ & $\begin{array}{l}\text { Turbidez } \\
\text { (uT) }\end{array}$ & $\begin{array}{l}\text { Cor } \\
\text { Apar. } \\
\text { (uH) }\end{array}$ \\
\hline & $(\mathrm{mg} / \mathrm{L})$ & $(\mathrm{mg} / \mathrm{L})$ & & & & & & & \\
\hline 1 & 130 & 15 & 5,71 & 8,38 & 190 & 6,53 & 141 & 3,63 & 63 \\
\hline 2 & 160 & 25 & 6,45 & 5,05 & 116 & 2,65 & 58 & 1,02 & 19 \\
\hline 3 & 220 & 35 & 7,43 & 6,48 & 164 & & & 6,44 & 163 \\
\hline 4 & 250 & 35 & 6,84 & 4,63 & 105 & 3,22 & 76 & 1,22 & 27 \\
\hline 5 & 250 & 50 & 7,38 & 6,89 & 166 & 6,78 & 167 & 6,55 & 165 \\
\hline 6 & 260 & 50 & 7,25 & 7,66 & 172 & 7,5 & 174 & 7,27 & 170 \\
\hline
\end{tabular}

Tabela A.11 - Resultados dos ensaios para construção do diagrama de coagulação

\begin{tabular}{|c|c|c|c|c|c|c|c|c|c|}
\hline \multirow{3}{*}{ Jarro } & Produtos qu & límicos & \multirow{3}{*}{$\begin{array}{l}\mathrm{pH} \quad \text { de } \\
\text { Coagulação }\end{array}$} & \multicolumn{2}{|c|}{$\mathrm{Vs} 1=3,0 \mathrm{~cm} / \mathrm{min}$} & \multicolumn{2}{|c|}{$\mathrm{Vs} 2=1,5 \mathrm{~cm} / \mathrm{min}$} & \multicolumn{2}{|c|}{$\mathrm{Vs} 3=1,0 \mathrm{~cm} / \mathrm{min}$} \\
\hline & $\begin{array}{l}\text { Sultato de } \\
\text { Alumínio } \\
\text { Líquido } \\
\text { Comercial } \\
\end{array}$ & $\begin{array}{l}\text { Hidróxido } \\
\text { de Sódio }\end{array}$ & & $\begin{array}{l}\text { Turbidez } \\
\text { (uT) }\end{array}$ & $\begin{array}{l}\text { Cor Apar. } \\
(\mathrm{uH})\end{array}$ & $\begin{array}{l}\text { Turbidez } \\
\text { (uT) }\end{array}$ & $\begin{array}{l}\text { Cor } \\
\text { Apar. } \\
\text { (uH) }\end{array}$ & $\begin{array}{l}\text { Turbidez } \\
\text { (uT) }\end{array}$ & $\begin{array}{l}\text { Cor } \\
\text { Apar. } \\
\text { (uH) }\end{array}$ \\
\hline & $(\mathrm{mg} / \mathrm{L})$ & $(\mathrm{mg} / \mathrm{L})$ & & & & & & & \\
\hline 1 & 60 & 12 & 6,15 & 5,76 & 157 & 5,64 & 157 & 5,9 & 160 \\
\hline 2 & 60 & 15 & 7,4 & 5,29 & 155 & 5,42 & 157 & 5,3 & 157 \\
\hline 3 & 160 & 15 & 4,96 & 9,48 & 190 & 9,17 & 192 & 9,21 & 195 \\
\hline 4 & 220 & 30 & 5,48 & 5,16 & 101 & 4,8 & 90 & 1,25 & 17 \\
\hline 5 & 240 & 35 & 5,8 & 4,55 & 88 & 3,41 & 63 & 0,85 & 12 \\
\hline 6 & 260 & 35 & 5,33 & 6,65 & 130 & 2,92 & 51 & 1,07 & 16 \\
\hline
\end{tabular}

Tabela A.12 - Resultados dos ensaios para construção do diagrama de coagulação

\begin{tabular}{|c|c|c|c|c|c|c|c|c|c|}
\hline \multirow{3}{*}{ Jarro } & \multicolumn{2}{|c|}{ Produtos químicos } & \multirow{3}{*}{$\begin{array}{l}\mathrm{pH} \quad \mathrm{de} \\
\text { Coagulação }\end{array}$} & \multicolumn{2}{|c|}{$\mathrm{Vs} 1=3,0 \mathrm{~cm} / \mathrm{min}$} & \multicolumn{2}{|c|}{$\mathrm{Vs} 2=1,5 \mathrm{~cm} / \mathrm{min}$} & \multicolumn{2}{|c|}{$\mathrm{Vs} 3=1,0 \mathrm{~cm} / \mathrm{min}$} \\
\hline & $\begin{array}{l}\text { Sulfato de } \\
\text { Alumínio } \\
\text { Líquido } \\
\text { Comercial } \\
\end{array}$ & $\begin{array}{l}\text { Hidróxido } \\
\text { de Sódio }\end{array}$ & & $\begin{array}{l}\text { Turbidez } \\
\text { (uT) }\end{array}$ & $\begin{array}{l}\text { Cor Apar. } \\
(\mathrm{uH})\end{array}$ & $\begin{array}{l}\text { Turbidez } \\
\text { (uT) }\end{array}$ & $\begin{array}{l}\text { Cor } \\
\text { Apar. } \\
(\mathrm{uH})\end{array}$ & $\begin{array}{l}\text { Turbidez } \\
\text { (uT) }\end{array}$ & $\begin{array}{l}\text { Cor } \\
\text { Apar. } \\
\text { (uH) }\end{array}$ \\
\hline & $(\mathrm{mg} / \mathrm{L})$ & $(\mathrm{mg} / \mathrm{L})$ & & & & & & & \\
\hline 1 & 300 & 35 & 4,96 & 7,45 & 138 & 3,2 & 55 & 0,96 & 14 \\
\hline 2 & 300 & 55 & 6,77 & 8,77 & 178 & 8,83 & 178 & 8,61 & 178 \\
\hline 3 & 340 & 50 & 5,82 & 7,26 & 135 & 3,28 & 57 & 1,04 & 14 \\
\hline 4 & 340 & 55 & 6,18 & 6,31 & 116 & 3,86 & 72 & 0,84 & 11 \\
\hline 5 & 340 & 60 & 6,71 & 3,66 & 72 & 2,11 & 43 & 1,15 & 25 \\
\hline 6 & 340 & 70 & 7,57 & 8,25 & 171 & 7,78 & 170 & 8,38 & 171 \\
\hline
\end{tabular}


Tabela A.13 - Resultados dos ensaios para construção do diagrama de coagulação

\begin{tabular}{|c|c|c|c|c|c|c|c|c|c|}
\hline \multirow{3}{*}{ Jarro } & Produtos q & límicos & \multirow{3}{*}{$\begin{array}{l}\text { pH de } \\
\text { Coagulação }\end{array}$} & \multicolumn{2}{|c|}{$\mathrm{Vs} 1=3,0 \mathrm{~cm} / \mathrm{min}$} & \multicolumn{2}{|c|}{$\mathrm{Vs} 2=1,5 \mathrm{~cm} / \mathrm{min}$} & \multicolumn{2}{|c|}{$\mathrm{Vs} 3=1,0 \mathrm{~cm} / \mathrm{min}$} \\
\hline & $\begin{array}{l}\text { Alumínio } \\
\text { Líquido } \\
\text { Comercial }\end{array}$ & $\begin{array}{l}\text { Hidróxido } \\
\text { de Sódio }\end{array}$ & & \multirow[t]{2}{*}{$\begin{array}{l}\text { Turbidez } \\
\text { (uT) }\end{array}$} & \multirow[t]{2}{*}{$\begin{array}{l}\text { Cor Apar. } \\
(\mathrm{uH})\end{array}$} & \multirow[t]{2}{*}{$\begin{array}{l}\text { Turbidez } \\
\text { (uT) }\end{array}$} & \multirow[t]{2}{*}{$\begin{array}{l}\text { Cor } \\
\text { Apar. } \\
(\mathrm{uH})\end{array}$} & \multirow[t]{2}{*}{$\begin{array}{l}\text { Turbidez } \\
\text { (uT) }\end{array}$} & \multirow[t]{2}{*}{$\begin{array}{l}\text { Cor } \\
\text { Apar. } \\
\text { (uH) }\end{array}$} \\
\hline & $(\mathrm{mg} / \mathrm{L})$ & $(\mathrm{mg} / \mathrm{L})$ & & & & & & & \\
\hline 1 & 70 & 12 & 6,65 & 6,03 & 163 & 6,35 & 163 & 5,96 & 162 \\
\hline 2 & 160 & 20 & 5,61 & 6,84 & 142 & 5,35 & 114 & 1,63 & 26 \\
\hline 3 & 220 & 40 & 6,64 & 5,28 & 123 & 4,63 & 111 & 2,38 & 64 \\
\hline 4 & 260 & 40 & 6,05 & 6,31 & 130 & 2,49 & 49 & 0,74 & 10 \\
\hline 5 & 260 & 45 & 6,56 & 5,21 & 109 & 3,14 & 66 & 0,77 & 11 \\
\hline 6 & 280 & 35 & 5,1 & 6,82 & 132 & 2,4 & 68 & 0,85 & 11 \\
\hline
\end{tabular}

Tabela A.14 - Resultados dos ensaios para construção do diagrama de coagulação

\begin{tabular}{|c|c|c|c|c|c|c|c|c|c|}
\hline \multirow{3}{*}{ Jarro } & Produtos q & uímicos & \multirow{3}{*}{$\begin{array}{l}\mathrm{pH} \quad \mathrm{de} \\
\text { Coagulação }\end{array}$} & \multicolumn{2}{|c|}{$\mathrm{Vs} 1=3,0 \mathrm{~cm} / \mathrm{min}$} & \multicolumn{2}{|c|}{$\mathrm{Vs} 2=1,5 \mathrm{~cm} / \mathrm{min}$} & \multicolumn{2}{|c|}{$\mathrm{Vs} 3=1,0 \mathrm{~cm} / \mathrm{min}$} \\
\hline & $\begin{array}{l}\text { Alumínio } \\
\text { Líquido } \\
\text { Comercial }\end{array}$ & $\begin{array}{l}\text { Hidróxido } \\
\text { de Sódio }\end{array}$ & & \multirow[t]{2}{*}{$\begin{array}{l}\text { Turbidez } \\
\text { (uT) }\end{array}$} & \multirow[t]{2}{*}{$\begin{array}{l}\text { Cor Apar. } \\
(\mathrm{uH})\end{array}$} & \multirow[t]{2}{*}{$\begin{array}{l}\text { Turbidez } \\
\text { (uT) }\end{array}$} & \multirow[t]{2}{*}{$\begin{array}{l}\text { Cor } \\
\text { Apar. } \\
\text { (uH) }\end{array}$} & \multirow[t]{2}{*}{$\begin{array}{l}\text { Turbidez } \\
\text { (uT) }\end{array}$} & \multirow[t]{2}{*}{$\begin{array}{l}\text { Cor } \\
\text { Apar. } \\
\text { (uH) }\end{array}$} \\
\hline & $(\mathrm{mg} / \mathrm{L})$ & $(\mathrm{mg} / \mathrm{L})$ & & & & & & & \\
\hline 1 & 360 & 30 & 4,69 & 5,78 & 110 & 3 & 58 & 1,33 & 23 \\
\hline 2 & 360 & 45 & 5,06 & 7,85 & 148 & 2,24 & 38 & 0,84 & 9 \\
\hline 3 & 360 & 60 & 6,21 & 7,13 & 134 & 2,53 & 46 & 0,89 & 10 \\
\hline 4 & 400 & 30 & 4,67 & 8,46 & 160 & 4,06 & 76 & 1,28 & 20 \\
\hline 5 & 400 & 45 & 4,94 & 8,08 & 141 & 2,92 & 49 & 0,75 & 8 \\
\hline 6 & 400 & 60 & 5,82 & 8,38 & 157 & 3,14 & 55 & 0,83 & 9 \\
\hline
\end{tabular}

Tabela A.15 - Resultados dos ensaios para construção do diagrama de coagulação

\begin{tabular}{|c|c|c|c|c|c|c|c|c|c|}
\hline \multirow{3}{*}{ Jarro } & Produtos q & dímicos & \multirow{3}{*}{$\begin{array}{l}\mathrm{pH} \quad \mathrm{de} \\
\text { Coagulação }\end{array}$} & \multicolumn{2}{|c|}{$\mathrm{Vs} 1=3,0 \mathrm{~cm} / \mathrm{min}$} & \multicolumn{2}{|c|}{$\mathrm{Vs} 2=1,5 \mathrm{~cm} / \mathrm{min}$} & \multicolumn{2}{|c|}{$\mathrm{Vs} 3=1,0 \mathrm{~cm} / \mathrm{min}$} \\
\hline & $\begin{array}{l}\text { Alumínio } \\
\text { Líquido } \\
\text { Comercial }\end{array}$ & $\begin{array}{l}\text { Hidróxido } \\
\text { de Sódio }\end{array}$ & & \multirow[t]{2}{*}{$\begin{array}{l}\text { Turbidez } \\
\text { (uT) }\end{array}$} & \multirow[t]{2}{*}{$\begin{array}{l}\text { Cor Apar. } \\
(\mathrm{uH})\end{array}$} & \multirow[t]{2}{*}{$\begin{array}{l}\text { Turbidez } \\
\text { (uT) }\end{array}$} & \multirow[t]{2}{*}{$\begin{array}{l}\text { Cor } \\
\text { Apar. } \\
(\mathrm{uH})\end{array}$} & \multirow[t]{2}{*}{$\begin{array}{l}\text { Turbidez } \\
\text { (uT) }\end{array}$} & \multirow[t]{2}{*}{$\begin{array}{l}\text { Cor } \\
\text { Apar. } \\
\text { (uH) }\end{array}$} \\
\hline & $(\mathrm{mg} / \mathrm{L})$ & $(\mathrm{mg} / \mathrm{L})$ & & & & & & & \\
\hline 1 & 360 & 50 & 5,2 & 8,37 & 164 & 1,84 & 32 & 1,07 & 10 \\
\hline 2 & 360 & 55 & 5,79 & 6,98 & 140 & 2,35 & 43 & 0,78 & 6 \\
\hline 3 & 360 & 65 & 6,6 & 6,02 & 124 & 1,54 & 29 & 0,92 & 9 \\
\hline 4 & 320 & 55 & 6,37 & 7,3 & 148 & 1,74 & 32 & 0,66 & 4 \\
\hline 5 & 300 & 47 & 6,12 & 6,18 & 128 & 2,36 & 48 & 0,82 & 6 \\
\hline 6 & 280 & 50 & 6,59 & 5,74 & 125 & 2,03 & 43 & 0,74 & 9 \\
\hline
\end{tabular}


Tabela A.16 - Resultados dos ensaios para construção do diagrama de coagulação

\begin{tabular}{|c|c|c|c|c|c|c|c|c|c|}
\hline \multirow{3}{*}{ Jarro } & Produtos qu & límicos & \multirow{3}{*}{$\begin{array}{l}\mathrm{pH} \quad \mathrm{de} \\
\text { Coagulação }\end{array}$} & \multicolumn{2}{|c|}{$\mathrm{Vs} 1=3,0 \mathrm{~cm} / \mathrm{min}$} & \multicolumn{2}{|c|}{$\mathrm{Vs} 2=1,5 \mathrm{~cm} / \mathrm{min}$} & \multicolumn{2}{|c|}{$\mathrm{Vs} 3=1,0 \mathrm{~cm} / \mathrm{min}$} \\
\hline & $\begin{array}{l}\text { Sulfato de } \\
\text { Alumínio } \\
\text { Líquido } \\
\text { Comercial } \\
\end{array}$ & $\begin{array}{l}\text { Hidróxido } \\
\text { de Sódio }\end{array}$ & & $\begin{array}{l}\text { Turbidez } \\
\text { (uT) }\end{array}$ & $\begin{array}{l}\text { Cor Apar. } \\
(\mathrm{uH})\end{array}$ & $\begin{array}{l}\text { Turbidez } \\
\text { (uT) }\end{array}$ & $\begin{array}{l}\text { Cor } \\
\text { Apar. } \\
(\mathrm{uH})\end{array}$ & $\begin{array}{l}\text { Turbidez } \\
\text { (uT) }\end{array}$ & $\begin{array}{l}\text { Cor } \\
\text { Apar. } \\
(\mathrm{uH})\end{array}$ \\
\hline & $(\mathrm{mg} / \mathrm{L})$ & $(\mathrm{mg} / \mathrm{L})$ & & & & & & & \\
\hline 1 & 260 & 27 & 5,76 & 7,04 & 139 & 2,52 & 43 & 0,9 & 8 \\
\hline 2 & 210 & 30 & 5,87 & 5,64 & 115 & 1,81 & 31 & 0,77 & 6 \\
\hline 3 & 180 & 27 & 6,05 & 4,46 & 98 & 2,25 & 41 & 0,77 & 6 \\
\hline 4 & 180 & 22 & 5,52 & 7,91 & 168 & 6,37 & 135 & 1,4 & 23 \\
\hline 5 & 160 & 27 & 6,57 & 6,89 & 157 & 4,36 & 93 & 1,06 & 19 \\
\hline 6 & 160 & 30 & 6,89 & 7,01 & 168 & 6,78 & 161 & 6,71 & 160 \\
\hline
\end{tabular}

Tabela A.17 - Resultados dos ensaios para construção do diagrama de coagulação

\begin{tabular}{|c|c|c|c|c|c|c|c|c|c|}
\hline \multirow{3}{*}{ Jarro } & Produtos qu & límicos & \multirow{3}{*}{$\begin{array}{l}\text { pH de } \\
\text { Coagulação }\end{array}$} & \multicolumn{2}{|c|}{$\mathrm{Vs} 1=3,0 \mathrm{~cm} / \mathrm{min}$} & \multicolumn{2}{|c|}{$\mathrm{Vs} 2=1,5 \mathrm{~cm} / \mathrm{min}$} & \multicolumn{2}{|c|}{$\mathrm{Vs} 3=1,0 \mathrm{~cm} / \mathrm{min}$} \\
\hline & $\begin{array}{l}\text { Alumínio } \\
\text { Líquido } \\
\text { Comercial }\end{array}$ & $\begin{array}{l}\text { Hidróxido } \\
\text { de Sódio }\end{array}$ & & $\begin{array}{l}\text { Turbidez } \\
\text { (uT) }\end{array}$ & $\begin{array}{l}\text { Cor Apar. } \\
\text { (uH) }\end{array}$ & $\begin{array}{l}\text { Turbidez } \\
\text { (uT) }\end{array}$ & $\begin{array}{l}\text { Cor } \\
\text { Apar. } \\
(\mathrm{uH})\end{array}$ & $\begin{array}{l}\text { Turbidez } \\
\text { (uT) }\end{array}$ & $\begin{array}{l}\text { Cor } \\
\text { Apar. } \\
(\mathrm{uH})\end{array}$ \\
\hline & $(\mathrm{mg} / \mathrm{L})$ & $(\mathrm{mg} / \mathrm{L})$ & & & & & & & \\
\hline 1 & 400 & 50 & 4,77 & 7,13 & 126 & 3,23 & 43 & 0,9 & 8 \\
\hline 2 & 400 & 65 & 5,86 & 7,74 & 144 & 3,09 & 31 & 0,77 & 6 \\
\hline 3 & 400 & 70 & 6,33 & 7,41 & 137 & 2,29 & 41 & 0,74 & 6 \\
\hline 4 & 400 & 75 & 6,93 & 9,98 & 188 & 10,2 & 135 & 1,4 & 23 \\
\hline 5 & 350 & 65 & 6,84 & 7,77 & 157 & 6,39 & 93 & 1,06 & 19 \\
\hline 6 & 300 & 38 & 5 & 6,35 & 121 & 3,39 & 161 & 6,71 & 160 \\
\hline
\end{tabular}

Tabela A.18 - Resultados dos ensaios para construção do diagrama de coagulação

\begin{tabular}{|c|c|c|c|c|c|c|c|c|c|}
\hline \multirow{3}{*}{ Jarro } & \multicolumn{2}{|c|}{ Produtos químicos } & \multirow{3}{*}{$\begin{array}{l}\mathrm{pH} \quad \mathrm{de} \\
\text { Coagulação }\end{array}$} & \multicolumn{2}{|c|}{$\mathrm{Vs} 1=3,0 \mathrm{~cm} / \mathrm{min}$} & \multicolumn{2}{|c|}{$\mathrm{Vs} 2=1,5 \mathrm{~cm} / \mathrm{min}$} & \multicolumn{2}{|c|}{$\mathrm{Vs} 3=1,0 \mathrm{~cm} / \mathrm{min}$} \\
\hline & $\begin{array}{l}\text { Sulfato de } \\
\text { Alumínio } \\
\text { Líquido } \\
\text { Comercial } \\
\end{array}$ & $\begin{array}{l}\text { Hidróxido } \\
\text { de Sódio }\end{array}$ & & $\begin{array}{l}\text { Turbidez } \\
\text { (uT) }\end{array}$ & $\begin{array}{l}\text { Cor Apar. } \\
(\mathrm{uH})\end{array}$ & $\begin{array}{l}\text { Turbidez } \\
\text { (uT) }\end{array}$ & $\begin{array}{l}\text { Cor } \\
\text { Apar. } \\
(\mathrm{uH})\end{array}$ & $\begin{array}{l}\text { Turbidez } \\
\text { (uT) }\end{array}$ & $\begin{array}{l}\text { Cor } \\
\text { Apar. } \\
\text { (uH) }\end{array}$ \\
\hline & $(\mathrm{mg} / \mathrm{L})$ & $(\mathrm{mg} / \mathrm{L})$ & & & & & & & \\
\hline 1 & 220 & 25 & 4,97 & 7,72 & 157 & 5,38 & 113 & 1,52 & 35 \\
\hline 2 & 220 & 35 & 6,15 & 6,67 & 137 & 2,93 & 61 & 0,93 & 18 \\
\hline 3 & 180 & 30 & 6,43 & 4,91 & 103 & 3,71 & 85 & 1,04 & 24 \\
\hline 4 & 160 & 20 & 5,86 & 6,27 & 108 & 2,35 & 49 & 0,95 & 19 \\
\hline 5 & 150 & 20 & 6,03 & 5,76 & 122 & 3,9 & 81 & 1 & 20 \\
\hline 6 & 140 & 15 & 5,57 & 7,54 & 156 & 6,14 & 130 & 2,12 & 48 \\
\hline
\end{tabular}


Tabela A.19 - Resultados dos ensaios para construção do diagrama de coagulação

\begin{tabular}{|c|c|c|c|c|c|c|c|c|c|}
\hline \multirow{3}{*}{ Jarro } & \multicolumn{2}{|c|}{ Produtos químicos } & \multirow{3}{*}{$\begin{array}{l}\mathrm{pH} \quad \mathrm{de} \\
\text { Coagulação }\end{array}$} & \multicolumn{2}{|c|}{$\mathrm{Vs} 1=3,0 \mathrm{~cm} / \mathrm{min}$} & \multicolumn{2}{|c|}{$\mathrm{Vs} 2=1,5 \mathrm{~cm} / \mathrm{min}$} & \multicolumn{2}{|c|}{$\mathrm{Vs} 3=1,0 \mathrm{~cm} / \mathrm{min}$} \\
\hline & $\begin{array}{l}\text { Alumínio } \\
\text { Líquido } \\
\text { Comercial } \\
\end{array}$ & $\begin{array}{l}\text { Hidróxido } \\
\text { de Sódio }\end{array}$ & & $\begin{array}{l}\text { Turbidez } \\
\text { (uT) }\end{array}$ & $\begin{array}{l}\text { Cor Apar. } \\
(\mathrm{uH})\end{array}$ & $\begin{array}{l}\text { Turbidez } \\
\text { (uT) }\end{array}$ & $\begin{array}{l}\text { Cor } \\
\text { Apar. } \\
(\mathrm{uH})\end{array}$ & $\begin{array}{l}\text { Turbidez } \\
\text { (uT) }\end{array}$ & $\begin{array}{l}\text { Cor } \\
\text { Apar. } \\
(\mathrm{uH})\end{array}$ \\
\hline & $(\mathrm{mg} / \mathrm{L})$ & $(\mathrm{mg} / \mathrm{L})$ & & & & & & & \\
\hline 1 & 400 & & 4,55 & 4,99 & 185 & 9,96 & 194 & 9,1 & 169 \\
\hline 2 & 170 & 25 & 6,3 & 5,1 & 108 & 1,9 & 36 & & \\
\hline 3 & 180 & 27 & 6,32 & 4,3 & 91 & 1,76 & 36 & 0,98 & 12 \\
\hline 4 & 200 & 31 & 6,34 & 4,79 & 101 & 1,71 & 31 & 0,79 & 12 \\
\hline 5 & 220 & 32 & 5,94 & 5,55 & 101 & 1,9 & 32 & 0,83 & 9 \\
\hline 6 & 240 & 36 & 6,07 & 4,51 & 89 & 2,45 & 49 & 0,81 & 8 \\
\hline
\end{tabular}




\section{ANEXO B}

Resultados dos ensaios para seleção dos parâmetros de mistura rápida com o Sulfato de Alumínio como coagulante 
Tabela B.1 - Resultados dos ensaios para seleção dos parâmetros de mistura rápida

\begin{tabular}{|c|c|c|c|c|c|c|c|c|c|c|}
\hline \multicolumn{11}{|c|}{ gradiente de mistura rápida $=400 \mathrm{~s}^{-1}$} \\
\hline \multirow{3}{*}{ Jarro } & Produtos qu & límicos & \multirow{3}{*}{$\begin{array}{l}\text { Tempo } \\
\text { de } \\
\text { mistura } \\
\text { rápida } \\
\text { (s) }\end{array}$} & \multirow{3}{*}{$\begin{array}{l}\mathrm{pH} \\
\text { de } \\
\text { Coag }\end{array}$} & $\mathrm{Vs} 1=3,0$ & $\mathrm{~cm} / \mathrm{min}$ & $\begin{array}{l}\mathrm{Vs} 2= \\
\mathrm{cm} / \mathrm{min}\end{array}$ & 1,5 & $\mathrm{Vs} 3=1,0$ & $\mathrm{~cm} / \mathrm{min}$ \\
\hline & $\begin{array}{l}\text { Alumínio } \\
\text { Líquido } \\
\text { Comercial } \\
\end{array}$ & $\begin{array}{l}\text { Hidróxido } \\
\text { de Sódio }\end{array}$ & & & \multirow[t]{2}{*}{$\begin{array}{l}\text { Turbidez } \\
\text { (uT) }\end{array}$} & \multirow[t]{2}{*}{$\begin{array}{l}\text { Cor } \\
\text { Apar. } \\
\text { (uH) }\end{array}$} & \multirow[t]{2}{*}{$\begin{array}{l}\text { Turbidez } \\
\text { (uT) }\end{array}$} & \multirow[t]{2}{*}{$\begin{array}{l}\text { Cor } \\
\text { Apar. } \\
(\mathrm{uH})\end{array}$} & \multirow[t]{2}{*}{$\begin{array}{l}\text { Turbidez } \\
\text { (uT) }\end{array}$} & \multirow[t]{2}{*}{$\begin{array}{l}\text { Cor } \\
\text { Apar. } \\
(\mathrm{uH})\end{array}$} \\
\hline & $(\mathrm{mg} / \mathrm{L})$ & $(\mathrm{mg} / \mathrm{L})$ & & & & & & & & \\
\hline 1 & 180 & 27 & 5 & 6,07 & 5,8 & 111 & 3,44 & 73 & 1,73 & 27 \\
\hline 2 & 180 & 27 & 10 & 6,14 & 4,08 & 82 & 4,02 & 83 & 1,43 & 24 \\
\hline 3 & 180 & 27 & 20 & 6,05 & 7,05 & 134 & 4,45 & 89 & 1,84 & 47 \\
\hline 4 & 180 & 27 & 30 & 6,1 & 7,55 & 155 & 4,89 & 94 & 1,96 & 49 \\
\hline 5 & 180 & 27 & 60 & 6,14 & 7,16 & 146 & 6,05 & 122 & 1,96 & 47 \\
\hline 6 & 180 & 27 & 90 & 6,09 & 8,04 & 163 & 6,32 & 131 & 2,54 & 63 \\
\hline
\end{tabular}

Tabela B.2 - Resultados dos ensaios para seleção dos parâmetros de mistura rápida

\begin{tabular}{|c|c|c|c|c|c|c|c|c|c|c|}
\hline gradie & ente de mistu & Ira rápida $=$ & $00 \mathrm{~s}^{-1}$ & & & & & & & \\
\hline \multirow{3}{*}{ Jarro } & Produtos qu & límicos & \multirow{3}{*}{$\begin{array}{l}\text { Tempo } \\
\text { de } \\
\text { mistura } \\
\text { rápida } \\
\text { (s) }\end{array}$} & \multirow{3}{*}{$\begin{array}{l}\mathrm{pH} \\
\text { de } \\
\text { Coag }\end{array}$} & \multicolumn{2}{|c|}{$\mathrm{Vs} 1=3,0 \mathrm{~cm} / \mathrm{min}$} & \multicolumn{2}{|l|}{$\begin{array}{l}\mathrm{Vs} 2= \\
\mathrm{cm} / \mathrm{min}\end{array}$} & \multicolumn{2}{|c|}{$\mathrm{Vs} 3=1,0 \mathrm{~cm} / \mathrm{min}$} \\
\hline & $\begin{array}{l}\text { Alumínio } \\
\text { Líquido } \\
\text { Comercial } \\
\end{array}$ & $\begin{array}{l}\text { Hidróxido } \\
\text { de Sódio }\end{array}$ & & & \multirow[t]{2}{*}{$\begin{array}{l}\text { Turbidez } \\
\text { (uT) }\end{array}$} & \multirow[t]{2}{*}{$\begin{array}{l}\text { Cor } \\
\text { Apar. } \\
(\mathrm{uH})\end{array}$} & \multirow[t]{2}{*}{$\begin{array}{l}\text { Turbidez } \\
\text { (uT) }\end{array}$} & \multirow[t]{2}{*}{$\begin{array}{l}\text { Cor } \\
\text { Apar. } \\
(\mathrm{uH})\end{array}$} & \multirow[t]{2}{*}{$\begin{array}{l}\text { Turbidez } \\
\text { (uT) }\end{array}$} & \multirow[t]{2}{*}{$\begin{array}{l}\text { Cor } \\
\text { Apar. } \\
(\mathrm{uH})\end{array}$} \\
\hline & $(\mathrm{mg} / \mathrm{L})$ & $(\mathrm{mg} / \mathrm{L})$ & & & & & & & & \\
\hline 1 & 180 & 27 & 5 & 6,06 & 3,98 & 80 & 2 & 35 & 1,02 & 13 \\
\hline 2 & 180 & 27 & 10 & 6,09 & 4,45 & 91 & 3,23 & 68 & 1,36 & 21 \\
\hline 3 & 180 & 27 & 20 & 6,15 & 7,95 & 165 & 4,73 & 96 & 2,14 & 36 \\
\hline 4 & 180 & 27 & 30 & 6,14 & 7,64 & 158 & 5,89 & 111 & 2,74 & 47 \\
\hline 5 & 180 & 27 & 60 & 6,17 & 8,28 & 169 & 6,31 & 130 & 2,55 & 47 \\
\hline 6 & 180 & 27 & 90 & 6,19 & 7,66 & 170 & 4,75 & 100 & 4,04 & 50 \\
\hline
\end{tabular}


Tabela B.3 - Resultados dos ensaios para seleção dos parâmetros de mistura rápida

\begin{tabular}{|c|c|c|c|c|c|c|c|c|c|c|}
\hline \multicolumn{11}{|c|}{ gradiente de mistura rápida $=800 \mathrm{~s}^{-1}$} \\
\hline \multirow{3}{*}{ Jarro } & Produtos qu & uímicos & \multirow{3}{*}{$\begin{array}{l}\text { Tempo } \\
\text { de } \\
\text { mistura } \\
\text { rápida } \\
\text { (s) }\end{array}$} & \multirow{3}{*}{$\begin{array}{l}\mathrm{pH} \\
\mathrm{de} \\
\text { Coag }\end{array}$} & $\mathrm{Vs} 1=3,0$ & $\mathrm{~cm} / \mathrm{min}$ & $\begin{array}{l}\mathrm{Vs} 2= \\
\mathrm{cm} / \mathrm{min}\end{array}$ & 1,5 & $\mathrm{Vs} 3=1,0$ & $\mathrm{~cm} / \mathrm{min}$ \\
\hline & $\begin{array}{l}\text { Alumínio } \\
\text { Líquido } \\
\text { Comercial } \\
\end{array}$ & $\begin{array}{l}\text { Hidróxido } \\
\text { de Sódio }\end{array}$ & & & \multirow[t]{2}{*}{$\begin{array}{l}\text { Turbidez } \\
\text { (uT) }\end{array}$} & \multirow[t]{2}{*}{$\begin{array}{l}\text { Cor } \\
\text { Apar. } \\
(\mathrm{uH})\end{array}$} & \multirow[t]{2}{*}{$\begin{array}{l}\text { Turbidez } \\
\text { (uT) }\end{array}$} & \multirow[t]{2}{*}{$\begin{array}{l}\text { Cor } \\
\text { Apar. } \\
(\mathrm{uH})\end{array}$} & \multirow[t]{2}{*}{$\begin{array}{l}\text { Turbidez } \\
\text { (uT) }\end{array}$} & \multirow[t]{2}{*}{$\begin{array}{l}\text { Cor } \\
\text { Apar. } \\
(\mathrm{uH})\end{array}$} \\
\hline & $(\mathrm{mg} / \mathrm{L})$ & $(\mathrm{mg} / \mathrm{L})$ & & & & & & & & \\
\hline 1 & 180 & 27 & 5 & 6,04 & 2,82 & 96 & 2,55 & 42 & 1,08 & 14 \\
\hline 2 & 180 & 27 & 10 & 6,05 & 3,47 & 66 & 2,8 & 45 & 1,32 & 18 \\
\hline 3 & 180 & 27 & 20 & 5,94 & 8,6 & 169 & 5,17 & 104 & 1,88 & 30 \\
\hline 4 & 180 & 27 & 30 & 5,99 & 8,47 & 167 & 6,57 & 116 & 2,2 & 32 \\
\hline 5 & 180 & 27 & 60 & 6,12 & 7,44 & 157 & 5,86 & 123 & 2,25 & 39 \\
\hline 6 & 180 & 27 & 90 & 6,18 & 8,58 & 170 & 7,52 & 155 & 3,07 & 60 \\
\hline
\end{tabular}

Tabela B.4 - Resultados dos ensaios para seleção dos parâmetros de mistura rápida

\begin{tabular}{|c|c|c|c|c|c|c|c|c|c|c|}
\hline \multicolumn{11}{|c|}{ gradiente de mistura rápida $=1000 \mathrm{~s}^{-1}$} \\
\hline \multirow{3}{*}{ Jarro } & Produtos qu & límicos & \multirow{3}{*}{$\begin{array}{l}\text { Tempo } \\
\text { de } \\
\text { mistura } \\
\text { rápida } \\
\text { (s) }\end{array}$} & \multirow{3}{*}{$\begin{array}{l}\mathrm{pH} \\
\text { de } \\
\text { Coag }\end{array}$} & $\mathrm{Vs} 1=3,0$ & $\mathrm{~cm} / \mathrm{min}$ & $\begin{array}{l}\mathrm{Vs} 2= \\
\mathrm{cm} / \mathrm{min}\end{array}$ & 1,5 & $\mathrm{Vs} 3=1,0$ & $\mathrm{~cm} / \mathrm{min}$ \\
\hline & $\begin{array}{l}\text { Alumínio } \\
\text { Líquido } \\
\text { Comercial }\end{array}$ & $\begin{array}{l}\text { Hidróxido } \\
\text { de Sódio }\end{array}$ & & & \multirow[t]{2}{*}{$\begin{array}{l}\text { Turbidez } \\
\text { (uT) }\end{array}$} & \multirow[t]{2}{*}{$\begin{array}{l}\text { Cor } \\
\text { Apar. } \\
\text { (uH) }\end{array}$} & \multirow[t]{2}{*}{$\begin{array}{l}\text { Turbidez } \\
\text { (uT) }\end{array}$} & \multirow[t]{2}{*}{$\begin{array}{l}\text { Cor } \\
\text { Apar. } \\
(\mathrm{uH})\end{array}$} & \multirow[t]{2}{*}{$\begin{array}{l}\text { Turbidez } \\
\text { (uT) }\end{array}$} & \multirow[t]{2}{*}{$\begin{array}{l}\text { Cor } \\
\text { Apar. } \\
(\mathrm{uH})\end{array}$} \\
\hline & $(\mathrm{mg} / \mathrm{L})$ & $(\mathrm{mg} / \mathrm{L})$ & & & & & & & & \\
\hline 1 & 180 & 27 & 5 & 5,97 & 1,06 & 51 & 1,96 & 28 & 1,18 & 16 \\
\hline 2 & 180 & 27 & 10 & 6,06 & 5,22 & 102 & 2,53 & 46 & 1,13 & 16 \\
\hline 3 & 180 & 27 & 20 & 6,12 & 7,54 & 146 & 2,46 & 46 & 1,38 & 19 \\
\hline 4 & 180 & 27 & 30 & 6,08 & 7,91 & 155 & 6,1 & 115 & 1,96 & 33 \\
\hline 5 & 180 & 27 & 60 & 6,12 & 8,36 & 161 & 6,24 & 121 & 2,26 & 41 \\
\hline 6 & 180 & 27 & 90 & 6,16 & 8,52 & 164 & 7,5 & 146 & 3,13 & 52 \\
\hline
\end{tabular}


Tabela B.5 - Resultados dos ensaios para seleção dos parâmetros de mistura rápida

\begin{tabular}{|c|c|c|c|c|c|c|c|c|c|c|}
\hline \multicolumn{11}{|c|}{ gradiente de mistura rápida $=1200 \mathrm{~s}^{-1}$} \\
\hline \multirow{3}{*}{ Jarro } & Produtos q & aímicos & \multirow{3}{*}{$\begin{array}{l}\text { Tempo } \\
\text { de } \\
\text { mistura } \\
\text { rápida } \\
\text { (s) }\end{array}$} & \multirow{3}{*}{$\begin{array}{l}\mathrm{pH} \\
\mathrm{de} \\
\text { Coag }\end{array}$} & $\mathrm{Vs} 1=3,0$ & $\mathrm{~cm} / \mathrm{min}$ & $\begin{array}{l}\mathrm{Vs} 2= \\
\mathrm{cm} / \mathrm{min}\end{array}$ & 1,5 & $\mathrm{Vs} 3=1,0$ & $\mathrm{~cm} / \mathrm{min}$ \\
\hline & $\begin{array}{l}\text { Alumínio } \\
\text { Líquido } \\
\text { Comercial }\end{array}$ & $\begin{array}{l}\text { Hidróxido } \\
\text { de Sódio }\end{array}$ & & & \multirow[t]{2}{*}{$\begin{array}{l}\text { Turbidez } \\
\text { (uT) }\end{array}$} & \multirow[t]{2}{*}{$\begin{array}{l}\text { Cor } \\
\text { Apar. } \\
(u H)\end{array}$} & \multirow[t]{2}{*}{$\begin{array}{l}\text { Turbidez } \\
\text { (uT) }\end{array}$} & \multirow[t]{2}{*}{$\begin{array}{l}\text { Cor } \\
\text { Apar. } \\
(\mathrm{uH})\end{array}$} & \multirow[t]{2}{*}{$\begin{array}{l}\text { Turbidez } \\
\text { (uT) }\end{array}$} & \multirow[t]{2}{*}{$\begin{array}{l}\text { Cor } \\
\text { Apar. } \\
\text { (uH) }\end{array}$} \\
\hline & $(\mathrm{mg} / \mathrm{L})$ & $(\mathrm{mg} / \mathrm{L})$ & & & & & & & & \\
\hline 1 & 180 & 27 & 5 & 6,05 & 7,85 & 141 & 5,34 & 95 & 1,45 & 22 \\
\hline 2 & 180 & 27 & 10 & 6,09 & 8,43 & 152 & 5,43 & 100 & 2,17 & 35 \\
\hline 3 & 180 & 27 & 20 & 5,98 & 8,39 & 153 & 7,76 & 153 & 4,78 & 97 \\
\hline 4 & 180 & 27 & 30 & 6,06 & 8,37 & 158 & 8,44 & 153 & 3,51 & 65 \\
\hline 5 & 180 & 27 & 60 & 6,03 & 9,93 & 179 & 9,17 & 159 & 3,91 & 71 \\
\hline 6 & 180 & 27 & 90 & 6,19 & 9,52 & 174 & 7,42 & 147 & 3,56 & 69 \\
\hline
\end{tabular}




\section{ANEXO C}

Resultados dos ensaios para seleção dos parâmetros de floculação com o Sulfato de Alumínio como coagulante 
Tabela C.1 - Resultados dos ensaios para seleção dos parâmetros de floculação

\begin{tabular}{|c|c|c|c|c|c|c|c|c|c|c|}
\hline \multicolumn{11}{|c|}{ gradiente de floculação $=10 \mathrm{~s}^{-1}$} \\
\hline \multirow{3}{*}{ Jarro } & Produtos q & aímicos & \multirow{3}{*}{$\begin{array}{l}\text { Tempo de } \\
\text { floculação } \\
\text { (min) }\end{array}$} & \multirow{3}{*}{$\begin{array}{l}\mathrm{pH} \\
\text { de } \\
\text { Coag }\end{array}$} & \multicolumn{2}{|c|}{$\mathrm{Vs} 1=3,0 \mathrm{~cm} / \mathrm{min}$} & \multicolumn{2}{|l|}{$\begin{array}{l}\mathrm{Vs} 2= \\
\mathrm{cm} / \mathrm{min}\end{array}$} & \multicolumn{2}{|c|}{$\mathrm{Vs} 3=1,0 \mathrm{~cm} / \mathrm{min}$} \\
\hline & $\begin{array}{l}\text { Sulfato de } \\
\text { Alumínio } \\
\text { Líquido } \\
\text { Comercial } \\
\end{array}$ & $\begin{array}{l}\text { Hidróxido } \\
\text { de Sódio }\end{array}$ & & & \multirow[t]{2}{*}{$\begin{array}{l}\text { Turbidez } \\
\text { (uT) }\end{array}$} & \multirow[t]{2}{*}{$\begin{array}{l}\text { Cor } \\
\text { Apar. } \\
(\mathrm{uH})\end{array}$} & \multirow[t]{2}{*}{$\begin{array}{l}\text { Turbidez } \\
\text { (uT) }\end{array}$} & \multirow[t]{2}{*}{$\begin{array}{l}\text { Cor } \\
\text { Apar. } \\
(\mathrm{uH})\end{array}$} & \multirow[t]{2}{*}{$\begin{array}{l}\text { Turbidez } \\
\text { (uT) }\end{array}$} & \multirow[t]{2}{*}{$\begin{array}{l}\text { Cor } \\
\text { Apar. } \\
(\mathrm{uH})\end{array}$} \\
\hline & $(\mathrm{mg} / \mathrm{L})$ & $(\mathrm{mg} / \mathrm{L})$ & & & & & & & & \\
\hline 1 & 180 & 27 & 5 & 6,34 & 2,6 & 50 & 1,96 & 39 & 1,65 & 32 \\
\hline 2 & 180 & 27 & 10 & 6,09 & 1,94 & 39 & 1,29 & 22 & 1,18 & 19 \\
\hline 3 & 180 & 27 & 15 & 6,15 & 1,79 & 31 & 1,2 & 18 & 0,99 & 13 \\
\hline 4 & 180 & 27 & 20 & 6,08 & 2,74 & 50 & 1,48 & 23 & 1,26 & 17 \\
\hline 5 & 180 & 27 & 25 & 6,36 & 1,4 & 38 & 1,41 & 22 & 1,33 & 16 \\
\hline 6 & 180 & 27 & 30 & 6,07 & 2,59 & 47 & 1,57 & 28 & 1,08 & 13 \\
\hline
\end{tabular}

Tabela C.2 - Resultados dos ensaios para seleção dos parâmetros de floculação

\begin{tabular}{|c|c|c|c|c|c|c|c|c|c|c|}
\hline \multicolumn{11}{|c|}{ gradiente de floculação $=10 \mathrm{~s}^{-1}$} \\
\hline \multirow{3}{*}{ Jarro } & Produtos q & límicos & \multirow{3}{*}{$\begin{array}{l}\text { Tempo de } \\
\text { floculação } \\
\text { (min) }\end{array}$} & \multirow{3}{*}{$\begin{array}{l}\mathrm{pH} \\
\text { de } \\
\text { Coag }\end{array}$} & $\mathrm{Vs} 1=3,0$ & $\mathrm{~cm} / \mathrm{min}$ & $\begin{array}{l}\mathrm{Vs} 2= \\
\mathrm{cm} / \mathrm{min}\end{array}$ & 1,5 & $\mathrm{Vs} 3=1,0$ & $\mathrm{~cm} / \mathrm{min}$ \\
\hline & $\begin{array}{l}\text { Alumínio } \\
\text { Líquido } \\
\text { Comercial }\end{array}$ & $\begin{array}{l}\text { Hidróxido } \\
\text { de Sódio }\end{array}$ & & & \multirow[t]{2}{*}{$\begin{array}{l}\text { Turbidez } \\
\text { (uT) }\end{array}$} & \multirow[t]{2}{*}{$\begin{array}{l}\text { Cor } \\
\text { Apar. } \\
(\mathrm{uH})\end{array}$} & \multirow[t]{2}{*}{$\begin{array}{l}\text { Turbidez } \\
\text { (uT) }\end{array}$} & \multirow[t]{2}{*}{$\begin{array}{l}\text { Cor } \\
\text { Apar. } \\
(\mathrm{uH})\end{array}$} & \multirow[t]{2}{*}{$\begin{array}{l}\text { Turbidez } \\
\text { (uT) }\end{array}$} & \multirow[t]{2}{*}{$\begin{array}{l}\text { Cor } \\
\text { Apar. } \\
(\mathrm{uH})\end{array}$} \\
\hline & $(\mathrm{mg} / \mathrm{L})$ & $(\mathrm{mg} / \mathrm{L})$ & & & & & & & & \\
\hline 1 & 180 & 27 & 35 & 6,05 & 2,81 & 52 & 1,77 & 28 & 0,93 & 9 \\
\hline 2 & 180 & 27 & 40 & 6,18 & 2,76 & 49 & 1,88 & 29 & 1,81 & 14 \\
\hline 3 & 180 & 27 & 45 & 6,14 & 2,44 & 40 & 2,14 & 29 & 1,37 & 12 \\
\hline 4 & 180 & 27 & 50 & 6,18 & 3,21 & 55 & 2,03 & 31 & 1,23 & 12 \\
\hline 5 & 180 & 27 & 55 & 6,13 & 3,74 & 63 & 1,4 & 26 & 1,12 & 11 \\
\hline 6 & 180 & 27 & 60 & 6,07 & 3,8 & 69 & 2,38 & 36 & 1,35 & 16 \\
\hline
\end{tabular}


Tabela C.3 - Resultados dos ensaios para seleção dos parâmetros de floculação

\begin{tabular}{|c|c|c|c|c|c|c|c|c|c|c|}
\hline \multicolumn{11}{|c|}{ gradiente de floculação $=15 \mathrm{~s}^{-1}$} \\
\hline \multirow{3}{*}{ Jarro } & Produtos qu & límicos & \multirow{3}{*}{$\begin{array}{l}\text { Tempo de } \\
\text { floculação } \\
\text { (min) }\end{array}$} & \multirow{3}{*}{$\begin{array}{l}\mathrm{pH} \\
\mathrm{de} \\
\text { Coag }\end{array}$} & $\mathrm{Vs} 1=3,0$ & $\mathrm{~cm} / \mathrm{min}$ & $\begin{array}{l}\mathrm{Vs} 2= \\
\mathrm{cm} / \mathrm{min}\end{array}$ & 1,5 & $\mathrm{Vs} 3=1,0$ & $\mathrm{~cm} / \mathrm{min}$ \\
\hline & $\begin{array}{l}\text { Sulfato de } \\
\text { Alumínio } \\
\text { Líquido } \\
\text { Comercial } \\
\end{array}$ & $\begin{array}{l}\text { Hidróxido } \\
\text { de Sódio }\end{array}$ & & & \multirow[t]{2}{*}{$\begin{array}{l}\text { Turbidez } \\
\text { (uT) }\end{array}$} & \multirow[t]{2}{*}{$\begin{array}{l}\text { Cor } \\
\text { Apar. } \\
(\mathrm{uH})\end{array}$} & \multirow[t]{2}{*}{$\begin{array}{l}\text { Turbidez } \\
\text { (uT) }\end{array}$} & \multirow[t]{2}{*}{$\begin{array}{l}\text { Cor } \\
\text { Apar. } \\
(\mathrm{uH})\end{array}$} & \multirow[t]{2}{*}{$\begin{array}{l}\text { Turbidez } \\
\text { (uT) }\end{array}$} & \multirow[t]{2}{*}{$\begin{array}{l}\text { Cor } \\
\text { Apar. } \\
(\mathrm{uH})\end{array}$} \\
\hline & $(\mathrm{mg} / \mathrm{L})$ & $(\mathrm{mg} / \mathrm{L})$ & & & & & & & & \\
\hline 1 & 180 & 27 & 5 & 5,99 & 3,01 & 57 & 2,81 & 54 & 2,11 & 32 \\
\hline 2 & 180 & 27 & 10 & 6,07 & 2,27 & 41 & 1,47 & 27 & 1,05 & 14 \\
\hline 3 & 180 & 27 & 15 & 6,01 & 2,41 & 43 & 1,73 & 29 & 1,06 & 12 \\
\hline 4 & 180 & 27 & 20 & 6,08 & 3,49 & 65 & 1,58 & 26 & 1,02 & 12 \\
\hline 5 & 180 & 27 & 25 & 6,17 & 2,8 & 56 & 1,32 & 18 & 0,88 & 12 \\
\hline 6 & 180 & 27 & 30 & 6,11 & 3,78 & 80 & 2,15 & 40 & 1,03 & 15 \\
\hline
\end{tabular}

Tabela C.4 - Resultados dos ensaios para seleção dos parâmetros de floculação

\begin{tabular}{|c|c|c|c|c|c|c|c|c|c|c|}
\hline \multicolumn{11}{|c|}{ gradiente de floculação $=15 \mathrm{~s}^{-1}$} \\
\hline \multirow{3}{*}{ Jarro } & Produtos q & límicos & \multirow{3}{*}{$\begin{array}{l}\text { Tempo de } \\
\text { floculação } \\
\text { (min) }\end{array}$} & \multirow{3}{*}{$\begin{array}{l}\mathrm{pH} \\
\text { de } \\
\text { Coag }\end{array}$} & $\mathrm{Vs} 1=3,0$ & $\mathrm{~cm} / \mathrm{min}$ & $\begin{array}{l}\mathrm{Vs} 2= \\
\mathrm{cm} / \mathrm{min}\end{array}$ & 1,5 & $\mathrm{Vs} 3=1,0$ & $\mathrm{~cm} / \mathrm{min}$ \\
\hline & $\begin{array}{l}\text { Alumínio } \\
\text { Líquido } \\
\text { Comercial }\end{array}$ & $\begin{array}{l}\text { Hidróxido } \\
\text { de Sódio }\end{array}$ & & & \multirow[t]{2}{*}{$\begin{array}{l}\text { Turbidez } \\
\text { (uT) }\end{array}$} & \multirow[t]{2}{*}{$\begin{array}{l}\text { Cor } \\
\text { Apar. } \\
(\mathrm{uH})\end{array}$} & \multirow[t]{2}{*}{$\begin{array}{l}\text { Turbidez } \\
\text { (uT) }\end{array}$} & \multirow[t]{2}{*}{$\begin{array}{l}\text { Cor } \\
\text { Apar. } \\
(\mathrm{uH})\end{array}$} & \multirow[t]{2}{*}{$\begin{array}{l}\text { Turbidez } \\
\text { (uT) }\end{array}$} & \multirow[t]{2}{*}{$\begin{array}{l}\text { Cor } \\
\text { Apar. } \\
(\mathrm{uH})\end{array}$} \\
\hline & $(\mathrm{mg} / \mathrm{L})$ & $(\mathrm{mg} / \mathrm{L})$ & & & & & & & & \\
\hline 1 & 180 & 27 & 35 & 6,18 & 3,39 & 67 & 1,6 & 24 & 1,11 & 14 \\
\hline 2 & 180 & 27 & 40 & 6,09 & 4,51 & 91 & 2,59 & 42 & 1,1 & 13 \\
\hline 3 & 180 & 27 & 45 & 6,12 & 3 & 65 & 2,74 & 51 & 1,14 & 15 \\
\hline 4 & 180 & 27 & 50 & 6,16 & 3,47 & 74 & 3,01 & 55 & 1,17 & 19 \\
\hline 5 & 180 & 27 & 55 & 6,09 & 4,24 & 77 & 2,26 & 42 & 1,35 & 17 \\
\hline 6 & 180 & 27 & 60 & 6,22 & 5,12 & 113 & 3 & 54 & 1,55 & 23 \\
\hline
\end{tabular}


Tabela C.5 - Resultados dos ensaios para seleção dos parâmetros de floculação

\begin{tabular}{|c|c|c|c|c|c|c|c|c|c|c|}
\hline \multicolumn{11}{|c|}{ gradiente de floculação $=20 \mathrm{~s}^{-1}$} \\
\hline \multirow{3}{*}{ Jarro } & Produtos qu & límicos & \multirow{3}{*}{$\begin{array}{l}\text { Tempo de } \\
\text { floculação } \\
\text { (min) }\end{array}$} & \multirow{3}{*}{$\begin{array}{l}\mathrm{pH} \\
\text { de } \\
\text { Coag }\end{array}$} & $\mathrm{Vs} 1=3,0$ & $\mathrm{~cm} / \mathrm{min}$ & $\begin{array}{l}\mathrm{Vs} 2= \\
\mathrm{cm} / \mathrm{min}\end{array}$ & 1,5 & $\mathrm{Vs} 3=1,0$ & $\mathrm{~cm} / \mathrm{min}$ \\
\hline & $\begin{array}{l}\text { Sulfato de } \\
\text { Alumínio } \\
\text { Líquido } \\
\text { Comercial } \\
\end{array}$ & $\begin{array}{l}\text { Hidróxido } \\
\text { de Sódio }\end{array}$ & & & \multirow[t]{2}{*}{$\begin{array}{l}\text { Turbidez } \\
\text { (uT) }\end{array}$} & \multirow[t]{2}{*}{$\begin{array}{l}\text { Cor } \\
\text { Apar. } \\
(\mathrm{uH})\end{array}$} & \multirow[t]{2}{*}{$\begin{array}{l}\text { Turbidez } \\
\text { (uT) }\end{array}$} & \multirow[t]{2}{*}{$\begin{array}{l}\text { Cor } \\
\text { Apar. } \\
(\mathrm{uH})\end{array}$} & \multirow[t]{2}{*}{$\begin{array}{l}\text { Turbidez } \\
\text { (uT) }\end{array}$} & \multirow[t]{2}{*}{$\begin{array}{l}\text { Cor } \\
\text { Apar. } \\
(\mathrm{uH})\end{array}$} \\
\hline & $(\mathrm{mg} / \mathrm{L})$ & $(\mathrm{mg} / \mathrm{L})$ & & & & & & & & \\
\hline 1 & 180 & 27 & 5 & 6,01 & 3,59 & 70 & 2,57 & 48 & 1,56 & 30 \\
\hline 2 & 180 & 27 & 10 & 6,01 & 3,03 & 53 & 1,95 & 35 & 1,12 & 18 \\
\hline 3 & 180 & 27 & 15 & 6,06 & 3,17 & 65 & 2,28 & 48 & 1,11 & 19 \\
\hline 4 & 180 & 27 & 20 & 6,12 & 4,07 & 83 & 2,78 & 56 & 1,23 & 21 \\
\hline 5 & 180 & 27 & 25 & 5,99 & 4,62 & 101 & 3,03 & 60 & 1,32 & 22 \\
\hline 6 & 180 & 27 & 30 & 6,02 & 5,02 & 111 & 3,68 & 69 & 1,6 & 28 \\
\hline
\end{tabular}

Tabela C.6 - Resultados dos ensaios para seleção dos parâmetros de floculação

\begin{tabular}{|c|c|c|c|c|c|c|c|c|c|c|}
\hline gradie & nte de flocu & lação $=20$ & & & & & & & & \\
\hline \multirow{3}{*}{ Jarro } & Produtos q & límicos & \multirow{3}{*}{$\begin{array}{l}\text { Tempo de } \\
\text { floculação } \\
\text { (min) }\end{array}$} & \multirow{3}{*}{$\begin{array}{l}\mathrm{pH} \\
\mathrm{de} \\
\text { Coag }\end{array}$} & \multicolumn{2}{|c|}{$\mathrm{Vs} 1=3,0 \mathrm{~cm} / \mathrm{min}$} & \multicolumn{2}{|l|}{$\begin{array}{l}\mathrm{Vs} 2= \\
\mathrm{cm} / \mathrm{min}\end{array}$} & \multicolumn{2}{|c|}{$\mathrm{Vs} 3=1,0 \mathrm{~cm} / \mathrm{min}$} \\
\hline & $\begin{array}{l}\text { Sulfato de } \\
\text { Alumínio } \\
\text { Líquido } \\
\text { Comercial } \\
\end{array}$ & $\begin{array}{l}\text { Hidróxido } \\
\text { de Sódio }\end{array}$ & & & \multirow[t]{2}{*}{$\begin{array}{l}\text { Turbidez } \\
\text { (uT) }\end{array}$} & \multirow[t]{2}{*}{$\begin{array}{l}\text { Cor } \\
\text { Apar. } \\
\text { (uH) }\end{array}$} & \multirow[t]{2}{*}{$\begin{array}{l}\text { Turbidez } \\
\text { (uT) }\end{array}$} & \multirow[t]{2}{*}{$\begin{array}{l}\text { Cor } \\
\text { Apar. } \\
\text { (uH) }\end{array}$} & \multirow[t]{2}{*}{$\begin{array}{l}\text { Turbidez } \\
\text { (uT) }\end{array}$} & \multirow[t]{2}{*}{$\begin{array}{l}\text { Cor } \\
\text { Apar. } \\
(\mathrm{uH})\end{array}$} \\
\hline & $(\mathrm{mg} / \mathrm{L})$ & $(\mathrm{mg} / \mathrm{L})$ & & & & & & & & \\
\hline 1 & 180 & 27 & 35 & 6,14 & 4,56 & 88 & 3,41 & 60 & 1,72 & 26 \\
\hline 2 & 180 & 27 & 40 & 6,16 & 5,17 & 100 & 3,22 & 66 & 1,35 & 23 \\
\hline 3 & 180 & 27 & 45 & 6,09 & 4,13 & 88 & 3,1 & 61 & 1,39 & 23 \\
\hline 4 & 180 & 27 & 50 & 6,05 & 5,49 & 119 & 2,78 & 50 & 1,65 & 27 \\
\hline 5 & 180 & 27 & 55 & 6,1 & 5,05 & 98 & 3,95 & 74 & 1,59 & 28 \\
\hline 6 & 180 & 27 & 60 & 6,12 & 7,05 & 134 & 3,76 & 73 & 1,74 & 29 \\
\hline
\end{tabular}


Tabela C.7 - Resultados dos ensaios para seleção dos parâmetros de floculação

\begin{tabular}{|c|c|c|c|c|c|c|c|c|c|c|}
\hline \multicolumn{11}{|c|}{ gradiente de floculação $=25 \mathrm{~s}^{-1}$} \\
\hline \multirow{3}{*}{ Jarro } & Produtos qu & límicos & \multirow{3}{*}{$\begin{array}{l}\text { Tempo de } \\
\text { floculação } \\
\text { (min) }\end{array}$} & \multirow{3}{*}{$\begin{array}{l}\mathrm{pH} \\
\mathrm{de} \\
\text { Coag }\end{array}$} & $\mathrm{Vs} 1=3,0$ & $\mathrm{~cm} / \mathrm{min}$ & $\begin{array}{l}\mathrm{Vs} 2= \\
\mathrm{cm} / \mathrm{min}\end{array}$ & $\overline{1,5}$ & $\mathrm{Vs} 3=1,0$ & $\mathrm{~cm} / \mathrm{min}$ \\
\hline & $\begin{array}{l}\text { Sulfato de } \\
\text { Alumínio } \\
\text { Líquido } \\
\text { Comercial } \\
\end{array}$ & $\begin{array}{l}\text { Hidróxido } \\
\text { de Sódio }\end{array}$ & & & \multirow[t]{2}{*}{$\begin{array}{l}\text { Turbidez } \\
\text { (uT) }\end{array}$} & \multirow[t]{2}{*}{$\begin{array}{l}\text { Cor } \\
\text { Apar. } \\
(\mathrm{uH})\end{array}$} & \multirow[t]{2}{*}{$\begin{array}{l}\text { Turbidez } \\
\text { (uT) }\end{array}$} & \multirow[t]{2}{*}{$\begin{array}{l}\text { Cor } \\
\text { Apar. } \\
(\mathrm{uH})\end{array}$} & \multirow[t]{2}{*}{$\begin{array}{l}\text { Turbidez } \\
\text { (uT) }\end{array}$} & \multirow[t]{2}{*}{$\begin{array}{l}\text { Cor } \\
\text { Apar. } \\
(\mathrm{uH})\end{array}$} \\
\hline & $(\mathrm{mg} / \mathrm{L})$ & $(\mathrm{mg} / \mathrm{L})$ & & & & & & & & \\
\hline 1 & 180 & 27 & 5 & 6,12 & 3,25 & 48 & 2,02 & 41 & 1,36 & 24 \\
\hline 2 & 180 & 27 & 10 & 6,25 & 2,91 & 54 & 1,95 & 44 & 1,15 & 15 \\
\hline 3 & 180 & 27 & 15 & 6,14 & 2,86 & 57 & 2,03 & 35 & 1,25 & 16 \\
\hline 4 & 180 & 27 & 20 & 6,28 & 2,99 & 64 & 2,57 & 46 & 1,36 & 17 \\
\hline 5 & 180 & 27 & 25 & 6,19 & 4,51 & 88 & 2,39 & 40 & 1,44 & 21 \\
\hline 6 & 180 & 27 & 30 & 6,12 & 4,93 & 107 & 2,63 & 48 & 1,41 & 21 \\
\hline
\end{tabular}

Tabela C.8 - Resultados dos ensaios para seleção dos parâmetros de floculação

\begin{tabular}{|c|c|c|c|c|c|c|c|c|c|c|}
\hline$\overline{\text { grad }}$ & te de flocu & lação $=25$ & & & & & & & & \\
\hline \multirow{3}{*}{ Jarro } & Produtos qu & límicos & \multirow{3}{*}{$\begin{array}{l}\text { Tempo de } \\
\text { floculação } \\
\text { (min) }\end{array}$} & \multirow{3}{*}{$\begin{array}{l}\mathrm{pH} \\
\mathrm{de} \\
\text { Coag }\end{array}$} & \multicolumn{2}{|c|}{$\mathrm{Vs} 1=3,0 \mathrm{~cm} / \mathrm{min}$} & \multicolumn{2}{|l|}{$\begin{array}{l}\mathrm{Vs} 2= \\
\mathrm{cm} / \mathrm{min}\end{array}$} & \multicolumn{2}{|c|}{$\mathrm{Vs} 3=1,0 \mathrm{~cm} / \mathrm{min}$} \\
\hline & $\begin{array}{l}\text { Alumínio } \\
\text { Líquido } \\
\text { Comercial }\end{array}$ & $\begin{array}{l}\text { Hidróxido } \\
\text { de Sódio }\end{array}$ & & & \multirow[t]{2}{*}{$\begin{array}{l}\text { Turbidez } \\
\text { (uT) }\end{array}$} & \multirow[t]{2}{*}{$\begin{array}{l}\text { Cor } \\
\text { Apar. } \\
\text { (uH) }\end{array}$} & \multirow[t]{2}{*}{$\begin{array}{l}\text { Turbidez } \\
\text { (uT) }\end{array}$} & \multirow[t]{2}{*}{$\begin{array}{l}\text { Cor } \\
\text { Apar. } \\
(\mathrm{uH})\end{array}$} & \multirow[t]{2}{*}{$\begin{array}{l}\text { Turbidez } \\
\text { (uT) }\end{array}$} & \multirow[t]{2}{*}{$\begin{array}{l}\text { Cor } \\
\text { Apar. } \\
(\mathrm{uH})\end{array}$} \\
\hline & $(\mathrm{mg} / \mathrm{L})$ & $(\mathrm{mg} / \mathrm{L})$ & & & & & & & & \\
\hline 1 & 180 & 27 & 35 & 6,07 & 9,3 & 164 & 7,55 & 125 & 3,14 & 52 \\
\hline 2 & 180 & 27 & 40 & 6,12 & 9,02 & 170 & 7,82 & 143 & 2,84 & 47 \\
\hline 3 & 180 & 27 & 45 & 6,02 & 9,55 & 178 & 7,59 & 151 & 3,76 & 60 \\
\hline 4 & 180 & 27 & 50 & 6,13 & 8,6 & 172 & 8,28 & 148 & 3 & 52 \\
\hline 5 & 180 & 27 & 55 & 6,15 & 7,75 & 155 & 6,31 & 116 & 2,92 & 45 \\
\hline 6 & 180 & 27 & 60 & 6,09 & 7,95 & 158 & 6,37 & 117 & 2,39 & 40 \\
\hline
\end{tabular}


Tabela C.9 - Resultados dos ensaios para seleção dos parâmetros de floculação

\begin{tabular}{|c|c|c|c|c|c|c|c|c|c|c|}
\hline \multicolumn{11}{|c|}{ gradiente de floculação $=30 \mathrm{~s}^{-1}$} \\
\hline \multirow{3}{*}{ Jarro } & Produtos q & aímicos & \multirow{3}{*}{$\begin{array}{l}\text { Tempo de } \\
\text { floculação } \\
\text { (min) }\end{array}$} & \multirow{3}{*}{$\begin{array}{l}\mathrm{pH} \\
\mathrm{de} \\
\text { Coag }\end{array}$} & \multicolumn{2}{|c|}{$\mathrm{Vs} 1=3,0 \mathrm{~cm} / \mathrm{min}$} & \multicolumn{2}{|l|}{$\begin{array}{l}\mathrm{Vs} 2= \\
\mathrm{cm} / \mathrm{min}\end{array}$} & \multicolumn{2}{|c|}{$\mathrm{Vs} 3=1,0 \mathrm{~cm} / \mathrm{min}$} \\
\hline & $\begin{array}{l}\text { Sulfato de } \\
\text { Alumínio } \\
\text { Líquido } \\
\text { Comercial } \\
\end{array}$ & $\begin{array}{l}\text { Hidróxido } \\
\text { de Sódio }\end{array}$ & & & $\begin{array}{l}\text { Turbidez } \\
\text { (uT) }\end{array}$ & $\begin{array}{l}\text { Cor } \\
\text { Apar. } \\
\text { (uH) }\end{array}$ & $\begin{array}{l}\text { Turbidez } \\
\text { (uT) }\end{array}$ & $\begin{array}{l}\text { Cor } \\
\text { Apar. } \\
(\mathrm{uH})\end{array}$ & $\begin{array}{l}\text { Turbidez } \\
\text { (uT) }\end{array}$ & $\begin{array}{l}\text { Cor } \\
\text { Apar. } \\
(\mathrm{uH})\end{array}$ \\
\hline & $(\mathrm{mg} / \mathrm{L})$ & $(\mathrm{mg} / \mathrm{L})$ & & & & & & & & \\
\hline 1 & 180 & 27 & 5 & 6,08 & 5,05 & 92 & 2,77 & 56 & 1,63 & 33 \\
\hline 2 & 180 & 27 & 10 & 6,17 & 4,28 & 90 & 2,43 & 50 & 1,52 & 23 \\
\hline 3 & 180 & 27 & 15 & 6,12 & 5,32 & 112 & 2,8 & 51 & 1,13 & 21 \\
\hline 4 & 180 & 27 & 20 & 6,07 & 5,21 & 103 & 3,8 & 76 & 1,62 & 29 \\
\hline 5 & 180 & 27 & 25 & 6,14 & 6,71 & 141 & 3,35 & 69 & 1,63 & 31 \\
\hline 6 & 180 & 27 & 30 & 6,03 & 6,71 & 146 & 3,58 & 70 & 2,34 & 39 \\
\hline
\end{tabular}

Tabela C.10 - Resultados dos ensaios para seleção dos parâmetros de floculação

\begin{tabular}{|c|c|c|c|c|c|c|c|c|c|c|}
\hline \multicolumn{11}{|c|}{ gradiente de floculação $=30 \mathrm{~s}^{-1}$} \\
\hline \multirow{3}{*}{ Jarro } & Produtos q & límicos & \multirow{3}{*}{$\begin{array}{l}\text { Tempo de } \\
\text { floculação } \\
\text { (min) }\end{array}$} & \multirow{3}{*}{$\begin{array}{l}\mathrm{pH} \\
\text { de } \\
\text { Coag }\end{array}$} & $\mathrm{Vs} 1=3,0$ & $\mathrm{~cm} / \mathrm{min}$ & $\begin{array}{l}\mathrm{Vs} 2= \\
\mathrm{cm} / \mathrm{min}\end{array}$ & 1,5 & $\mathrm{Vs} 3=1,0$ & $\mathrm{~cm} / \mathrm{min}$ \\
\hline & $\begin{array}{l}\text { Alumínio } \\
\text { Líquido } \\
\text { Comercial }\end{array}$ & $\begin{array}{l}\text { Hidróxido } \\
\text { de Sódio }\end{array}$ & & & \multirow[t]{2}{*}{$\begin{array}{l}\text { Turbidez } \\
\text { (uT) }\end{array}$} & \multirow[t]{2}{*}{$\begin{array}{l}\text { Cor } \\
\text { Apar. } \\
(\mathrm{uH})\end{array}$} & \multirow[t]{2}{*}{$\begin{array}{l}\text { Turbidez } \\
\text { (uT) }\end{array}$} & \multirow[t]{2}{*}{$\begin{array}{l}\text { Cor } \\
\text { Apar. } \\
(\mathrm{uH})\end{array}$} & \multirow[t]{2}{*}{$\begin{array}{l}\text { Turbidez } \\
\text { (uT) }\end{array}$} & \multirow[t]{2}{*}{$\begin{array}{l}\text { Cor } \\
\text { Apar. } \\
(\mathrm{uH})\end{array}$} \\
\hline & $(\mathrm{mg} / \mathrm{L})$ & $(\mathrm{mg} / \mathrm{L})$ & & & & & & & & \\
\hline 1 & 180 & 27 & 35 & 6,07 & 6,69 & 117 & 3,81 & 67 & 2,56 & 42 \\
\hline 2 & 180 & 27 & 40 & 6,07 & 6,22 & 121 & 5,11 & 94 & 2,27 & 40 \\
\hline 3 & 180 & 27 & 45 & 5,97 & 8,44 & 161 & 5,05 & 94 & 2,49 & 43 \\
\hline 4 & 180 & 27 & 50 & 6,09 & 7,57 & 150 & 5,19 & 92 & 2,55 & 41 \\
\hline 5 & 180 & 27 & 55 & 5,93 & 7,69 & 147 & 7,2 & 114 & 2,72 & 43 \\
\hline 6 & 180 & 27 & 60 & 5,99 & 8,89 & 159 & 7,42 & 118 & 3,28 & 52 \\
\hline
\end{tabular}


Tabela C.11 - Resultados dos ensaios para seleção dos parâmetros de floculação

\begin{tabular}{|c|c|c|c|c|c|c|c|c|c|c|}
\hline \multicolumn{11}{|c|}{ gradiente de floculação $=40 \mathrm{~s}^{-1}$} \\
\hline \multirow{3}{*}{ Jarro } & Produtos q & uímicos & \multirow{3}{*}{$\begin{array}{l}\text { Tempo de } \\
\text { floculação } \\
\text { (min) }\end{array}$} & \multirow{3}{*}{$\begin{array}{l}\mathrm{pH} \\
\mathrm{de} \\
\text { Coag }\end{array}$} & \multicolumn{2}{|c|}{$\mathrm{Vs} 1=3,0 \mathrm{~cm} / \mathrm{min}$} & \multicolumn{2}{|l|}{$\begin{array}{l}\mathrm{Vs} 2= \\
\mathrm{cm} / \mathrm{min}\end{array}$} & \multicolumn{2}{|c|}{$\mathrm{Vs} 3=1,0 \mathrm{~cm} / \mathrm{min}$} \\
\hline & $\begin{array}{l}\text { Sulfato de } \\
\text { Alumínio } \\
\text { Líquido } \\
\text { Comercial } \\
\end{array}$ & $\begin{array}{l}\text { Hidróxido } \\
\text { de Sódio }\end{array}$ & & & $\begin{array}{l}\text { Turbidez } \\
\text { (uT) }\end{array}$ & $\begin{array}{l}\text { Cor } \\
\text { Apar. } \\
(\mathrm{uH})\end{array}$ & $\begin{array}{l}\text { Turbidez } \\
\text { (uT) }\end{array}$ & $\begin{array}{l}\text { Cor } \\
\text { Apar. } \\
\text { (uH) }\end{array}$ & $\begin{array}{l}\text { Turbidez } \\
\text { (uT) }\end{array}$ & $\begin{array}{l}\text { Cor } \\
\text { Apar. } \\
(\mathrm{uH})\end{array}$ \\
\hline & $(\mathrm{mg} / \mathrm{L})$ & $(\mathrm{mg} / \mathrm{L})$ & & & & & & & & \\
\hline 1 & 180 & 27 & 5 & 6,06 & 5,15 & 90 & 2,78 & 60 & 1,9 & 37 \\
\hline 2 & 180 & 27 & 10 & 6,08 & 5,19 & 117 & 2,54 & 54 & 1,68 & 30 \\
\hline 3 & 180 & 27 & 15 & 6,02 & 5,82 & 127 & 3,35 & 69 & 1,69 & 28 \\
\hline 4 & 180 & 27 & 20 & 6,05 & 4,9 & 101 & 3,64 & 78 & 2,27 & 38 \\
\hline 5 & 180 & 27 & 25 & 5,93 & 6,98 & 139 & 5,05 & 97 & 2,08 & 35 \\
\hline 6 & 180 & 27 & 30 & 5,94 & 7,5 & 147 & 5,92 & 124 & 2,4 & 42 \\
\hline
\end{tabular}


Tabela C.12 - Resultados dos ensaios para seleção dos parâmetros de floculação

\begin{tabular}{|c|c|c|c|c|c|c|c|c|c|c|}
\hline \multicolumn{11}{|c|}{ gradiente de floculação $=40 \mathrm{~s}^{-1}$} \\
\hline \multirow{3}{*}{ Jarro } & Produtos q & uímicos & \multirow{3}{*}{$\begin{array}{l}\text { Tempo de } \\
\text { floculação } \\
\text { (min) }\end{array}$} & \multirow{3}{*}{$\begin{array}{l}\mathrm{pH} \\
\text { de } \\
\text { Coag }\end{array}$} & \multicolumn{2}{|c|}{$\mathrm{Vs} 1=3,0 \mathrm{~cm} / \mathrm{min}$} & \multicolumn{2}{|l|}{$\begin{array}{l}\mathrm{Vs} 2= \\
\mathrm{cm} / \mathrm{min}\end{array}$} & \multicolumn{2}{|c|}{$\mathrm{Vs} 3=1,0 \mathrm{~cm} / \mathrm{min}$} \\
\hline & $\begin{array}{l}\text { Sulfato de } \\
\text { Alumínio } \\
\text { Líquido } \\
\text { Comercial }\end{array}$ & $\begin{array}{l}\text { Hidróxido } \\
\text { de Sódio }\end{array}$ & & & $\begin{array}{l}\text { Turbidez } \\
\text { (uT) }\end{array}$ & $\begin{array}{l}\text { Cor } \\
\text { Apar. } \\
\text { (uH) }\end{array}$ & $\begin{array}{l}\text { Turbidez } \\
\text { (uT) }\end{array}$ & $\begin{array}{l}\text { Cor } \\
\text { Apar. } \\
(\mathrm{uH})\end{array}$ & $\begin{array}{l}\text { Turbidez } \\
\text { (uT) }\end{array}$ & $\begin{array}{l}\text { Cor } \\
\text { Apar. } \\
\text { (uH) }\end{array}$ \\
\hline & $(\mathrm{mg} / \mathrm{L})$ & $(\mathrm{mg} / \mathrm{L})$ & & & & & & & & \\
\hline 1 & 180 & 27 & 35 & 6,12 & 6,54 & 96 & 3,85 & 99 & 2,94 & 45 \\
\hline 2 & 180 & 27 & 40 & 6,15 & 5,89 & 120 & 5,07 & 123 & 3,05 & 45 \\
\hline 3 & 180 & 27 & 45 & 6,04 & 7,84 & 165 & 5,43 & 113 & 3,01 & 44 \\
\hline 4 & 180 & 27 & 50 & 6,01 & 6,74 & 143 & 5,32 & 107 & 3,39 & 49 \\
\hline 5 & 180 & 27 & 55 & 5,98 & 6,32 & 155 & 7,63 & 117 & 3,21 & 50 \\
\hline 6 & 180 & 27 & 60 & 6,1 & 8,95 & 167 & 8,77 & 135 & 3,67 & 45 \\
\hline
\end{tabular}




\section{ANEXO D}

Resultados dos ensaios de refloculação com o Sulfato de Alumínio como

coagulante 
Tabela D.1 - Resultados dos ensaios de refloculação, Grf $10 \mathrm{~s}^{-1}$, Gruptura $=50 \mathrm{~s}^{-1}$, e variados os tempos de refloculação

\begin{tabular}{|c|c|c|c|c|c|c|c|c|c|c|c|c|c|c|c|c|}
\hline \multirow[b]{2}{*}{ Jarro } & \multicolumn{2}{|c|}{ Produtos químicos } & \multirow[b]{2}{*}{$\begin{array}{l}\text { Tempo de } \\
\text { refloculação } \\
(\min )\end{array}$} & \multirow[b]{2}{*}{$\begin{array}{l}\mathrm{pH} \\
\mathrm{de} \\
\text { Coag }\end{array}$} & \multicolumn{2}{|l|}{$\begin{array}{l}\mathrm{Vs} 1= \\
\mathrm{cm} / \mathrm{mir}\end{array}$} & \multicolumn{2}{|c|}{$\begin{array}{l}\begin{array}{l}\mathrm{Vs} 1= \\
\mathrm{cm} / \mathrm{min}\end{array} \\
\end{array}$} & \multicolumn{2}{|c|}{$\begin{array}{l}\mathrm{Vs} 1=1,38 \\
\mathrm{~cm} / \mathrm{min}\end{array}$} & \multicolumn{2}{|c|}{$\begin{array}{l}\text { Vs1 } 1=0,97 \\
\mathrm{~cm} / \mathrm{min}\end{array}$} & \multicolumn{2}{|c|}{$\begin{array}{ll}\begin{array}{l}\text { Vs1 } 1= \\
\mathrm{cm} / \mathrm{min}\end{array} & 0,6 \\
\end{array}$} & \multicolumn{2}{|c|}{$\begin{array}{l}\mathrm{Vs} 1= \\
\mathrm{cm} / \mathrm{min}\end{array}$} \\
\hline & $\begin{array}{l}\text { Sulfato de } \\
\text { Alumínio } \\
\text { Líquido } \\
\text { Comercial } \\
(\mathrm{mg} / \mathrm{L})\end{array}$ & $\begin{array}{l}\text { Hidróxi } \\
\text { do de } \\
\text { Sódio }\end{array}$ & & & $\begin{array}{l}\text { Turbi } \\
\text { dez } \\
\text { (uT) }\end{array}$ & $\begin{array}{l}\text { Cor } \\
\text { Apar } \\
\text { (uH) }\end{array}$ & $\begin{array}{l}\text { Turbi } \\
\text { dez } \\
\text { (uT) }\end{array}$ & $\begin{array}{l}\text { Cor } \\
\text { Apar. } \\
\text { (uH) }\end{array}$ & $\begin{array}{l}\text { Turb } \\
\text { idez } \\
\text { (uT) }\end{array}$ & $\begin{array}{l}\text { Cor } \\
\text { Apar } \\
\text { (uH) }\end{array}$ & $\begin{array}{l}\text { Turb } \\
\text { idez } \\
\text { (uT) }\end{array}$ & $\begin{array}{l}\text { Cor } \\
\text { Apar } \\
\text { (uH) }\end{array}$ & $\begin{array}{l}\text { Turb } \\
\text { idez } \\
\text { (uT) }\end{array}$ & $\begin{array}{l}\text { Cor } \\
\text { Apar } \\
\text { (uH) }\end{array}$ & $\begin{array}{l}\text { Turb } \\
\text { idez } \\
\text { (uT) }\end{array}$ & $\begin{array}{l}\text { Cor } \\
\text { Apar } \\
\text { (uH) }\end{array}$ \\
\hline 1 & 180 & 27 & 0 & 5,9 & 9,26 & 168 & 5,71 & 110 & 4,61 & 84 & 3,21 & 53 & 2,08 & 31 & 1,7 & 25 \\
\hline 2 & 180 & 27 & 5 & 5,89 & 9,31 & 158 & 4,41 & 86 & 4,38 & 68 & 2,69 & 38 & 1,79 & 26 & 1,11 & 15 \\
\hline 3 & 180 & 27 & 10 & 6,03 & 8,89 & 178 & 7,34 & 127 & 4,6 & 76 & 2,66 & 45 & 2,43 & 32 & 1,45 & 19 \\
\hline 4 & 180 & 27 & 15 & 6,05 & 8,68 & 169 & 6,06 & 109 & 3,37 & 46 & 2,38 & 39 & 1,9 & 28 & 1,28 & 20 \\
\hline 5 & 180 & 27 & 20 & 6,07 & 9,47 & 169 & 6,14 & 108 & 4,33 & 73 & 2,66 & 46 & 1,82 & 30 & 1,64 & 23 \\
\hline 6 & 180 & 27 & 25 & 5,98 & 7,1 & 143 & 5,53 & 106 & 3,31 & 58 & 2,84 & 40 & 2,27 & 31 & 1,96 & 26 \\
\hline
\end{tabular}

Tabela D.2 - Resultados dos ensaios de refloculação, Grf $20 \mathrm{~s}^{-1}$, Gruptura $=50 \mathrm{~s}^{-1}$, e variados os tempos de refloculação

\begin{tabular}{|c|c|c|c|c|c|c|c|c|c|c|c|c|c|c|c|c|}
\hline \multirow[b]{2}{*}{ Jarro } & Produtos q & uímicos & \multirow[b]{2}{*}{$\begin{array}{l}\text { Tempo de } \\
\text { refloculação } \\
\text { (min) }\end{array}$} & \multirow[b]{2}{*}{$\begin{array}{l}\mathrm{pH} \\
\mathrm{de} \\
\text { Coag }\end{array}$} & \multicolumn{2}{|c|}{$\begin{array}{l}\mathrm{Vs} 1=4,67 \\
\mathrm{~cm} / \mathrm{min}\end{array}$} & \multicolumn{2}{|c|}{$\begin{array}{l}\mathrm{Vs} 1= \\
\mathrm{cm} / \mathrm{min}\end{array}$} & \multicolumn{2}{|c|}{$\begin{array}{l}\mathrm{Vs} 1=1,38 \\
\mathrm{~cm} / \mathrm{min}\end{array}$} & \multicolumn{2}{|c|}{$\begin{array}{l}\mathrm{Vs} 1=0,97 \\
\mathrm{~cm} / \mathrm{min}\end{array}$} & \multicolumn{2}{|c|}{$\begin{array}{l}\mathrm{Vs} 1=0,6 \\
\mathrm{~cm} / \mathrm{min}\end{array}$} & \multicolumn{2}{|c|}{$\begin{array}{l}\mathrm{Vs} 1=\quad 0,42 \\
\mathrm{~cm} / \mathrm{min}\end{array}$} \\
\hline & $\begin{array}{l}\text { Sulfato de } \\
\text { Alumínio } \\
\text { Líquido } \\
\text { Comercial } \\
(\mathrm{mg} / \mathrm{L})\end{array}$ & $\begin{array}{l}\text { Hidróxi } \\
\text { do de } \\
\text { Sódio }\end{array}$ & & & $\begin{array}{l}\text { Turbi } \\
\text { dez } \\
\text { (uT) }\end{array}$ & $\begin{array}{l}\text { Cor } \\
\text { Apar } \\
\text { (uH) }\end{array}$ & $\begin{array}{l}\text { Turbi } \\
\text { dez } \\
\text { (uT) }\end{array}$ & $\begin{array}{l}\text { Cor } \\
\text { Apar. } \\
\text { (uH) }\end{array}$ & $\begin{array}{l}\text { Turb } \\
\text { idez } \\
\text { (uT) }\end{array}$ & $\begin{array}{l}\text { Cor } \\
\text { Apar } \\
\text { (uH) }\end{array}$ & $\begin{array}{l}\text { Turb } \\
\text { idez } \\
\text { (uT) }\end{array}$ & $\begin{array}{l}\text { Cor } \\
\text { Apar } \\
\text { (uH) }\end{array}$ & $\begin{array}{l}\text { Turb } \\
\text { idez } \\
\text { (uT) }\end{array}$ & $\begin{array}{l}\text { Cor } \\
\text { Apar } \\
\text { (uH) }\end{array}$ & $\begin{array}{l}\text { Turb } \\
\text { idez } \\
\text { (uT) }\end{array}$ & $\begin{array}{l}\text { Cor } \\
\text { Apar } \\
\text { (uH) }\end{array}$ \\
\hline 1 & 180 & 27 & 0 & 5,9 & 9,26 & 168 & 5,71 & 110 & 4,61 & 84 & 3,21 & 53 & 2,08 & 31 & 1,7 & 25 \\
\hline 2 & 180 & 27 & 5 & 5,89 & 9,42 & 164 & 4,75 & 89 & 4,63 & 69 & 2,56 & 44 & 1,8 & 26 & 1,51 & 22 \\
\hline 3 & 180 & 27 & 10 & 6,03 & 9,23 & 171 & 7,23 & 148 & 4,72 & 70 & 3,12 & 50 & 2,35 & 35 & 1,69 & 27 \\
\hline 4 & 180 & 27 & 15 & 6,05 & 8,95 & 176 & 7,12 & 139 & 4,12 & 65 & 2,98 & 45 & 2,29 & 35 & 1,71 & 28 \\
\hline 5 & 180 & 27 & 20 & 6,07 & 9,09 & 174 & 7,23 & 145 & 4,9 & 75 & 3,2 & 48 & 2,45 & 41 & 1,89 & 30 \\
\hline 6 & 180 & 27 & 25 & 5,98 & 8,99 & 195 & 7,19 & 142 & 4,79 & 71 & 3,45 & 52 & 2,87 & 45 & 2,2 & 35 \\
\hline
\end{tabular}


Tabela D.3 - Resultados dos ensaios de refloculação, Grf $10 \mathrm{~s}^{-1}$, Gruptura $=100 \mathrm{~s}^{-1}$, e variados os tempos de refloculação

\begin{tabular}{|c|c|c|c|c|c|c|c|c|c|c|c|c|c|c|c|c|}
\hline \multirow[b]{2}{*}{ Jarro } & \multicolumn{2}{|c|}{ Produtos químicos } & \multirow[b]{2}{*}{$\begin{array}{l}\text { Tempo de } \\
\text { refloculação } \\
\text { (min) }\end{array}$} & \multirow[b]{2}{*}{$\begin{array}{l}\mathrm{pH} \\
\mathrm{de} \\
\text { Coag }\end{array}$} & \multicolumn{2}{|c|}{$\begin{array}{l}\begin{array}{l}\mathrm{Vs} 1= \\
\mathrm{cm} / \mathrm{min}\end{array} \\
\end{array}$} & \multicolumn{2}{|c|}{$\begin{array}{l}\mathrm{Vs} 1= \\
\mathrm{cm} / \mathrm{min}\end{array}$} & \multicolumn{2}{|c|}{$\begin{array}{l}\text { Vs1= } 1,38 \\
\mathrm{~cm} / \mathrm{min}\end{array}$} & \multicolumn{2}{|c|}{$\begin{array}{l}\mathrm{Vs} 1=\quad 0,97 \\
\mathrm{~cm} / \mathrm{min}\end{array}$} & \multicolumn{2}{|c|}{$\begin{array}{l}\begin{array}{l}\mathrm{Vs} 1= \\
\mathrm{cm} / \mathrm{min}\end{array} \\
\end{array}$} & \multicolumn{2}{|c|}{$\begin{array}{l}\mathrm{Vs} 1=\quad 0,42 \\
\mathrm{~cm} / \mathrm{min}\end{array}$} \\
\hline & $\begin{array}{l}\text { Sulfato de } \\
\text { Alumínio } \\
\text { Líquido } \\
\text { Comercial } \\
(\mathrm{mg} / \mathrm{L})\end{array}$ & $\begin{array}{l}\text { Hidróxi } \\
\text { do de } \\
\text { Sódio }\end{array}$ & & & $\begin{array}{l}\text { Turbi } \\
\text { dez } \\
\text { (uT) }\end{array}$ & $\begin{array}{l}\text { Cor } \\
\text { Apar } \\
\text { (uH) }\end{array}$ & $\begin{array}{l}\text { Turbi } \\
\text { dez } \\
\text { (uT) }\end{array}$ & $\begin{array}{l}\text { Cor } \\
\text { Apar. } \\
\text { (uH) }\end{array}$ & $\begin{array}{l}\text { Turb } \\
\text { idez } \\
\text { (uT) }\end{array}$ & $\begin{array}{l}\text { Cor } \\
\text { Apar } \\
\text { (uH) }\end{array}$ & $\begin{array}{l}\text { Turb } \\
\text { idez } \\
\text { (uT) }\end{array}$ & $\begin{array}{l}\text { Cor } \\
\text { Apar } \\
\text { (uH) }\end{array}$ & $\begin{array}{l}\text { Turb } \\
\text { idez } \\
\text { (uT) }\end{array}$ & $\begin{array}{l}\text { Cor } \\
\text { Apar } \\
\text { (uH) }\end{array}$ & $\begin{array}{l}\text { Turb } \\
\text { idez } \\
\text { (uT) }\end{array}$ & $\begin{array}{l}\text { Cor } \\
\text { Apar } \\
\text { (uH) }\end{array}$ \\
\hline 1 & 180 & 27 & 0 & 5,96 & 10,4 & 174 & 7,45 & 145 & 7,17 & 122 & 4,04 & 77 & 3,77 & 56 & 2,23 & 38 \\
\hline 2 & 180 & 27 & 5 & 5,97 & 10 & 170 & 5,96 & 103 & 4,14 & 67 & 3,3 & 48 & 1,45 & 20 & 1,5 & 18 \\
\hline 3 & 180 & 27 & 10 & 5,96 & 10,5 & 181 & 5,86 & 96 & 5,06 & 73 & 2,13 & 30 & 1,85 & 26 & 1,09 & 12 \\
\hline 4 & 180 & 27 & 15 & 6,03 & 7,13 & 148 & 7,03 & 121 & 4,39 & 67 & 2,36 & 40 & 2,57 & 31 & 2,19 & 21 \\
\hline 5 & 180 & 27 & 20 & 6,04 & 11,4 & 179 & 7,99 & 135 & 4,32 & 67 & 2,76 & 36 & 1,41 & 17 & 1,26 & 15 \\
\hline 6 & 180 & 27 & 25 & 5,94 & 8,14 & 150 & 8,91 & 158 & 4,22 & 61 & 2,93 & 40 & 2,32 & 29 & 1,38 & 17 \\
\hline
\end{tabular}

Tabela D.4 - Resultados dos ensaios de refloculação, Grf $20 \mathrm{~s}^{-1}$, Gruptura $=100 \mathrm{~s}^{-1}$, e variados os tempos de refloculação

\begin{tabular}{|c|c|c|c|c|c|c|c|c|c|c|c|c|c|c|c|c|}
\hline \multirow{3}{*}{ Jarro } & Produtos q & uímicos & \multirow{3}{*}{$\begin{array}{l}\text { Tempo de } \\
\text { refloculação } \\
(\mathrm{min})\end{array}$} & \multirow{3}{*}{$\begin{array}{l}\mathrm{pH} \\
\mathrm{de} \\
\text { Coag }\end{array}$} & \multicolumn{2}{|c|}{$\begin{array}{l}\begin{array}{l}\text { Vs1= } \\
\mathrm{cm} / \mathrm{min}\end{array} \\
\end{array}$} & \multicolumn{2}{|c|}{$\begin{array}{l}\text { Vs1= } \\
\mathrm{cm} / \mathrm{min}\end{array}$} & \multicolumn{2}{|c|}{$\begin{array}{l}\begin{array}{l}\text { Vs1 }=1,38 \\
\mathrm{~cm} / \mathrm{min}\end{array} \\
\end{array}$} & \multicolumn{2}{|c|}{$\begin{array}{l}\begin{array}{l}\mathrm{Vs} 1= \\
\mathrm{cm} / \mathrm{min}\end{array} \\
\end{array}$} & \multicolumn{2}{|c|}{$\begin{array}{l}\mathrm{Vs} 1= \\
\mathrm{cm} / \mathrm{min}\end{array}$} & \multicolumn{2}{|c|}{$\begin{array}{l}\mathrm{Vs} 1=0,42 \\
\mathrm{~cm} / \mathrm{min}\end{array}$} \\
\hline & $\begin{array}{l}\text { Sulfato de } \\
\text { Alumínio } \\
\text { Líquido } \\
\text { Comercial } \\
\end{array}$ & $\begin{array}{l}\text { Hidróxi } \\
\text { do de } \\
\text { Sódio }\end{array}$ & & & $\begin{array}{l}\text { Turbi } \\
\text { dez } \\
\text { (uT) }\end{array}$ & $\begin{array}{l}\text { Cor } \\
\text { Apar } \\
\text { (uH) }\end{array}$ & $\begin{array}{l}\text { Turbi } \\
\text { dez } \\
\text { (uT) }\end{array}$ & $\begin{array}{l}\text { Cor } \\
\text { Apar. } \\
\text { (uH) }\end{array}$ & $\begin{array}{l}\text { Turb } \\
\text { idez } \\
\text { (uT) }\end{array}$ & $\begin{array}{l}\text { Cor } \\
\text { Apar } \\
\text { (uH) }\end{array}$ & $\begin{array}{l}\text { Turb } \\
\text { idez } \\
\text { (uT) }\end{array}$ & $\begin{array}{l}\text { Cor } \\
\text { Apar } \\
\text { (uH) }\end{array}$ & $\begin{array}{l}\text { Turb } \\
\text { idez } \\
\text { (uT) }\end{array}$ & $\begin{array}{l}\text { Cor } \\
\text { Apar } \\
\cdot \\
(\mathrm{uH})\end{array}$ & $\begin{array}{l}\text { Turb } \\
\text { idez } \\
\text { (uT) }\end{array}$ & $\begin{array}{l}\text { Cor } \\
\text { Apar } \\
\cdot \\
(\mathrm{uH})\end{array}$ \\
\hline & $(\mathrm{mg} / \mathrm{L})$ & & & & & & & & & & & & & & & \\
\hline 1 & 180 & 27 & 0 & 6,22 & 10,4 & 174 & 7,45 & 145 & 7,17 & 122 & 4,04 & 77 & 3,77 & 56 & 2,23 & 38 \\
\hline 2 & 180 & 27 & 5 & 6,19 & 8,69 & 169 & 6,12 & 117 & 5,24 & 93 & 3,52 & 58 & 2,56 & 43 & 1,91 & 26 \\
\hline 3 & 180 & 27 & 10 & 6,15 & 8,92 & 184 & 6,98 & 127 & 5,98 & 102 & 3,92 & 70 & 2,59 & 42 & 1,87 & 27 \\
\hline 4 & 180 & 27 & 15 & 6,18 & 10,7 & 202 & 7,22 & 147 & 6,45 & 107 & 5,01 & 80 & 2,77 & 50 & 2,51 & 35 \\
\hline 5 & 180 & 27 & 20 & 6,25 & 10,5 & 208 & 8,2 & 159 & 6,54 & 105 & 5,94 & 82 & 2,82 & 53 & 2,66 & 40 \\
\hline 6 & 180 & 27 & 25 & 6,17 & 10,7 & 210 & 9 & 186 & 6,01 & 108 & 5,85 & 79 & 3,99 & 58 & 2,56 & 41 \\
\hline
\end{tabular}


Tabela D.5 - Resultados dos ensaios de refloculação, Grf $10 \mathrm{~s}^{-1}$, Gruptura $=150 \mathrm{~s}^{-1}$, e variados os tempos de refloculação

\begin{tabular}{|c|c|c|c|c|c|c|c|c|c|c|c|c|c|c|c|c|}
\hline \multirow[b]{2}{*}{ Jarro } & Produtos q & límicos & \multirow[b]{2}{*}{$\begin{array}{l}\text { Tempo de } \\
\text { refloculação } \\
\text { (min) }\end{array}$} & \multirow[b]{2}{*}{$\begin{array}{l}\mathrm{pH} \\
\text { de } \\
\text { Coag }\end{array}$} & \multicolumn{2}{|c|}{$\begin{array}{l}\begin{array}{l}\text { Vs1 } 1=4,67 \\
\mathrm{~cm} / \mathrm{min}\end{array} \\
\end{array}$} & \multicolumn{2}{|c|}{$\begin{array}{l}\begin{array}{l}\mathrm{Vs} 1= \\
\mathrm{cm} / \mathrm{min}\end{array} \\
\end{array}$} & \multicolumn{2}{|c|}{$\begin{array}{l}\mathrm{Vs} 1=1,38 \\
\mathrm{~cm} / \mathrm{min}\end{array}$} & \multicolumn{2}{|c|}{$\begin{array}{l}\text { Vs1 } 1=0,97 \\
\mathrm{~cm} / \mathrm{min}\end{array}$} & \multicolumn{2}{|c|}{$\begin{array}{ll}\begin{array}{l}\text { Vs1 } 1= \\
\mathrm{cm} / \mathrm{min}\end{array} & 0,6 \\
\end{array}$} & \multicolumn{2}{|c|}{$\begin{array}{l}\text { Vs } 1=\quad 0,42 \\
\mathrm{~cm} / \mathrm{min}\end{array}$} \\
\hline & $\begin{array}{l}\text { Sulfato de } \\
\text { Alumínio } \\
\text { Líquido } \\
\text { Comercial } \\
(\mathrm{mg} / \mathrm{L})\end{array}$ & $\begin{array}{l}\text { Hidróxi } \\
\text { do de } \\
\text { Sódio }\end{array}$ & & & $\begin{array}{l}\text { Turbi } \\
\text { dez } \\
\text { (uT) }\end{array}$ & $\begin{array}{l}\text { Cor } \\
\text { Apar } \\
\text { (uH) }\end{array}$ & $\begin{array}{l}\text { Turbi } \\
\text { dez } \\
\text { (uT) }\end{array}$ & $\begin{array}{l}\text { Cor } \\
\text { Apar. } \\
\text { (uH) }\end{array}$ & $\begin{array}{l}\text { Turb } \\
\text { idez } \\
\text { (uT) }\end{array}$ & $\begin{array}{l}\text { Cor } \\
\text { Apar } \\
\text { (uH) }\end{array}$ & $\begin{array}{l}\text { Turb } \\
\text { idez } \\
\text { (uT) }\end{array}$ & $\begin{array}{l}\text { Cor } \\
\text { Apar } \\
\text { (uH) }\end{array}$ & $\begin{array}{l}\text { Turb } \\
\text { idez } \\
\text { (uT) }\end{array}$ & $\begin{array}{l}\text { Cor } \\
\text { Apar } \\
\text { (uH) }\end{array}$ & $\begin{array}{l}\text { Turb } \\
\text { idez } \\
\text { (uT) }\end{array}$ & $\begin{array}{l}\text { Cor } \\
\text { Apar } \\
\text { (uH) }\end{array}$ \\
\hline 1 & 180 & 27 & 0 & 6,07 & 10,5 & 192 & 9,11 & 166 & 9,16 & 150 & 6,43 & 96 & 3,88 & 66 & 3,25 & 53 \\
\hline 2 & 180 & 27 & 5 & 6,08 & 8,75 & 170 & 7,07 & 118 & 5,8 & 78 & 2,71 & 39 & 2,26 & 29 & 1,63 & 24 \\
\hline 3 & 180 & 27 & 10 & 6,06 & 10,3 & 175 & 6,78 & 110 & 5,24 & 98 & 2,72 & 45 & 2,18 & 30 & 1,73 & 26 \\
\hline 4 & 180 & 27 & 15 & 6,1 & 9,81 & 181 & 7,09 & 125 & 5,04 & 86 & 4,26 & 60 & 2,56 & 38 & 2,02 & 27 \\
\hline 5 & 180 & 27 & 20 & 6,21 & 9,57 & 187 & 6,6 & 112 & 6,92 & 109 & 2,71 & 51 & 2,21 & 37 & 1,57 & 26 \\
\hline 6 & 180 & 27 & 25 & 6,18 & 11,2 & 176 & 8,96 & 169 & 6 & 108 & 3,99 & 69 & 3,28 & 46 & 1,91 & 34 \\
\hline
\end{tabular}

Tabela D.6 - Resultados dos ensaios de refloculação, Grf $20 \mathrm{~s}^{-1}$, Gruptura $=150 \mathrm{~s}^{-1}$, e variados os tempos de refloculação

\begin{tabular}{|c|c|c|c|c|c|c|c|c|c|c|c|c|c|c|c|c|}
\hline \multirow[b]{2}{*}{ Jarro } & Produtos q & uímicos & \multirow[b]{2}{*}{$\begin{array}{l}\text { Tempo de } \\
\text { refloculação } \\
\text { (min) }\end{array}$} & \multirow[b]{2}{*}{$\begin{array}{l}\mathrm{pH} \\
\mathrm{de} \\
\text { Coag }\end{array}$} & \multicolumn{2}{|c|}{$\begin{array}{l}\begin{array}{l}\text { Vs1 }=4,67 \\
\mathrm{~cm} / \min \end{array} \\
\end{array}$} & \multicolumn{2}{|c|}{$\begin{array}{l}\begin{array}{l}\mathrm{Vs} 1= \\
\mathrm{cm} / \mathrm{min}\end{array} \\
\end{array}$} & \multicolumn{2}{|c|}{$\begin{array}{l}\mathrm{Vs} 1= \\
\mathrm{cm} / \mathrm{min}\end{array}$} & \multicolumn{2}{|c|}{$\begin{array}{l}\begin{array}{l}\text { Vs1 }= \\
\mathrm{cm} / \mathrm{min}\end{array} \\
\end{array}$} & \multicolumn{2}{|c|}{$\begin{array}{l}\begin{array}{l}\mathrm{Vs} 1= \\
\mathrm{cm} / \mathrm{min}\end{array} \\
\end{array}$} & \multicolumn{2}{|c|}{$\begin{array}{l}\begin{array}{l}\mathrm{Vs} 1= \\
\mathrm{cm} / \mathrm{min}\end{array} \\
\end{array}$} \\
\hline & $\begin{array}{l}\text { Sulfato de } \\
\text { Alumínio } \\
\text { Líquido } \\
\text { Comercial } \\
(\mathrm{mg} / \mathrm{L}) \\
\end{array}$ & $\begin{array}{l}\text { Hidróxi } \\
\text { do de } \\
\text { Sódio }\end{array}$ & & & $\begin{array}{l}\text { Turbi } \\
\text { dez } \\
\text { (uT) }\end{array}$ & $\begin{array}{l}\text { Cor } \\
\text { Apar } \\
\text { (uH) }\end{array}$ & $\begin{array}{l}\text { Turbi } \\
\text { dez } \\
\text { (uT) }\end{array}$ & $\begin{array}{l}\text { Cor } \\
\text { Apar. } \\
\text { (uH) }\end{array}$ & $\begin{array}{l}\text { Turb } \\
\text { idez } \\
\text { (uT) }\end{array}$ & $\begin{array}{l}\text { Cor } \\
\text { Apar } \\
\text { (uH) }\end{array}$ & $\begin{array}{l}\text { Turb } \\
\text { idez } \\
\text { (uT) }\end{array}$ & $\begin{array}{l}\text { Cor } \\
\text { Apar } \\
\text { (uH) }\end{array}$ & $\begin{array}{l}\text { Turb } \\
\text { idez } \\
\text { (uT) }\end{array}$ & $\begin{array}{l}\text { Cor } \\
\text { Apar } \\
\text { (uH) }\end{array}$ & $\begin{array}{l}\text { Turb } \\
\text { idez } \\
\text { (uT) }\end{array}$ & $\begin{array}{l}\text { Cor } \\
\text { Apar } \\
\text { (uH) }\end{array}$ \\
\hline 1 & 180 & 27 & 0 & 6,07 & 10,5 & 192 & 9,11 & 166 & 9,16 & 150 & 6,43 & 96 & 3,88 & 66 & 3,25 & 53 \\
\hline 2 & 180 & 27 & 5 & 6,08 & 8,62 & 169 & 7,15 & 124 & 6,21 & 84 & 4,33 & 69 & 2,86 & 49 & 2,12 & 34 \\
\hline 3 & 180 & 27 & 10 & 6,06 & 9,1 & 177 & 7,06 & 125 & 6,39 & 101 & 4,69 & 71 & 2,96 & 57 & 2,1 & 32 \\
\hline 4 & 180 & 27 & 15 & 6,1 & 9,92 & 205 & 7,05 & 128 & 6,19 & 96 & 5,9 & 89 & 3,1 & 58 & 2,56 & 42 \\
\hline 5 & 180 & 27 & 20 & 6,21 & 10,56 & 211 & 7,12 & 129 & 7,42 & 125 & 5,53 & 81 & 2,97 & 58 & 2,32 & 37 \\
\hline 6 & 180 & 27 & 25 & 6,18 & 11,25 & 208 & 9,15 & 174 & 7,2 & 119 & 6,12 & 85 & 4,02 & 66 & 2,89 & 54 \\
\hline
\end{tabular}




\section{ANEXO E}

Resultados dos ensaios para construção dos diagramas

de coagulação como o Cloreto Férrico como coagulante 
Tabela E.1 - Resultados dos ensaios para construção do diagrama de coagulação

\begin{tabular}{|c|c|c|c|c|c|c|c|c|c|}
\hline \multirow{3}{*}{ Jarro } & \multicolumn{2}{|c|}{ Produtos químicos } & \multirow{3}{*}{$\begin{array}{l}\text { pH de } \\
\text { Coagulação }\end{array}$} & \multicolumn{2}{|c|}{$\mathrm{Vs} 1=3,0 \mathrm{~cm} / \mathrm{min}$} & \multicolumn{2}{|c|}{$\mathrm{Vs} 2=1,5 \mathrm{~cm} / \mathrm{min}$} & \multicolumn{2}{|c|}{$\mathrm{Vs} 3=1,0 \mathrm{~cm} / \mathrm{min}$} \\
\hline & $\begin{array}{l}\text { Férrico } \\
\text { Líquido } \\
\text { Comercial }\end{array}$ & $\begin{array}{l}\text { Hidróxido } \\
\text { de Sódio }\end{array}$ & & $\begin{array}{l}\text { Turbidez } \\
\text { (uT) }\end{array}$ & $\begin{array}{l}\text { Cor Apar. } \\
(\mathrm{uH})\end{array}$ & $\begin{array}{l}\text { Turbidez } \\
\text { (uT) }\end{array}$ & $\begin{array}{l}\text { Cor } \\
\text { Apar. } \\
(\mathrm{uH})\end{array}$ & $\begin{array}{l}\text { Turbidez } \\
\text { (uT) }\end{array}$ & $\begin{array}{l}\text { Cor } \\
\text { Apar. } \\
(\mathrm{uH})\end{array}$ \\
\hline & $(\mathrm{mg} / \mathrm{L})$ & $(\mathrm{mg} / \mathrm{L})$ & & & & & & & \\
\hline 1 & 40 & & 3,94 & 5,16 & 237 & 7,12 & 185 & 3,45 & 84 \\
\hline 2 & 40 & 5 & 4,71 & 6,22 & 160 & 5,35 & 138 & 2,51 & 54 \\
\hline 3 & 40 & 10 & 6,15 & 6,57 & 241 & 6,48 & 246 & 5,7 & 235 \\
\hline 4 & 40 & 20 & 7,75 & 5,76 & 214 & 5,63 & 211 & 5,3 & 207 \\
\hline 5 & 60 & 10 & 4,36 & 3,25 & 112 & 2,6 & 83 & 1,37 & 40 \\
\hline 6 & 60 & 12 & 4,95 & 5,19 & 135 & 3,68 & 105 & 1,51 & 25 \\
\hline
\end{tabular}

Tabela E.2 - Resultados dos ensaios para construção do diagrama de coagulação

\begin{tabular}{|c|c|c|c|c|c|c|c|c|c|}
\hline \multirow{3}{*}{ Jarro } & Produtos q & límicos & \multirow{3}{*}{$\begin{array}{l}\text { pH de } \\
\text { Coagulação }\end{array}$} & \multicolumn{2}{|c|}{$\mathrm{Vs} 1=3,0 \mathrm{~cm} / \mathrm{min}$} & \multicolumn{2}{|c|}{$\mathrm{Vs} 2=1,5 \mathrm{~cm} / \mathrm{min}$} & \multicolumn{2}{|c|}{$\mathrm{Vs} 3=1,0 \mathrm{~cm} / \mathrm{min}$} \\
\hline & $\begin{array}{l}\text { Férrico } \\
\text { Líquido } \\
\text { Comercial }\end{array}$ & $\begin{array}{l}\text { Hidróxido } \\
\text { de Sódio }\end{array}$ & & \multirow[t]{2}{*}{$\begin{array}{l}\text { Turbidez } \\
\text { (uT) }\end{array}$} & \multirow[t]{2}{*}{$\begin{array}{l}\text { Cor Apar. } \\
(\mathrm{uH})\end{array}$} & \multirow[t]{2}{*}{$\begin{array}{l}\text { Turbidez } \\
\text { (uT) }\end{array}$} & \multirow[t]{2}{*}{$\begin{array}{l}\text { Cor } \\
\text { Apar. } \\
(\mathrm{uH})\end{array}$} & \multirow[t]{2}{*}{$\begin{array}{l}\text { Turbidez } \\
\text { (uT) }\end{array}$} & \multirow[t]{2}{*}{$\begin{array}{l}\text { Cor } \\
\text { Apar. } \\
\text { (uH) }\end{array}$} \\
\hline & $(\mathrm{mg} / \mathrm{L})$ & $(\mathrm{mg} / \mathrm{L})$ & & & & & & & \\
\hline 1 & 60 & 14 & 5,31 & 5,7 & 170 & 3,8 & 120 & 1,8 & 56 \\
\hline 2 & 60 & 16 & 6,02 & 6,55 & 267 & 6,62 & 266 & 6,07 & 265 \\
\hline 3 & 60 & 20 & 6,9 & 6,1 & 263 & 6,34 & 262 & 6 & 257 \\
\hline 4 & 60 & 25 & 7,65 & 5,95 & 281 & 6,14 & 282 & 5,6 & 282 \\
\hline 5 & 80 & & 3,56 & 6,7 & 285 & 6,71 & 285 & 6,37 & 288 \\
\hline 6 & 80 & 10 & 3,77 & 5,36 & 296 & 5,54 & 302 & 5,84 & 306 \\
\hline
\end{tabular}

Tabela E.3 - Resultados dos ensaios para construção do diagrama de coagulação

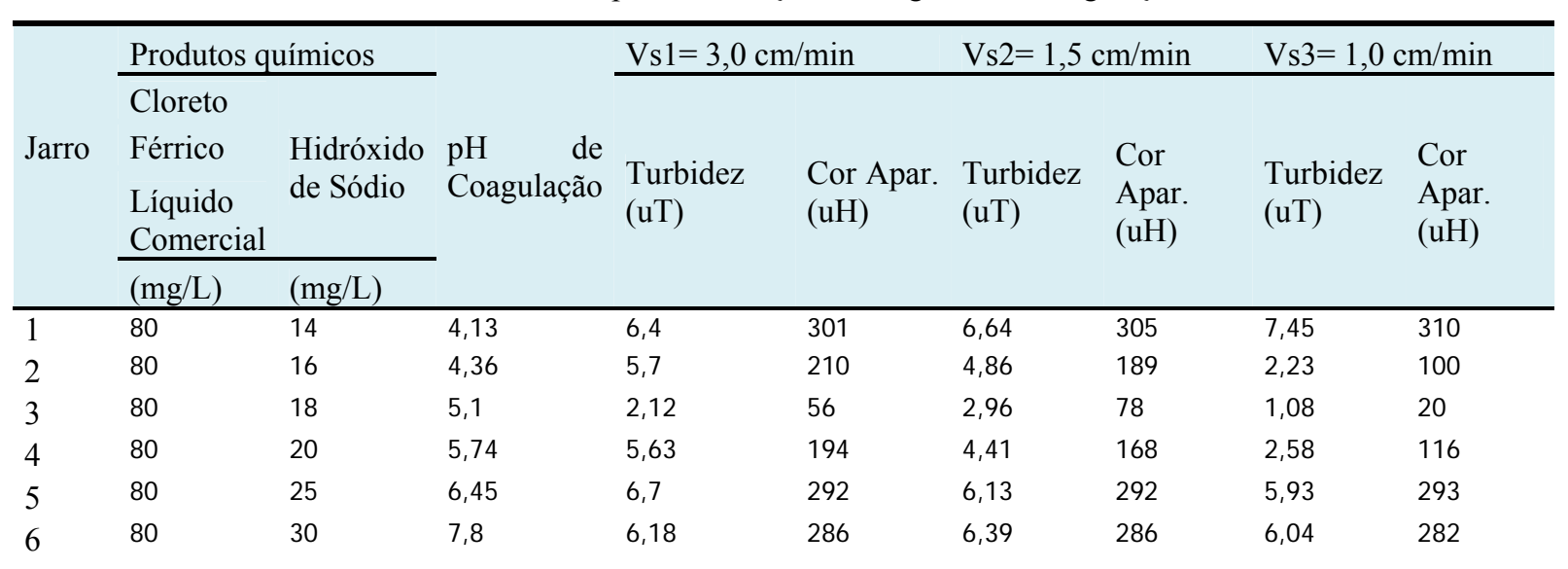

Tabela E.4 - Resultados dos ensaios para construção do diagrama de coagulação 


\begin{tabular}{|c|c|c|c|c|c|c|c|c|c|}
\hline \multirow{3}{*}{ Jarro } & \multicolumn{2}{|c|}{ Produtos químicos } & \multirow{3}{*}{$\begin{array}{l}\text { pH de } \\
\text { Coagulação }\end{array}$} & \multicolumn{2}{|c|}{$\mathrm{Vs} 1=3,0 \mathrm{~cm} / \mathrm{min}$} & \multicolumn{2}{|c|}{$\mathrm{Vs} 2=1,5 \mathrm{~cm} / \mathrm{min}$} & \multicolumn{2}{|c|}{$\mathrm{Vs} 3=1,0 \mathrm{~cm} / \mathrm{min}$} \\
\hline & $\begin{array}{l}\text { Férrico } \\
\text { Líquido } \\
\text { Comercial } \\
\end{array}$ & $\begin{array}{l}\text { Hidróxido } \\
\text { de Sódio }\end{array}$ & & $\begin{array}{l}\text { Turbidez } \\
\text { (uT) }\end{array}$ & $\begin{array}{l}\text { Cor Apar. } \\
(\mathrm{uH})\end{array}$ & $\begin{array}{l}\text { Turbidez } \\
\text { (uT) }\end{array}$ & $\begin{array}{l}\text { Cor } \\
\text { Apar. } \\
(\mathrm{uH})\end{array}$ & $\begin{array}{l}\text { Turbidez } \\
\text { (uT) }\end{array}$ & $\begin{array}{l}\text { Cor } \\
\text { Apar. } \\
(\mathrm{uH})\end{array}$ \\
\hline & $(\mathrm{mg} / \mathrm{L})$ & $(\mathrm{mg} / \mathrm{L})$ & & & & & & & \\
\hline 1 & 100 & & 3,53 & 6,63 & 297 & 6,28 & 300 & 6,08 & 304 \\
\hline 2 & 100 & 20 & 4,02 & 8,19 & 326 & 9,51 & 325 & 8,94 & 333 \\
\hline 3 & 100 & 22 & 4,3 & 8,69 & 346 & 8,72 & 326 & 8,44 & 372 \\
\hline 4 & 100 & 24 & 4,7 & 1,94 & 35 & 1,02 & 22 & 0,88 & 14 \\
\hline 5 & 100 & 25 & 5,18 & 1,93 & 42 & 1,19 & 17 & 0,66 & 9 \\
\hline 6 & 100 & 26 & 5,62 & 2,95 & 101 & 1,69 & 48 & 0,7 & 14 \\
\hline
\end{tabular}

Tabela E.5 - Resultados dos ensaios para construção do diagrama de coagulação

\begin{tabular}{|c|c|c|c|c|c|c|c|c|c|}
\hline \multirow{3}{*}{ Jarro } & \multicolumn{2}{|c|}{ Produtos químicos } & \multirow{3}{*}{$\begin{array}{l}\mathrm{pH} \quad \text { de } \\
\text { Coagulação }\end{array}$} & \multicolumn{2}{|c|}{$\mathrm{Vs} 1=3,0 \mathrm{~cm} / \mathrm{min}$} & \multicolumn{2}{|c|}{$\mathrm{Vs} 2=1,5 \mathrm{~cm} / \mathrm{min}$} & \multicolumn{2}{|c|}{$\mathrm{Vs} 3=1,0 \mathrm{~cm} / \mathrm{min}$} \\
\hline & $\begin{array}{l}\text { Cloreto } \\
\text { Férrico } \\
\text { Líquido } \\
\text { Comercial } \\
\end{array}$ & $\begin{array}{l}\text { Hidróxido } \\
\text { de Sódio }\end{array}$ & & $\begin{array}{l}\text { Turbidez } \\
\text { (uT) }\end{array}$ & $\begin{array}{l}\text { Cor Apar. } \\
(\mathrm{uH})\end{array}$ & $\begin{array}{l}\text { Turbidez } \\
\text { (uT) }\end{array}$ & $\begin{array}{l}\text { Cor } \\
\text { Apar. } \\
(\mathrm{uH})\end{array}$ & $\begin{array}{l}\text { Turbidez } \\
\text { (uT) }\end{array}$ & $\begin{array}{l}\text { Cor } \\
\text { Apar. } \\
(\mathrm{uH})\end{array}$ \\
\hline & $(\mathrm{mg} / \mathrm{L})$ & $(\mathrm{mg} / \mathrm{L})$ & & & & & & & \\
\hline 1 & 100 & 28 & 5,77 & 3,87 & 122 & 2,26 & 67 & 0,98 & 27 \\
\hline 2 & 100 & 30 & 6,1 & 7,98 & 318 & 5,68 & 257 & 4,27 & 231 \\
\hline 3 & 100 & 35 & 6,94 & 6,91 & 322 & 6,27 & 321 & 6,29 & 323 \\
\hline 4 & 100 & 40 & 7,35 & 6,44 & 282 & 6,7 & 284 & 6,33 & 282 \\
\hline 5 & 100 & 60 & 7,65 & 5,82 & 276 & 5,76 & 277 & 5,83 & 276 \\
\hline 6 & 100 & 80 & 7,75 & 7,09 & 295 & 7,04 & 294 & 6,63 & 295 \\
\hline
\end{tabular}

Tabela E.6 - Resultados dos ensaios para construção do diagrama de coagulação

\begin{tabular}{|c|c|c|c|c|c|c|c|c|c|}
\hline \multirow{3}{*}{ Jarro } & \multicolumn{2}{|c|}{ Produtos químicos } & \multirow{3}{*}{$\begin{array}{l}\mathrm{pH} \quad \text { de } \\
\text { Coagulação }\end{array}$} & \multicolumn{2}{|c|}{$\mathrm{Vs} 1=3,0 \mathrm{~cm} / \mathrm{min}$} & \multicolumn{2}{|c|}{$\mathrm{Vs} 2=1,5 \mathrm{~cm} / \mathrm{min}$} & \multicolumn{2}{|c|}{$\mathrm{Vs} 3=1,0 \mathrm{~cm} / \mathrm{min}$} \\
\hline & $\begin{array}{l}\text { Cloreto } \\
\text { Férrico } \\
\text { Líquido } \\
\text { Comercial } \\
\end{array}$ & $\begin{array}{l}\text { Hidróxido } \\
\text { de Sódio }\end{array}$ & & $\begin{array}{l}\text { Turbidez } \\
\text { (uT) }\end{array}$ & $\begin{array}{l}\text { Cor Apar. } \\
(\mathrm{uH})\end{array}$ & $\begin{array}{l}\text { Turbidez } \\
\text { (uT) }\end{array}$ & $\begin{array}{l}\text { Cor } \\
\text { Apar. } \\
(\mathrm{uH})\end{array}$ & $\begin{array}{l}\text { Turbidez } \\
\text { (uT) }\end{array}$ & $\begin{array}{l}\text { Cor } \\
\text { Apar. } \\
(\mathrm{uH})\end{array}$ \\
\hline & $(\mathrm{mg} / \mathrm{L})$ & $(\mathrm{mg} / \mathrm{L})$ & & & & & & & \\
\hline 1 & 120 & & 3,5 & 6,41 & 304 & 6,57 & 308 & 6,09 & 315 \\
\hline 2 & 120 & 25 & 3,96 & 5,8 & 350 & 5,67 & 350 & 5,51 & 353 \\
\hline 3 & 120 & 27 & 4,05 & 6,62 & 348 & 6,65 & 345 & 6,34 & 350 \\
\hline 4 & 120 & 30 & 5,25 & 1,5 & 37 & 1,01 & 25 & 0,75 & 15 \\
\hline 5 & 120 & 35 & 5,9 & 1,66 & 47 & 1,75 & 54 & 0,95 & 23 \\
\hline 6 & 120 & 40 & 6,7 & 7,81 & 363 & 7,78 & 361 & 7,25 & 358 \\
\hline
\end{tabular}

Tabela E.7 - Resultados dos ensaios para construção do diagrama de coagulação 


\begin{tabular}{|c|c|c|c|c|c|c|c|c|c|}
\hline \multirow{3}{*}{ Jarro } & \multicolumn{2}{|c|}{ Produtos químicos } & \multirow{3}{*}{$\begin{array}{l}\mathrm{pH} \quad \mathrm{de} \\
\text { Coagulação }\end{array}$} & \multicolumn{2}{|c|}{$\mathrm{Vs} 1=3,0 \mathrm{~cm} / \mathrm{min}$} & \multicolumn{2}{|c|}{$\mathrm{Vs} 2=1,5 \mathrm{~cm} / \mathrm{min}$} & \multicolumn{2}{|c|}{$\mathrm{Vs} 3=1,0 \mathrm{~cm} / \mathrm{min}$} \\
\hline & $\begin{array}{l}\text { Férrico } \\
\text { Líquido } \\
\text { Comercial }\end{array}$ & $\begin{array}{l}\text { Hidróxido } \\
\text { de Sódio }\end{array}$ & & $\begin{array}{l}\text { Turbidez } \\
\text { (uT) }\end{array}$ & $\begin{array}{l}\text { Cor Apar. } \\
(\mathrm{uH})\end{array}$ & $\begin{array}{l}\text { Turbidez } \\
\text { (uT) }\end{array}$ & $\begin{array}{l}\text { Cor } \\
\text { Apar. } \\
(\mathrm{uH})\end{array}$ & $\begin{array}{l}\text { Turbidez } \\
\text { (uT) }\end{array}$ & $\begin{array}{l}\text { Cor } \\
\text { Apar. } \\
(\mathrm{uH})\end{array}$ \\
\hline & $(\mathrm{mg} / \mathrm{L})$ & $(\mathrm{mg} / \mathrm{L})$ & & & & & & & \\
\hline 1 & 140 & & 3,48 & 6,06 & 310 & 6,07 & 314 & 5,91 & 324 \\
\hline 2 & 140 & 30 & 3,74 & 6,09 & 376 & 6,16 & 384 & 5,62 & 376 \\
\hline 3 & 140 & 35 & 4,25 & 7,49 & 389 & 7,6 & 391 & 7,3 & 391 \\
\hline 4 & 140 & 36 & 4,53 & 9,18 & 394 & 9,35 & 396 & 9,07 & 411 \\
\hline 5 & 140 & 38 & 5,08 & 2,13 & 55 & 1,53 & 33 & 0,76 & 10 \\
\hline 6 & 140 & 40 & 5,82 & 2,53 & 80 & 1,96 & 55 & 0,98 & 19 \\
\hline
\end{tabular}

Tabela E. 8 - Resultados dos ensaios para construção do diagrama de coagulação

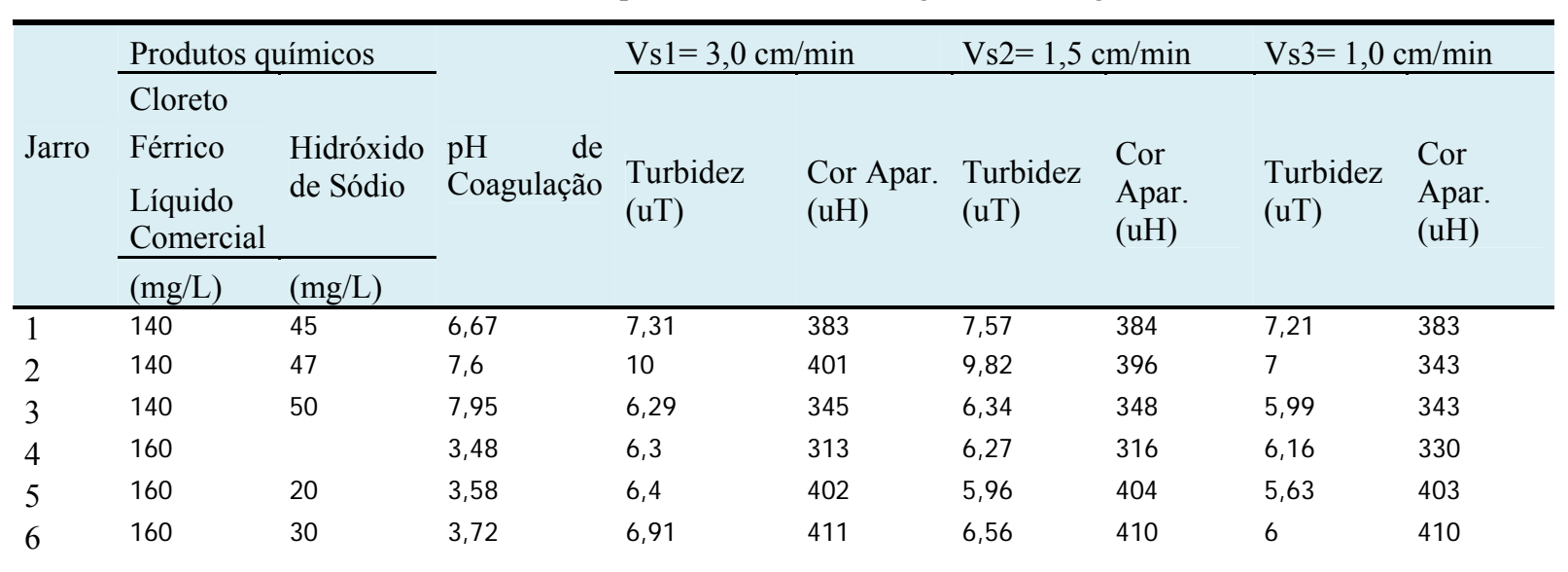

Tabela E.9 - Resultados dos ensaios para construção do diagrama de coagulação

\begin{tabular}{|c|c|c|c|c|c|c|c|c|c|}
\hline \multirow{3}{*}{ Jarro } & Produtos q & uímicos & \multirow{3}{*}{$\begin{array}{l}\mathrm{pH} \quad \mathrm{de} \\
\text { Coagulação }\end{array}$} & \multicolumn{2}{|c|}{$\mathrm{Vs} 1=3,0 \mathrm{~cm} / \mathrm{min}$} & \multicolumn{2}{|c|}{$\mathrm{Vs} 2=1,5 \mathrm{~cm} / \mathrm{min}$} & \multicolumn{2}{|c|}{$\mathrm{Vs} 3=1,0 \mathrm{~cm} / \mathrm{min}$} \\
\hline & $\begin{array}{l}\text { Férrico } \\
\text { Líquido } \\
\text { Comercial } \\
\end{array}$ & $\begin{array}{l}\text { Hidróxido } \\
\text { de Sódio }\end{array}$ & & $\begin{array}{l}\text { Turbidez } \\
\text { (uT) }\end{array}$ & $\begin{array}{l}\text { Cor Apar. } \\
(\mathrm{uH})\end{array}$ & $\begin{array}{l}\text { Turbidez } \\
\text { (uT) }\end{array}$ & $\begin{array}{l}\text { Cor } \\
\text { Apar. } \\
(\mathrm{uH})\end{array}$ & $\begin{array}{l}\text { Turbidez } \\
\text { (uT) }\end{array}$ & $\begin{array}{l}\text { Cor } \\
\text { Apar. } \\
\text { (uH) }\end{array}$ \\
\hline & $(\mathrm{mg} / \mathrm{L})$ & $(\mathrm{mg} / \mathrm{L})$ & & & & & & & \\
\hline 1 & 160 & 35 & 3,83 & 6,8 & 401 & 6,29 & 401 & 6,29 & 403 \\
\hline 2 & 160 & 40 & 4,05 & 7,44 & 403 & 7,15 & 403 & 6,52 & 404 \\
\hline 3 & 160 & 42 & 4,25 & 8,2 & 415 & 8,09 & 416 & 7,83 & 415 \\
\hline 4 & 160 & 45 & 5,52 & 1,77 & 46 & 1,36 & 37 & 0,58 & 9 \\
\hline 5 & 160 & 50 & 6,35 & 1,09 & 35 & 1,01 & 33 & 0,69 & 21 \\
\hline 6 & 180 & & 3,45 & 5,54 & 418 & 5,98 & 426 & 5,68 & 418 \\
\hline
\end{tabular}


Tabela E.10 - Resultados dos ensaios para construção do diagrama de coagulação

\begin{tabular}{|c|c|c|c|c|c|c|c|c|c|}
\hline \multirow{3}{*}{ Jarro } & \multicolumn{2}{|c|}{ Produtos químicos } & \multirow{3}{*}{$\begin{array}{l}\mathrm{pH} \quad \mathrm{de} \\
\text { Coagulação }\end{array}$} & \multicolumn{2}{|c|}{$\mathrm{Vs} 1=3,0 \mathrm{~cm} / \mathrm{min}$} & \multicolumn{2}{|c|}{$\mathrm{Vs} 2=1,5 \mathrm{~cm} / \mathrm{min}$} & \multicolumn{2}{|c|}{$\mathrm{Vs} 3=1,0 \mathrm{~cm} / \mathrm{min}$} \\
\hline & $\begin{array}{l}\text { Cloreto } \\
\text { Férrico } \\
\text { Líquido } \\
\text { Comercial } \\
\end{array}$ & $\begin{array}{l}\text { Hidróxido } \\
\text { de Sódio }\end{array}$ & & $\begin{array}{l}\text { Turbidez } \\
\text { (uT) }\end{array}$ & $\begin{array}{l}\text { Cor Apar. } \\
(\mathrm{uH})\end{array}$ & $\begin{array}{l}\text { Turbidez } \\
\text { (uT) }\end{array}$ & $\begin{array}{l}\text { Cor } \\
\text { Apar. } \\
(\mathrm{uH})\end{array}$ & $\begin{array}{l}\text { Turbidez } \\
\text { (uT) }\end{array}$ & $\begin{array}{l}\text { Cor } \\
\text { Apar. } \\
(\mathrm{uH})\end{array}$ \\
\hline & $(\mathrm{mg} / \mathrm{L})$ & $(\mathrm{mg} / \mathrm{L})$ & & & & & & & \\
\hline 1 & 180 & 20 & 3,45 & 5,88 & 322 & 6,27 & 323 & 5,93 & 338 \\
\hline 2 & 180 & 40 & 3,74 & 5,92 & 432 & 6,3 & 432 & 5,86 & 421 \\
\hline 3 & 180 & 45 & 4 & 7,48 & 445 & 7,27 & 448 & 6,92 & 451 \\
\hline 4 & 180 & 52 & 5,03 & 1,11 & 30 & 1,53 & 41 & 0,7 & 14 \\
\hline 5 & 180 & 54 & 5,6 & 1,34 & 30 & 1,23 & 27 & 1,17 & 7 \\
\hline 6 & 180 & 56 & 6,3 & 0,93 & 29 & 0,78 & 20 & 0,69 & 19 \\
\hline
\end{tabular}

Tabela E.11 - Resultados dos ensaios para construção do diagrama de coagulação

\begin{tabular}{|c|c|c|c|c|c|c|c|c|c|}
\hline \multirow{3}{*}{ Jarro } & Produtos q & límicos & \multirow{3}{*}{$\begin{array}{l}\mathrm{pH} \quad \mathrm{de} \\
\text { Coagulação }\end{array}$} & \multicolumn{2}{|c|}{$\mathrm{Vs} 1=3,0 \mathrm{~cm} / \mathrm{min}$} & \multicolumn{2}{|c|}{$\mathrm{Vs} 2=1,5 \mathrm{~cm} / \mathrm{min}$} & \multicolumn{2}{|c|}{$\mathrm{Vs} 3=1,0 \mathrm{~cm} / \mathrm{min}$} \\
\hline & $\begin{array}{l}\text { Cloreto } \\
\text { Férrico } \\
\text { Líquido } \\
\text { Comercial }\end{array}$ & $\begin{array}{l}\text { Hidróxido } \\
\text { de Sódio }\end{array}$ & & $\begin{array}{l}\text { Turbidez } \\
\text { (uT) }\end{array}$ & $\begin{array}{l}\text { Cor Apar. } \\
(\mathrm{uH})\end{array}$ & $\begin{array}{l}\text { Turbidez } \\
\text { (uT) }\end{array}$ & $\begin{array}{l}\text { Cor } \\
\text { Apar. } \\
(\mathrm{uH})\end{array}$ & $\begin{array}{l}\text { Turbidez } \\
\text { (uT) }\end{array}$ & $\begin{array}{l}\text { Cor } \\
\text { Apar. } \\
(\mathrm{uH})\end{array}$ \\
\hline & $(\mathrm{mg} / \mathrm{L})$ & $(\mathrm{mg} / \mathrm{L})$ & & & & & & & \\
\hline 1 & 180 & 60 & 6,86 & 9,49 & 453 & 9,48 & 440 & 9,13 & 440 \\
\hline 2 & 180 & 75 & 7,54 & 6,43 & 399 & 6,41 & 375 & 6,31 & 374 \\
\hline 3 & 180 & 80 & 7,75 & 6,94 & 404 & 7,02 & 390 & 6,8 & 388 \\
\hline 4 & 180 & 85 & 7,9 & 8,38 & 428 & 8,12 & 414 & 7,82 & 413 \\
\hline 5 & 200 & & 3,44 & 6,05 & 312 & 6,05 & 316 & 5,59 & 331 \\
\hline 6 & 200 & 53 & 4,06 & 9,1 & 479 & 8,79 & 481 & 7,99 & 477 \\
\hline
\end{tabular}

Tabela E.12 - Resultados dos ensaios para construção do diagrama de coagulação

\begin{tabular}{|c|c|c|c|c|c|c|c|c|c|}
\hline \multirow{3}{*}{ Jarro } & \multicolumn{2}{|c|}{ Produtos químicos } & \multirow{3}{*}{$\begin{array}{l}\mathrm{pH} \quad \mathrm{de} \\
\text { Coagulação }\end{array}$} & \multicolumn{2}{|c|}{$\mathrm{Vs} 1=3,0 \mathrm{~cm} / \mathrm{min}$} & \multicolumn{2}{|c|}{$\mathrm{Vs} 2=1,5 \mathrm{~cm} / \mathrm{min}$} & \multicolumn{2}{|c|}{$\mathrm{Vs} 3=1,0 \mathrm{~cm} / \mathrm{min}$} \\
\hline & $\begin{array}{l}\text { Cloreto } \\
\text { Férrico } \\
\text { Líquido } \\
\text { Comercial } \\
\end{array}$ & $\begin{array}{l}\text { Hidróxido } \\
\text { de Sódio }\end{array}$ & & $\begin{array}{l}\text { Turbidez } \\
\text { (uT) }\end{array}$ & $\begin{array}{l}\text { Cor Apar. } \\
(\mathrm{uH})\end{array}$ & $\begin{array}{l}\text { Turbidez } \\
\text { (uT) }\end{array}$ & $\begin{array}{l}\text { Cor } \\
\text { Apar. } \\
(\mathrm{uH})\end{array}$ & $\begin{array}{l}\text { Turbidez } \\
\text { (uT) }\end{array}$ & $\begin{array}{l}\text { Cor } \\
\text { Apar. } \\
\text { (uH) }\end{array}$ \\
\hline & $(\mathrm{mg} / \mathrm{L})$ & $(\mathrm{mg} / \mathrm{L})$ & & & & & & & \\
\hline 1 & 200 & 55 & 4,4 & 7,31 & 465 & 7,49 & 466 & 6,85 & 466 \\
\hline 2 & 200 & 57 & 5,4 & 0,77 & 18 & 0,69 & 15 & 0,54 & 7 \\
\hline 3 & 200 & 60 & 6,05 & 3,45 & 125 & 1,41 & 35 & 0,76 & 11 \\
\hline 4 & 220 & & 3,34 & 5,66 & 478 & 5,53 & 481 & 5,18 & 484 \\
\hline 5 & 220 & 40 & 3,42 & 6,03 & 306 & 6,1 & 311 & 5,54 & 326 \\
\hline 6 & 220 & 45 & 3,7 & 5,7 & 480 & 5,7 & 483 & 5,56 & 483 \\
\hline
\end{tabular}


Tabela E.13 - Resultados dos ensaios para construção do diagrama de coagulação

\begin{tabular}{|c|c|c|c|c|c|c|c|c|c|}
\hline \multirow{3}{*}{ Jarro } & Produtos qu & límicos & \multirow{3}{*}{$\begin{array}{l}\text { pH de } \\
\text { Coagulação }\end{array}$} & \multicolumn{2}{|c|}{$\mathrm{Vs} 1=3,0 \mathrm{~cm} / \mathrm{min}$} & \multicolumn{2}{|c|}{$\mathrm{Vs} 2=1,5 \mathrm{~cm} / \mathrm{min}$} & \multicolumn{2}{|c|}{$\mathrm{Vs} 3=1,0 \mathrm{~cm} / \mathrm{min}$} \\
\hline & $\begin{array}{l}\text { Férrico } \\
\text { Líquido } \\
\text { Comercial }\end{array}$ & $\begin{array}{l}\text { Hidróxido } \\
\text { de Sódio }\end{array}$ & & $\begin{array}{l}\text { Turbidez } \\
\text { (uT) }\end{array}$ & $\begin{array}{l}\text { Cor Apar. } \\
(\mathrm{uH})\end{array}$ & $\begin{array}{l}\text { Turbidez } \\
\text { (uT) }\end{array}$ & $\begin{array}{l}\text { Cor } \\
\text { Apar. } \\
(\mathrm{uH})\end{array}$ & $\begin{array}{l}\text { Turbidez } \\
\text { (uT) }\end{array}$ & $\begin{array}{l}\text { Cor } \\
\text { Apar. } \\
(\mathrm{uH})\end{array}$ \\
\hline & $(\mathrm{mg} / \mathrm{L})$ & $(\mathrm{mg} / \mathrm{L})$ & & & & & & & \\
\hline 1 & 220 & 50 & 3,7 & 7,1 & 440 & 6,78 & 444 & 6,8 & 441 \\
\hline 2 & 220 & 52 & 3,8 & 6,3 & 489 & 6,14 & 490 & 5,79 & 490 \\
\hline 3 & 220 & 54 & 3,8 & 7,15 & 449 & 6,91 & 449 & 7,07 & 446 \\
\hline 4 & 220 & 56 & 4,2 & 8,88 & 512 & 8,35 & 513 & 8,58 & 515 \\
\hline 5 & 220 & 58 & 4,33 & 8,11 & 499 & 8,03 & 501 & 7,41 & 501 \\
\hline 6 & 220 & 60 & 4,7 & 11 & 520 & 10,6 & 520 & 10,1 & 520 \\
\hline
\end{tabular}

Tabela E.14 - Resultados dos ensaios para construção do diagrama de coagulação

\begin{tabular}{|c|c|c|c|c|c|c|c|c|c|}
\hline \multirow{3}{*}{ Jarro } & Produtos q & límicos & \multirow{3}{*}{$\begin{array}{l}\text { pH de } \\
\text { Coagulação }\end{array}$} & \multicolumn{2}{|c|}{$\mathrm{Vs} 1=3,0 \mathrm{~cm} / \mathrm{min}$} & \multicolumn{2}{|c|}{$\mathrm{Vs} 2=1,5 \mathrm{~cm} / \mathrm{min}$} & \multicolumn{2}{|c|}{$\mathrm{Vs} 3=1,0 \mathrm{~cm} / \mathrm{min}$} \\
\hline & $\begin{array}{l}\text { Férrico } \\
\text { Líquido } \\
\text { Comercial }\end{array}$ & $\begin{array}{l}\text { Hidróxido } \\
\text { de Sódio }\end{array}$ & & \multirow[t]{2}{*}{$\begin{array}{l}\text { Turbidez } \\
\text { (uT) }\end{array}$} & \multirow[t]{2}{*}{$\begin{array}{l}\text { Cor Apar. } \\
(\mathrm{uH})\end{array}$} & \multirow[t]{2}{*}{$\begin{array}{l}\text { Turbidez } \\
\text { (uT) }\end{array}$} & \multirow[t]{2}{*}{$\begin{array}{l}\text { Cor } \\
\text { Apar. } \\
(\mathrm{uH})\end{array}$} & \multirow[t]{2}{*}{$\begin{array}{l}\text { Turbidez } \\
\text { (uT) }\end{array}$} & \multirow[t]{2}{*}{$\begin{array}{l}\text { Cor } \\
\text { Apar. } \\
\text { (uH) }\end{array}$} \\
\hline & $(\mathrm{mg} / \mathrm{L})$ & $(\mathrm{mg} / \mathrm{L})$ & & & & & & & \\
\hline 1 & 220 & 62 & 5,15 & 2,54 & 66 & 1,27 & 15 & 0,91 & 15 \\
\hline 2 & 220 & 64 & 5,4 & 0,78 & 22 & 1 & 22 & 0,69 & 8 \\
\hline 3 & 220 & 66 & 5,9 & 2,07 & 56 & 1,13 & 23 & 0,95 & 9 \\
\hline 4 & 220 & 68 & 6,3 & 0,93 & 21 & 0,79 & 21 & 0,49 & 6 \\
\hline 5 & 220 & 70 & 6,6 & 2,46 & 120 & 2,32 & 98 & 1,85 & 98 \\
\hline 6 & 220 & 72 & 7 & 10,8 & 520 & 10,6 & 520 & 10,3 & 520 \\
\hline
\end{tabular}

Tabela E.15 - Resultados dos ensaios para construção do diagrama de coagulação

\begin{tabular}{|c|c|c|c|c|c|c|c|c|c|}
\hline \multirow{3}{*}{ Jarro } & \multicolumn{2}{|c|}{ Produtos químicos } & \multirow{3}{*}{$\begin{array}{l}\mathrm{pH} \quad \mathrm{de} \\
\text { Coagulação }\end{array}$} & \multicolumn{2}{|c|}{$\mathrm{Vs} 1=3,0 \mathrm{~cm} / \mathrm{min}$} & \multicolumn{2}{|c|}{$\mathrm{Vs} 2=1,5 \mathrm{~cm} / \mathrm{min}$} & \multicolumn{2}{|c|}{$\mathrm{Vs} 3=1,0 \mathrm{~cm} / \mathrm{min}$} \\
\hline & $\begin{array}{l}\text { Cloreto } \\
\text { Férrico } \\
\text { Líquido } \\
\text { Comercial } \\
\end{array}$ & $\begin{array}{l}\text { Hidróxido } \\
\text { de Sódio }\end{array}$ & & $\begin{array}{l}\text { Turbidez } \\
\text { (uT) }\end{array}$ & $\begin{array}{l}\text { Cor Apar. } \\
(\mathrm{uH})\end{array}$ & $\begin{array}{l}\text { Turbidez } \\
\text { (uT) }\end{array}$ & $\begin{array}{l}\text { Cor } \\
\text { Apar. } \\
(\mathrm{uH})\end{array}$ & $\begin{array}{l}\text { Turbidez } \\
\text { (uT) }\end{array}$ & $\begin{array}{l}\text { Cor } \\
\text { Apar. } \\
(\mathrm{uH})\end{array}$ \\
\hline & $(\mathrm{mg} / \mathrm{L})$ & $(\mathrm{mg} / \mathrm{L})$ & & & & & & & \\
\hline 1 & 240 & & 3,42 & 6,15 & 301 & 6,07 & 306 & 5,53 & 321 \\
\hline 2 & 240 & 60 & 3,89 & 6,12 & 508 & 6,07 & 513 & 5,88 & 514 \\
\hline 3 & 240 & 67 & 4,17 & 8,88 & 501 & 8,21 & 504 & 7,26 & 508 \\
\hline 4 & 240 & 68 & 4,44 & 9.25 & 520 & 9,1 & 520 & 7,71 & 512 \\
\hline 5 & 240 & 69 & 4,67 & 11,5 & 520 & 11,3 & 520 & 10 & 520 \\
\hline 6 & 240 & 70 & 4,9 & 1,44 & 64 & 1,73 & 77 & 1,22 & 58 \\
\hline
\end{tabular}


Tabela E.16 - Resultados dos ensaios para construção do diagrama de coagulação

\begin{tabular}{|c|c|c|c|c|c|c|c|c|c|}
\hline \multirow{3}{*}{ Jarro } & \multicolumn{2}{|c|}{ Produtos químicos } & \multirow{3}{*}{$\begin{array}{l}\mathrm{pH} \quad \mathrm{de} \\
\text { Coagulação }\end{array}$} & \multicolumn{2}{|c|}{$\mathrm{Vs} 1=3,0 \mathrm{~cm} / \mathrm{min}$} & \multicolumn{2}{|c|}{$\mathrm{Vs} 2=1,5 \mathrm{~cm} / \mathrm{min}$} & \multicolumn{2}{|c|}{$\mathrm{Vs} 3=1,0 \mathrm{~cm} / \mathrm{min}$} \\
\hline & $\begin{array}{l}\text { Cloreto } \\
\text { Férrico } \\
\text { Líquido } \\
\text { Comercial } \\
\end{array}$ & $\begin{array}{l}\text { Hidróxido } \\
\text { de Sódio }\end{array}$ & & $\begin{array}{l}\text { Turbidez } \\
\text { (uT) }\end{array}$ & $\begin{array}{l}\text { Cor Apar. } \\
(\mathrm{uH})\end{array}$ & $\begin{array}{l}\text { Turbidez } \\
\text { (uT) }\end{array}$ & $\begin{array}{l}\text { Cor } \\
\text { Apar. } \\
(\mathrm{uH})\end{array}$ & $\begin{array}{l}\text { Turbidez } \\
\text { (uT) }\end{array}$ & $\begin{array}{l}\text { Cor } \\
\text { Apar. } \\
(\mathrm{uH})\end{array}$ \\
\hline & $(\mathrm{mg} / \mathrm{L})$ & $(\mathrm{mg} / \mathrm{L})$ & & & & & & & \\
\hline 1 & 240 & 71 & 5,1 & 1,45 & 26 & 0,76 & 17 & 0,59 & 11 \\
\hline 2 & 240 & 73 & 6 & 2,03 & 66 & 1,1 & 25 & 0,67 & 9 \\
\hline 3 & 240 & 74 & 6,21 & 1,43 & 38 & 0,84 & 21 & 0,57 & 7 \\
\hline 4 & 240 & 75 & 6,4 & 1,06 & 32 & 0,82 & 19 & 0,59 & 7 \\
\hline 5 & 240 & 76 & 6,55 & 1,03 & 30 & 0,81 & 16 & 0,53 & 10 \\
\hline 6 & 260 & 60 & 3,65 & 8,25 & 520 & 7,04 & 520 & 6,74 & 520 \\
\hline
\end{tabular}

Tabela E.17 - Resultados dos ensaios para construção do diagrama de coagulação

\begin{tabular}{|c|c|c|c|c|c|c|c|c|c|}
\hline \multirow{3}{*}{ Jarro } & Produtos q & límicos & \multirow{3}{*}{$\begin{array}{l}\text { pH de } \\
\text { Coagulação }\end{array}$} & \multicolumn{2}{|c|}{$\mathrm{Vs} 1=3,0 \mathrm{~cm} / \mathrm{min}$} & \multicolumn{2}{|c|}{$\mathrm{Vs} 2=1,5 \mathrm{~cm} / \mathrm{min}$} & \multicolumn{2}{|c|}{$\mathrm{Vs} 3=1,0 \mathrm{~cm} / \mathrm{min}$} \\
\hline & $\begin{array}{l}\text { Cloreto } \\
\text { Férrico } \\
\text { Líquido } \\
\text { Comercial } \\
\end{array}$ & $\begin{array}{l}\text { Hidróxido } \\
\text { de Sódio }\end{array}$ & & $\begin{array}{l}\text { Turbidez } \\
\text { (uT) }\end{array}$ & $\begin{array}{l}\text { Cor Apar. } \\
(\mathrm{uH})\end{array}$ & $\begin{array}{l}\text { Turbidez } \\
\text { (uT) }\end{array}$ & $\begin{array}{l}\text { Cor } \\
\text { Apar. } \\
(\mathrm{uH})\end{array}$ & $\begin{array}{l}\text { Turbidez } \\
\text { (uT) }\end{array}$ & $\begin{array}{l}\text { Cor } \\
\text { Apar. } \\
(\mathrm{uH})\end{array}$ \\
\hline & $(\mathrm{mg} / \mathrm{L})$ & $(\mathrm{mg} / \mathrm{L})$ & & & & & & & \\
\hline 1 & 260 & 70 & 4,05 & 8,38 & 520 & 8,17 & 520 & 7,71 & 520 \\
\hline 2 & 260 & 72 & 4,32 & 8,1 & 520 & 8,5 & 520 & 7,8 & 520 \\
\hline 3 & 260 & 74 & 4,7 & 11,6 & 520 & 11,5 & 520 & 10,9 & 520 \\
\hline 4 & 260 & 76 & 4,82 & 3,47 & 218 & 3,03 & 195 & 2,89 & 184 \\
\hline 5 & 260 & 78 & 5,68 & 1,96 & 60 & 1,1 & 20 & 0,6 & 6 \\
\hline 6 & 260 & 80 & 6,11 & 1 & 24 & 1,05 & 22 & 0,52 & 5 \\
\hline
\end{tabular}

Tabela E.18 - Resultados dos ensaios para construção do diagrama de coagulação

\begin{tabular}{|c|c|c|c|c|c|c|c|c|c|}
\hline \multirow{3}{*}{ Jarro } & \multicolumn{2}{|c|}{ Produtos químicos } & \multirow{3}{*}{$\begin{array}{l}\mathrm{pH} \quad \mathrm{de} \\
\text { Coagulação }\end{array}$} & \multicolumn{2}{|c|}{$\mathrm{Vs} 1=3,0 \mathrm{~cm} / \mathrm{min}$} & \multicolumn{2}{|c|}{$\mathrm{Vs} 2=1,5 \mathrm{~cm} / \mathrm{min}$} & \multicolumn{2}{|c|}{$\mathrm{Vs} 3=1,0 \mathrm{~cm} / \mathrm{min}$} \\
\hline & $\begin{array}{l}\text { Cloreto } \\
\text { Férrico } \\
\text { Líquido } \\
\text { Comercial } \\
\end{array}$ & $\begin{array}{l}\text { Hidróxido } \\
\text { de Sódio }\end{array}$ & & $\begin{array}{l}\text { Turbidez } \\
\text { (uT) }\end{array}$ & $\begin{array}{l}\text { Cor Apar. } \\
(\mathrm{uH})\end{array}$ & $\begin{array}{l}\text { Turbidez } \\
\text { (uT) }\end{array}$ & $\begin{array}{l}\text { Cor } \\
\text { Apar. } \\
(\mathrm{uH})\end{array}$ & $\begin{array}{l}\text { Turbidez } \\
\text { (uT) }\end{array}$ & $\begin{array}{l}\text { Cor } \\
\text { Apar. } \\
(\mathrm{uH})\end{array}$ \\
\hline & $(\mathrm{mg} / \mathrm{L})$ & $(\mathrm{mg} / \mathrm{L})$ & & & & & & & \\
\hline 1 & 260 & 82 & 6,3 & 0,72 & 19 & 0,65 & 11 & 0,52 & 7 \\
\hline 2 & 260 & 84 & 6,48 & 0,98 & 25 & 0,83 & 12 & 0,61 & 10 \\
\hline 3 & 260 & 86 & 6,69 & 1,1 & 33 & 0,77 & 16 & 0,6 & 12 \\
\hline 4 & 260 & 88 & 7,08 & 2,65 & 158 & 2,77 & 153 & 2,49 & 150 \\
\hline 5 & 260 & 90 & 7,55 & 11,3 & 520 & 9,21 & 520 & 9,33 & 520 \\
\hline 6 & 280 & & 3,41 & 6,09 & 287 & 5,96 & 293 & 5,29 & 311 \\
\hline
\end{tabular}


Tabela E.19 - Resultados dos ensaios para construção do diagrama de coagulação

\begin{tabular}{|c|c|c|c|c|c|c|c|c|c|}
\hline \multirow{3}{*}{ Jarro } & Produtos qu & límicos & \multirow{3}{*}{$\begin{array}{l}\text { pH de } \\
\text { Coagulação }\end{array}$} & \multicolumn{2}{|c|}{$\mathrm{Vs} 1=3,0 \mathrm{~cm} / \mathrm{min}$} & \multicolumn{2}{|c|}{$\mathrm{Vs} 2=1,5 \mathrm{~cm} / \mathrm{min}$} & \multicolumn{2}{|c|}{$\mathrm{Vs} 3=1,0 \mathrm{~cm} / \mathrm{min}$} \\
\hline & $\begin{array}{l}\text { Férrico } \\
\text { Líquido } \\
\text { Comercial }\end{array}$ & $\begin{array}{l}\text { Hidróxido } \\
\text { de Sódio }\end{array}$ & & $\begin{array}{l}\text { Turbidez } \\
\text { (uT) }\end{array}$ & $\begin{array}{l}\text { Cor Apar. } \\
(\mathrm{uH})\end{array}$ & $\begin{array}{l}\text { Turbidez } \\
\text { (uT) }\end{array}$ & $\begin{array}{l}\text { Cor } \\
\text { Apar. } \\
(\mathrm{uH})\end{array}$ & $\begin{array}{l}\text { Turbidez } \\
\text { (uT) }\end{array}$ & $\begin{array}{l}\text { Cor } \\
\text { Apar. } \\
(\mathrm{uH})\end{array}$ \\
\hline & $(\mathrm{mg} / \mathrm{L})$ & $(\mathrm{mg} / \mathrm{L})$ & & & & & & & \\
\hline 1 & 280 & 80 & 4,21 & 11,4 & 520 & 10,3 & 520 & 9,72 & 520 \\
\hline 2 & 280 & 82 & 5,15 & 1,2 & 40 & 1,23 & 40 & 1 & 30 \\
\hline 3 & 280 & 85 & 5,89 & 1,17 & 27 & 0,92 & 25 & 0,56 & 8 \\
\hline 4 & 280 & 86 & 6,21 & 1,22 & 24 & 0,94 & 20 & 0,57 & 6 \\
\hline 5 & 280 & 90 & 6,72 & 1,49 & 69 & 1,54 & 68 & 1,46 & 65 \\
\hline 6 & 280 & 91 & 6,95 & 2,17 & 124 & 1,99 & 115 & 1,89 & 114 \\
\hline
\end{tabular}

Tabela E.20 - Resultados dos ensaios para construção do diagrama de coagulação

\begin{tabular}{|c|c|c|c|c|c|c|c|c|c|}
\hline \multirow{3}{*}{ Jarro } & Produtos C & uímicos & \multirow{3}{*}{$\begin{array}{l}\mathrm{pH} \quad \mathrm{de} \\
\text { Coagulação }\end{array}$} & \multicolumn{2}{|c|}{$\mathrm{Vs} 1=3,0 \mathrm{~cm} / \mathrm{min}$} & \multicolumn{2}{|c|}{$\mathrm{Vs} 2=1,5 \mathrm{~cm} / \mathrm{min}$} & \multicolumn{2}{|c|}{$\mathrm{Vs} 3=1,0 \mathrm{~cm} / \mathrm{min}$} \\
\hline & $\begin{array}{l}\text { Férrico } \\
\text { Líquido } \\
\text { Comercial }\end{array}$ & $\begin{array}{l}\text { Hidróxido } \\
\text { de Sódio }\end{array}$ & & \multirow[t]{2}{*}{$\begin{array}{l}\text { Turbidez } \\
\text { (uT) }\end{array}$} & \multirow[t]{2}{*}{$\begin{array}{l}\text { Cor Apar. } \\
(\mathrm{uH})\end{array}$} & \multirow[t]{2}{*}{$\begin{array}{l}\text { Turbidez } \\
\text { (uT) }\end{array}$} & \multirow[t]{2}{*}{$\begin{array}{l}\text { Cor } \\
\text { Apar. } \\
\text { (uH) }\end{array}$} & \multirow[t]{2}{*}{$\begin{array}{l}\text { Turbidez } \\
\text { (uT) }\end{array}$} & \multirow[t]{2}{*}{$\begin{array}{l}\text { Cor } \\
\text { Apar. } \\
\text { (uH) }\end{array}$} \\
\hline & $(\mathrm{mg} / \mathrm{L})$ & $(\mathrm{mg} / \mathrm{L})$ & & & & & & & \\
\hline 1 & 280 & 100 & 7,55 & 9,7 & 520 & 9,3 & 520 & 8,63 & 520 \\
\hline 2 & 280 & 110 & 9,17 & 8,99 & 520 & 8,53 & 520 & 7,56 & 520 \\
\hline 3 & 300 & 80 & 4,01 & 7,29 & 520 & 7,14 & 520 & 6,78 & 520 \\
\hline 4 & 300 & 81 & 4,21 & 9,58 & 520 & 9,89 & 520 & 9,48 & 520 \\
\hline 5 & 300 & 82 & 4,35 & 8,05 & 520 & 7,56 & 520 & 7,58 & 520 \\
\hline 6 & 300 & 84 & 4,61 & 9,86 & 520 & 10,1 & 520 & 9,71 & 520 \\
\hline
\end{tabular}

Tabela E.21 - Resultados dos ensaios para construção do diagrama de coagulação

\begin{tabular}{|c|c|c|c|c|c|c|c|c|c|}
\hline \multirow{3}{*}{ Jarro } & Produtos q & uímicos & \multirow{3}{*}{$\begin{array}{l}\mathrm{pH} \quad \mathrm{de} \\
\text { Coagulação }\end{array}$} & \multicolumn{2}{|c|}{$\mathrm{Vs} 1=3,0 \mathrm{~cm} / \mathrm{min}$} & \multicolumn{2}{|c|}{$\mathrm{Vs} 2=1,5 \mathrm{~cm} / \mathrm{min}$} & \multicolumn{2}{|c|}{$\mathrm{Vs} 3=1,0 \mathrm{~cm} / \mathrm{min}$} \\
\hline & $\begin{array}{l}\text { Cloreto } \\
\text { Férrico } \\
\text { Líquido } \\
\text { Comercial } \\
\end{array}$ & $\begin{array}{l}\text { Hidróxido } \\
\text { de Sódio }\end{array}$ & & \multirow[t]{2}{*}{$\begin{array}{l}\text { Turbidez } \\
\text { (uT) }\end{array}$} & \multirow[t]{2}{*}{$\begin{array}{l}\text { Cor Apar. } \\
(\mathrm{uH})\end{array}$} & \multirow[t]{2}{*}{$\begin{array}{l}\text { Turbidez } \\
\text { (uT) }\end{array}$} & \multirow[t]{2}{*}{$\begin{array}{l}\text { Cor } \\
\text { Apar. } \\
(\mathrm{uH})\end{array}$} & \multirow[t]{2}{*}{$\begin{array}{l}\text { Turbidez } \\
\text { (uT) }\end{array}$} & \multirow[t]{2}{*}{$\begin{array}{l}\text { Cor } \\
\text { Apar } \\
\text { (uH) }\end{array}$} \\
\hline & $(\mathrm{mg} / \mathrm{L})$ & $(\mathrm{mg} / \mathrm{L})$ & & & & & & & \\
\hline 1 & 300 & 86 & 4,72 & 9,5 & 520 & 9,54 & 520 & 9,57 & 520 \\
\hline 2 & 300 & 88 & 4,92 & 4,91 & 302 & 4,15 & 275 & 3,76 & 257 \\
\hline 3 & 300 & 90 & 5,28 & 1,12 & 39 & 0,92 & 14 & 0,69 & 8 \\
\hline 4 & 300 & 92 & 6 & 0,96 & 29 & 0,91 & 23 & 0,6 & 5 \\
\hline 5 & 300 & 95 & 6,4 & 0,72 & 21 & 0,64 & 16 & 0,57 & 9 \\
\hline 6 & 300 & 97 & 6,48 & 1,09 & 30 & 0,86 & 17 & 0,71 & 10 \\
\hline
\end{tabular}


Tabela E.22 - Resultados dos ensaios para construção do diagrama de coagulação

\begin{tabular}{|c|c|c|c|c|c|c|c|c|c|}
\hline \multirow{3}{*}{ Jarro } & \multicolumn{2}{|c|}{ Produtos químicos } & \multirow{3}{*}{$\begin{array}{l}\mathrm{pH} \quad \mathrm{de} \\
\text { Coagulação }\end{array}$} & \multicolumn{2}{|c|}{$\mathrm{Vs} 1=3,0 \mathrm{~cm} / \mathrm{min}$} & \multicolumn{2}{|c|}{$\mathrm{Vs} 2=1,5 \mathrm{~cm} / \mathrm{min}$} & \multicolumn{2}{|c|}{$\mathrm{Vs} 3=1,0 \mathrm{~cm} / \mathrm{min}$} \\
\hline & $\begin{array}{l}\text { Cloreto } \\
\text { Férrico } \\
\text { Líquido } \\
\text { Comercial } \\
\end{array}$ & $\begin{array}{l}\text { Hidróxido } \\
\text { de Sódio }\end{array}$ & & $\begin{array}{l}\text { Turbidez } \\
\text { (uT) }\end{array}$ & $\begin{array}{l}\text { Cor Apar. } \\
(\mathrm{uH})\end{array}$ & $\begin{array}{l}\text { Turbidez } \\
\text { (uT) }\end{array}$ & $\begin{array}{l}\text { Cor } \\
\text { Apar. } \\
(\mathrm{uH})\end{array}$ & $\begin{array}{l}\text { Turbidez } \\
\text { (uT) }\end{array}$ & $\begin{array}{l}\text { Cor } \\
\text { Apar. } \\
(\mathrm{uH})\end{array}$ \\
\hline & $(\mathrm{mg} / \mathrm{L})$ & $(\mathrm{mg} / \mathrm{L})$ & & & & & & & \\
\hline 1 & 300 & 100 & 7,7 & 7,73 & 508 & 7,63 & 505 & 7,42 & 505 \\
\hline 2 & 320 & & 3,36 & 6,06 & 272 & 5,91 & 275 & 5,66 & 292 \\
\hline 3 & 320 & 80 & 3,6 & 7,19 & 520 & 6,96 & 520 & 6,57 & 520 \\
\hline 4 & 320 & 82 & 3,84 & 8,42 & 520 & 8,27 & 520 & 8,06 & 520 \\
\hline 5 & 320 & 85 & 4,15 & 9,76 & 520 & 9,73 & 520 & 10,1 & 520 \\
\hline 6 & 320 & 90 & 4,33 & 10,7 & 520 & 10,6 & 520 & 10,3 & 520 \\
\hline
\end{tabular}

Tabela E.23 - Resultados dos ensaios para construção do diagrama de coagulação

\begin{tabular}{|c|c|c|c|c|c|c|c|c|c|}
\hline \multirow{3}{*}{ Jarro } & Produtos q & límicos & \multirow{3}{*}{$\begin{array}{l}\mathrm{pH} \quad \mathrm{de} \\
\text { Coagulação }\end{array}$} & \multicolumn{2}{|c|}{$\mathrm{Vs} 1=3,0 \mathrm{~cm} / \mathrm{min}$} & \multicolumn{2}{|c|}{$\mathrm{Vs} 2=1,5 \mathrm{~cm} / \mathrm{min}$} & \multicolumn{2}{|c|}{$\mathrm{Vs} 3=1,0 \mathrm{~cm} / \mathrm{min}$} \\
\hline & $\begin{array}{l}\text { Cloreto } \\
\text { Férrico } \\
\text { Líquido } \\
\text { Comercial }\end{array}$ & $\begin{array}{l}\text { Hidróxido } \\
\text { de Sódio }\end{array}$ & & $\begin{array}{l}\text { Turbidez } \\
\text { (uT) }\end{array}$ & $\begin{array}{l}\text { Cor Apar. } \\
(\mathrm{uH})\end{array}$ & $\begin{array}{l}\text { Turbidez } \\
\text { (uT) }\end{array}$ & $\begin{array}{l}\text { Cor } \\
\text { Apar. } \\
(\mathrm{uH})\end{array}$ & $\begin{array}{l}\text { Turbidez } \\
\text { (uT) }\end{array}$ & $\begin{array}{l}\text { Cor } \\
\text { Apar. } \\
(\mathrm{uH})\end{array}$ \\
\hline & $(\mathrm{mg} / \mathrm{L})$ & $(\mathrm{mg} / \mathrm{L})$ & & & & & & & \\
\hline 1 & 320 & 92 & 4,79 & 15,1 & 520 & 12 & 520 & 8,08 & 520 \\
\hline 2 & 320 & 9,5 & 5 & 1,89 & 77 & 1,6 & 61 & 1,1 & 61 \\
\hline 3 & 320 & 98 & 6 & 1,32 & 48 & 0,82 & 21 & 0,51 & 6 \\
\hline 4 & 320 & 100 & 6,2 & 1,05 & 33 & 0,59 & 9 & 0,55 & 8 \\
\hline 5 & 320 & 102 & 6,29 & 1,29 & 44 & 1,02 & 30 & 0,5 & 5 \\
\hline 6 & 320 & 104 & 7,36 & 1,39 & 37 & 0,98 & 33 & 0,87 & 31 \\
\hline
\end{tabular}

Tabela E.24 - Resultados dos ensaios para construção do diagrama de coagulação

\begin{tabular}{|c|c|c|c|c|c|c|c|c|c|}
\hline \multirow{3}{*}{ Jarro } & \multicolumn{2}{|c|}{ Produtos químicos } & \multirow{3}{*}{$\begin{array}{l}\mathrm{pH} \quad \mathrm{de} \\
\text { Coagulação }\end{array}$} & \multicolumn{2}{|c|}{$\mathrm{Vs} 1=3,0 \mathrm{~cm} / \mathrm{min}$} & \multicolumn{2}{|c|}{$\mathrm{Vs} 2=1,5 \mathrm{~cm} / \mathrm{min}$} & \multicolumn{2}{|c|}{$\mathrm{Vs} 3=1,0 \mathrm{~cm} / \mathrm{min}$} \\
\hline & $\begin{array}{l}\text { Cloreto } \\
\text { Férrico } \\
\text { Líquido } \\
\text { Comercial } \\
\end{array}$ & $\begin{array}{l}\text { Hidróxido } \\
\text { de Sódio }\end{array}$ & & $\begin{array}{l}\text { Turbidez } \\
\text { (uT) }\end{array}$ & $\begin{array}{l}\text { Cor Apar. } \\
(\mathrm{uH})\end{array}$ & $\begin{array}{l}\text { Turbidez } \\
\text { (uT) }\end{array}$ & $\begin{array}{l}\text { Cor } \\
\text { Apar. } \\
(\mathrm{uH})\end{array}$ & $\begin{array}{l}\text { Turbidez } \\
\text { (uT) }\end{array}$ & $\begin{array}{l}\text { Cor } \\
\text { Apar. } \\
(\mathrm{uH})\end{array}$ \\
\hline & $(\mathrm{mg} / \mathrm{L})$ & $(\mathrm{mg} / \mathrm{L})$ & & & & & & & \\
\hline 1 & 320 & 106 & 7,75 & 13,6 & 520 & 11,3 & 520 & 8,97 & 494 \\
\hline 2 & 320 & 108 & 7,85 & 7,43 & 492 & 7,5 & 490 & 7,35 & 489 \\
\hline
\end{tabular}




\section{ANEXO F}

Resultados dos ensaios para seleção dos parâmetros de mistura rápida com o Cloreto Férrico como coagulante 
Tabela F.1 - Resultados dos ensaios para seleção dos parâmetros de mistura rápida

\begin{tabular}{|c|c|c|c|c|c|c|c|c|c|c|}
\hline \multicolumn{11}{|c|}{ gradiente de mistura rápida $=300 \mathrm{~s}^{-1}$} \\
\hline \multirow{3}{*}{ Jarro } & Produtos q & uímicos & \multirow{3}{*}{$\begin{array}{l}\text { Tempo } \\
\text { de } \\
\text { mistura } \\
\text { rápida } \\
\text { (s) }\end{array}$} & \multirow{3}{*}{$\begin{array}{l}\mathrm{pH} \\
\mathrm{de} \\
\text { Coag }\end{array}$} & $\mathrm{Vs} 1=3,0$ & $\mathrm{~cm} / \mathrm{min}$ & $\begin{array}{l}\mathrm{Vs} 2= \\
\mathrm{cm} / \mathrm{min}\end{array}$ & 1,5 & $\mathrm{Vs} 3=1,0$ & $\mathrm{~cm} / \mathrm{min}$ \\
\hline & $\begin{array}{l}\text { Férrico } \\
\text { Líquido } \\
\text { Comercial }\end{array}$ & $\begin{array}{l}\text { Hidróxido } \\
\text { de Sódio }\end{array}$ & & & \multirow[t]{2}{*}{$\begin{array}{l}\text { Turbidez } \\
\text { (uT) }\end{array}$} & \multirow[t]{2}{*}{$\begin{array}{l}\text { Cor } \\
\text { Apar. } \\
(\mathrm{uH})\end{array}$} & \multirow[t]{2}{*}{$\begin{array}{l}\text { Turbidez } \\
\text { (uT) }\end{array}$} & \multirow[t]{2}{*}{$\begin{array}{l}\text { Cor } \\
\text { Apar. } \\
(\mathrm{uH})\end{array}$} & \multirow[t]{2}{*}{$\begin{array}{l}\text { Turbidez } \\
\text { (uT) }\end{array}$} & \multirow[t]{2}{*}{$\begin{array}{l}\text { Cor } \\
\text { Apar. } \\
(\mathrm{uH})\end{array}$} \\
\hline & $(\mathrm{mg} / \mathrm{L})$ & $(\mathrm{mg} / \mathrm{L})$ & & & & & & & & \\
\hline 1 & 260 & 80 & 5 & 6,44 & 1,34 & 32 & 1,4 & 15 & 0,92 & 14 \\
\hline 2 & 260 & 80 & 10 & 6,51 & 1,41 & 32 & 1,38 & 18 & 0,98 & 17 \\
\hline 3 & 260 & 80 & 20 & 6,39 & 1,89 & 48 & 1,71 & 37 & 1,07 & 25 \\
\hline 4 & 260 & 80 & 30 & 6,35 & 1,43 & 55 & 1,48 & 34 & 1,14 & 30 \\
\hline 5 & 260 & 80 & 60 & 6,39 & 2,26 & 75 & 1,7 & 37 & 1,24 & 39 \\
\hline 6 & 260 & 80 & 90 & 6,29 & 2,51 & 98 & 2,51 & 55 & 1,57 & 44 \\
\hline
\end{tabular}

Tabela F.2 - Resultados dos ensaios para seleção dos parâmetros de mistura rápida

\begin{tabular}{|c|c|c|c|c|c|c|c|c|c|c|}
\hline \multicolumn{11}{|c|}{ gradiente de mistura rápida $=400 \mathrm{~s}^{-1}$} \\
\hline \multirow{3}{*}{ Jarro } & Produtos qu & dímicos & \multirow{3}{*}{$\begin{array}{l}\text { Tempo } \\
\text { de } \\
\text { mistura } \\
\text { rápida } \\
\text { (s) }\end{array}$} & \multirow{3}{*}{$\begin{array}{l}\mathrm{pH} \\
\text { de } \\
\text { Coag }\end{array}$} & $\mathrm{Vs} 1=3,0$ & $\mathrm{~cm} / \mathrm{min}$ & $\begin{array}{l}\mathrm{Vs} 2= \\
\mathrm{cm} / \mathrm{min}\end{array}$ & 1,5 & $\mathrm{Vs} 3=1,0$ & $\mathrm{~cm} / \mathrm{min}$ \\
\hline & $\begin{array}{l}\text { Férrico } \\
\text { Líquido } \\
\text { Comercial }\end{array}$ & $\begin{array}{l}\text { Hidróxido } \\
\text { de Sódio }\end{array}$ & & & \multirow[t]{2}{*}{$\begin{array}{l}\text { Turbidez } \\
\text { (uT) }\end{array}$} & \multirow[t]{2}{*}{$\begin{array}{l}\text { Cor } \\
\text { Apar. } \\
\text { (uH) }\end{array}$} & \multirow[t]{2}{*}{$\begin{array}{l}\text { Turbidez } \\
\text { (uT) }\end{array}$} & \multirow[t]{2}{*}{$\begin{array}{l}\text { Cor } \\
\text { Apar. } \\
(\mathrm{uH})\end{array}$} & \multirow[t]{2}{*}{$\begin{array}{l}\text { Turbidez } \\
\text { (uT) }\end{array}$} & \multirow[t]{2}{*}{$\begin{array}{l}\text { Cor } \\
\text { Apar. } \\
(\mathrm{uH})\end{array}$} \\
\hline & $(\mathrm{mg} / \mathrm{L})$ & $(\mathrm{mg} / \mathrm{L})$ & & & & & & & & \\
\hline 1 & 260 & 80 & 5 & 6,33 & 1,34 & 27 & 0,97 & 15 & 0,92 & 12 \\
\hline 2 & 260 & 80 & 10 & 6,48 & 1,41 & 27 & 1,1 & 18 & 0,98 & 13 \\
\hline 3 & 260 & 80 & 20 & 6,26 & 1,89 & 54 & 1,46 & 37 & 1,07 & 15 \\
\hline 4 & 260 & 80 & 30 & 6,49 & 1,43 & 36 & 1,33 & 34 & 1,14 & 19 \\
\hline 5 & 260 & 80 & 60 & 6,39 & 2,26 & 70 & 1,54 & 37 & 1,24 & 22 \\
\hline 6 & 260 & 80 & 90 & 6,43 & 2,51 & 84 & 2,04 & 55 & 1,57 & 24 \\
\hline
\end{tabular}


Tabela F.3 - Resultados dos ensaios para seleção dos parâmetros de mistura rápida

\begin{tabular}{|c|c|c|c|c|c|c|c|c|c|c|}
\hline \multicolumn{11}{|c|}{ gradiente de mistura rápida $=600 \mathrm{~s}^{-1}$} \\
\hline \multirow{3}{*}{ Jarro } & Produtos qu & límicos & \multirow{3}{*}{$\begin{array}{l}\text { Tempo } \\
\text { de } \\
\text { mistura } \\
\text { rápida } \\
\text { (s) }\end{array}$} & \multirow{3}{*}{$\begin{array}{l}\mathrm{pH} \\
\text { de } \\
\text { Coag }\end{array}$} & $\mathrm{Vs} 1=3,0$ & $\mathrm{~cm} / \mathrm{min}$ & $\begin{array}{l}\mathrm{Vs} 2= \\
\mathrm{cm} / \mathrm{min}\end{array}$ & 1,5 & $\mathrm{Vs} 3=1,0$ & $\mathrm{~cm} / \mathrm{min}$ \\
\hline & $\begin{array}{l}\text { Férrico } \\
\text { Líquido } \\
\text { Comercial } \\
\end{array}$ & $\begin{array}{l}\text { Hidróxido } \\
\text { de Sódio }\end{array}$ & & & \multirow[t]{2}{*}{$\begin{array}{l}\text { Turbidez } \\
\text { (uT) }\end{array}$} & \multirow[t]{2}{*}{$\begin{array}{l}\text { Cor } \\
\text { Apar. } \\
(u H)\end{array}$} & \multirow[t]{2}{*}{$\begin{array}{l}\text { Turbidez } \\
\text { (uT) }\end{array}$} & \multirow[t]{2}{*}{$\begin{array}{l}\text { Cor } \\
\text { Apar. } \\
(\mathrm{uH})\end{array}$} & \multirow[t]{2}{*}{$\begin{array}{l}\text { Turbidez } \\
\text { (uT) }\end{array}$} & \multirow[t]{2}{*}{$\begin{array}{l}\text { Cor } \\
\text { Apar. } \\
(\mathrm{uH})\end{array}$} \\
\hline & $(\mathrm{mg} / \mathrm{L})$ & $(\mathrm{mg} / \mathrm{L})$ & & & & & & & & \\
\hline 1 & 260 & 80 & 5 & 6,47 & 1,4 & 32 & 1,18 & 28 & 0,78 & 12 \\
\hline 2 & 260 & 80 & 10 & 6,3 & 1,33 & 32 & 1,17 & 22 & 0,99 & 14 \\
\hline 3 & 260 & 80 & 20 & 6,29 & 2,3 & 72 & 1,5 & 38 & 1,14 & 22 \\
\hline 4 & 260 & 80 & 30 & 6,38 & 1,94 & 61 & 1,34 & 38 & 1,24 & 24 \\
\hline 5 & 260 & 80 & 60 & 6,38 & 2,47 & 84 & 1,55 & 41 & 1,53 & 31 \\
\hline 6 & 260 & 80 & 90 & 6,44 & 3,88 & 150 & 2,26 & 80 & 1,42 & 37 \\
\hline
\end{tabular}

Tabela F.4 - Resultados dos ensaios para seleção dos parâmetros de mistura rápida

\begin{tabular}{|c|c|c|c|c|c|c|c|c|c|c|}
\hline \multicolumn{11}{|c|}{ gradiente de mistura rápida $=800 \mathrm{~s}^{-1}$} \\
\hline \multirow{3}{*}{ Jarro } & Produtos qu & límicos & \multirow{3}{*}{$\begin{array}{l}\text { Tempo } \\
\text { de } \\
\text { mistura } \\
\text { rápida } \\
\text { (s) }\end{array}$} & \multirow{3}{*}{$\begin{array}{l}\mathrm{pH} \\
\text { de } \\
\text { Coag }\end{array}$} & $V_{s} 1=3,0$ & $\mathrm{~cm} / \mathrm{min}$ & $\begin{array}{l}\mathrm{Vs} 2= \\
\mathrm{cm} / \mathrm{min}\end{array}$ & $\overline{1,5}$ & $\mathrm{Vs} 3=1,0$ & $\mathrm{~cm} / \mathrm{min}$ \\
\hline & $\begin{array}{l}\text { Férrico } \\
\text { Líquido } \\
\text { Comercial }\end{array}$ & $\begin{array}{l}\text { Hidróxido } \\
\text { de Sódio }\end{array}$ & & & \multirow[t]{2}{*}{$\begin{array}{l}\text { Turbidez } \\
\text { (uT) }\end{array}$} & \multirow[t]{2}{*}{$\begin{array}{l}\text { Cor } \\
\text { Apar. } \\
(\mathrm{uH})\end{array}$} & \multirow[t]{2}{*}{$\begin{array}{l}\text { Turbidez } \\
\text { (uT) }\end{array}$} & \multirow[t]{2}{*}{$\begin{array}{l}\text { Cor } \\
\text { Apar. } \\
(\mathrm{uH})\end{array}$} & \multirow[t]{2}{*}{$\begin{array}{l}\text { Turbidez } \\
\text { (uT) }\end{array}$} & \multirow[t]{2}{*}{$\begin{array}{l}\text { Cor } \\
\text { Apar. } \\
(\mathrm{uH})\end{array}$} \\
\hline & $(\mathrm{mg} / \mathrm{L})$ & $(\mathrm{mg} / \mathrm{L})$ & & & & & & & & \\
\hline 1 & 260 & 80 & 5 & 6,57 & 1,18 & 27 & 1,39 & 33 & 1,69 & 27 \\
\hline 2 & 260 & 80 & 10 & 6,45 & 1,68 & 36 & 1,03 & 24 & 1,71 & 25 \\
\hline 3 & 260 & 80 & 20 & 6,37 & 1,93 & 54 & 1,66 & 40 & 1,12 & 21 \\
\hline 4 & 260 & 80 & 30 & 6,56 & 1,83 & 53 & 1,45 & 42 & 1,67 & 42 \\
\hline 5 & 260 & 80 & 60 & 6,51 & 2,24 & 76 & 2,03 & 72 & 1,39 & 44 \\
\hline 6 & 260 & 80 & 90 & 6,61 & 3,89 & 164 & 2,11 & 74 & 1,58 & 47 \\
\hline
\end{tabular}


Tabela F.5 - Resultados dos ensaios para seleção dos parâmetros de mistura rápida

\begin{tabular}{|c|c|c|c|c|c|c|c|c|c|c|}
\hline \multicolumn{11}{|c|}{ gradiente de mistura rápida $=1000 \mathrm{~s}^{-1}$} \\
\hline \multirow{3}{*}{ Jarro } & Produtos qu & uímicos & \multirow{3}{*}{$\begin{array}{l}\text { Tempo } \\
\text { de } \\
\text { mistura } \\
\text { rápida } \\
\text { (s) }\end{array}$} & \multirow{3}{*}{$\begin{array}{l}\mathrm{pH} \\
\mathrm{de} \\
\text { Coag }\end{array}$} & $\mathrm{Vs} 1=3,0$ & $\mathrm{~cm} / \mathrm{min}$ & $\begin{array}{l}\mathrm{Vs} 2= \\
\mathrm{cm} / \mathrm{min}\end{array}$ & 1,5 & $\mathrm{Vs} 3=1,0$ & $\mathrm{~cm} / \mathrm{min}$ \\
\hline & $\begin{array}{l}\text { Férrico } \\
\text { Líquido } \\
\text { Comercial } \\
\end{array}$ & $\begin{array}{l}\text { Hidróxido } \\
\text { de Sódio }\end{array}$ & & & \multirow[t]{2}{*}{$\begin{array}{l}\text { Turbidez } \\
\text { (uT) }\end{array}$} & \multirow[t]{2}{*}{$\begin{array}{l}\text { Cor } \\
\text { Apar. } \\
(\mathrm{uH})\end{array}$} & \multirow[t]{2}{*}{$\begin{array}{l}\text { Turbidez } \\
\text { (uT) }\end{array}$} & \multirow[t]{2}{*}{$\begin{array}{l}\text { Cor } \\
\text { Apar. } \\
(\mathrm{uH})\end{array}$} & \multirow[t]{2}{*}{$\begin{array}{l}\text { Turbidez } \\
\text { (uT) }\end{array}$} & \multirow[t]{2}{*}{$\begin{array}{l}\text { Cor } \\
\text { Apar. } \\
(\mathrm{uH})\end{array}$} \\
\hline & $(\mathrm{mg} / \mathrm{L})$ & $(\mathrm{mg} / \mathrm{L})$ & & & & & & & & \\
\hline 1 & 260 & 80 & 5 & 6,39 & 1,72 & 35 & 1,52 & 38 & 1,03 & 14 \\
\hline 2 & 260 & 80 & 10 & 6,38 & 1,55 & 48 & 1,23 & 27 & 1,31 & 18 \\
\hline 3 & 260 & 80 & 20 & 6,36 & 2,39 & 85 & 1,66 & 50 & 1,3 & 27 \\
\hline 4 & 260 & 80 & 30 & 6,52 & 1,95 & 66 & 1,61 & 49 & 1,59 & 33 \\
\hline 5 & 260 & 80 & 60 & 6,46 & 6,09 & 207 & 2,62 & 103 & 1,75 & 45 \\
\hline 6 & 260 & 80 & 90 & 6,54 & 5,46 & 231 & 2,6 & 87 & 1,71 & 44 \\
\hline
\end{tabular}

Tabela F.6 - Resultados dos ensaios para seleção dos parâmetros de mistura rápida

\begin{tabular}{|c|c|c|c|c|c|c|c|c|c|c|}
\hline \multicolumn{11}{|c|}{ gradiente de mistura rápida $=1200 \mathrm{~s}^{-1}$} \\
\hline \multirow{3}{*}{ Jarro } & Produtos qu & límicos & \multirow{3}{*}{$\begin{array}{l}\text { Tempo } \\
\text { de } \\
\text { mistura } \\
\text { rápida } \\
\text { (s) }\end{array}$} & \multirow{3}{*}{$\begin{array}{l}\mathrm{pH} \\
\text { de } \\
\text { Coag }\end{array}$} & $\mathrm{Vs} 1=3,0$ & $\mathrm{~cm} / \mathrm{min}$ & $\begin{array}{l}\mathrm{Vs} 2= \\
\mathrm{cm} / \mathrm{min}\end{array}$ & 1,5 & $\mathrm{Vs} 3=1,0$ & $\mathrm{~cm} / \mathrm{min}$ \\
\hline & $\begin{array}{l}\text { Férrico } \\
\text { Líquido } \\
\text { Comercial }\end{array}$ & $\begin{array}{l}\text { Hidróxido } \\
\text { de Sódio }\end{array}$ & & & \multirow[t]{2}{*}{$\begin{array}{l}\text { Turbidez } \\
\text { (uT) }\end{array}$} & \multirow[t]{2}{*}{$\begin{array}{l}\text { Cor } \\
\text { Apar. } \\
(\mathrm{uH})\end{array}$} & \multirow[t]{2}{*}{$\begin{array}{l}\text { Turbidez } \\
\text { (uT) }\end{array}$} & \multirow[t]{2}{*}{$\begin{array}{l}\text { Cor } \\
\text { Apar. } \\
(\mathrm{uH})\end{array}$} & \multirow[t]{2}{*}{$\begin{array}{l}\text { Turbidez } \\
\text { (uT) }\end{array}$} & \multirow[t]{2}{*}{$\begin{array}{l}\text { Cor } \\
\text { Apar. } \\
(\mathrm{uH})\end{array}$} \\
\hline & $(\mathrm{mg} / \mathrm{L})$ & $(\mathrm{mg} / \mathrm{L})$ & & & & & & & & \\
\hline 1 & 260 & 80 & 5 & 6,26 & 1,48 & 29 & 1,17 & 22 & 1,29 & 15 \\
\hline 2 & 260 & 80 & 10 & 6,35 & 1,63 & 47 & 1,27 & 30 & 1,03 & 16 \\
\hline 3 & 260 & 80 & 20 & 6,46 & 2,15 & 68 & 1,32 & 32 & 1,38 & 28 \\
\hline 4 & 260 & 80 & 30 & 6,47 & 1,74 & 54 & 1,61 & 50 & 1,67 & 34 \\
\hline 5 & 260 & 80 & 60 & 6,5 & 2,41 & 91 & 1,73 & 57 & 1,69 & 44 \\
\hline 6 & 260 & 80 & 90 & 6,46 & 4,69 & 199 & 2,38 & 88 & 1,92 & 55 \\
\hline
\end{tabular}


ANEXO G

Resultados dos ensaios para seleção dos parâmetros de floculação com o Cloreto Férrico como coagulante 
Tabela G.1 - Resultados dos ensaios para seleção dos parâmetros de floculação

\begin{tabular}{|c|c|c|c|c|c|c|c|c|c|c|}
\hline \multicolumn{11}{|c|}{ gradiente de floculação $=10 \mathrm{~s}^{-1}$} \\
\hline \multirow{3}{*}{ Jarro } & Produtos q & uímicos & \multirow{3}{*}{$\begin{array}{l}\text { Tempo de } \\
\text { floculação } \\
\text { (min) }\end{array}$} & \multirow{3}{*}{$\begin{array}{l}\mathrm{pH} \\
\mathrm{de} \\
\text { Coag }\end{array}$} & $\mathrm{Vs} 1=3,0$ & $\mathrm{~cm} / \mathrm{min}$ & $\begin{array}{l}\mathrm{Vs} 2= \\
\mathrm{cm} / \mathrm{min}\end{array}$ & 1,5 & $\mathrm{Vs} 3=1,0$ & $\mathrm{~cm} / \mathrm{min}$ \\
\hline & $\begin{array}{l}\text { Cloreto } \\
\text { Férrico } \\
\text { Líquido } \\
\text { Comercial } \\
\end{array}$ & $\begin{array}{l}\text { Hidróxido } \\
\text { de Sódio }\end{array}$ & & & \multirow[t]{2}{*}{$\begin{array}{l}\text { Turbidez } \\
\text { (uT) }\end{array}$} & \multirow[t]{2}{*}{$\begin{array}{l}\text { Cor } \\
\text { Apar. } \\
(\mathrm{uH})\end{array}$} & \multirow[t]{2}{*}{$\begin{array}{l}\text { Turbidez } \\
\text { (uT) }\end{array}$} & \multirow[t]{2}{*}{$\begin{array}{l}\text { Cor } \\
\text { Apar. } \\
(\mathrm{uH})\end{array}$} & \multirow[t]{2}{*}{$\begin{array}{l}\text { Turbidez } \\
\text { (uT) }\end{array}$} & \multirow[t]{2}{*}{$\begin{array}{l}\text { Cor } \\
\text { Apar. } \\
(\mathrm{uH})\end{array}$} \\
\hline & $(\mathrm{mg} / \mathrm{L})$ & $(\mathrm{mg} / \mathrm{L})$ & & & & & & & & \\
\hline 1 & 260 & 80 & 5 & 6,25 & 1,91 & 69 & 2,08 & 68 & 1,73 & 66 \\
\hline 2 & 260 & 80 & 10 & 6,31 & 1,28 & 37 & 1,32 & 38 & $1,, 21$ & 36 \\
\hline 3 & 260 & 80 & 15 & 6,32 & 1,19 & 24 & 0,99 & 22 & 1,05 & 21 \\
\hline 4 & 260 & 80 & 20 & 6,34 & 1,17 & 10 & 0,93 & 8 & 0,91 & 8 \\
\hline 5 & 260 & 80 & 25 & 6,32 & 1,18 & 9 & 0,89 & 7 & 1 & 6 \\
\hline 6 & 260 & 80 & 30 & 6,43 & 0,92 & 8 & 0,9 & 7 & 0,88 & 6 \\
\hline
\end{tabular}

Tabela G.2 - Resultados dos ensaios para seleção dos parâmetros de floculação

\begin{tabular}{|c|c|c|c|c|c|c|c|c|c|c|}
\hline \multicolumn{11}{|c|}{ gradiente de floculação $=10 \mathrm{~s}^{-1}$} \\
\hline \multirow{3}{*}{ Jarro } & Produtos q & químicos & \multirow{3}{*}{$\begin{array}{l}\text { Tempo de } \\
\text { floculação } \\
\text { (min) }\end{array}$} & \multirow{3}{*}{$\begin{array}{l}\mathrm{pH} \\
\mathrm{de} \\
\text { Coag }\end{array}$} & $\mathrm{Vs} 1=3,0$ & $\mathrm{~cm} / \mathrm{min}$ & $\begin{array}{l}\mathrm{Vs} 2= \\
\mathrm{cm} / \mathrm{min}\end{array}$ & 1,5 & $\mathrm{Vs} 3=1,0$ & $\mathrm{~cm} / \mathrm{min}$ \\
\hline & $\begin{array}{l}\text { Cloreto } \\
\text { Férrico } \\
\text { Líquido } \\
\text { Comercial } \\
\end{array}$ & $\begin{array}{l}\text { Hidróxido } \\
\text { de Sódio }\end{array}$ & & & \multirow[t]{2}{*}{$\begin{array}{l}\text { Turbidez } \\
\text { (uT) }\end{array}$} & \multirow[t]{2}{*}{$\begin{array}{l}\text { Cor } \\
\text { Apar. } \\
(\mathrm{uH})\end{array}$} & \multirow[t]{2}{*}{$\begin{array}{l}\text { Turbidez } \\
\text { (uT) }\end{array}$} & \multirow[t]{2}{*}{$\begin{array}{l}\text { Cor } \\
\text { Apar. } \\
(\mathrm{uH})\end{array}$} & \multirow[t]{2}{*}{$\begin{array}{l}\text { Turbidez } \\
\text { (uT) }\end{array}$} & \multirow[t]{2}{*}{$\begin{array}{l}\text { Cor } \\
\text { Apar. } \\
\text { (uH) }\end{array}$} \\
\hline & $(\mathrm{mg} / \mathrm{L})$ & $(\mathrm{mg} / \mathrm{L})$ & & & & & & & & \\
\hline 1 & 260 & 80 & 35 & 6,44 & 1,19 & 14 & 0,83 & 8 & 0,89 & 6 \\
\hline 2 & 260 & 80 & 40 & 6,38 & 0,99 & 9 & 0,9 & 8 & 0,93 & 6 \\
\hline 3 & 260 & 80 & 45 & 6,35 & 1,19 & 11 & 1,15 & 11 & 0,87 & 6 \\
\hline 4 & 260 & 80 & 50 & 6,46 & 0,95 & 13 & 0,81 & 7 & 0,98 & 7 \\
\hline 5 & 260 & 80 & 55 & 6,21 & 0,79 & 6 & 0,81 & 5 & 0,71 & 2 \\
\hline 6 & 260 & 80 & 60 & 6,33 & 1,3 & 29 & 1,46 & 16 & 0,78 & 5 \\
\hline
\end{tabular}


Tabela G.3 - Resultados dos ensaios para seleção dos parâmetros de floculação

\begin{tabular}{|c|c|c|c|c|c|c|c|c|c|c|}
\hline \multicolumn{11}{|c|}{ gradiente de floculação $=15 \mathrm{~s}^{-1}$} \\
\hline \multirow{3}{*}{ Jarro } & Produtos q & límicos & \multirow{3}{*}{$\begin{array}{l}\text { Tempo de } \\
\text { floculação } \\
\text { (min) }\end{array}$} & \multirow{3}{*}{$\begin{array}{l}\mathrm{pH} \\
\mathrm{de} \\
\text { Coag }\end{array}$} & \multicolumn{2}{|c|}{$\mathrm{Vs} 1=3,0 \mathrm{~cm} / \mathrm{min}$} & \multicolumn{2}{|l|}{$\begin{array}{l}\mathrm{Vs} 2= \\
\mathrm{cm} / \mathrm{min}\end{array}$} & \multicolumn{2}{|c|}{$\mathrm{Vs} 3=1,0 \mathrm{~cm} / \mathrm{min}$} \\
\hline & $\begin{array}{l}\text { Cloreto } \\
\text { Férrico } \\
\text { Líquido } \\
\text { Comercial } \\
\end{array}$ & $\begin{array}{l}\text { Hidróxido } \\
\text { de Sódio }\end{array}$ & & & $\begin{array}{l}\text { Turbidez } \\
\text { (uT) }\end{array}$ & $\begin{array}{l}\text { Cor } \\
\text { Apar. } \\
\text { (uH) }\end{array}$ & $\begin{array}{l}\text { Turbidez } \\
\text { (uT) }\end{array}$ & $\begin{array}{l}\text { Cor } \\
\text { Apar. } \\
(\mathrm{uH})\end{array}$ & $\begin{array}{l}\text { Turbidez } \\
\text { (uT) }\end{array}$ & $\begin{array}{l}\text { Cor } \\
\text { Apar. } \\
(\mathrm{uH})\end{array}$ \\
\hline & $(\mathrm{mg} / \mathrm{L})$ & $(\mathrm{mg} / \mathrm{L})$ & & & & & & & & \\
\hline 1 & 260 & 80 & 5 & 6,38 & 2,53 & 72 & 2,02 & 63 & 2,06 & 61 \\
\hline 2 & 260 & 80 & 10 & 6,32 & 1,83 & 33 & 1,46 & 28 & 1,52 & 28 \\
\hline 3 & 260 & 80 & 15 & 6,29 & 1,3 & 21 & 1,14 & 18 & 1,2 & 16 \\
\hline 4 & 260 & 80 & 20 & 6,42 & 1,28 & 16 & 1,19 & 13 & 1,07 & 10 \\
\hline 5 & 260 & 80 & 25 & 6,41 & 1,4 & 18 & 1,09 & 10 & 1,06 & 8 \\
\hline 6 & 260 & 80 & 30 & 6,27 & 1,19 & 18 & 1,02 & 12 & 0,94 & 6 \\
\hline
\end{tabular}

Tabela G.4 - Resultados dos ensaios para seleção dos parâmetros de floculação

\begin{tabular}{|c|c|c|c|c|c|c|c|c|c|c|}
\hline \multicolumn{11}{|c|}{ gradiente de floculação $=15 \mathrm{~s}^{-1}$} \\
\hline \multirow{3}{*}{ Jarro } & Produtos q & límicos & \multirow{3}{*}{$\begin{array}{l}\text { Tempo de } \\
\text { floculação } \\
\text { (min) }\end{array}$} & \multirow{3}{*}{$\begin{array}{l}\mathrm{pH} \\
\text { de } \\
\text { Coag }\end{array}$} & $\mathrm{Vs} 1=3,0$ & $\mathrm{~cm} / \mathrm{min}$ & $\begin{array}{l}\mathrm{Vs} 2= \\
\mathrm{cm} / \mathrm{min}\end{array}$ & 1,5 & $\mathrm{Vs} 3=1,0$ & $\mathrm{~cm} / \mathrm{min}$ \\
\hline & $\begin{array}{l}\text { Cloreto } \\
\text { Férrico } \\
\text { Líquido } \\
\text { Comercial }\end{array}$ & $\begin{array}{l}\text { Hidróxido } \\
\text { de Sódio }\end{array}$ & & & \multirow[t]{2}{*}{$\begin{array}{l}\text { Turbidez } \\
\text { (uT) }\end{array}$} & \multirow[t]{2}{*}{$\begin{array}{l}\text { Cor } \\
\text { Apar. } \\
\text { (uH) }\end{array}$} & \multirow[t]{2}{*}{$\begin{array}{l}\text { Turbidez } \\
\text { (uT) }\end{array}$} & \multirow[t]{2}{*}{$\begin{array}{l}\text { Cor } \\
\text { Apar. } \\
\text { (uH) }\end{array}$} & \multirow[t]{2}{*}{$\begin{array}{l}\text { Turbidez } \\
\text { (uT) }\end{array}$} & \multirow[t]{2}{*}{$\begin{array}{l}\text { Cor } \\
\text { Apar. } \\
(\mathrm{uH})\end{array}$} \\
\hline & $(\mathrm{mg} / \mathrm{L})$ & $(\mathrm{mg} / \mathrm{L})$ & & & & & & & & \\
\hline 1 & 260 & 80 & 35 & 6,24 & 1,38 & 25 & 1,02 & 14 & 0,95 & 8 \\
\hline 2 & 260 & 80 & 40 & 6,3 & 1,16 & 20 & 1,08 & 18 & 1,06 & 7 \\
\hline 3 & 260 & 80 & 45 & 6,35 & 1,32 & 17 & 1,09 & 14 & 0,98 & 7 \\
\hline 4 & 260 & 80 & 50 & 6,25 & 1,32 & 18 & 0,93 & 12 & 0,97 & 7 \\
\hline 5 & 260 & 80 & 55 & 6,44 & 1,26 & 32 & 1 & 8 & 0,94 & 8 \\
\hline 6 & 260 & 80 & 60 & 6,45 & 1,7 & 42 & 1,32 & 21 & 0,98 & 10 \\
\hline
\end{tabular}


Tabela G.5 - Resultados dos ensaios para seleção dos parâmetros de floculação

\begin{tabular}{|c|c|c|c|c|c|c|c|c|c|c|}
\hline \multicolumn{11}{|c|}{ gradiente de floculação $=20 \mathrm{~s}^{-1}$} \\
\hline \multirow{3}{*}{ Jarro } & Produtos qu & uímicos & \multirow{3}{*}{$\begin{array}{l}\text { Tempo de } \\
\text { floculação } \\
\text { (min) }\end{array}$} & \multirow{3}{*}{$\begin{array}{l}\mathrm{pH} \\
\mathrm{de} \\
\text { Coag }\end{array}$} & \multicolumn{2}{|c|}{$\mathrm{Vs} 1=3,0 \mathrm{~cm} / \mathrm{min}$} & \multicolumn{2}{|l|}{$\begin{array}{l}\mathrm{Vs} 2= \\
\mathrm{cm} / \mathrm{min}\end{array}$} & \multicolumn{2}{|c|}{$\mathrm{Vs} 3=1,0 \mathrm{~cm} / \mathrm{min}$} \\
\hline & $\begin{array}{l}\text { Cloreto } \\
\text { Férrico } \\
\text { Líquido } \\
\text { Comercial } \\
\end{array}$ & $\begin{array}{l}\text { Hidróxido } \\
\text { de Sódio }\end{array}$ & & & $\begin{array}{l}\text { Turbidez } \\
\text { (uT) }\end{array}$ & $\begin{array}{l}\text { Cor } \\
\text { Apar. } \\
\text { (uH) }\end{array}$ & $\begin{array}{l}\text { Turbidez } \\
\text { (uT) }\end{array}$ & $\begin{array}{l}\text { Cor } \\
\text { Apar. } \\
(\mathrm{uH})\end{array}$ & $\begin{array}{l}\text { Turbidez } \\
\text { (uT) }\end{array}$ & $\begin{array}{l}\text { Cor } \\
\text { Apar. } \\
(\mathrm{uH})\end{array}$ \\
\hline & $(\mathrm{mg} / \mathrm{L})$ & $(\mathrm{mg} / \mathrm{L})$ & & & & & & & & \\
\hline 1 & 260 & 80 & 5 & 6,5 & 1,67 & 65 & 1,4 & 51 & 1,39 & 49 \\
\hline 2 & 260 & 80 & 10 & 6,49 & 1,09 & 35 & 1,03 & 30 & 0,91 & 23 \\
\hline 3 & 260 & 80 & 15 & 6,44 & 1,03 & 25 & 0,95 & 15 & 0,69 & 12 \\
\hline 4 & 260 & 80 & 20 & 6,5 & 1,33 & 38 & 1,13 & 28 & 0,98 & 15 \\
\hline 5 & 260 & 80 & 25 & 6,46 & 1,43 & 42 & 0,86 & 19 & 0,74 & 9 \\
\hline 6 & 260 & 80 & 30 & 6,39 & 1,34 & 40 & 0,88 & 21 & 0,86 & 12 \\
\hline
\end{tabular}

Tabela G.6 - Resultados dos ensaios para seleção dos parâmetros de floculação

\begin{tabular}{|c|c|c|c|c|c|c|c|c|c|c|}
\hline$\overline{\text { gradi }}$ & nte de flocu & lação $=20 \mathrm{~s}$ & & & & & & & & \\
\hline \multirow{3}{*}{ Jarro } & Produtos qu & límicos & \multirow{3}{*}{$\begin{array}{l}\text { Tempo de } \\
\text { floculação } \\
\text { (min) }\end{array}$} & \multirow{3}{*}{$\begin{array}{l}\mathrm{pH} \\
\mathrm{de} \\
\text { Coag }\end{array}$} & \multicolumn{2}{|c|}{$\mathrm{Vs} 1=3,0 \mathrm{~cm} / \mathrm{min}$} & \multicolumn{2}{|l|}{$\begin{array}{l}\mathrm{Vs} 2= \\
\mathrm{cm} / \mathrm{min}\end{array}$} & \multicolumn{2}{|c|}{$\mathrm{Vs} 3=1,0 \mathrm{~cm} / \mathrm{min}$} \\
\hline & $\begin{array}{l}\text { Cloreto } \\
\text { Férrico } \\
\text { Líquido } \\
\text { Comercial }\end{array}$ & $\begin{array}{l}\text { Hidróxido } \\
\text { de Sódio }\end{array}$ & & & \multirow[t]{2}{*}{$\begin{array}{l}\text { Turbidez } \\
\text { (uT) }\end{array}$} & \multirow[t]{2}{*}{$\begin{array}{l}\text { Cor } \\
\text { Apar. } \\
(\mathrm{uH})\end{array}$} & \multirow[t]{2}{*}{$\begin{array}{l}\text { Turbidez } \\
\text { (uT) }\end{array}$} & \multirow[t]{2}{*}{$\begin{array}{l}\text { Cor } \\
\text { Apar. } \\
(\mathrm{uH})\end{array}$} & \multirow[t]{2}{*}{$\begin{array}{l}\text { Turbidez } \\
\text { (uT) }\end{array}$} & \multirow[t]{2}{*}{$\begin{array}{l}\text { Cor } \\
\text { Apar. } \\
(\mathrm{uH})\end{array}$} \\
\hline & $(\mathrm{mg} / \mathrm{L})$ & $(\mathrm{mg} / \mathrm{L})$ & & & & & & & & \\
\hline 1 & 260 & 80 & 35 & 6,47 & 1,05 & 26 & 0,75 & 19 & 0,88 & 13 \\
\hline 2 & 260 & 80 & 40 & 6,41 & 2,13 & 33 & 0,95 & 27 & 0,77 & 14 \\
\hline 3 & 260 & 80 & 45 & 6,46 & 1,62 & 45 & 0,87 & 26 & 0,92 & 15 \\
\hline 4 & 260 & 80 & 50 & 6,52 & 1,32 & 46 & 0,92 & 26 & 1,19 & 20 \\
\hline 5 & 260 & 80 & 55 & 6,48 & 1,64 & 47 & 0,95 & 30 & 1,21 & 19 \\
\hline 6 & 260 & 80 & 60 & 6,44 & 1,71 & 46 & 1,03 & 29 & 1,2 & 20 \\
\hline
\end{tabular}


Tabela G.7 - Resultados dos ensaios para seleção dos parâmetros de floculação

\begin{tabular}{|c|c|c|c|c|c|c|c|c|c|c|}
\hline grad & de floc & ז̃̃o $=25$ & & & & & & & & \\
\hline \multirow{3}{*}{ Jarro } & Produtos q & límicos & \multirow{3}{*}{$\begin{array}{l}\text { Tempo de } \\
\text { floculação } \\
\text { (min) }\end{array}$} & \multirow{3}{*}{$\begin{array}{l}\mathrm{pH} \\
\text { de } \\
\text { Coag }\end{array}$} & \multicolumn{2}{|c|}{$\mathrm{Vs} 1=3,0 \mathrm{~cm} / \mathrm{min}$} & \multicolumn{2}{|l|}{$\begin{array}{l}\mathrm{Vs} 2= \\
\mathrm{cm} / \mathrm{min}\end{array}$} & \multicolumn{2}{|c|}{$\mathrm{Vs} 3=1,0 \mathrm{~cm} / \mathrm{min}$} \\
\hline & $\begin{array}{l}\text { Cloreto } \\
\text { Férrico } \\
\text { Líquido } \\
\text { Comercial } \\
\end{array}$ & $\begin{array}{l}\text { Hidróxido } \\
\text { de Sódio }\end{array}$ & & & \multirow[t]{2}{*}{$\begin{array}{l}\text { Turbidez } \\
\text { (uT) }\end{array}$} & \multirow[t]{2}{*}{$\begin{array}{l}\text { Cor } \\
\text { Apar. } \\
(\mathrm{uH})\end{array}$} & \multirow[t]{2}{*}{$\begin{array}{l}\text { Turbidez } \\
\text { (uT) }\end{array}$} & \multirow[t]{2}{*}{$\begin{array}{l}\text { Cor } \\
\text { Apar. } \\
\text { (uH) }\end{array}$} & \multirow[t]{2}{*}{$\begin{array}{l}\text { Turbidez } \\
\text { (uT) }\end{array}$} & \multirow[t]{2}{*}{$\begin{array}{l}\text { Cor } \\
\text { Apar. } \\
(\mathrm{uH})\end{array}$} \\
\hline & $(\mathrm{mg} / \mathrm{L})$ & $(\mathrm{mg} / \mathrm{L})$ & & & & & & & & \\
\hline 1 & 260 & 80 & 5 & 6,55 & 0,98 & 54 & 1,31 & 55 & 1,25 & 49 \\
\hline 2 & 260 & 80 & 10 & 6,44 & 1,08 & 29 & 0,87 & 26 & 0,78 & 20 \\
\hline 3 & 260 & 80 & 15 & 6,39 & 1,33 & 33 & 0,8 & 20 & 0,72 & 15 \\
\hline 4 & 260 & 80 & 20 & 6,34 & 0,96 & 30 & 0,78 & 26 & 0,79 & 18 \\
\hline 5 & 260 & 80 & 25 & 6,51 & 1,15 & 36 & 1,04 & 36 & 0,69 & 16 \\
\hline 6 & 260 & 80 & 30 & 6,31 & 1,18 & 45 & 0,91 & 29 & 0,58 & 15 \\
\hline
\end{tabular}

Tabela G.8 - Resultados dos ensaios para seleção dos parâmetros de floculação

\begin{tabular}{|c|c|c|c|c|c|c|c|c|c|c|}
\hline \multicolumn{11}{|c|}{ gradiente de floculação $=25 \mathrm{~s}^{-1}$} \\
\hline \multirow{3}{*}{ Jarro } & Produtos q & dímicos & \multirow{3}{*}{$\begin{array}{l}\text { Tempo de } \\
\text { floculação } \\
\text { (min) }\end{array}$} & \multirow{3}{*}{$\begin{array}{l}\mathrm{pH} \\
\mathrm{de} \\
\text { Coag }\end{array}$} & $\mathrm{Vs} 1=3,0$ & $\mathrm{~cm} / \mathrm{min}$ & $\begin{array}{l}\mathrm{Vs} 2= \\
\mathrm{cm} / \mathrm{min}\end{array}$ & 1,5 & $\mathrm{Vs} 3=1,0$ & $\mathrm{~cm} / \mathrm{min}$ \\
\hline & $\begin{array}{l}\text { Cloreto } \\
\text { Férrico } \\
\text { Líquido } \\
\text { Comercial } \\
\end{array}$ & $\begin{array}{l}\text { Hidróxido } \\
\text { de Sódio }\end{array}$ & & & \multirow[t]{2}{*}{$\begin{array}{l}\text { Turbidez } \\
\text { (uT) }\end{array}$} & \multirow[t]{2}{*}{$\begin{array}{l}\text { Cor } \\
\text { Apar. } \\
(\mathrm{uH})\end{array}$} & \multirow[t]{2}{*}{$\begin{array}{l}\text { Turbidez } \\
\text { (uT) }\end{array}$} & \multirow[t]{2}{*}{$\begin{array}{l}\text { Cor } \\
\text { Apar. } \\
(\mathrm{uH})\end{array}$} & \multirow[t]{2}{*}{$\begin{array}{l}\text { Turbidez } \\
\text { (uT) }\end{array}$} & \multirow[t]{2}{*}{$\begin{array}{l}\text { Cor } \\
\text { Apar. } \\
(\mathrm{uH})\end{array}$} \\
\hline & $(\mathrm{mg} / \mathrm{L})$ & $(\mathrm{mg} / \mathrm{L})$ & & & & & & & & \\
\hline 1 & 260 & 80 & 35 & 6,32 & 0,99 & 45 & 0,84 & 27 & 0,79 & 18 \\
\hline 2 & 260 & 80 & 40 & 6,29 & 1,01 & 41 & 1,05 & 34 & 0,96 & 20 \\
\hline 3 & 260 & 80 & 45 & 6,26 & 1,23 & 49 & 1,12 & 37 & 0,92 & 23 \\
\hline 4 & 260 & 80 & 50 & 6,23 & 1,33 & 55 & 1,1 & 45 & 0,77 & 19 \\
\hline 5 & 260 & 80 & 55 & 6,20 & 1,56 & 54 & 1,09 & 44 & 1,27 & 37 \\
\hline 6 & 260 & 80 & 60 & 6,17 & 1,67 & 47 & 1,38 & 39 & 1,15 & 29 \\
\hline
\end{tabular}


Tabela G.9 - Resultados dos ensaios para seleção dos parâmetros de floculação

\begin{tabular}{|c|c|c|c|c|c|c|c|c|c|c|}
\hline \multicolumn{11}{|c|}{ gradiente de floculação $=30 \mathrm{~s}^{-1}$} \\
\hline \multirow{3}{*}{ Jarro } & Produtos qu & uímicos & \multirow{3}{*}{$\begin{array}{l}\text { Tempo de } \\
\text { floculação } \\
\text { (min) }\end{array}$} & \multirow{3}{*}{$\begin{array}{l}\mathrm{pH} \\
\mathrm{de} \\
\text { Coag }\end{array}$} & $\mathrm{Vs} 1=3,0$ & $\mathrm{~cm} / \mathrm{min}$ & $\begin{array}{l}\mathrm{Vs} 2= \\
\mathrm{cm} / \mathrm{min}\end{array}$ & 1,5 & $\mathrm{Vs} 3=1,0$ & $\mathrm{~cm} / \mathrm{min}$ \\
\hline & $\begin{array}{l}\text { Cloreto } \\
\text { Férrico } \\
\text { Líquido } \\
\text { Comercial } \\
\end{array}$ & $\begin{array}{l}\text { Hidróxido } \\
\text { de Sódio }\end{array}$ & & & \multirow[t]{2}{*}{$\begin{array}{l}\text { Turbidez } \\
\text { (uT) }\end{array}$} & \multirow[t]{2}{*}{$\begin{array}{l}\text { Cor } \\
\text { Apar. } \\
(\mathrm{uH})\end{array}$} & \multirow[t]{2}{*}{$\begin{array}{l}\text { Turbidez } \\
\text { (uT) }\end{array}$} & \multirow[t]{2}{*}{$\begin{array}{l}\text { Cor } \\
\text { Apar. } \\
(\mathrm{uH})\end{array}$} & \multirow[t]{2}{*}{$\begin{array}{l}\text { Turbidez } \\
\text { (uT) }\end{array}$} & \multirow[t]{2}{*}{$\begin{array}{l}\text { Cor } \\
\text { Apar. } \\
(\mathrm{uH})\end{array}$} \\
\hline & $(\mathrm{mg} / \mathrm{L})$ & $(\mathrm{mg} / \mathrm{L})$ & & & & & & & & \\
\hline 1 & 260 & 80 & 5 & 6,4 & 1,41 & 50 & 1,08 & 41 & 0,96 & 31 \\
\hline 2 & 260 & 80 & 10 & 6,39 & 1,23 & 45 & 1,2 & 33 & 0,73 & 17 \\
\hline 3 & 260 & 80 & 15 & 6,31 & 1,36 & 37 & 0,85 & 26 & 0,71 & 14 \\
\hline 4 & 260 & 80 & 20 & 6,42 & 1,44 & 55 & 1,34 & 35 & 0,91 & 23 \\
\hline 5 & 260 & 80 & 25 & 6,32 & 1,76 & 63 & 1,2 & 39 & 0,73 & 19 \\
\hline 6 & 260 & 80 & 30 & 6,34 & 1,95 & 75 & 1,2 & 41 & 0,84 & 19 \\
\hline
\end{tabular}

Tabela G.10 - Resultados dos ensaios para seleção dos parâmetros de floculação

\begin{tabular}{|c|c|c|c|c|c|c|c|c|c|c|}
\hline$\overline{\text { gradi }}$ & ente de flocu & lação = 30 & & & & & & & & \\
\hline \multirow{3}{*}{ Jarro } & Produtos q & límicos & \multirow{3}{*}{$\begin{array}{l}\text { Tempo de } \\
\text { floculação } \\
\text { (min) }\end{array}$} & \multirow{3}{*}{$\begin{array}{l}\mathrm{pH} \\
\mathrm{de} \\
\text { Coag }\end{array}$} & $\mathrm{Vs} 1=3,0$ & $\mathrm{~cm} / \mathrm{min}$ & $\begin{array}{l}\mathrm{Vs} 2= \\
\mathrm{cm} / \mathrm{min}\end{array}$ & 1,5 & $\mathrm{Vs} 3=1,0$ & $\mathrm{~cm} / \mathrm{min}$ \\
\hline & $\begin{array}{l}\text { Férrico } \\
\text { Líquido } \\
\text { Comercial }\end{array}$ & $\begin{array}{l}\text { Hidróxido } \\
\text { de Sódio }\end{array}$ & & & \multirow[t]{2}{*}{$\begin{array}{l}\text { Turbidez } \\
\text { (uT) }\end{array}$} & \multirow[t]{2}{*}{$\begin{array}{l}\text { Cor } \\
\text { Apar. } \\
(\mathrm{uH})\end{array}$} & \multirow[t]{2}{*}{$\begin{array}{l}\text { Turbidez } \\
\text { (uT) }\end{array}$} & \multirow[t]{2}{*}{$\begin{array}{l}\text { Cor } \\
\text { Apar. } \\
(\mathrm{uH})\end{array}$} & \multirow[t]{2}{*}{$\begin{array}{l}\text { Turbidez } \\
\text { (uT) }\end{array}$} & \multirow[t]{2}{*}{$\begin{array}{l}\text { Cor } \\
\text { Apar. } \\
(\mathrm{uH})\end{array}$} \\
\hline & $(\mathrm{mg} / \mathrm{L})$ & $(\mathrm{mg} / \mathrm{L})$ & & & & & & & & \\
\hline 1 & 260 & 80 & 35 & 6,5 & 1,73 & 60 & 1,1 & 41 & 1,09 & 21 \\
\hline 2 & 260 & 80 & 40 & 6,41 & 1,69 & 55 & 1,23 & 44 & 1,23 & 22 \\
\hline 3 & 260 & 80 & 45 & 6,36 & 1,85 & 59 & 2,15 & 53 & 0,79 & 20 \\
\hline 4 & 260 & 80 & 50 & 6,42 & 1,17 & 41 & 1,28 & 45 & 1,53 & 30 \\
\hline 5 & 260 & 80 & 55 & 6,4 & 2,21 & 101 & 1,27 & 41 & 0,97 & 29 \\
\hline 6 & 260 & 80 & 60 & 6,38 & 2,12 & 95 & 1,38 & 55 & 0,98 & 33 \\
\hline
\end{tabular}


Tabela G.11 - Resultados dos ensaios para seleção dos parâmetros de floculação

\begin{tabular}{|c|c|c|c|c|c|c|c|c|c|c|}
\hline \multicolumn{11}{|c|}{ gradiente de floculação $=40 \mathrm{~s}^{-1}$} \\
\hline \multirow{3}{*}{ Jarro } & Produtos q & límicos & \multirow{3}{*}{$\begin{array}{l}\text { Tempo de } \\
\text { floculação } \\
\text { (min) }\end{array}$} & \multirow{3}{*}{$\begin{array}{l}\mathrm{pH} \\
\text { de } \\
\text { Coag }\end{array}$} & \multicolumn{2}{|c|}{$\mathrm{Vs} 1=3,0 \mathrm{~cm} / \mathrm{min}$} & \multicolumn{2}{|l|}{$\begin{array}{l}\mathrm{Vs} 2= \\
\mathrm{cm} / \mathrm{min}\end{array}$} & \multicolumn{2}{|c|}{$\mathrm{Vs} 3=1,0 \mathrm{~cm} / \mathrm{min}$} \\
\hline & $\begin{array}{l}\text { Cloreto } \\
\text { Férrico } \\
\text { Líquido } \\
\text { Comercial } \\
\end{array}$ & $\begin{array}{l}\text { Hidróxido } \\
\text { de Sódio }\end{array}$ & & & $\begin{array}{l}\text { Turbidez } \\
\text { (uT) }\end{array}$ & $\begin{array}{l}\text { Cor } \\
\text { Apar. } \\
\text { (uH) }\end{array}$ & $\begin{array}{l}\text { Turbidez } \\
\text { (uT) }\end{array}$ & $\begin{array}{l}\text { Cor } \\
\text { Apar. } \\
(\mathrm{uH})\end{array}$ & $\begin{array}{l}\text { Turbidez } \\
\text { (uT) }\end{array}$ & $\begin{array}{l}\text { Cor } \\
\text { Apar. } \\
(\mathrm{uH})\end{array}$ \\
\hline & $(\mathrm{mg} / \mathrm{L})$ & $(\mathrm{mg} / \mathrm{L})$ & & & & & & & & \\
\hline 1 & 260 & 80 & 5 & 6,55 & 1,2 & 41 & 1,24 & 39 & 1,11 & 34 \\
\hline 2 & 260 & 80 & 10 & 6,48 & 1,52 & 44 & 1,14 & 41 & 1,27 & 20 \\
\hline 3 & 260 & 80 & 15 & 6,49 & 1,84 & 66 & 0,98 & 28 & 0,96 & 19 \\
\hline 4 & 260 & 80 & 20 & 6,5 & 1,51 & 51 & 1,17 & 38 & 1,07 & 23 \\
\hline 5 & 260 & 80 & 25 & 6,35 & 1,68 & 62 & 1,33 & 44 & 0,91 & 21 \\
\hline 6 & 260 & 80 & 30 & 6,46 & 2,2 & 91 & 1,93 & 61 & 1,18 & 21 \\
\hline
\end{tabular}

Tabela G.12 - Resultados dos ensaios para seleção dos parâmetros de floculação

\begin{tabular}{|c|c|c|c|c|c|c|c|c|c|c|}
\hline \multicolumn{11}{|c|}{ gradiente de floculação $=40 \mathrm{~s}^{-1}$} \\
\hline \multirow{3}{*}{ Jarro } & Produtos q & límicos & \multirow{3}{*}{$\begin{array}{l}\text { Tempo de } \\
\text { floculação } \\
\text { (min) }\end{array}$} & \multirow{3}{*}{$\begin{array}{l}\mathrm{pH} \\
\text { de } \\
\text { Coag }\end{array}$} & $\mathrm{Vs} 1=3,0$ & $\mathrm{~cm} / \mathrm{min}$ & $\begin{array}{l}\mathrm{Vs} 2= \\
\mathrm{cm} / \mathrm{min}\end{array}$ & 1,5 & $\mathrm{Vs} 3=1,0$ & $\mathrm{~cm} / \mathrm{min}$ \\
\hline & $\begin{array}{l}\text { Férrico } \\
\text { Líquido } \\
\text { Comercial }\end{array}$ & $\begin{array}{l}\text { Hidróxido } \\
\text { de Sódio }\end{array}$ & & & \multirow[t]{2}{*}{$\begin{array}{l}\text { Turbidez } \\
\text { (uT) }\end{array}$} & \multirow[t]{2}{*}{$\begin{array}{l}\text { Cor } \\
\text { Apar. } \\
(\mathrm{uH})\end{array}$} & \multirow[t]{2}{*}{$\begin{array}{l}\text { Turbidez } \\
\text { (uT) }\end{array}$} & \multirow[t]{2}{*}{$\begin{array}{l}\text { Cor } \\
\text { Apar. } \\
(\mathrm{uH})\end{array}$} & \multirow[t]{2}{*}{$\begin{array}{l}\text { Turbidez } \\
\text { (uT) }\end{array}$} & \multirow[t]{2}{*}{$\begin{array}{l}\text { Cor } \\
\text { Apar. } \\
(\mathrm{uH})\end{array}$} \\
\hline & $(\mathrm{mg} / \mathrm{L})$ & $(\mathrm{mg} / \mathrm{L})$ & & & & & & & & \\
\hline 1 & 260 & 80 & 35 & 6,39 & 1,67 & 89 & 1,43 & 54 & 1,01 & 22 \\
\hline 2 & 260 & 80 & 40 & 6,36 & 1,54 & 70 & 1,32 & 69 & 1,15 & 25 \\
\hline 3 & 260 & 80 & 45 & 6,34 & 1,52 & 72 & 1,23 & 62 & 1,09 & 26 \\
\hline 4 & 260 & 80 & 50 & 6,32 & 1,67 & 69 & 1,5 & 52 & 1,22 & 22 \\
\hline 5 & 260 & 80 & 55 & 6,29 & 1,39 & 67 & 1,2 & 60 & 1,04 & 23 \\
\hline 6 & 180 & 80 & 60 & 6,27 & 2,58 & 107 & 1,89 & 90 & 1,6 & 34 \\
\hline
\end{tabular}




\section{ANEXO H}

Resultados dos ensaios de refloculação com o Cloreto Férrico como coagulante 
Tabela H.1 - Resultados dos ensaios de refloculação, Grf 10 s-1, Gruptura = 50 s-1, e variados os tempos de refloculação

\begin{tabular}{|c|c|c|c|c|c|c|c|c|c|c|c|c|c|c|c|c|}
\hline \multirow[b]{2}{*}{ Jarro } & \multicolumn{2}{|c|}{ Produtos químicos } & \multirow[b]{2}{*}{$\begin{array}{l}\text { Tempo de } \\
\text { refloculação } \\
\text { (min) }\end{array}$} & \multirow[b]{2}{*}{$\begin{array}{l}\mathrm{pH} \\
\mathrm{de} \\
\text { Coag }\end{array}$} & \multicolumn{2}{|c|}{$\begin{array}{l}\begin{array}{l}\text { Vs1= } \\
\mathrm{cm} / \mathrm{min}\end{array} \\
\end{array}$} & \multicolumn{2}{|c|}{$\begin{array}{l}\begin{array}{l}\text { Vs1 }= \\
\mathrm{cm} / \mathrm{min}\end{array} \\
\end{array}$} & \multicolumn{2}{|c|}{$\begin{array}{l}\begin{array}{l}\text { Vs1 }=1,38 \\
\mathrm{~cm} / \mathrm{min}\end{array} \\
\end{array}$} & \multicolumn{2}{|c|}{$\begin{array}{l}\begin{array}{l}\text { Vs1 } 1=0,97 \\
\mathrm{~cm} / \mathrm{min}\end{array} \\
\end{array}$} & \multicolumn{2}{|c|}{$\begin{array}{l}\begin{array}{l}\mathrm{Vs} 1= \\
\mathrm{cm} / \mathrm{min}\end{array} \\
\end{array}$} & \multicolumn{2}{|c|}{$\begin{array}{l}\mathrm{Vs} 1= \\
\mathrm{cm} / \mathrm{min}\end{array}$} \\
\hline & $\begin{array}{l}\text { Sulfato de } \\
\text { Alumínio } \\
\text { Líquido } \\
\text { Comercial } \\
(\mathrm{mg} / \mathrm{L})\end{array}$ & $\begin{array}{l}\text { Hidróxi } \\
\text { do de } \\
\text { Sódio }\end{array}$ & & & $\begin{array}{l}\text { Turbi } \\
\text { dez } \\
\text { (uT) }\end{array}$ & $\begin{array}{l}\text { Cor } \\
\text { Apar } \\
\text { (uH) }\end{array}$ & $\begin{array}{l}\text { Turbi } \\
\text { dez } \\
\text { (uT) }\end{array}$ & $\begin{array}{l}\text { Cor } \\
\text { Apar. } \\
\text { (uH) }\end{array}$ & $\begin{array}{l}\text { Turb } \\
\text { idez } \\
\text { (uT) }\end{array}$ & $\begin{array}{l}\text { Cor } \\
\text { Apar } \\
\text { (uH) }\end{array}$ & $\begin{array}{l}\text { Turb } \\
\text { idez } \\
\text { (uT) }\end{array}$ & $\begin{array}{l}\text { Cor } \\
\text { Apar } \\
\text { (uH) }\end{array}$ & $\begin{array}{l}\text { Turb } \\
\text { idez } \\
\text { (uT) }\end{array}$ & $\begin{array}{l}\text { Cor } \\
\text { Apar } \\
\text { (uH) }\end{array}$ & $\begin{array}{l}\text { Turb } \\
\text { idez } \\
\text { (uT) }\end{array}$ & $\begin{array}{l}\text { Cor } \\
\text { Apar } \\
\text { (uH) }\end{array}$ \\
\hline 1 & 260 & 80 & 0 & 6,65 & 4,56 & 121 & 1,1 & 46 & 1,09 & 35 & 0,89 & 33 & 1,15 & 30 & 0,82 & 30 \\
\hline 2 & 260 & 80 & 5 & 6,41 & 1,59 & 54 & 1,07 & 31 & 0,72 & 22 & 0,73 & 21 & 0,82 & 22 & 0,73 & 21 \\
\hline 3 & 260 & 80 & 10 & 6,42 & 2,4 & 63 & 1,47 & 29 & 0,76 & 24 & 0,7 & 24 & 0,59 & 21 & 0,57 & 19 \\
\hline 4 & 260 & 80 & 15 & 6,52 & 1,75 & 53 & 0,81 & 32 & 0,74 & 28 & 0,8 & 25 & 0,82 & 25 & 0,64 & 23 \\
\hline 5 & 260 & 80 & 20 & 6,4 & 1,74 & 65 & 1 & 36 & 1,15 & 26 & 0,9 & 23 & 0,79 & 20 & 1,02 & 20 \\
\hline 6 & 260 & 80 & 25 & 6,33 & 1,6 & 75 & 1,23 & 44 & 1,34 & 34 & 0,78 & 26 & 0,88 & 24 & 0,96 & 20 \\
\hline
\end{tabular}

Tabela H.2 - Resultados dos ensaios de refloculação, Grf $20 \mathrm{~s}^{-1}$, Gruptura $=50 \mathrm{~s}^{-1}$, e variados os tempos de refloculação

\begin{tabular}{|c|c|c|c|c|c|c|c|c|c|c|c|c|c|c|c|c|}
\hline \multirow[b]{2}{*}{ Jarro } & Produtos q & uímicos & \multirow[b]{2}{*}{$\begin{array}{l}\text { Tempo de } \\
\text { refloculação } \\
(\mathrm{min})\end{array}$} & \multirow[b]{2}{*}{$\begin{array}{l}\mathrm{pH} \\
\mathrm{de} \\
\text { Coag }\end{array}$} & \multicolumn{2}{|c|}{$\begin{array}{l}\begin{array}{l}\text { Vs1 } 1 \\
\mathrm{~cm} / \min \end{array} \\
\end{array}$} & \multicolumn{2}{|c|}{$\begin{array}{l}\begin{array}{l}\mathrm{Vs} 1= \\
\mathrm{cm} / \mathrm{min}\end{array} \\
\end{array}$} & \multicolumn{2}{|c|}{$\begin{array}{l}\begin{array}{l}\text { Vs1 }=1,38 \\
\mathrm{~cm} / \mathrm{min}\end{array} \\
\end{array}$} & \multicolumn{2}{|c|}{$\begin{array}{l}\begin{array}{l}\text { Vs1 }=\quad 0,97 \\
\mathrm{~cm} / \mathrm{min}\end{array}\end{array}$} & \multicolumn{2}{|c|}{$\begin{array}{l}\begin{array}{l}\mathrm{Vs} 1= \\
\mathrm{cm} / \mathrm{min}\end{array} \\
\end{array}$} & \multicolumn{2}{|c|}{$\begin{array}{l}\text { Vs1= } 0,42 \\
\mathrm{~cm} / \mathrm{min}\end{array}$} \\
\hline & $\begin{array}{l}\text { Sulfato de } \\
\text { Alumínio } \\
\text { Líquido } \\
\text { Comercial } \\
(\mathrm{mg} / \mathrm{L})\end{array}$ & $\begin{array}{l}\text { Hidróxi } \\
\text { do de } \\
\text { Sódio }\end{array}$ & & & $\begin{array}{l}\text { Turbi } \\
\text { dez } \\
\text { (uT) }\end{array}$ & $\begin{array}{l}\text { Cor } \\
\text { Apar } \\
\text { (uH) }\end{array}$ & $\begin{array}{l}\text { Turbi } \\
\text { dez } \\
\text { (uT) }\end{array}$ & $\begin{array}{l}\text { Cor } \\
\text { Apar. } \\
\text { (uH) }\end{array}$ & $\begin{array}{l}\text { Turb } \\
\text { idez } \\
\text { (uT) }\end{array}$ & $\begin{array}{l}\text { Cor } \\
\text { Apar } \\
\text { (uH) }\end{array}$ & $\begin{array}{l}\text { Turb } \\
\text { idez } \\
\text { (uT) }\end{array}$ & $\begin{array}{l}\text { Cor } \\
\text { Apar } \\
\text { (uH) }\end{array}$ & $\begin{array}{l}\text { Turb } \\
\text { idez } \\
\text { (uT) }\end{array}$ & $\begin{array}{l}\text { Cor } \\
\text { Apar } \\
\text { (uH) }\end{array}$ & $\begin{array}{l}\text { Turb } \\
\text { idez } \\
\text { (uT) }\end{array}$ & $\begin{array}{l}\text { Cor } \\
\text { Apar } \\
\text { (uH) }\end{array}$ \\
\hline 1 & 260 & 80 & 0 & 6,65 & 4,56 & 121 & 1,1 & 46 & 1,09 & 35 & 0,89 & 33 & 1,15 & 30 & 0,82 & 30 \\
\hline 2 & 260 & 80 & 5 & 6,41 & 2,6 & 64 & 1,45 & 40 & 1,05 & 26 & 1,06 & 23 & 0,95 & 23 & 0,85 & 23 \\
\hline 3 & 260 & 80 & 10 & 6,42 & 2,56 & 60 & 1,55 & 45 & 1,19 & 30 & 1,46 & 26 & 0,94 & 25 & 0,89 & 22 \\
\hline 4 & 260 & 80 & 15 & 6,52 & 3,41 & 85 & 2,33 & 57 & 1,68 & 29 & 1,5 & 25 & 1,12 & 23 & 0,91 & 23 \\
\hline 5 & 260 & 80 & 20 & 6,4 & 3,82 & 123 & 2,78 & 68 & 1,71 & 51 & 1,27 & 44 & 1,25 & 32 & 1,04 & 25 \\
\hline 6 & 260 & 80 & 25 & 6,33 & 4,88 & 159 & 3,92 & 75 & 2,1 & 52 & 1,78 & 49 & 1,33 & 33 & 1 & 24 \\
\hline
\end{tabular}


Tabela H.3 - Resultados dos ensaios de refloculação, Grf $10 \mathrm{~s}^{-1}$, Gruptura $=100 \mathrm{~s}^{-1}$, e variados os tempos de refloculação

\begin{tabular}{|c|c|c|c|c|c|c|c|c|c|c|c|c|c|c|c|c|}
\hline \multirow[b]{2}{*}{ Jarro } & \multicolumn{2}{|c|}{ Produtos químicos } & \multirow[b]{2}{*}{$\begin{array}{l}\text { Tempo de } \\
\text { refloculação } \\
\text { (min) }\end{array}$} & \multirow[b]{2}{*}{$\begin{array}{l}\mathrm{pH} \\
\mathrm{de} \\
\text { Coag }\end{array}$} & \multicolumn{2}{|c|}{$\begin{array}{l}\mathrm{Vs} 1= \\
\mathrm{cm} / \mathrm{min}\end{array}$} & \multicolumn{2}{|c|}{$\begin{array}{l}\mathrm{Vs} 1= \\
\mathrm{cm} / \mathrm{min}\end{array}$} & \multicolumn{2}{|c|}{$\begin{array}{l}\text { Vs1= } 1,38 \\
\mathrm{~cm} / \mathrm{min}\end{array}$} & \multicolumn{2}{|c|}{$\begin{array}{l}\mathrm{Vs} 1=\quad 0,97 \\
\mathrm{~cm} / \mathrm{min}\end{array}$} & \multicolumn{2}{|c|}{$\begin{array}{l}\begin{array}{l}\mathrm{Vs} 1= \\
\mathrm{cm} / \mathrm{min}\end{array} \\
\end{array}$} & \multicolumn{2}{|c|}{$\begin{array}{l}\mathrm{Vs} 1=\quad 0,42 \\
\mathrm{~cm} / \mathrm{min}\end{array}$} \\
\hline & $\begin{array}{l}\text { Sulfato de } \\
\text { Alumínio } \\
\text { Líquido } \\
\text { Comercial } \\
(\mathrm{mg} / \mathrm{L})\end{array}$ & $\begin{array}{l}\text { Hidróxi } \\
\text { do de } \\
\text { Sódio }\end{array}$ & & & $\begin{array}{l}\text { Turbi } \\
\text { dez } \\
\text { (uT) }\end{array}$ & $\begin{array}{l}\text { Cor } \\
\text { Apar } \\
\text { (uH) }\end{array}$ & $\begin{array}{l}\text { Turbi } \\
\text { dez } \\
\text { (uT) }\end{array}$ & $\begin{array}{l}\text { Cor } \\
\text { Apar. } \\
\text { (uH) }\end{array}$ & $\begin{array}{l}\text { Turb } \\
\text { idez } \\
\text { (uT) }\end{array}$ & $\begin{array}{l}\text { Cor } \\
\text { Apar } \\
\text { (uH) }\end{array}$ & $\begin{array}{l}\text { Turb } \\
\text { idez } \\
\text { (uT) }\end{array}$ & $\begin{array}{l}\text { Cor } \\
\text { Apar } \\
\text { (uH) }\end{array}$ & $\begin{array}{l}\text { Turb } \\
\text { idez } \\
\text { (uT) }\end{array}$ & $\begin{array}{l}\text { Cor } \\
\text { Apar } \\
\text { (uH) }\end{array}$ & $\begin{array}{l}\text { Turb } \\
\text { idez } \\
\text { (uT) }\end{array}$ & $\begin{array}{l}\text { Cor } \\
\text { Apar } \\
\text { (uH) }\end{array}$ \\
\hline 1 & 260 & 80 & 0 & 6,44 & 5,18 & 178 & 1,61 & 67 & 1,33 & 50 & 1,31 & 44 & 1,03 & 34 & 0,9 & 31 \\
\hline 2 & 260 & 80 & 5 & 6,39 & 2,83 & 106 & 1,24 & 38 & 1,19 & 33 & 0,9 & 23 & 1,27 & 22 & 0,96 & 22 \\
\hline 3 & 260 & 80 & 10 & 6,37 & 2,66 & 97 & 1,33 & 37 & 0,96 & 23 & 0,89 & 21 & 0,84 & 18 & 0,74 & 15 \\
\hline 4 & 260 & 80 & 15 & 6,43 & 3,82 & 127 & 1,3 & 37 & 0,95 & 26 & 1,18 & 27 & 1 & 20 & 0,73 & 18 \\
\hline 5 & 260 & 80 & 20 & 6,32 & 3,57 & 135 & 0,96 & 24 & 1 & 24 & 0,78 & 20 & 0,7 & 16 & 0,92 & 15 \\
\hline 6 & 260 & 80 & 25 & 6,35 & 3,73 & 123 & 1,32 & 35 & 1,67 & 25 & 0,73 & 23 & 0,84 & 17 & 0,93 & 16 \\
\hline
\end{tabular}

Tabela H.4 - Resultados dos ensaios de refloculação, Grf $20 \mathrm{~s}^{-1}$, Gruptura $=100 \mathrm{~s}^{-1}$, e variados os tempos de refloculação

\begin{tabular}{|c|c|c|c|c|c|c|c|c|c|c|c|c|c|c|c|c|}
\hline \multirow{3}{*}{ Jarro } & Produtos qu & uímicos & \multirow{3}{*}{$\begin{array}{l}\text { Tempo de } \\
\text { refloculação } \\
(\min )\end{array}$} & \multirow{3}{*}{$\begin{array}{l}\mathrm{pH} \\
\mathrm{de} \\
\text { Coag }\end{array}$} & \multicolumn{2}{|c|}{$\begin{array}{l}\mathrm{Vs} 1= \\
\mathrm{cm} / \mathrm{min}\end{array}$} & \multicolumn{2}{|c|}{$\begin{array}{l}\begin{array}{l}\mathrm{Vs} 1= \\
\mathrm{cm} / \mathrm{min}\end{array} \\
\end{array}$} & \multicolumn{2}{|c|}{$\begin{array}{l}\text { Vs1= } 1,38 \\
\mathrm{~cm} / \mathrm{min}\end{array}$} & \multicolumn{2}{|c|}{$\begin{array}{l}\text { Vs1 }=0,97 \\
\mathrm{~cm} / \mathrm{min}\end{array}$} & \multicolumn{2}{|c|}{$\begin{array}{l}\text { Vs1= } \\
\mathrm{cm} / \mathrm{min}\end{array}$} & \multicolumn{2}{|c|}{$\begin{array}{l}\text { Vs1= } 0,42 \\
\mathrm{~cm} / \mathrm{min}\end{array}$} \\
\hline & $\begin{array}{l}\text { Sulfato de } \\
\text { Alumínio } \\
\text { Líquido } \\
\text { Comercial } \\
\end{array}$ & $\begin{array}{l}\text { Hidróxi } \\
\text { do de } \\
\text { Sódio }\end{array}$ & & & $\begin{array}{l}\text { Turbi } \\
\text { dez } \\
\text { (uT) }\end{array}$ & $\begin{array}{l}\text { Cor } \\
\text { Apar } \\
\text { (uH) }\end{array}$ & $\begin{array}{l}\text { Turbi } \\
\text { dez } \\
\text { (uT) }\end{array}$ & $\begin{array}{l}\text { Cor } \\
\text { Apar. } \\
\text { (uH) }\end{array}$ & $\begin{array}{l}\text { Turb } \\
\text { idez } \\
\text { (uT) }\end{array}$ & $\begin{array}{l}\text { Cor } \\
\text { Apar } \\
\text { (uH) }\end{array}$ & $\begin{array}{l}\text { Turb } \\
\text { idez } \\
\text { (uT) }\end{array}$ & $\begin{array}{l}\text { Cor } \\
\text { Apar } \\
\text { (uH) }\end{array}$ & $\begin{array}{l}\text { Turb } \\
\text { idez } \\
\text { (uT) }\end{array}$ & $\begin{array}{l}\text { Cor } \\
\text { Apar } \\
\text { (uH) }\end{array}$ & $\begin{array}{l}\text { Turb } \\
\text { idez } \\
\text { (uT) }\end{array}$ & $\begin{array}{l}\text { Cor } \\
\text { Apar } \\
\text { (uH) }\end{array}$ \\
\hline & $(\mathrm{mg} / \mathrm{L})$ & & & & & & & & & & & & & & & \\
\hline 1 & 260 & 80 & 0 & 6,14 & 5,18 & 178 & 1,61 & 67 & 1,33 & 50 & 1,31 & 44 & 1,03 & 34 & 0,9 & 31 \\
\hline 2 & 260 & 80 & 5 & 6 & 4,41 & 100 & 1,87 & 39 & 1,1 & 31 & 0,86 & 25 & 0,72 & 19 & 0,7 & 19 \\
\hline 3 & 260 & 80 & 10 & 6,11 & 4,85 & 159 & 2,21 & 52 & 1,29 & 45 & 1,07 & 38 & 1,04 & 23 & 0,82 & 19 \\
\hline 4 & 260 & 80 & 15 & 6,05 & 6,51 & 248 & 2,5 & 60 & 1,64 & 51 & 1,19 & 44 & 0,83 & 29 & 0,89 & 21 \\
\hline 5 & 260 & 80 & 20 & 6,12 & 6,77 & 251 & 2,44 & 59 & 1,65 & 51 & 1,21 & 42 & 0,89 & 30 & 0,85 & 22 \\
\hline 6 & 260 & 80 & 25 & 6,01 & 6,65 & 250 & 2,51 & 63 & 1,78 & 54 & 1,26 & 39 & 0,9 & 30 & 0,84 & 19 \\
\hline
\end{tabular}


Tabela H.5 - Resultados dos ensaios de refloculação, Grf $10 \mathrm{~s}^{-1}$, Gruptura $=150 \mathrm{~s}^{-1}$, e variados os tempos de refloculação

\begin{tabular}{|c|c|c|c|c|c|c|c|c|c|c|c|c|c|c|c|c|}
\hline \multirow{3}{*}{ Jarro } & Produtos q & uímicos & \multirow{3}{*}{$\begin{array}{l}\text { Tempo de } \\
\text { refloculação } \\
\text { (min) }\end{array}$} & \multirow{3}{*}{$\begin{array}{l}\mathrm{pH} \\
\mathrm{de} \\
\text { Coag }\end{array}$} & \multicolumn{2}{|c|}{$\begin{array}{l}\begin{array}{l}\text { Vs1 } 1=4,67 \\
\mathrm{~cm} / \min \end{array} \\
\end{array}$} & \multicolumn{2}{|c|}{$\begin{array}{l}\text { Vsl= } \\
\mathrm{cm} / \mathrm{min}\end{array}$} & \multicolumn{2}{|c|}{$\begin{array}{l}\begin{array}{l}\text { Vs1 }=1,38 \\
\mathrm{~cm} / \mathrm{min}\end{array} \\
\end{array}$} & \multicolumn{2}{|c|}{$\begin{array}{l}\begin{array}{l}\text { Vs1 }=\quad 0,97 \\
\mathrm{~cm} / \mathrm{min}\end{array}\end{array}$} & \multicolumn{2}{|c|}{$\begin{array}{ll}\mathrm{Vs} 1= & 0,6 \\
\mathrm{~cm} / \mathrm{min}\end{array}$} & \multicolumn{2}{|c|}{$\begin{array}{l}\text { Vs1= } 0,42 \\
\mathrm{~cm} / \mathrm{min}\end{array}$} \\
\hline & $\begin{array}{l}\text { Sulfato de } \\
\text { Alumínio } \\
\text { Líquido } \\
\text { Comercial } \\
\end{array}$ & $\begin{array}{l}\text { Hidróxi } \\
\text { do de } \\
\text { Sódio }\end{array}$ & & & $\begin{array}{l}\text { Turbi } \\
\text { dez } \\
\text { (uT) }\end{array}$ & $\begin{array}{l}\text { Cor } \\
\text { Apar } \\
\text { (uH) }\end{array}$ & $\begin{array}{l}\text { Turbi } \\
\text { dez } \\
\text { (uT) }\end{array}$ & $\begin{array}{l}\text { Cor } \\
\text { Apar. } \\
\text { (uH) }\end{array}$ & $\begin{array}{l}\text { Turb } \\
\text { idez } \\
\text { (uT) }\end{array}$ & $\begin{array}{l}\text { Cor } \\
\text { Apar } \\
\text { (uH) }\end{array}$ & $\begin{array}{l}\text { Turb } \\
\text { idez } \\
\text { (uT) }\end{array}$ & $\begin{array}{l}\text { Cor } \\
\text { Apar } \\
\text { (uH) }\end{array}$ & $\begin{array}{l}\text { Turb } \\
\text { idez } \\
\text { (uT) }\end{array}$ & $\begin{array}{l}\text { Cor } \\
\text { Apar } \\
\text { (uH) }\end{array}$ & $\begin{array}{l}\text { Turb } \\
\text { idez } \\
\text { (uT) }\end{array}$ & $\begin{array}{l}\text { Cor } \\
\text { Apar } \\
\text { (uH) }\end{array}$ \\
\hline & $(\mathrm{mg} / \mathrm{L})$ & & & & & & & & & & & & & & & \\
\hline 1 & 260 & 80 & 0 & 6,51 & 7,91 & 335 & 2,73 & 104 & 2,71 & 90 & 2,61 & 84 & 2,22 & 60 & 1,42 & 44 \\
\hline 2 & 260 & 80 & 5 & 6,49 & 2,66 & 95 & 1,64 & 46 & 1,45 & 30 & 0,98 & 27 & 0,88 & 25 & 1,19 & 22 \\
\hline 3 & 260 & 80 & 10 & 6,36 & 3,67 & 106 & 1,54 & 43 & 1,08 & 29 & 0,87 & 22 & 1,11 & 22 & 0,9 & 19 \\
\hline 4 & 260 & 80 & 15 & 6,51 & 3,86 & 155 & 2,65 & 55 & 1,25 & 37 & 1,34 & 32 & 1,15 & 25 & 1,01 & 24 \\
\hline 5 & 260 & 80 & 20 & 6,46 & 3,55 & 142 & 1,54 & 39 & 0,98 & 26 & 1,39 & 33 & 0,99 & 18 & 1,31 & 18 \\
\hline 6 & 260 & 80 & 25 & 6,45 & 5,44 & 171 & 2,01 & 51 & 1,17 & 42 & 1,09 & 32 & 1,08 & 21 & 1 & 19 \\
\hline
\end{tabular}

Tabela H.6 - Resultados dos ensaios de refloculação, Grf $20 \mathrm{~s}^{-1}$, Gruptura $=150 \mathrm{~s}^{-1}$, e variados os tempos de refloculação

\begin{tabular}{|c|c|c|c|c|c|c|c|c|c|c|c|c|c|c|c|c|}
\hline \multirow[b]{2}{*}{ Jarro } & Produtos q & uímicos & \multirow[b]{2}{*}{$\begin{array}{l}\text { Tempo de } \\
\text { refloculação } \\
(\min )\end{array}$} & \multirow[b]{2}{*}{$\begin{array}{l}\mathrm{pH} \\
\mathrm{de} \\
\text { Coag }\end{array}$} & \multicolumn{2}{|c|}{$\begin{array}{l}\begin{array}{l}\text { Vs1 } 1 \\
\mathrm{~cm} / \min \end{array} \\
\end{array}$} & \multicolumn{2}{|c|}{$\begin{array}{l}\begin{array}{l}\mathrm{Vs} 1= \\
\mathrm{cm} / \mathrm{min}\end{array} \\
\end{array}$} & \multicolumn{2}{|c|}{$\begin{array}{l}\mathrm{Vs} 1=1,38 \\
\mathrm{~cm} / \mathrm{min}\end{array}$} & \multicolumn{2}{|c|}{$\begin{array}{l}\begin{array}{l}\text { Vs1 }=\quad 0,97 \\
\mathrm{~cm} / \mathrm{min}\end{array}\end{array}$} & \multicolumn{2}{|c|}{$\begin{array}{l}\begin{array}{l}\mathrm{Vs} 1= \\
\mathrm{cm} / \mathrm{min}\end{array} \\
\end{array}$} & \multicolumn{2}{|c|}{$\begin{array}{l}\text { Vs1= } 0,42 \\
\mathrm{~cm} / \mathrm{min}\end{array}$} \\
\hline & $\begin{array}{l}\text { Sulfato de } \\
\text { Alumínio } \\
\text { Líquido } \\
\text { Comercial } \\
(\mathrm{mg} / \mathrm{L})\end{array}$ & $\begin{array}{l}\text { Hidróxi } \\
\text { do de } \\
\text { Sódio }\end{array}$ & & & $\begin{array}{l}\text { Turbi } \\
\text { dez } \\
\text { (uT) }\end{array}$ & $\begin{array}{l}\text { Cor } \\
\text { Apar } \\
\text { (uH) }\end{array}$ & $\begin{array}{l}\text { Turbi } \\
\text { dez } \\
\text { (uT) }\end{array}$ & $\begin{array}{l}\text { Cor } \\
\text { Apar. } \\
\text { (uH) }\end{array}$ & $\begin{array}{l}\text { Turb } \\
\text { idez } \\
\text { (uT) }\end{array}$ & $\begin{array}{l}\text { Cor } \\
\text { Apar } \\
\text { (uH) }\end{array}$ & $\begin{array}{l}\text { Turb } \\
\text { idez } \\
\text { (uT) }\end{array}$ & $\begin{array}{l}\text { Cor } \\
\text { Apar } \\
\text { (uH) }\end{array}$ & $\begin{array}{l}\text { Turb } \\
\text { idez } \\
\text { (uT) }\end{array}$ & $\begin{array}{l}\text { Cor } \\
\text { Apar } \\
\text { (uH) }\end{array}$ & $\begin{array}{l}\text { Turb } \\
\text { idez } \\
\text { (uT) }\end{array}$ & $\begin{array}{l}\text { Cor } \\
\text { Apar } \\
\text { (uH) }\end{array}$ \\
\hline 1 & 260 & 80 & 0 & 6,51 & 7,91 & 335 & 2,73 & 104 & 2,71 & 90 & 2,61 & 84 & 2,22 & 60 & 1,42 & 44 \\
\hline 2 & 260 & 80 & 5 & 6,49 & 3,59 & 101 & 2,22 & 51 & 2,09 & 32 & 1,6 & 27 & 1,06 & 23 & 1,08 & 21 \\
\hline 3 & 260 & 80 & 10 & 6,36 & 4,92 & 178 & 3,05 & 78 & 2,4 & 56 & 1,56 & 45 & 1,21 & 29 & 1,1 & 25 \\
\hline 4 & 260 & 80 & 15 & 6,51 & 6 & 205 & 2,98 & 85 & 2,74 & 62 & 2,18 & 52 & 1,31 & 35 & 1,05 & 24 \\
\hline 5 & 260 & 80 & 20 & 6,46 & 6,23 & 225 & 3,25 & 87 & 2,51 & 61 & 2,45 & 58 & 1,45 & 36 & 1,02 & 21 \\
\hline 6 & 260 & 80 & 25 & 6,45 & 6,98 & 269 & 3,87 & 95 & 2,94 & 68 & 2,65 & 66 & 1,34 & 39 & 1,12 & 22 \\
\hline
\end{tabular}


